\title{
GOVERNING ADDICTION: THE ALCOHOL AND OTHER DRUG TREATMENT COURT \\ IN NEW ZEALAND
}

Toni Carr

A thesis submitted to the Victoria University of Wellington in fulfilment of the requirements for the degree of Doctor of Philosophy

Victoria University of Wellington

2020 
Dedicated to the memory of my uncle Cyril Wright 


\begin{abstract}
The New Zealand Alcohol and other Drug Treatment Court (AODTC) is an innovative approach to addressing offending by people with an alcohol or other drug addiction. Based on the United States Drug Treatment Court model, the AODTC aims to reduce reoffending, reduce addiction and support offenders' health and wellbeing. Most studies of DTCs are quantitative and focus on recidivism rates and cost-effectiveness. There have been relatively few in-depth studies of how DTCs operate and even fewer that focus on the offender's experience.

This thesis is a critical study of the Auckland and Waitakere AODTCs and is the first study of its kind in New Zealand. Conducted over seven months, the fieldwork involved 536 hours of observations, interviews with offenders and informal conversations with court workers, treatment providers and offenders' families. The research also included extensive analysis of documents produced by and about the AODTC pilot and the US counterparts.

The research found that the AODTC operates in a largely unregulated problem-solving court zone. The wide discretion of judges and collaboration with community treatment providers, lauded by proponents of the AODTC as key to its therapeutic effectiveness, were found to create a number of significant harms for participants. In addition, the focus on addiction as a disease and abstinence as a goal and measure of progress invites judicial subjectivity and places considerable burdens on participants.
\end{abstract}

The research also found that the AODTC metes out punishment under the guise of treatment, preventing participants from accessing treatment and breach the principle of proportionality in their responses to offending and non-compliance. The competing goals of treatment and punishment also prevent participants from receiving adequate support in the AODTC programme. In particular, Māori, women, transgender, offenders with a coexisting disorder and brain injury are less likely to have access to the right treatment and proper support. These findings challenge the assumptions that the AODTC therapeutic mandate treats AOD related offending and supports offenders' health and wellbeing. In order to protect AODTC offenders, a series of recommendations for change are made to constrain judicial involvement in treatment, to provide better options for community-based treatment and to ensure appropriate addiction treatment services.

Overall, the thesis provides valuable empirical insight into how the AODTC and the criminal justice system constitute AOD offending, addiction treatment policies, and manage the addicted offender to accomplish recovery. It also adds important data to the international pool 
of DTC ethnographies and problem-solving court literature, providing a point of focus from which to consider broader policy and evaluative criteria of people's experiences of treatment in the problem-solving court. It is hoped that this research is able to contribute to law reform involving specialist problem solving courts in New Zealand. 


\section{Acknowledgements}

This thesis would not have been possible without the AODTC judges and the participants who took part. I would like to thank the AODTC Steering Committee for permitting me access to interview AODTC participants. The thesis is all the richer for the participants' stories.

Over the course of the thesis, I have received guidance, inspiration and support from many people. I would like to thank my supervisors Yvette and Trevor for their time and encouragement. Julian and Wayne for the advice and direction involving the court. Michelle, for her presence and care. Wendi for showing me the work of the Salvation Army Bridge program and Stormy for providing me with the vision of the Te Toi o Matariki, therapeutic model.

I would like to say a special thank you to my peers past and present, at the Institute of Criminology and Faculty of Law who have shared in my thesis journey, I feel extremely fortunate to have had you around me. Claudia, thank you for standing beside me when the going got tough.

Finally, I would like to thank my family. I could not have done the thesis without their support, love, tolerance and belief in my abilities, these have been unwavering over the years and I am truly grateful for the encouragement. 


\section{Contents}

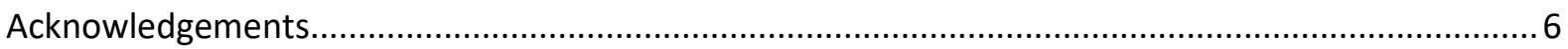

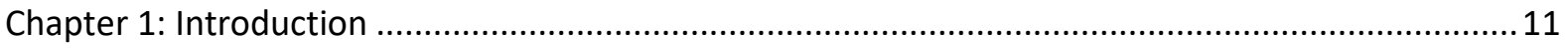

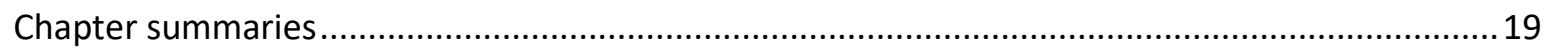

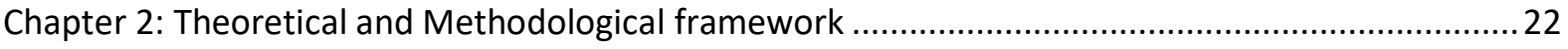

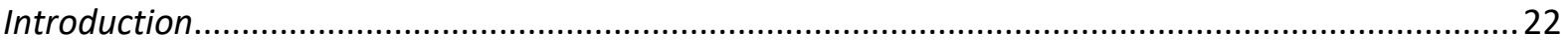

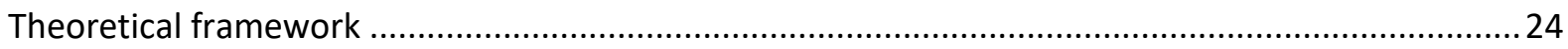

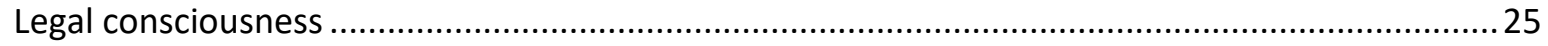

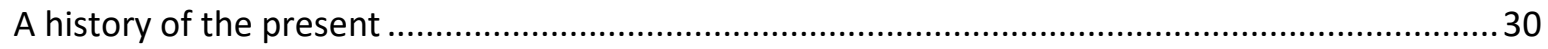

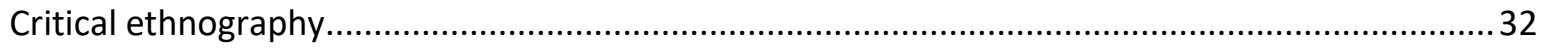

Addressing challenges to critical ethnography: Pre-fieldwork data and intersectionality ................33

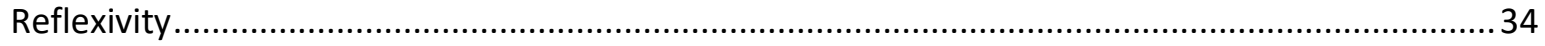

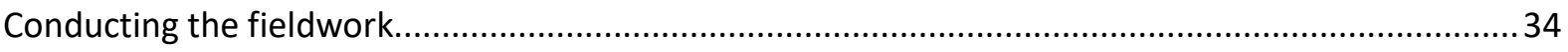

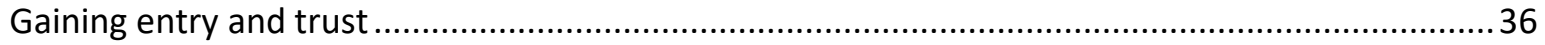

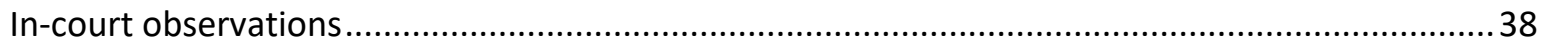

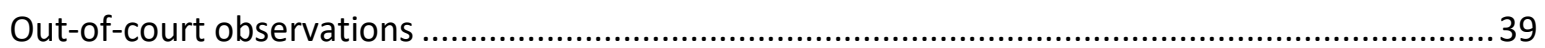

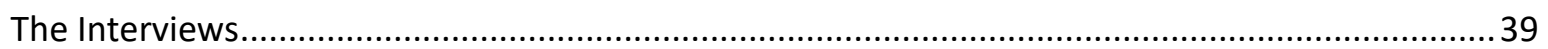

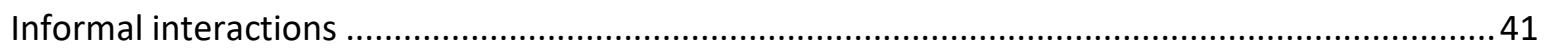

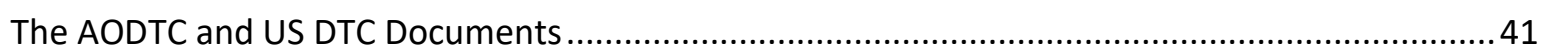

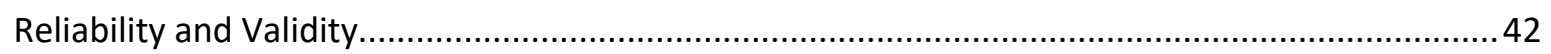

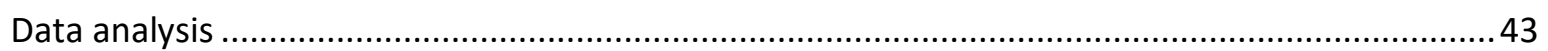

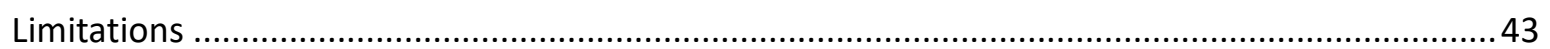

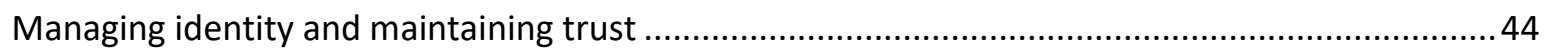

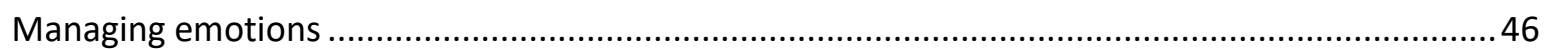

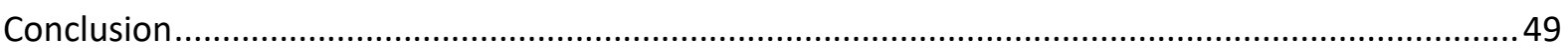

Chapter 3: A Brief History of Addiction \& Penal Treatment in New Zealand ...................................... 51

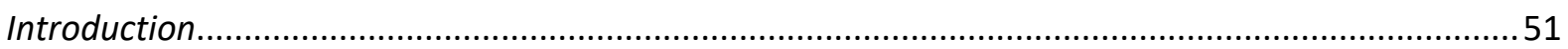

A brief history of the constitution of AOD addiction and compulsion .............................................. 52

Early conceptualisations of addiction and penal treatment in New Zealand..................................54

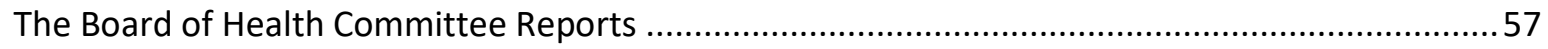

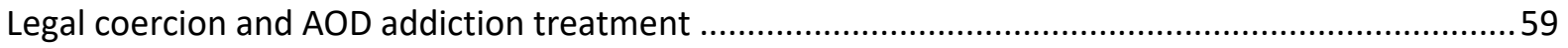

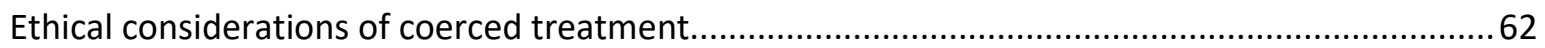

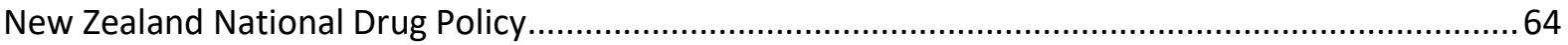

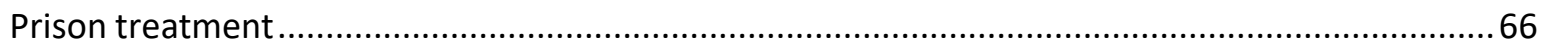

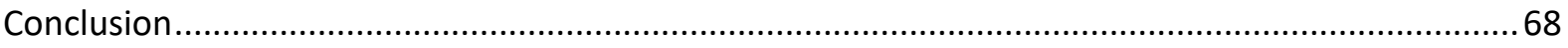

Chapter 4: The New Zealand Alcohol and Other Drug Treatment Court........................................... 70 


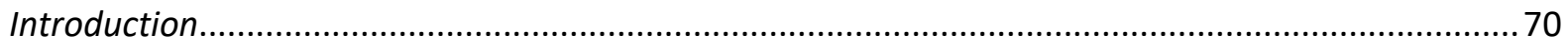

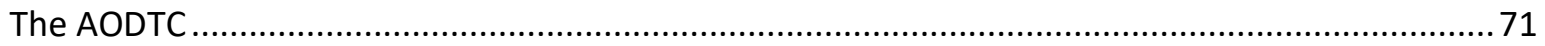

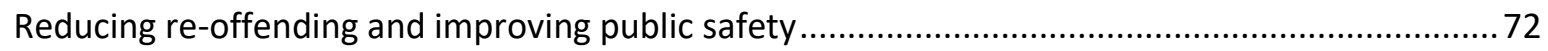

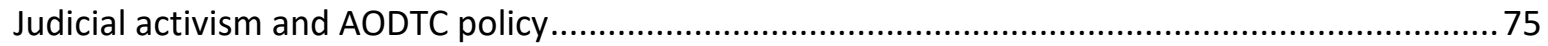

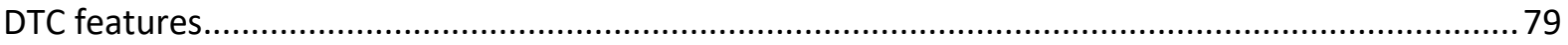

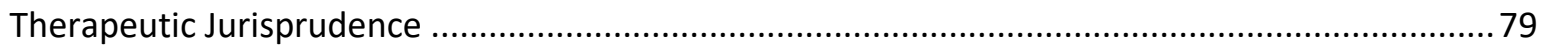

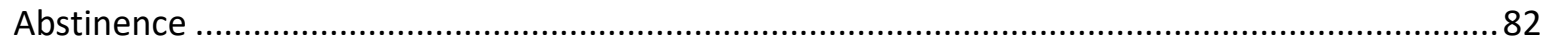

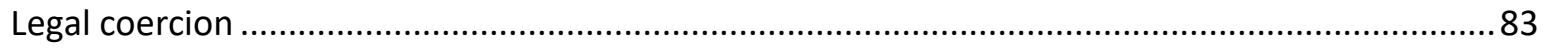

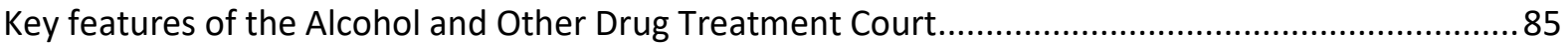

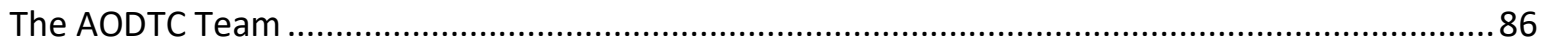

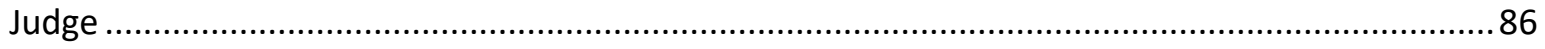

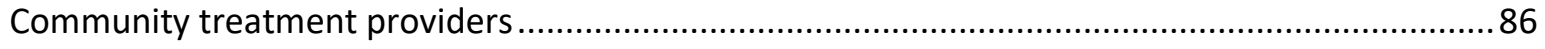

The Alcohol and Other Drug Treatment Court process ................................................................. 87

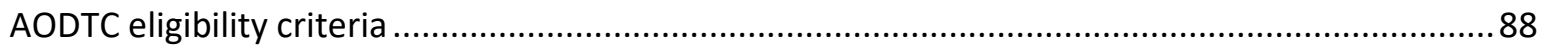

AODTC Handbook, AODTC Participant Agreement and Participant Handbook ............................... 90

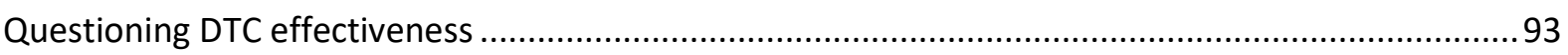

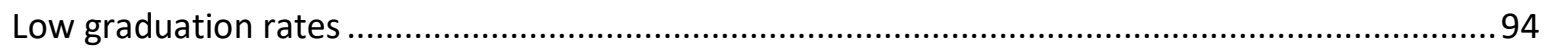

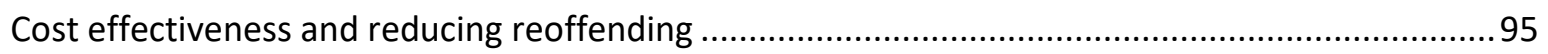

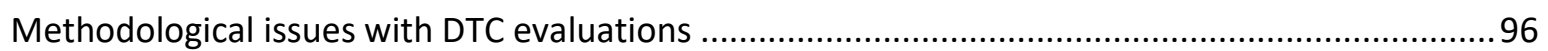

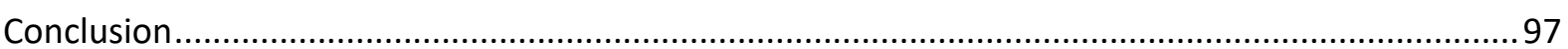

Chapter 5: Addiction and Treatment in the Alcohol and Other Drug Treatment Court......................99

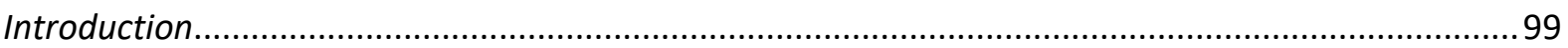

Conceptualising addiction in the Alcohol and Other Drug Treatment Court .................................... 101

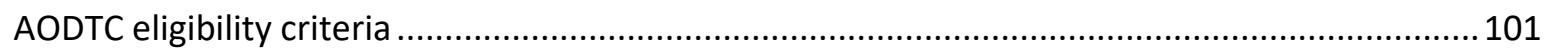

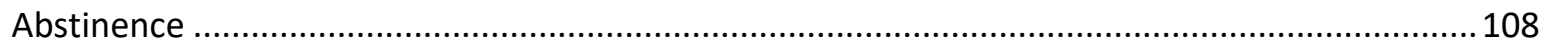

Defining substances and behaviours as addictive, illegal and dangerous ...................................113

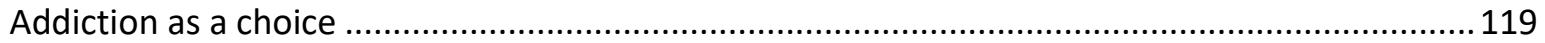

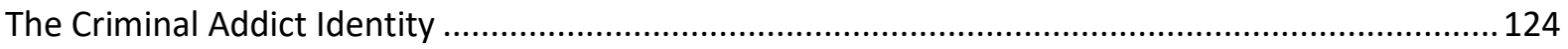

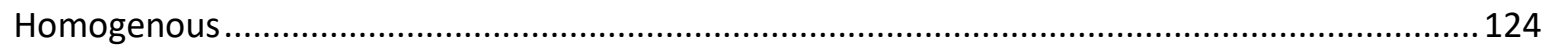

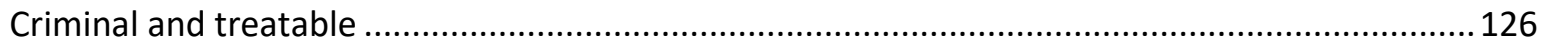

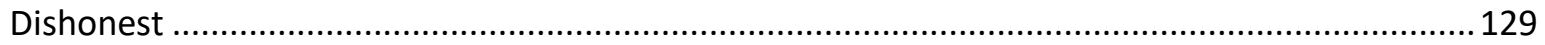

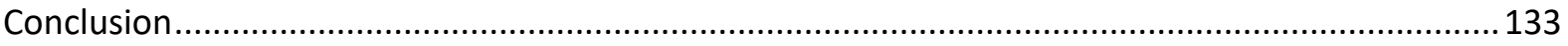

Chapter 6: Recovery in the Alcohol and Other Drug Treatment Court .........................................135

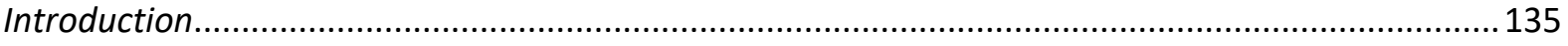

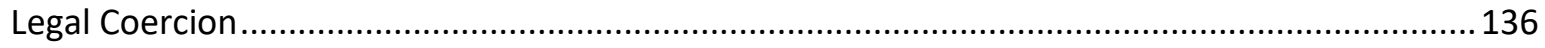

The 12 Steps of Alcoholics Anonymous and Narcotics Anonymous ............................................139 


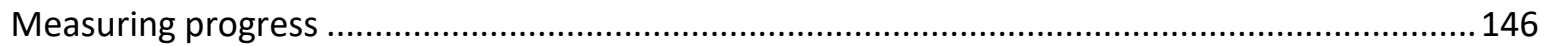

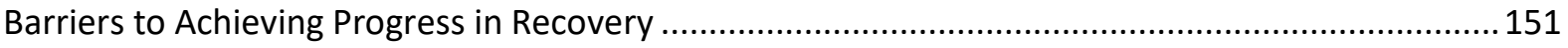

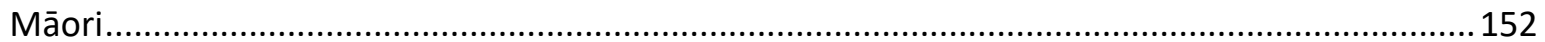

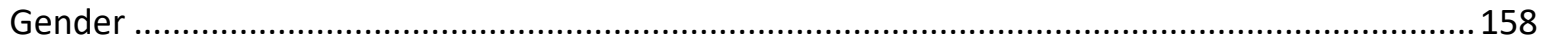

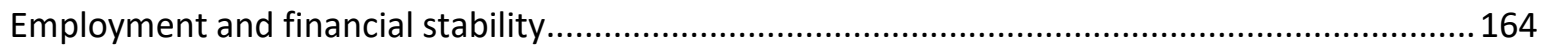

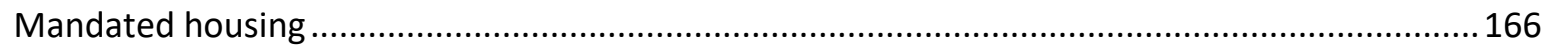

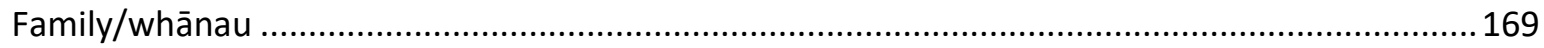

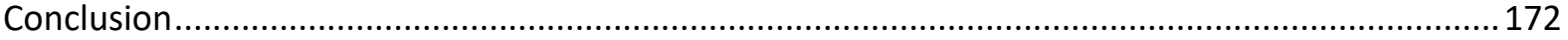

Chapter 7: Punishment under the Guise of Treatment in the Alcohol and Other Drug Treatment

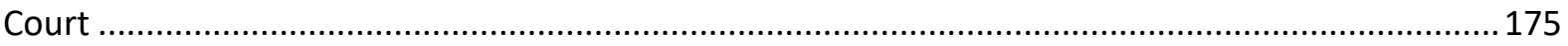

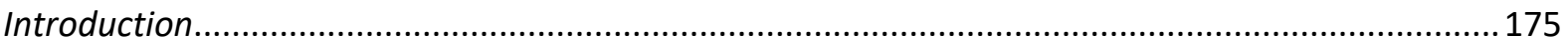

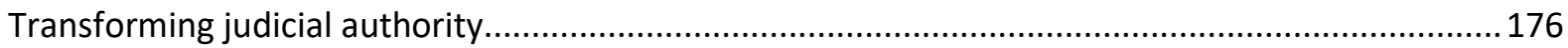

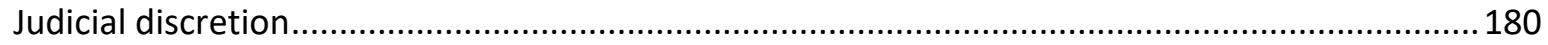

"Is she more deserving than someone else?" Inconsistent judicial intervention ..........................183

"Can you put him in prison for the weekend?" The role of AODTC residential treatment providers

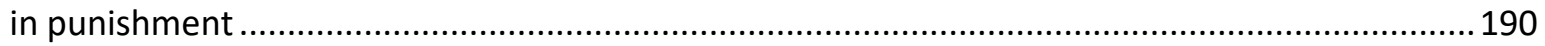

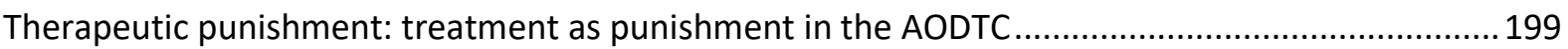

Therapeutic Surveillance: AOD testing as establishing honesty and trust ....................................200

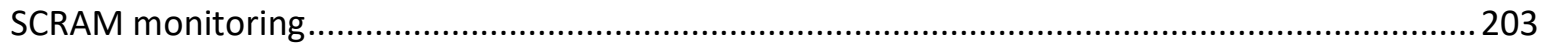

Therapeutic sanctions: Creating opportunities for a teachable moment ....................................204

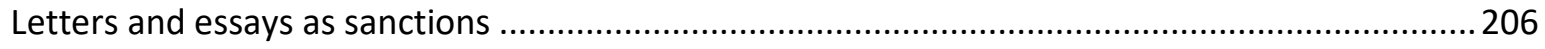

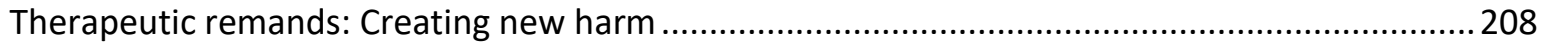

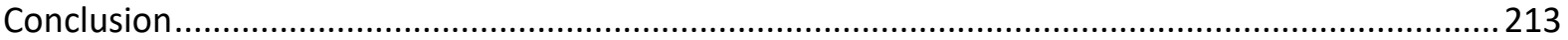

Chapter 8: Addressing the Harms Arising from the Alcohol and Other Drug Treatment Court.........215

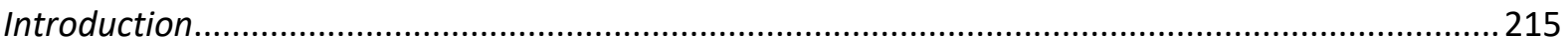

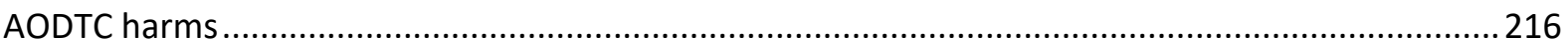

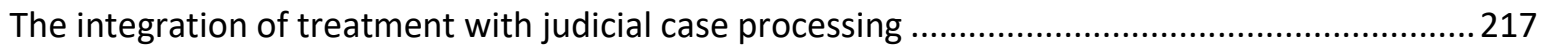

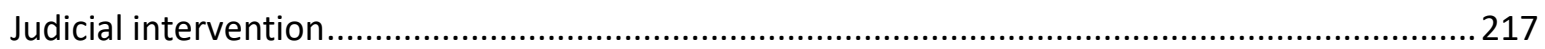

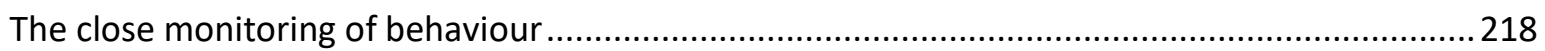

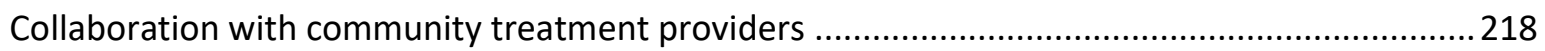

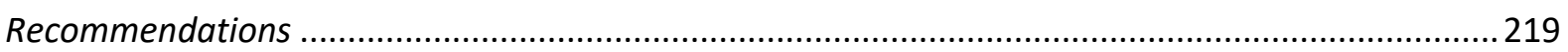

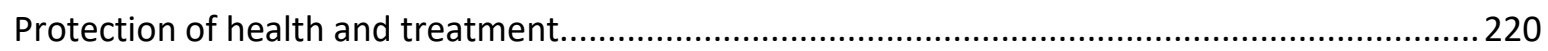

A departure from individual responses to AOD offending and addiction .....................................221

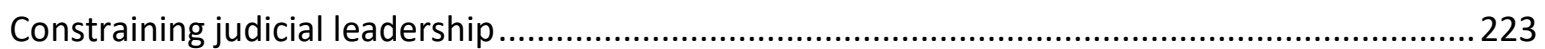

Confining community treatment providers to the provision of health-based practice .................2224 


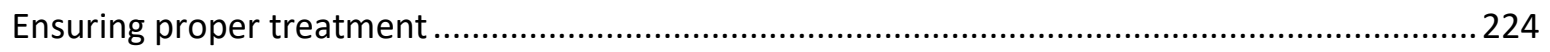

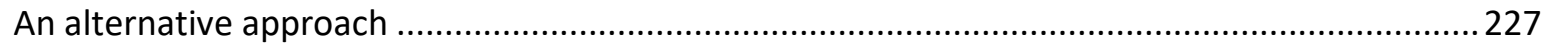

Conducting truly independent evaluation studies and further research ...................................229

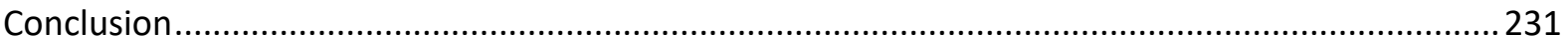

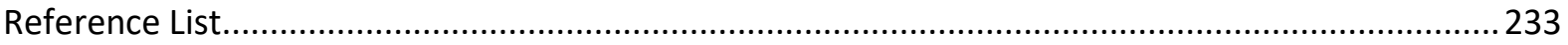

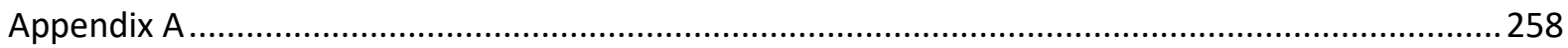

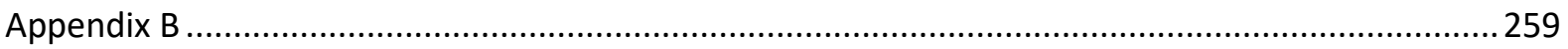

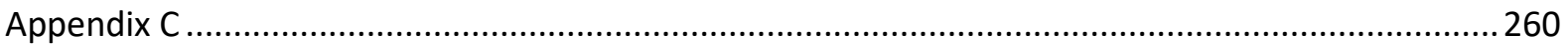

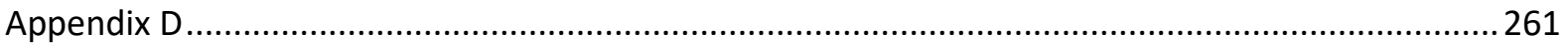




\section{Chapter 1: Introduction}

This thesis investigates the treatment policies and practices of the New Zealand Alcohol and Other Drug Treatment Court (AODTC). Established in the Auckland and Waitakere District Courts in 2012, the AODTC is based on the ten key components of the United States drug treatment court (DTC) model and adult best practice standards. ${ }^{1}$ The origins of the AODTC lie mainly in the Law Commission's (2011) recommendation of a drug court pilot aimed at balancing the social, economic and cultural needs of offenders with the priorities of health and justice through treatment.

The claimed benefits of the AODTC are to 'reduce' Alcohol and other Drug (AOD) reoffending, 'reduce' AOD consumption, and 'reduce' imprisonment, thus positively affecting offenders' health and wellbeing (Ministry of Justice, 2012a; 2014). Focussed primarily on the health and wellbeing aspect of the AODTC, the thesis establishes that the AODTC model, underpinned by the principles and practices of the US DTC model, introduces a problemsolving mandate that seeks to address the revolving door of AOD related crime through a therapeutic mandate. The AODTC endeavours to do this by changing the role of the judiciary in managing AOD offending and by introducing collaboration with community agencies in the treatment of addiction (Ministry of Justice, 2012a; 2014).

The thesis critically examines the AODTC adoption of the US DTC model, the assertion that the court signifies a 'smarter system of justice' to AOD addiction (Tremewan, 2013:6) and the experiences of participants in treatment. ${ }^{2}$ In addition, the principles and practices adopted by the AODTC have practical importance for participants' rights as the court utilises the law to coerce and enforce treatment compliance in collaboration with community agencies. Beyond a series of government evaluations (Litmus, 2014; 2015; 2016), the available information about the courts, community treatment providers, and the roles of participants' in the treatment programme, is very limited. The thesis aims to address this deficit. Moreover, and equally important, in recognition of the limited examinations of the AODTC to date the research brings participants' experiences to the fore (Litmus, 2014; 2015; 2016).

\footnotetext{
${ }^{1}$ In line with drug court proponent retired US Judge Hora (2002), I use the term DTC to refer in general to the drug court model. See Appendix C for an outline of the United States DTC 10 key components and Adult DTC Best Practice Standards

2 While US DTCS were developed as a pragmatic and alternative response to 'the revolving door' of drug offending and increased incarceration rates (Hora, 2002:1470). By way of contrast, the New Zealand AODTC was established at a time when AOD crime trends were declining; but incarceration rates were high and steady (New Zealand Police, 2013).
} 
Despite the proclaimed popularity of DTCs and problem-solving courts as 'courting new solutions' (Hora, Schma and Rosenthal, 1999), there are various criticisms about DTC therapeutic interventions that I draw upon in the thesis. First is the role of coercion and therapeutic 'interventions' under the guise of therapeutic jurisprudence (Boldt, 2006; Malkin, 2005). Therapeutic jurisprudence (TJ) is a perspective developed to address the anti-therapeutic effects of legal rules and procedures, bringing a new focus onto the law's effects on offenders' wellbeing (Boldt, 2006). ${ }^{3}$ The DTC utilises TJ to coerce participant compliance, with the goal of maximising therapeutic interventions 'on the social, emotional, and psychological functioning of individuals and families' (Boldt, 2006: 95).

Proponents argue that DTCs signify 'the evolution of therapeutic jurisprudence from theory to practice' (Hora, Schma, Rosenthal, 1999:448). However, previous research has established that DTCs and problem solving courts owe their values and practice to both TJ and the rehabilitative ideal (Boldt, 1998; Nolan, 2003), with each being characterised by tensions between 'treatment' and 'justice', 'procedural informality' and 'judicial activism' (Boldt, 1998:1215). It has been argued that both undermine due process and proportionality through the DTC 'problem-solving' mandate of coercion and therapeutic interventions, (Hoffman, 2002; Husak, 2011; Miller, 2004), making it possible to speak of 'justice' as 'treatment' (Nolan, 2003:1553). The dangers are that 'treatment' can be spoken of as punishment and vice versa. This means that the distinction between punishment and treatment is blurred (Nolan, 2003; von Hirsch and Maher, 1992), leading to the assertion that DTCs represent 'rehabilitative punishment' (Boldt, 1998).

Second, while proponents claim DTCs represent an alternative to the 'revolving door' of crime and punishment (Hora, Schema and Rosenthal, 1999), DTC addiction treatment has in fact, been rarely examined by scholars (Cooper, 2017; Gallagher, 2013; Gowan and Whetstone, 2012; Lutze and van Wormer, 2007). Of particular concern is the evidence that, demonstrates DTCs blur the boundaries of justice and treatment through the 'myth' that 'addiction is a brain disease' (Peele, 1987:207), while at the same time warrants criminal responsibility (Husak, 2011; Miller, 2009). In this context, 'disease' is made to fit into the 'discourse of criminal responsibility' under a framework of 'choice and accountability' (Miller, 2009). Accordingly, DTCs conceptualise 'addicts as sick' and their offending 'as symptomatic of illness only as

\footnotetext{
${ }^{3}$ While I discuss the DTC practice of TJ in greater depth in Chapter 4, I acknowledge the criticisms that TJ 'descends' theoretically from the rehabilitative ideal (Hoffman, 2002:2083).
} 
long as they transform their behaviour' (Husak, 2011:225). However, and of concern is that when treatment is unsuccessful the court resorts to punishment (Boldt, 1998).

Third, some proponents of the DTC framework have translated the accountability mandate into one that helps, heals and reforms offenders through incentives and sanctions utilised by the court (Hora et al, 1999; Goldkamp, 2000; Marlowe, 2012). However, these practices raise doubts and questions regarding the provision of 'treatment', giving way to claims that these courts are 'theoretically incoherent' (Bowers in Husak, 2011:224) 'extremely controversial', 'imprecise' (Boldt, 2010:21), and exaggerate the harmful effects of law reform (Hoffman, 2002:2067) to the offender 'in principle and practice' (Fischer in Boldt, 2010:22).

In making an argument for the AODTC, AODTC Judge Tremewan ${ }^{4}$ (2013) presents a description of the programme as 'coerced' treatment, 'a more humane and fitting criminal justice response' to 'the revolving door of crime', pointing out that:

'...participants do choose to be coerced in the treatment court when offered a place - even though dealing with their addiction issues is considerably harder than avoiding them and generally also harder than serving another prison sentence .... By using a 'carrot and stick' approach to the proceedings, to hang the charges over the offender's head... the Court closely monitors progress and encourages recovery... The participant need not even be that 'motivated ...remembering that addiction relates to a chronic often relapsing disease' (2013:3-6).

I argue that the belief that the AODTC serves as a humane and fitting 'criminal justice' response in principle and practice, raises important questions as to how New Zealand approaches the use of law aimed at targeting the treatment of addiction related offending. Moreover, section 25 of the Sentencing Act 2002, the governing provision of the AODTC, allows the judge to adjourn sentencing to enable the participant to enter the programme and complete treatment. Section 25 also permits wide judicial discretion to hold participants accountable for the court goal of abstinence, to determine recovery, and to apply punishment for treatment non-compliance (Litmus, 2016). Therefore, the belief that addiction is a chronic 'relapsing disease' and that participants 'choose to be coerced' in the programme and, as a result, will show less potential for crime, is concerning because there is nothing to stop the judges from using their power to justify punishment as treatment in the AODTC. ${ }^{5}$ This means that the programme can become burdensome and harmful for the participants, potentially

\footnotetext{
${ }^{4}$ Judge Lisa Tremewan is one of the founding judges of the New Zealand AODTC and an advocate of therapeutic jurisprudence. https://cij.org.au/video-podcast/judge-lisa-tremewan-2/

${ }^{5}$ In saying this, I acknowledge that 'punishment' is a contested term.
} 
hindering their progress and recovery, undermining their health and wellbeing (the implications of which I discuss in greater depth in Chapter's 6, 7 and 8).

The thesis incorporates the following interrelated research questions:

- First, how does the AODTC define addiction as a disease and identify it in practice;

- Second, how is the addicted offender conceptualised in the AODTC;

- Third, how does this translate into treatment practices, and;

- Fourth, what are the implications of these understandings of addiction for the treatment of the offender and those treatment practices?

The results of this thesis offer valuable insights into how the problem-solving court manages treatment, governs addiction, and transforms the criminal addict. It also generates insight into larger questions of power, with an examination of the AODTC providing an understanding of the assumptions, principles and legal practices involved in treating addiction as a criminal justice problem, and the incorporation of community treatment in the justice system.

This thesis is interdisciplinary. It contributes to the fields of criminology, law and socio-legal scholarship. It draws on participant observations of precourt and in-court meetings and hearings, out of-court observations, 18 interviews with AODTC participants, informal conversations with court workers, participants' families, treatment providers, policy analysts, and US DTC and AODTC document analysis. This is the first study of its kind in New Zealand, and one of few international ethnographic studies that details the experiences of participants. It is designed to make a valuable contribution to New Zealand and international scholarship and provide a resource for further research.

The thesis examines AODTC processes that constitute addiction treatment and punishment. Most of the existing DTC research is US based, quantitative, and seeks to determine whether DTCs are effective in reducing recidivism, are cost effective, or produce effective court processing (Carey and Finigan, 2004; Carey, Finigan and Pukstas, 2008; Hora and Stalcup, 2008; Wilson, Mitchell and Mackenzie, 2006). While proponents claim that DTCs treat addiction, and thus reduce recidivism and justice costs (Hora, Schma and Rosenthal, 1999), many of these studies examine DTC cost-effectiveness, and thus overlook the implications of mandated treatment on offenders' health and wellbeing. They are also fraught with methodological issues (Kornhauser, 2016; Fischer, 2003; Goldkamp, White and Robinson, 2001; Hoffman, 2000) because they target drug court graduates instead of all drug court 
participants (Belenko, 1998). A small percentage of the literature supporting the work of DTCs is focussed on identifying the role of $\mathrm{TJ}$ as a way of facilitating treatment that does no harm (Hora, 2002; Nored and Carlen, 2008), but that ignores the consequences of these therapeutic procedures for the participant (Nolan, 2003).

Not all studies show that DTCs reduce recidivism or criminal justice involvement, reduce costs, improve public safety, or provide appropriate treatment (Drug Policy Alliance, 2014; Csete and Tomasini-Joshi, 2016; Justice Policy Institute, 2011; SSRC, 2018). Further, in spite of the growing problem-solving court trend and criminal justice community partnerships (Fischer, 2003), few studies have examined the effects of treatment on participants (Gallagher, Nordberg \& Kennard, 2015).

To date, the existing body of critical literature highlights the coercing of individuals into DTC treatment (Boldt, 1998; 2009; Gowan and Whetstone, 2012; Lyons, 2011; Miethe, Lu and Reese, 2000; Miller, 2004; 2009; Murphy, 2011; Nolan, 2002; 2003; 2009; O’Hear, 2009; Seddon, 2007; Stevens, 2012; Tiger, 2011). Tiger's (2011) study, for example, involved analysis of some US DTC documents and interviews with proponents. Despite the importance of that research, there remains a paucity of evidence of participants' experiences of legal coercion.

Drawing on 'in-court' and 'out-of-court' observations, my research presents a more balanced view as to how the AODTC governs treatment, and how participants respond to the court's therapeutic expectations. In addition, and in contrast to most other DTC studies, my semistructured interviews included declined applicants, exited participants, a graduated participant, and participants actively involved in the court programme. My thesis contributes important data to the existing qualitative DTC research, because to date there are few ethnographic studies of DTCs, and almost none of them involve interviews with participants that were currently engaged in the court programme.

Until now, most DTC studies have been conducted in the US and Canada, and have involved observations of court hearings and interviews with DTC judges, treatment workers and proponents. For instance, Miethe Lu and Reese (2000) conducted observations of a Las Vegas DTC courtroom over three months, while Burns and Peyrot conducted observations of two Californian DTCs. Together, these studies demonstrate the value of conducting courtroom observations of DTC as a method of data gathering. Similarly, Whetstone and Gowan (2011) conducted observations comparing a drug court in the U.S. to a treatment provider used by the 
DTC. Other research, such as that of Mackinem [a DTC coordinator], and Higgins (2007) involved a study of three DTCs in the US involving observations and interviews with staff. Likewise, Nolan $(2001$; 2009) conducted observations and interviews with DTC professionals. His research provides insight into how DTC professionals put into practice their understanding of the courts' requirements. Murphy (2011) conducted observations of DTC sessions, and interviews with people being treated in separate drug treatment facilities. Overall, this research is limited, because it tends to focus on the social construction of drugs and the medicalization of deviance and social control, so, to a degree, it excludes the lived experiences of DTC participants.

Relatively few adult DTC studies employ qualitative methods. The small number of studies of participants' experiences are limited to interviews with people post-DTC graduation, or with people involved in a treatment facility used by DTCs. For instance, Kaye (2012) conducted observations of a residential treatment facility and interviews with DTC proponents and providers, and people in treatment. Lyons (2011) conducted observations of DTC sessions and interviews with 11 (7 men and four women) former court participants. Moore and Hirai (2014) relied on observations of court sessions and interviews with court participants to gain data on the experiences of other people exited from the programme. While their research combines observations with interviews, it presents a description only of the court process (Moore and Hirai, 2014). Of the available data, interviews with participants are confined to those that have graduated from the programme or are from a residential treatment facility (Kaye, 2012; Lyons, 2011). They tend to demonstrate how participants negotiate treatment practice, rather than identify the barriers participants encounter through mandated treatment.

Given the potential for a wide range of outcomes for the court participants, my approach is to examine AODTC policies, practices, and the interactions between the AODTC judges and participants, and to focus on court procedures, judicial monitoring and community provider involvement in treatment. In this way, I identify the type and the degree of therapeutic practice that conceptualises addiction and offending as a disease, and which justifies treating participants as accountable for their recovery. I argue that AODTC requirements such as responsibility and accountability for addiction take on a particular significance in the context of criminal punishment, involving sanctions and potentially serious intrusions into participants' lives. Much of the DTC research has focussed on the relationship between treatment and recidivism rates. In contrast, this thesis pursues an analysis of the AODTC 'treatment' focus and the effects on participants' health and wellbeing. 
It should be noted that the approach adopted in this thesis does not take in the various social and political constructs of addiction, because the AODTC in line with US model upon which it is based, readily accepts and thus does not contest the view of addiction as a disease. However, given that the thesis is focussed on participant experiences, the impact of the AODTC on their health and wellbeing, treatment, and punishment practices and that the court simply has not and does not engage with the sociology of 'drugs' and 'addiction', I am forced to work with the conceptions that they do hold and the effect and impact of those practices. I do, however, recognise that the AODTC's assumptions of AOD use and users are essentially heavily contested concepts that have the potential to define addicts 'as pathological and risky' (Keane, 2004:197). Thus, discourses of addiction can include all kinds of 'substance and behaviour' that can in turn, inform programmes targeting an individual's willpower (Sedgewick in Nicoll, 2012:175). The AODTC has its own 'constructions' of AOD use. The conceptions held by the court are themselves particular constructions, that is, they construct 'addiction as a disease', conflate alcohol with drugs and other drugs including methamphetamine and tobacco and construct other things as dangerous to recovery, such as sweets. Accordingly, the court has adopted and is informed by a conventional and uncritical conception of AODs.

These points are important, because historically, addiction treatment in New Zealand has involved tensions between disease, responsibility and coercion, cure and abstinence and the view that drunkenness is an illness afflicted by race (Mancall, Robertson and Huriwai, 2000). As I argue in the following chapters, the range of possibilities for a humane and fitting criminal justice response to AOD related offending are neither entirely straightforward nor fair for the participants.

Very little is known about whether drug court monitored treatment is likely to promote the health and wellbeing of people. The literature that criticises the DTC portrayal of addiction as a disease, responsibility and the pursuit of abstinence-based treatment reveals that the model has the potential to undermine social and cultural factors instrumental to offending (Hoffman, 2000). However, to date, surprisingly few studies have examined the ways that treatment takes into consideration ethnicity, gender, and people with coexisting health issues. Dannerbeck, Harris and Lloyd's (2006) data analysis of DTC outcomes for African American offenders identified that this group are less likely to graduate in comparison to white offenders. They pointed out how DTC treatment entrenches stigma and oppression for African American participants, thereby undermining success. The existing research on the treatment of gender is 
similarly limited (Koetzle Shaffer, Hartman and Listwan, 2009), with the exception of Lyons' (2011) observations of how 4 women negotiate treatment, and Fischer and Geiger's (2011) study of women graduates experiences of sanctions.

Some American literature has documented barriers to treatment for people taking opioid substitutes (Csete and Catania, 2013; Matusow, Dickman, Rich, Fong, Dumont, Hardin, Marlowe and Rosenblum, 2013). One US survey study recommended that future research take in the experiences of participants with 'interviews and analyses based on 'gender, race and ethnicity' (Gallagher, Nordberg and Lefebvre, 2016:471). There is also limited literature on the treatment experiences of people with a coexisting disorder, disability, or brain injury in problem-solving courts (Schopp, 2013). Accordingly, my research provides an important contribution to the literature by giving attention to the AODTC experiences of Māori, women, transgender people, and people with coexisting health needs, in addition to the experiences of participants with families. ${ }^{6}$

The thesis will also add important empirical data to the international pool of DTC ethnographies and problem-solving court literature, providing a point of focus from which to consider broader policy, and evaluative criteria of people's experiences of treatment in the problem solving court. New Zealand is no stranger to importing problem-solving policies and practices from overseas. The Christchurch Youth Drug Court pilot established in 2002 is the first example of a problem solving court based on the US drug court model (Searle and Spier, 2006). There are also adult specialist court models such as the Matariki Court in Kaikohe; Te Kooti o Timatanga Hou (the New Beginnings Court) aimed at homeless people in Auckland, and the Court of Special Circumstances in Wellington (Ministry of Justice, 2017).

By examining the governing of AOD addiction and treatment in the AODTC through a critical qualitative lens, I bring a focus onto the development of this problem solving court, the treatment of the participants, and their experiences of treatment. My thesis provides valuable empirical insight into how the New Zealand AODTC and the criminal justice system constitute AOD offending, addiction treatment policies, and how they manage the transformation of the addicted offender to accomplish recovery.

\footnotetext{
${ }^{6}$ In New Zealand, Māori make up 15 percent of the general population, but 50 percent of the prison population, with Māori offending credited to mainly ethnicity (McIntosh and Workman 2017). Of concern is that the proportion of convicted adults who are Māori has risen over the past 10 years (Ministry of Justice, 2019). As will be discussed in Chapter 4, addressing Māori offending rates played an important part in the emergence and development of the AODTC pilot.
} 


\section{Thesis overview}

The AODTC is relatively new to the New Zealand criminal justice system, and there is little research beyond three evaluations. These evaluations are limited in that are confined to examinations of recidivism rates among participants/graduates, and programme cost effectiveness (Litmus, 2014, 2015; 2016). My thesis presents an alternative to these evaluations, by focussing on the day-to-day running of the courts, the interactions between the judges and participants, and the treatment experiences of participants. It draws attention to the AODTC's linkage between addiction as a disease, AOD offending and responsibility, monitoring compliance through unfettered judicial discretion, and the deployment of this knowledge in the context of coercive treatment, punishment and proportionality. I also draw attention to how the AODTC governs abstinence-based treatment and responsibility for addiction as a disease and recovery. Largely, I raise important concerns regarding the appropriateness of treatment for the participants.

\section{Chapter summaries}

The overall structure of the thesis covers eight chapters, including the introduction.

Chapter 2 outlines the thesis methodology used to investigate the governing of addiction and treatment in the AODTC. I employ the theoretical and methodological frameworks of legal consciousness, and a history of the present to aid understanding of addiction treatment in the AODTC. I also outline the critical ethnographic data collection methods used in the research, ethical considerations, and the practical aspects of managing the researcher identity whilst conducting the fieldwork. I also detail how I managed my identity whilst gaining access to the AODTC, and the difficulties encountered while carrying out the research that informs the thesis.

Chapter 3 contextualises the AODTC within a brief historical analysis of the constitution of AOD addiction and treatment in the New Zealand criminal justice system. Given the aims and scope of the thesis, it is not feasible to take in the complete history of addiction in New Zealand this would require a thesis in its own right. Nevertheless, the chapter makes a contribution to the literature by revealing that there is very little historical research into the role of coercion in the treatment of addiction and in the criminal justice system. Further context is supplied via analyses of the state's responsibilities to ensure the health of AOD users. I also introduce the national drug policy (NDP) and highlight how the NDP is underpinned by the goals of crime prevention and law enforcement, which have negative consequences for the criminal justice 
treatment of AOD addiction through involuntary withdrawal practices. I argue that, even though there is no official definition of addiction in the NDP, its brief description of the AODTC pilot in the context of drugs policy strongly suggests a dual approach to treatment and punishment.

Chapter 4 traces the emergence and development of the AODTC and the use of political rhetoric in justifying the AODTC as a means of bridging the justice/health divide. In particular, it highlights the role of the Law Commission (2011) and judicial activism in the development of the AODTC, and the adoption of US DTC policy and best practice. The chapter then details the key DTC features: therapeutic jurisprudence, abstinence, and legal coercion. Each of these features underpin the AODTC model as representing the principles of best practice and process. This chapter also briefly summarises the AODTC evaluations, and challenges the claims therein that DTCs are appropriate and effective (Nolan, 2003; Goldkamp, 2000).

Chapters 5, 6 and 7 contain the thesis findings. In these chapters, I draw from the AODTC participant observations, participant interviews, informal conversations, and document analysis, and set out the groundwork for the discussion and recommendations. In particular, Chapter 5 presents the institutional context. Here the focus is on how the AODTC defines addiction, and how it constructs the criminal addict identity for the purposes of treatment. In Chapter 6, I describe how the AODTC defines recovery, and how the court assesses recovery through an emphasis on participants taking responsibility for their treatment, accountability and programme compliance. I highlight ambiguity and inconsistency in the definition and meaning and measurement of progress, and outline the structural consequences for any failure by participants to take responsibility for their own recovery and non-compliance. The consequences include the barriers to treatment, health and wellbeing for Māori, women and transgender, and participants with families and in employment.

In Chapter 7, I discuss the implications of merging treatment with punishment in the AODTC. I advance a critical view of the impact of treatment in the AODTC, particularly regarding tensions between addiction, responsibility, and proportionality, and introduce the concepts of therapeutic punishment, therapeutic surveillance, and therapeutic remand. Chapter 8 summarises the findings, their implications, and the significance of the research. It shows that there are harms arising from the AODTC's therapeutic practices. These are caused by the following overlapping DTC therapeutic features: the integration of treatment with judicial case 
processing; judicial intervention; the close monitoring of participants' behaviour; and collaboration with community treatment providers.

In keeping with the focus on the AODTC's governing practices, and the participants' experiences of negotiating the courts requirements, I propose a series of recommendations and options for a new approach that facilitates a treatment focus inclusive of the right to health in order to avoid further structural discrimination. A treatment focus that confines judicial leadership to out of court administrative duties, and provisions be put in place to prevent the community treatment providers from engaging in punitive treatment practices. Overall, the focus is on placing greater emphasis on regulated health based responses inclusive of social, cultural, and economic needs. In the absence of fundamental change, I recommend the undertaking of independent studies and further research, because there is little known about the courts beyond the Ministry of Justice evaluations.

The thesis conclusion argues that the AODTC conceptualises addiction as a disease and a responsibility, the criminal addict is conceptualised as dishonest but honest, criminal and treatable. The treatment practices of the AODTC do not resemble the best practice consensus of the US DTC National Association of Drug Court Professionals (NADCPs), nor does the court reflect New Zealand health and treatment policies and practices as enshrined in international and domestic policy. The implications are that the AODTC treatment practices documented in this thesis show that the court excludes offenders from the humane and effective treatment to which they are entitled. Ultimately, the thesis concludes that the AODTC has failed to effectively govern the treatment of AOD addiction. 


\section{Chapter 2: Theoretical and Methodological framework}

\section{Introduction}

This thesis critically examines the role of the Alcohol and other Drug Treatment Court (AODTC) in the governance of addiction treatment. As outlined in the previous chapter, the AODTC introduces a new problem-solving mandate that changes the judicial role, and introduces collaboration with community agencies in treating addiction related offending. The purpose of this thesis is to provide evidence of the AODTC rationale, in both its documentation and its practice, and the experiences of those undergoing the mandated treatment programme. This is achieved by combining data analysis with participant observations, and in-depth interviews with court participants.

This chapter details the theoretical framework, methodology, and methods of data collection underpinning the research into the AODTC. I begin with a brief overview of the combined theoretical framework of 'legal consciousness' and 'history of the present'. Both theoretical approaches help us to understand the mechanics of liberal governance, which is a feature of the AODTC.

Legal consciousness has been broadly understood as 'the ways people understand and use the law' (Merry 1990:5) and 'participation in the process of constructing legality' (Ewick and Silbey, 1998). Silbey (2005) used the word 'legality' to refer to the law's invisible restraint and the cultural practices that constitute the power and authority of the law. Legality also refers to 'the experiences of law in everyday life', which can be rendered irrelevant by the power and privilege of the rule of law (Silbey, 2005:350). Legal consciousness therefore covers the perceptions and values of law-making bodies and the court system. In using legal consciousness, the thesis takes a critical socio-legal approach by researching the AODTC as sites of law making and legality (Ewick and Silbey, 1998).

In an effort to understand the role of the AODTC in the governing of addiction treatment, I utilise legal consciousness to examine the AODTC in legitimising new knowledge of AOD related offending, addiction as a disease and abstinence as a goal of the court, recovery, and punishment. There is therefore a focus on AODTC policies, practices and the participants' voices, to illustrate the court's governing approach to AOD addiction, treatment and punishment. In particular, legal consciousness helps us to understand the everyday experiences of participants in the programme and the role of the court in merging treatment with punishment. 
The thesis also draws on Foucault's concept of 'history of the present' to better understand the issue of addiction and penal treatment AODTC (Gutting, 1994). A history of the present allows us to understand how the AODTC was not preordained but is in part a product of a 'contingency of the past on the present' (Yeomans, 2018:3). As such, history of the present is used to illuminate how the historical knowledge of addiction and penal treatment (as discussed in Chapter 3) is a process that has consequences for the AODTC. Essentially, a history of the present is deployed in this thesis to complement legal consciousness, because there is some criticism that legal consciousness studies' reliance on empirical data lead to it being an overly descriptive of everyday practices and experiences of law (Garcia-Villegas, 2003). In my research, I emphasise the connections between the rationalities that problematise the governing of addiction and law reform (Garland, 2014). As I discuss below, the combined theoretical approach permits me to consider the historical and socio-political context that supports the criminal justice system in adopting policies aimed at 'treating' offending.

Overall, this research will create a thesis that is 'attuned to historical context' as it is to the contemporary use of the law in reproducing existing tensions in the merging of health with justice in the contemporary AODTC (Yeomans, 2018:1; Silbey, 2005).

The chapter then outlines the data gathering process employed in my fieldwork. First, I outline the mixed methods used, which combine observations with interviews and document analysis. This section describes critical ethnography as providing the methodology. It is used to explore the role of the AODTC in governing addiction treatment and the legal consciousness of participants and I discuss how these methods were used to gain insight into participant experiences of the AODTC. Second, I detail my entry into the field, and the use of pre-field work data and intersectionality to draw attention as to how the state came to the point of incorporating addiction, ethnicity, and gender into AOD governance. Third, I outline the methods of data collection, including participant observations, semi-structured interviews, informal meetings, and document analysis, and discuss how these make for a deeper, more contextualised approach to the research. Fourth, I detail my method of data analysis and address reliability and validity in my research. Finally, I discuss how engaging in multiple allegiances is a methodological, emotional, and ethical challenge to conducting research in the AODTC. In doing so, I provide an account of managing ethical considerations and emotions in the research process. 
In providing an empirical analysis of the AODTC in the governing of addiction and treatment, I argue that it is also important to locate the court within broader social, cultural, and historical contexts. To be precise, criminal justice processes are comprised of discourses and practices that intersect with the concepts of addiction and subjectivity (Valverde, 2003). By viewing the AODTC as a specific site where these discourses of addiction, treatment, and punishment practices unite, the AODTC offers a unique opportunity for exploring the institutional and organisational context of governing of addiction treatment in the criminal justice system.

\section{Theoretical framework}

The legitimacy of the DTC is grounded in the claim that the criminal justice is an appropriate site for 'merging justice and treatment', through a problem solving court mandate (Boldt, 2009:15). In considering the legitimacy of the DTC, Boldt (2009) contends that the growing influence of therapeutic jurisprudence (TJ) and the knowledge that traditional judicial processes are inadequate for dealing with addiction related offending, support the problematic merging of justice and treatment. However, a negative outcome is that offenders are seen as 'suffering from a chronic relapsing disorder' while at the same time they are 'constructed as responsible moral agents' (p.14) to be held accountable for their choices. He argued that the troubling partnership between justice and treatment:

'....can be explored by examining the ways in which individuals are conceptualised in drug treatment courts... by examining the roles assumed by judges, defense lawyers and other actors in the hybrid settings' (Boldt, 2009:14).

As demonstrated in the previous chapter, the legitimacy of the AODTC rests on the problematic confluence of addiction as a chronic relapsing disease and offenders as choosing to be coerced into treatment (Tremewan, 2013). Taking in this illegitimacy, my thesis has adopted a critical perspective and approach in its investigation of the AODTC as a new institution of addiction treatment and punishment. I critically examine the AODTC treatment policies and practices and bring into focus the ways in which the participants are conceptualised, treated and punished. My research offers a new empirical contribution to DTC scholarship and socio-legal research. It is also hoped that this research is able to contribute to law reform involving specialist problem solving courts.

In this section, I outline the theoretical concepts of legal consciousness and a history of the present, and the ways in which they are employed in the thesis. It should be noted that I have 
utilised these different but complimentary concepts to examine the historical and organisational structures of legal knowledge and power in the AODTC.

\section{Legal consciousness}

Drawing on the insights of critical legal studies, legal consciousness is useful for examining how law is constituted through the formal rules and informal governing processes that institute knowledge and power, (Silbey, 2005), including the values and beliefs of those who practice it (Marshall and Barclay, 2003). The benefits of using legal consciousness is that it shines a light on the role of law within society (Nielsen, 2000), revealing 'the often hidden operations of power, inequality, and oppression' while highlighting the capacity of law to change people's lives (Chua and Engel, 2019:17). Accordingly, 'legal consciousness research is thus a flexible paradigm capable of different kinds of applications in the hands of researchers with different goals and perspectives' (ibid). In my research, legal consciousness is useful for identifying and bringing attention to the tensions between criminal justice and health policies and practices aimed at treating addiction related offending (Boldt, 2010). I employ legal consciousness to investigate both the instrumental policies adopted from the US DTC model and their relationship to AODTC policies and court practices, and participants' experiences of mandated treatment (Harding, 2010; Silbey, 2005).

Methodologically, legal consciousness studies have commonly attempted to de-centre the law in order to capture legality through observation and in-depth interviews (Ewick and Silbey, 1998; Sarat, 1990). Legal consciousness studies have examined people's perceptions of the law, such as individual perceptions of the American Disabilities Act (Engel and Munger; 2003), the impact of globalisation on citizenship and constitutional reform in Thailand (Munger; 2007), and the role of anti-violence services in the cultural production of law (Singh, 2012). Further studies have explored the understandings of law that circulate among working class people and litigants in small claims courts (Ewick and Silbey, 1998; Merry, 2001, Nielsen, 2000; Sarat, 1990). Others have examined the impact of legal consciousness on juries (FleurySteiner, 2002), and among vulnerable people with stigmatized social identities (Engel and Munger, 2003; Harding, 2010; Hull, 2016; Knauer (2012). These studies stem from a concerted effort within socio-legal scholarship to address the fact that there is a gap between law on the books and the law in action (Ewick and Silbey, 1998; Silbey, 2005). In accounting for this gap, socio-legal research is concerned with how law and legal culture can speak to identity, power and the ways in which power affirms structure in everyday life (Ewick and Silbey, 1998; Merry, 2001; Silbey, 2005). In these respects, socio-legal research is useful for bringing attention to 
the role of Law Commission and judicial activism in the adoption of the DTC model, and the effects of bringing together health and justice on AODTC participants' rights to treatment.

There is, however, an absence of legal consciousness research examining the criminal law and how it is applied in the court setting (Young, 2009). This is particularly so in terms of the relationship between the judiciary, the interpretation of criminal procedure and offenders understanding of their rights. Given the importance of law in the lives of offenders, Young (2009) argued that such research is important because the 'naming-blaming-claiming paradigm operates differently in the criminal context' (p.72). Indeed, within the context of the DTC, Miller (2004) and Boldt (2009) argued how procedurally, the addiction-choice mandate constructs criminal blame when participants do not respond to treatment. The implications here are that DTC participants may be coerced into treatment, or legal decisions might blur or merge treatment with punishment. This is also important because, in the DTC, the distinction between punishment and treatment 'withers away' (Nolan, 2003:1563). Therefore, research is needed to understand how court participants understand the effects of law. That is, how they understand the court programme on their rights to treatment. This research will also offer a valuable means of understanding as to how criminal justice policies and procedures merge treatment with punishment (Boldt, 2009).

As Silbey (2005) argued, legal consciousness research looks at both the 'institutional practices' and everyday experiences of law, because the law 'both promises and fails to live up to its promises' (p.360). Therefore, the place to begin is to describe the mechanisms by which law is disseminated and received such as in the context of the AODTC.

\section{Procedural fairness}

Merry (2001) argued that people's willingness to use the law as a problem-solving tool is closely related to their understanding of law and legality. Undoubtedly judges, in line with their values and observations of addiction related offending, and TJ, developed the problem solving philosophy underlying the DTC model (Hora et al, 1999). As a result, the DTC constitutes a noticeable distinction from the regular courtroom model in terms of the cultural production of law (Silbey, 2005), most notably when it comes to TJ. Through the 'cultural practice of TJ' (Castellano, 2011:962), which in short involves closed court meetings, the judges becoming problem solvers though their values, unfettered coercion and discretion, lawyers supporting the aims of the court, and case managers advancing to the forefront of legal and treatment authority (Boldt, 2009; Castellano, 2011; Hora, 2002; Miller, 2009). In this context, court procedure 
intersects with TJ in the cultural production of law as a therapeutic process. However, these processes have been found to not only comprise 'a dangerous mix for court participants' (Boldt, 2009:26), but have been criticised for undermining procedural safeguards through judicial power and inconsistency (Colyer, 2007). As a result, a 'coercive version of justice' based on treatment is produced (Miller, 2009:102), rather than by reference to notions of formal justice' (Boldt, 2009:22). Accordingly, my research examines the connection between the adoption of the US DTC model, and emergence of the AODTC model, by situating criminal justice knowledge that shapes the therapeutic practices of the courtroom. I argue that it is important to investigate the judicial role and the degree of discretion, which characterises treatment decision-making, because the judges have prescribed roles in monitoring accountability and treatment compliance (Ministry of Justice, 2012a; 2014). Thus, by conducting observations and interviews in addition to document analysis, this research captures the importance of 'context, time and place' (Seron and Silbey, 2004:30) in investigating the AODTC assumption that AOD related offending is underpinned by disease and that therapeutic intervention involves punishment.

Context is also important when examining the ways in which unconscious ideas and bias can affect legal decision-making (Nielsen, 2000), especially in the 'shaping' of legally mandated treatment through the 'coercive power' of the law (Hirsch, 1992:842). For instance, the largely unregulated AODTC environment has the potential to become a place for stirring up of unconscious ideas of addiction and of addicts as risky, requiring greater control in treatment. Bias can also be triggered by previous history with an offender or through knowledge of an offender's personal details (Boldt, 2010). That is, the court problem-solving mandate could provoke an unconscious desire to punish or to control behaviours that otherwise would not require censorship (ibid), resulting in disproportionately severe punishment. Essentially, this is punishment made to fit the individual characteristic of the offender rather than the offence (Boldt, 1998). As will be shown in Chapter's 5, 6 and 7 my research examines the coercive power of the law, by observing the judicial role and decision making that reinforce the AODTC in mandating treatment and constructing participants as responsible for their choices.

More recently Boldt (2014) pointed out how collaboration with community treatment providers, and the DTC accountability mandate have become a common set of governing principles in the DTC. As a result, community treatment providers that are not normally involved in the criminal justice setting, are given the power to conduct control and surveillance on behalf of the court. In this context, unlike the legislative and policy boundaries for 
Corrections in carrying out community sentences, the boundaries here are muddy, therefore the power wielded by community treatment providers is harder to challenge. Therefore, I investigate AODTC policy in practice, by observing the practices and decision making of the community treatment providers and case managers in the management of participants treatment (Silbey, 2005).

\section{Individualised approach}

As discussed above, an underlying assumption of the DTC is that offenders have a chronic relapsing disorder-addiction, yet, at the same time, they are responsible for their autonomy and choices (Boldt, 2009; Hoffman, 2001). It has also been taken for granted that the US model, with its emphasis on abstinence and individual accountability (Boldt, 2010), is an appropriate model for responding to AOD related offending in New Zealand. Indeed, the distinctive US DTC policies and practices underpinned by judicial activism take on an individualised approach to the treatment of AOD addiction, to reduce AOD offending. AODTC Judge Tremewan has made it clear that 'taking responsibility' for the 'disease of addiction' (2013:3) is key to programme success. However, as discussed in Chapter 1, the problem with viewing criminal offending as a result of a disease is the potential for punishment to be justified as treatment (von Hirsch and Maher, 1992). In part, this is the danger of the DTC model itself, as the model tends to reinforce the dominance of criminal justice responses over treatment practices (Nolan, 2003). I argue that extending the power of criminal justice into addiction treatment is meaningful only if clinical decision-making takes precedence.

As discussed, accountability and compliance are key governing principles in the AODTC, and are made clear in both the Participant Handbook (2013) and the Participant Agreement (n.d). Accordingly, by conducting document analysis, observations, and interviews, I investigate how the AODTC governs participant accountability and compliance. Keeping in mind that the court accepts the disease-crime-abstinence mandate, I explore in Chapter's 5, 6 and 7 how these legal procedures influence the participants' treatment, progress, health and wellbeing.

\section{Participants'voices}

Despite the central role of treatment in the DTC, the voices and experiences of participants is largely absent in the existing body of DTC literature (Boldt, 1998, 2009; Csete and Catania, 2013; Gallagher, 2013; Gallagher and Nordberg, 2016; Lyons, 2011; Saum, Scarpitti, Butzin, Perez, Jennings and Gray, 2002; Tiger, 2013). In recognition of this neglect, this thesis aims to give voice to the AODTC participants. Moreover, by drawing on their experience, I investigate 
the degree to which the AODTC therapeutic processes effectively support their treatment, health and wellbeing. That is, by examining the AODTC participants' experiences 'more comprehensively, one may do a better job of evaluating the legitimacy of the drug court as a [therapeutic] model' (Saum, Scarpitti, Butzin, Perez, Jennings and Gray, 2002:44). Here, the purpose of the research is to utilise the interview narrative, in addition to observations, as empirical evidence of the AODTCs' policies and decision making that sustain the addictiondisease-responsibility mandate (Boldt, 2009), and justify punishment as treatment. When utilised this way, legal consciousness is a valuable tool for exploring the connections between court knowledge of addiction, the court role in treatment practices, and the participants' experiences and insights of the court programme (Hull, 2016).

New Zealand research has shown that ethnicity and gender have a significant impact on experiences in the criminal justice system (Ferguson, Horwood and Swain-Campbell, 2003; Jackson, 1988; Kingi, 2005). I argue that a recognition of the way that ethnicity and gender intersect with AODTC processes is an important area of consideration. With this in mind, I bring attention to mandated therapeutic practices through the participant's stories in Chapter's 5, 6 and 7. The stories the participants tell of their experiences with the court, and how they negotiate the treatment requirements, focus attention on how the law sustains inequality and powerlessness (Ewick and Silbey, 1998). The individuals observed and interviewed for this thesis came from a range of different ethnicities, genders, and age groups. This feature of the data collection enabled a comparison of different participant experiences, particularly in terms of ethnicity and gender. As will be shown in the following chapters, the empirical data from the observations and interviews form an important part of the thesis findings.

Taking in the wide range of outcomes experienced by different participants in DTCs, Boldt (2010:26) argued that 'further research is warranted to focus on the ways in which failure is defined and life courses altered as a result of legal and moral sorting accomplished by these courts'. This research presents the participants' voices as empirical evidence of the AODTC 'therapeutic policies and practices', and will draw attention to the ways in which the court conceptualises participants, implements treatment and punishment, and the factors that contribute to programme failure.

In summary, the observations and interviews inform and support a critical empirical analysis of the significance of law and the role of treatment within the AODTC, an area unexamined in other AODTC research, and in socio-legal studies generally. 


\section{A history of the present}

According to Foucault, 'the things that make up our present world'... 'can be unmade, as long as we know how it was that they were made' (Gutting, 1994:85). It is within this frame that a history of the present works, by identifying present day practices such as criminal justice reform (Garland, 2014), and which then 'seeks to trace the power struggles' that produced it (p.373). By using a history of the present, this thesis critically traces the socio-political 'forces' that gave birth to the 'present-day' AODTC, and identifies the 'historical conditions' upon which the targeting of addiction depends (Garland, 2014). In this way, the thesis draws on a history of the present in order to present a genealogical account of addiction, the pathologisation of AOD related offending and penal treatment in New Zealand, the emergence and development of the AODTC itself and contingencies upon which it depended. These chapters therefore contribute important background to the role of state power in general, and how DTCs build on enormous symbolic and political power particularly in the area of 'addiction policy' (Fischer, 2003:17).

It might be that a history of the present may help us to explore the connections between knowledge of addiction within discourses involving biopolitics ${ }^{7}$, contemporary 'neurobiology', 'drugs and addiction in the context of the US War on Drugs' (Vrecko, 2016). However, my focus is on the socio-political construction of addiction and penal treatment in New Zealand and the AODTC. Because, this approach enables the presentation of a series of 'associations' and 'lineages' (Garland, 2014:372) involving the socio-politico identification of addiction, treatment, and the justice response to treatment. Therefore, my research will feature in Chapter 3, a genealogical account of the state's attempts to treat addiction by merging health with justice in New Zealand. Here, I briefly illustrate the ways in which addiction, and treatment have been understood historically, and how they continue to be understood in the New Zealand criminal justice system. This is important for three reasons. First, there are tensions between AOD addiction as a disease and coercion and treatment in New Zealand (Board of Health Report, 1973). Second, the identification of AOD 'addiction' related offending has provided support for the merging of the goals of health with the goals of criminal justice. Third, there are New Zealand reports (IPCA, 2015; Smith, 2007; Tinsley and Young, 2017; Wakem and McGee, 2012) which indicate that merging health with justice does not meet offenders' health needs.

\footnotetext{
${ }^{7}$ Foucault's (1990) concept of biopolitics and biopower 'indexes the connections between the state and expert authority that are formed in relation to efforts to administer the health and well-being of populations' (Vrecko, 2016:63).
} 
When considering the development of the AODTC, a history of the present is an appropriate tool for emphasising the connections between law reform, the role played by judicial activism, treatment policy, and the various modes of 'targeting' the treatment of AOD related offending (Yeomans, 2018). This is important because, according to Nolan (2003:1556), 'simply altering the nomenclature...' '...does not make therapeutic legal practices any less punitive'. Given that the DTC model is readily accepted as an alternative to traditional criminal justice measures in reducing AOD related offending, a history of the present assists in understanding the political interests and policies behind the AODTC pilot. For example, in Chapter 4 I discuss how and why AOD offending and addiction became the justification for the AODTC to merge treatment with punishment. In this context, I outline the emergence and development of the AODTC, making connections between political knowledge of AOD offending as driven by addiction, law reform, and the focus on treating related offending. In particular, Chapter 4 examines how addiction and AOD related offending became to be problematised to inform the development of the AODTC. I illustrate the instrumental role of the Law Commission in the recommendation of the AODTC pilot and the role of judicial activism in the adoption of the US DTC model. I show that while the court is in part the product of the Law Commission (2011) recommendation to merge the fields of health and justice to address AOD offending, it is also informed by sociopolitical descriptions of disease, offender pathology and curative treatment. The chapter also provides an important insight into the principles and practices of the DTC model, the role of TJ, legal coercion and abstinence in treatment.

The approach taken in Chapter's 3 and 4, locates the knowledge of addiction and treatment in its wider socio-political context (Garland, 2014). Accordingly, I draw attention to the various forms of knowledge that have informed the contemporary policies directed at treating AOD addiction related offending. As such, I question the AODTC as a means of expanding knowledge of AOD related offending, addiction treatment, and punishment. I argue that to consider the historical construct of addiction helps to draw attention to the various modes of power in the constitution of penal treatment (Vrecko, 2016).

In summary, the thesis is concerned with the political and judicial rationale shaping and legitimising of the establishment of the AODTC, and its treatment of court participants and participants' experiences. The purpose of my approach is to provide empirical evidence of criminal justice reform, and the organisational practices and cultural symbols that sustain the legitimacy of merging treatment with punishment in the AODTC (Boldt, 1998, 2009; Nielsen, 2000). Drawing this data together provides valuable insight into the everyday practices and 
experiences of what constitutes addiction treatment and punishment in the AODTC programme.

While I have adopted a framework that adopts legal consciousness and a history of the present, I also use critical ethnography as a method for highlighting the role of power relations that underpin the combining of health and justice policies in the cultural production of law within the AODTC (Silbey, 2005).

\section{Critical ethnography}

Critical ethnography is a method that assumes cultures are positioned unequally in power relations, therefore culture reflects the interests of dominant communities (Anderson, 1989; Thomas, 1993). Accordingly, knowledge and truth are produced through the continuous construction of power relations and in social-cultural-historical contexts (Lyons, 2011). As a method of explaining the cultural production of law (Silbey, 2005), legal consciousness compliments ethnographic methods as an interpretive framework to understand the governing of treatment (Ewick and Silbey, 1995; Sarat, 2014). Thus, critical ethnography permits an investigation of court practices through direct observations and in-depth interviews, as to how the AODTC participants negotiate the court's requirements.

Thomas (1993:7) describes critical ethnography as, 'the study of the process of domestication'. This refers to the ways in which individuals' behaviours are 'tamed' by ideologies that 'construct advance meanings and justifications for our actions, and the actions of others' (Thomas, 1993: 9). The critical ethnographer seeks to explore the broader processes of control and power, and the mechanisms that impose one set of preferred meanings over another (Thomas, 1993). A critical ethnographic method challenges symbolic and structural conditions of law and legal process (Thomas, 1993). Historically, socio-legal studies, focussing on the structural processes of law, present descriptions of contradictions in legal process and the ideology of law (McBarnet, 1981), and describe tensions between the power of the state and the autonomy of law, in maintaining cultural order (Balbus, in Roach Anleu, 2000). These studies offer insights into ethnographic accounts of the role of law as punishment, and law as regulation (Roach Anleu, 2000). Accordingly, applying legal consciousness as a method for examining treatment and punishment in the AODTC, and the AODTC participants' experiences, serves to document how the AODTC understands the law, addiction, and treatment. 
Critical ethnography seeks to make positive social change for disadvantaged groups such as prisoners, drug users, and indigenous people (Thomas, 1993). This is important given the disproportionate rates of Māori imprisonment, and the emphasis on descriptions of Māori offenders' needs in New Zealand AODTC policies (Ministry of Justice, 2014). A critical ethnography approaches fieldwork and analysis with an explicit agenda of elucidating power and economic and social inequalities. In the context of DTCs, this works by unveiling social constructions, examining who benefits from these social constructions, challenging injustices, and putting forth alternative possibilities (Lyons, 2011). Consequently, critical ethnographic researchers challenge traditional scientific methods requiring the separation of research subjects and researchers. They are active researchers, rather than "passive recorders of narratives and events' (Thomas, 1993:46).

\section{Addressing challenges to critical ethnography: Pre-fieldwork data and intersectionality}

Critical ethnography has been criticised for being grounded on narrow understandings of social and cultural trends and for a failure to acknowledge the gap 'between participant's interactions and social and cultural systems rooted in historical traditions' (Fonow and Cook, 2005:150). Hence, the goal for the researcher is to identify how to link these processes. I address these challenges as part of my pre-field work data collection, and through an intersectionality analysis (Potter, 2013).

Stemming from critical race studies and feminist theory, an intersectional approach exposes the 'power dynamics in socially constructed identities and how they affect, or are affected by, crime, criminality, and formal sanctioning of acts deemed criminal' (Potter, 2013:316). Methodologically, there is a developing body of criminological literature addressing intersectionality (Potter, 2013; Trahan, 2011) that draws attention to the governance strategies reproducing existing forms of inequality (Olofsson, Zinn, Griffin, Giritli Nygren, Cebulla and Hannah-Moffatt, 2013).

I argue that a focus on intersectionality draws attention to how the state came to the point of incorporating constructs of addiction, ethnicity, and gender into governance. Thus, intersectionality provides the tools for situating any overlaps and links between historical and contemporary practices of governing addiction. This is useful in the investigation of the development of prohibition, and the treatment of addiction in New Zealand criminal justice and health policies. It further complements the legal consciousness and a history of the present analyses and, provides the tools to situate the institutional factors that construct the addict 
identity and how they are affected by criminal justice initiatives that act to impose treatment (Potter, 2013).

\section{Reflexivity}

Reflexivity is central to critical ethnography (Anderson, 1989; Hammersley and Atkinson, 2007; Thomas, 1993). Reflexivity is also tied to epistemology, and refers to the researcher's chosen methods, her role in research, relationships, and how her position affects the research (Duncan, 2002). Reflexivity refers to how researchers include themselves in the writing and rewriting about the research, and their emotional reaction (Charmaz, 2006). As a method, reflexivity situates the 'researcher to examine how and where some of her assumptions and views might affect her interpretation of the respondent's words, or how she later writes about the person' (Mauthner and Doucet, 2003:418). Yet, reflexivity cannot completely erase bias from research, nor assumptions, nor or power inequalities, because like the institutions of law and government, academic research has the potential to further marginalise certain individuals, while reinforcing the privilege of those in positions of power (Harding and Norberg, 2005).

Fieldwork is an important area in which critical scholarship has tried to minimize or eliminate power differences between the researcher and the researched (Harding and Norberg, 2005). In recognition of the fact that the researcher and the researched bring different levels of social power to the research situation (Parker and Lynn, 2002; Fonow and Cook, 2005), my approach was to focus on participants' experiences over and above my privilege as a researcher. In the interests of reflexivity, it is important that I note my former experience in policing, which provides me with insider knowledge of law and criminal justice processes such as governance and accountability, evidence, the obligation to release a person under bail, and bail conditions. Also, I acknowledge my experience as a health and disability advocate, giving me insider knowledge of New Zealand health and disability regulations, services, and consumer rights. The potential downsides are that are that while I am empathetic with both professional and personal experience to draw on, I had to be mindful that I have a different lived experience to the participants. Therefore, by incorporating reflexivity into the research while writing up, I bring attention to any biases or assumptions (Hunter, 2002), and do my best to avoid reproducing the 'other' (Lyons, 2011).

\section{Conducting the fieldwork}

The primary research for this thesis was conducted over two periods of fieldwork in the Auckland and Waitakere AODTC. The first spanned September 2013 to December 2014, and 
the second August 2014 to December 2014. During the first, I conducted in-court observations, and during the second I engaged in out-of-court observations and interviews. Both the in-court and out-of-court observations consisted of various interactions firstly between the judges and participants, then the participants and their case managers, peer support workers, treatment provider representatives, lawyers, police, court workers, and participants' support people/families. As part of the in-court observations, I also observed discussions between judges, case managers, court workers, police, and treatment providers during the precourt meetings.

Overall, I conducted 536 hours of AODTC observations, including 246 hours of in-court observations, and 290 hours of out-of-court observations; 18 semi-structured interviews with participants that ranged from 40 minutes to 2 hours; and informal meetings with lawyers, treatment providers, court workers, policy analysts, and family members of AODTC participants. As discussed earlier, I chose to focus my interviews on AODTC participants' experiences because of the gap in the literature, and because of the pressing need to give them a voice. Also informing this decision was the fact that I could get a good idea of the views of the judges from the participant observations, conference papers, and available sources such as radio and television interviews. In addition, the observations in court provided a clear view of the judge's knowledge of, and perspective on, addiction and treatment. The document analysis provided a clear connection between their activism, and the development of the court in New Zealand.

In New Zealand, there is a cultural preference that research involving Māori be conducted in a committed, participatory manner (Walsh-Tapiata, 2003) by Māori for Māori (Cram, 2009). This preference is based on the need to recognise the tapu of knowledge (Pere and Barnes, 2009). Stokes (1985) referred to this view as the spiritual dimension of Māori research, a dimension suggested as alien to most Pākehā research and researchers. As a researcher, and in keeping with my responsibilities to Māori participants, I reflected upon my knowledge of tikanga and the role of trust during fieldwork (Pere and Barnes, 2009). I also adopted a position guided by the Victoria University Ethics Committee, under the ethical concept of do no harm, and was further guided by the Treaty of Waitangi ${ }^{8}$ principles of partnership, protection, participation and practice (Hudson, Milne, Reynolds, Russel and Smith, 2010; Tolich and Davidson, 1999; Shaw, Howe, Beazer and Carr, 2019). I am not suggesting that my relationship

\footnotetext{
${ }^{8}$ The Treaty of Waitangi is a document that defines the relationship between Māori and the Crown (Pihama, 2000). It also affirms the status of whanau, hapu and iwi in New Zealand and their rights as citizens.
} 
with Māori participants is reducible to the application of Human Ethics; rather, I considered power differences in the field by locating an ethical focus on Māori, and on my responsibility to the Māori community (Mihaere, 2015). Through the research principles of whakawhanaungatanga, (building relationships), tika (ensuring good research design), manaakitanga (cultural and social responsibility), and mana (justice and equity) I took steps to ensure that I did not disregard the effects of socio-economic disadvantages, colonialism, and cultural deprivation as experienced by many Māori (Jackson, 1988), and participants in the AODTC (Shaw et al, 2019).

According to Milroy, (in Pere and Barnes, 2009:453), the overriding rule for those conducting research involving Māori is that 'the researcher's responsibility is to the people being studied'. That is, placing the voices of Māori participants in research over my voice is important (WalshTapiata, 2003) if knowledge is to be produced for the benefit of the community (Awatere, 1984). During the observations and interviews, I guided my research in a way which included whakawhanaungatanga in the field (Huriwai, Robertson, Armstrong, Kingi \& Huata, 2001). As part of this process I sometimes came into contact with members of Ngati Whatua while sitting at the back of the Auckland court, and with the Pou Oranga [cultural adviser] when we sat incourt at pre court meetings and shared coffee or a meal. In these contexts, I shared where I came from, and my knowledge of the AODTC.

I engaged in a similar process with the court participants, reinforcing the practice of whanaungatanga (kinship in a wider sense) that also supports commitment and connection to whānau, both of which are an integral part of Māori identity and culture (Cram, 2005). As good practice, I engaged in te reo in conversation, requested permission to take notes, provided kai and a koha, and offered to follow up in order to give back to the participants. All of these processes were guided and approved by the Victoria University Ethics Committee.

\section{Gaining entry and trust}

My initial approach to this project was to collate as much background data on the AODTC pilot as possible. This process became twofold. First, I found that there is very little known about how addiction and the law are constituted in the context of treatment in the New Zealand criminal justice system. Second, since the AODTC pilot was in its first year, no research had hitherto been conducted, and there was therefore very little information available on the Pilot and its operation beyond government and policy documents. To further develop my familiarity with the AODTC, I initially contacted the AODTC court co-ordinator seeking advice as to the 
formal process involved in gaining access to the courts in order to conduct observations. I was respectful of the fact that the AODTC pilot was in its first year, and that I needed to accommodate this in my approach. The co-ordinator's response was that I needed to provide a brief summary of my interest in the AODTC, and a description of the academic work I was doing.

I also contacted the Ministry of Justice, requesting all AODTC background documents. The Ministry did not object to observations, but they did request that I plan my fieldwork observations around the Ministry evaluators ${ }^{9}$, and provided me with a brief timeline of their own planned fieldwork over 3 years. Following my request, I was directed to seek formal permission from either one or both of the AODTC judges in order to discuss and formalise an arrangement. Some negotiation occurred between AODTC Judge Tremewan and my supervisor in order to arrange access, and it was agreed that I call Judge Tremewan to introduce myself.

Following our communication, Judge Tremewan emailed a copy of her 2013 Criminal Justice Symposium speech, a selection of National Association of Drug Court Professionals (NADCP) documents, and You Tube links to a series on Drug Courts as transforming lives. I was grateful for the early information which helped me plan out my data and fieldwork. I arranged to fly to Auckland the following week to formalise permission to conduct court observations.

Once I was granted permission to attend court and take notes, Judge Tremewan also invited me to sit in on the pre-court meetings (in addition to the afternoon hearings), although it was stipulated that I email the AODTC judges prior to my visits in order for them to formally permit my attendance. From that point on, my position in the court remained the same until the interviews began. I had initially sought Victoria University Human Ethics approval ${ }^{10}$ to conduct participant observations in 2013.

After analysis of the in-court observations, in 2014 I established a plan to interview participants, and sought further Victoria University Ethics approval ${ }^{11}$. The ethics application identified the possibility that I would be recruiting participants who would be Māori, Pacifica,

\footnotetext{
${ }^{9}$ The Ministry of Justice evaluation team also had a plan to conduct fieldwork around the same time, email Angela Lee Ministry of Justice July 2013.

${ }^{10}$ Ethics approval: 0000020220.

${ }^{11}$ Ethics Approval: 0000020807.
} 
and people who are offenders and/or victims of crime. The approval therefore included additional scrutiny by Māori members of the Victoria University human ethics committee.

Since the interviews involved a cohort of AODTC participants, I sought permission from the Ministry of Justice AODTC Steering Committee. Following this contact, I received a request for my, and my supervisors', curriculum vitae, as well as 21 specific questions and suggestions from the Ministry of Justice JSRRG committee ${ }^{12}$. These revolved around my experience in conducting qualitative interviews for research, the design of the research recruitment flyer and the research information sheet, and consent. Once I addressed these points, the Ministry of Justice AODTC Steering Group ${ }^{13}$ agreed that I could interview participants in the AODTC subject to the conditions that:

- The research I undertake is as described in my ethics application

- I interview up to only 10 AODTC participants

- No further observations of AODTC hearings or pre-hearings take place

- All interviews be completed by the end of 2014

- The Ministry of Justice is provided with a copy of the PhD thesis.

\section{In-court observations}

The in-court observations were conducted from September to December 2013. During the fieldwork, I observed the in-court experiences of 56 participants. From these, I created 13 profiles of participants who regularly appeared in court during my observational days ${ }^{14}$. These profiles included the participants' offence history, how they came to the attention of the AODTC, how the AODTC identified their offending as AOD addiction related, their treatment in the AODTC, what that treatment involved and how it was managed by the team, and how the participants responded to the treatment programme. The concepts of addiction, the criminal, coercion, treatment, and punishment helped me to identify key themes from the observations. These were perceived dishonesty, the dualistic notion of clean/dirty, dangerousness, surveillance, the blurring of boundaries between therapy and punishment, the judge's role, and judicial pathologisation of offending (Boldt, 1998; Nolan, 2002; O’Hear, 2009).

The observations also focussed on verbal exchanges in pre-court meetings and court sessions, the majority of which I recorded verbatim in a handbook. I added my reflections to the notes

\footnotetext{
12 The JSRRG is a group of senior government researchers and two academics that the justice sector agencies refer research proposals to for review.

${ }^{13}$ Email 15 August 2014.

${ }^{14}$ I interviewed 7 participants out of the 13 profiles created.
} 
as soon as possible on leaving the court. Pseudonyms were used for all participants in the recorded notes. While reviewing and rewriting the notes I added more context to my observations. The benefit of this is a detailed account of the interactions that informed the practices of governing the addicted offender in the AODTC. This approach also brought attention to the use of law and meanings of language, which contributed to the coercive use of law in treatment and punishment (Valverde, 2010). According to Goodall (2000), field notes are socially constructed and somewhat biased. I tried to minimise bias through reflexivity, and in keeping with my field notes I focussed on what was significant for my research. My in-court observations therefore paid closer attention to the offenders' interactions with the judges and the key treatment team members, than what occurred outside of court.

\section{Out-of-court observations}

The out-of-court observations were conducted from August to December 2014. These observations consisted of events and conversations that occurred before court, during breaks, and after court. The AODTC differs from the usual District Court process due to the considerable influence that non-state actors exert on the treatment process, and the significant degree of law-making occurring on the periphery of formal legal proceedings. For example, I found that some of the most significant exchanges and conversations in the treatment process occurred in the foyer before court and during the court break, which I recorded in my fieldwork book.

The out-of-court observations meant that I was sitting with offenders and their support people/families for the court day. In this context, I became witness as to how the offender negotiated their agreement with counsel and treatment representatives. I also witnessed offenders meeting the court requirements of on the spot urine testing, managing SCRAM electronic monitoring, dealing with residential treatment, case managers and peer support workers, preparing for custody, and exiting the programme, as well as negotiating family and job commitments.

\section{The Interviews}

Of the 18 interviewees, 14 identified as Māori, and 4 identified exclusively as Pākehā or European. 13 identified as men, 3 as women, and 2 as transgender; they were of mixed age groups ranging from 20-60 years of age. 10 involved AODTC participants, including one who had graduated. 8 interviews were conducted with people who had been declined, exited or selfexited from the AODTC programme. Since these people were no longer in the court, I was 
under no obligation to request permission from the Ministry of Justice to conduct interviews with them; neither did I use the Ministry of Justice to get the participants' contact details. Rather, I picked up participant's details through informal conversations and through flyers, which I discuss further in the sections below.

Orb, Eisenhauer, Wynaden (2001) argue that qualitative researchers have an 'ethical obligation to anticipate the possible outcomes of an interview and to weigh both benefits and potential harm' for participants (p.94). Conducting research in the Auckland and Waitakere AODTCs was a challenge because this is the only programme of its type in New Zealand. As a result, it became apparent to me that the participants I interviewed would likely be identifiable to the judges and treatment team members. Even though some of the participants were happy for me to use their identities, all had extensive histories within the criminal justice system, many had families, and many are still within the justice system. Weighing up the benefits of the research and the potential for harm to their confidentiality and wellbeing, my approach to the research was in accordance with the Victoria University Human Ethics Committee and the Ministry of Justice research group requirements under the ethical principle of 'informed consent'.

Specifically, I addressed confidentiality in the consent form and by restricting access to the data to only the investigator, by using pseudonyms, and removing other identifiable characteristics of the participants and key informants. If anything came up during the observations and interviews, I made sure that I requested permission to use that information, or, at the least discussed it with the participants involved, ensuring their contribution to the research while respecting the principles of ethics and autonomy without revealing their identities (Orb et al, 2001). Accordingly, I have presented the research in a way that ensures the confidentiality and autonomy of the participants, while anticipating the minimising the potential for harm. I do not consider this a limitation to the research as other DTC ethnographic studies have conducted research in a similar way (Lyons, 2011).

The range of interviewees meant that I conducted interviews in either a meeting room in the court building, in a public space such as a library meeting room, or in a private courtyard outside a café, and a park where the participants could not be overheard. Like the participant observations, individuals were given a pseudonym that I used as a code for transcribing. It was clearly explained to the interviewees that participation was voluntary, that they were under no obligation to answer questions, and that they could withdraw at any time. All unanimously gave their consent because each wanted to have their experiences formally documented, and 
all were happy to be recorded. According to Adler (1993), research relationships are reciprocal. I agree. I provided kai/refreshments as described above, and a koha (gift card) to the value of $\$ 30.00$ as a token of my gratitude to participants once interviewed. ${ }^{15}$

\section{Informal interactions}

Informal interactions ${ }^{16}$ or, as some refer to them, informal interviews (Sandberg and Copes, 2012) with AODTC participants, took place out of court. These interactions occurred naturally, in conjunction with my observations prior to the participants' appearance, after court, and during my out-of-court observations. I was mindful to not breach any agreement I had with the Ministry of Justice. I used this approach to build rapport, to discover how the participants connected to the AODTC, and to conceptualise and understand the court culture and the legal consciousness of participants in the court programme (Ewick and Silbey, 1998).

I also engaged in informal interactions with AODTC coordinators, AODTC judges, AODTC Māori representative, lawyers, AODTC peer support workers and court workers, legal counsel, policy analysts, Ministry of Justice evaluators, SCRAM monitoring employees, representatives of the Salvation Army Bridge programme, Odyssey House, Higher Ground and Te Ara Hou. The interactions variously occurred during observations, visits to one of the treatment providers, over coffee, and outside of the court. Even though all parties were aware of my researcher status, I routinely asked them if I could take notes, thus I did not take notes, unless the parties consented to it.

\section{The AODTC and US DTC Documents}

As a method, document collection helped contextualise the AODTC within broader criminal justice policy, health policy, political history and debates, and also within the context of governing addiction. My document collection and analysis incorporated an extensive list of AODTC documents, including:

- $\quad$ AODT Court programme logic model

- $\quad$ Alcohol and Other Drug Court evaluation planning Final Report, July 2012

- The Alcohol and Other Drug Court, Te Whare Whakapiki Wairua, Evaluation Plan October 2012

\footnotetext{
${ }^{15}$ The JSSRG and AODTC Steering Committee believed that my gift card should not be from a supermarket as they felt that the participants would use the card to purchase alcohol or cigarettes. As a result, I agreed to give the participants a Warehouse gift card.

${ }^{16}$ Ethics approval: 0000020220
} 
- Alcohol and Other Drug Treatment Court, Te Whare Whakapiki Wairua, Handbook $2012 ; 2014$

- $\quad$ AODT Court Information Sheet for Participants

- $\quad$ AODT Court Participant Handbook

- $\quad$ AODT Court Participant Agreement

- Address for the NZLS CLE Criminal Law Symposium, District Court Judge Tremewan, (2013)

- Formative Evaluation for the Alcohol and other Drug Treatment Court Pilot (Litmus, 2014)

- Interim Process Evaluation for the Alcohol and Other Drug Treatment Court Pilot (Litmus, 2015)

- Final Process Evaluation for the Alcohol and Other Drug Treatment Court Pilot (Litmus, 2016)

- $\quad$ Ministry of Health AODTC request for tender for drug testing services, July 2012

- Ministry of Health AODTC presentation used at meetings for parties interested in tendering for the treatment services, July 2012

- $\quad$ Ministry of Health AODTC service provider contract, Odyssey House Trust, December 2012

A close reading of the above documents revealed that there are tensions between guiding definitions of addiction and treatment as expressed in the documents, and treatment expectations as articulated in the AODTC. This is explained in Chapter 4, where I illustrate the tensions in the development of the AODTC pilot. In addition to the New Zealand documents, I also analysed the US National Association of Drug Court Professionals (NADCP), and its branch the National Drug Court Institute (NDCI) documents including:

- Defining Drug Courts: The Key Components, (NADCP, 1997)

- Painting the Current Picture: A National Report on Drug Courts and Other Problem Solving Courts in the United States, NDCI (Marlowe, Harden and Fox, 2016)

- The Drug Court Judicial Benchbook, NDCI (Marlowe and Meyer, 2011)

- Adult Drug Court Best Practice Standards Volume I (NADCP, 2013)

- Adult Drug Court Best Practice Standards Volume II (NADCP, 2015)

\section{Reliability and Validity}

Thomas (1993) proposed five safeguards for the accuracy of ethnographic data: (i) careful reading and analysis; (ii) triangulation of data; (iii) review of data by colleagues or participants; (iv) replication of the study; and, (v) researcher reflection. With the exception of replication of 
the research, I engaged with all of these methods. As previously discussed, I undertook note taking during pre-court and in-court observations, and rewrote these and my out-of-court conversations promptly afterwards (Lyons, 2011). I further engaged with reflexivity and my position throughout the fieldwork, and during data analysis. In the interests of research validity, I situated my position by focussing on marginal voices of the participants in the AODTC spaces (Lather, 1993). I also engaged a fellow PhD Candidate familiar with qualitative fieldwork and the New Zealand legal system to attend two AODTC sessions as a comparative note taker. I compared their notes to mine for reliability and validity.

\section{Data analysis}

This thesis employs qualitative data analysis. Using data analysis allowed me to prepare the field notes, participant profiles, observations, and interviews by transcribing the verbal and written data into text (Richards and Morse, 2007). To analyse the data, I used a grounded approach (Corbin and Strauss, 2008). This involved separating the research into fields and using NVivo 10 qualitative data analysis software for coding themes and concepts. As well as providing an empirical examination of the governance of addiction through the AODTC, data analysis can also challenge socially accepted understandings of addiction and the law, and the governing of AOD users.

Upon completion of the fieldwork and transcription process, I uploaded the observations, participant's profiles, interviews, field notes, and word documents into NVivo 10 qualitative data analysis software for coding. My research questions were a good starting point for this process. The concepts of the constitution of the addict identity, treatment practices, and punishment helped me to identify key themes from the initial research. I then broke the concepts down into nodes. These included the addict identity, abstinence, recovery, judge, provider, surveillance, and punishment, then further into, disease, sobriety, help, responsible, gender, race, dirty, clean, cure, relapse and recovery, deterrence, incapacitation and stigma. I then analysed the data covered in the nodes as the discourses frequently deployed in the AODTC. Often intertwined with the courts governing practices, these discourses provided me with the context of legal practice and legality in the courts and treatment.

\section{Limitations}

Due to the small size of the AODTC Pilot, it is possible that the two judges and the treatment teams were aware of my presence during observations and may have changed their behaviour to accommodate my presence. Even if that were the case, I do not believe I could have done 
anything about it. It may be argued that the sample size of 18 interviews is a limitation of the research. However, the interviews were not the sole component of the thesis. Rather, the interviews permitted me to gain in-depth information of the participants' experiences, and assisted my elaboration on the constitution of addiction and the governing of treatment. In addition, it was never my intention to use the interviews to generalise about all AODTC participant experiences or the AODTC population. The data I collected helped me to derive an understanding of AODTC constituted addiction, how treatment is managed, participants' experiences of treatment and how these practices relate to the process of recovery.

Despite an international body of DTC research, there is an absence of interviews with women, limited observations of graduations, and little research focussed on the experiences of DTC graduates (Fischer and Geiger, 2008; Williams, Mee-Lee, Gallagher and Irwin, 2017). A further limitation in this research is that, due to the low number of women and graduates in the AODTC, their voices are limited in the thesis. Thus, research focussed specifically on women and graduates would be a good option for future work on problem solving courts, in order to broaden the understanding of court treatment interventions, and to assist in the ongoing evaluation of the court process.

As I worked through the transcripts and commenced the data analysis, I was working with many of the participants' life stories. While I draw upon their stories for context, I decided to omit the majority of this from the data presented in this thesis, because I was concerned that revealing too much of their life story could push the boundary of confidentiality. That said, I do acknowledge the life impact of how the participants got to the court. In addition, I also acknowledge I have not included data on how participants resisted the court or managed to evade the strict bail conditions, and treatment programme (Ewick and Silbey, 1998). This is because I want to ensure that this data does not harm the participants in this thesis, nor future participants in the AODTC.

\section{Managing identity and maintaining trust}

When conducting research in the relatively closed realm of the AODTC my researcher identity initially shielded me from criticism and mistrust from the AODTC team members. I recognised that establishing and maintaining trust was key to establishing a positive relationship between myself and the courts during observations. For instance, after conducting my first AODTC observation, the judge called me back to her chambers for coffee and a 'power chat' about the legitimacy of my research. On some occasions the judge would ask me a question, or look to 
me to reaffirm a point during the pre-court meeting or at the end of the court day. However, it was during the AODTC hearings and observations that I encountered unexpected challenges, such as court staff paying close attention as to whom I was associating with, in and out of the courts. This is because I was under scrutiny by the AODTC judges, team members, and court workers.

During pre-court observations, I was encouraged by the judges to sit amongst their team and invited to share coffee during the break, meaning that I would be engaging with the judge, police, counsel, and case managers, under observation. This gave the impression that the aim was to encourage the sense that I was 'part of the court team'. During these observations, I dressed in ways that catered for both traditional, formal, and researcher performances. In the afternoon hearings, I sat at the back of court in a corner, so as not to make my presence so obvious to the AODTC participants. However, conducting observations in the AODTC during the first year also involved negotiating the presence of media and politicians. Sections from my field notes conducted in each AODTC in September 2013 follow:

Notable Pictures are filming during the first part of court this afternoon, it is difficult to gauge what is real and what is staged. Some of the participants have been briefed on what to say by legal counsel and their case managers. The court hearing appears 'staged' and out of sorts, with one of the participants requesting to appear on camera before the judge.

On another occasion the Minister of Justice, her staff, and accompanying television crew attended the pre-court meeting:

Today the pre-court hearing has taken on a more formal dimension as Television New Zealand are present along with the Minister of Justice and her party. I sat opposite the Minister and the two AODTC judges and between members of both treatment teams, the TV cameras set up behind, as I did not want to be filmed. I became acutely aware of how powerful this situation is as a researcher, and aware of accountability and my position in the court. More so since I was required by the judge to formally introduce myself to the Minister and others present.

Sometimes AODTC team members and peer support workers shadowed my movements and observed my communication with participants inside and outside of the courts. For instance, a member of the current affairs programme Campbell Live tried to approach me outside the Waitakere AODTC. Although I did not invite this attention, a member of court staff intervened. I managed this by either leaving court early or by avoiding sharing information about my research. Over time, I learnt that I had to negotiate my position in the field so as not to breach 
ethical agreements (Becker, 1963; Liebling, 2001; Moore and Maher, 2002). This is also a requirement of critical ethnography (Thomas, 1993).

Seven months after the in-court observations, the fieldwork changed form and I interviewed the participants. This shift also involved a change in the way I dressed, and necessitated a different demeanour because I wanted to make sure that the participants and their families felt comfortable having me around. This essentially presented me with two challenges. The first was around negotiating security and the second involved establishing rapport with AODTC participants. Due to my change in clothing and demeanour, I encountered regular court security checks of my backpack and physical pat downs as I entered the building. Beyond the security $\mathrm{X}$-ray machine, I did not experience this response during the in-court observations. To counteract any security response, My PhD supervisor suggested that I wear a name badge. While this seemed a sensible option, I instead opted to immerse myself as an involved researcher', one who is able to connect with the participants. In order to avoid any bias, I employed reflexivity to decentre my position from the participants and whilst writing up my out-of-court observations. I also had a plan to deal with challenges such as personal safety during the course of doing fieldwork.

From time to time AODTC participants described how they had produced false negatives in their testing, manipulated the SCRAM bracelet, or had lied. Some would abscond from the programme, thereby breaching their bail conditions. As a researcher, I considered that I might come across these situations, and decided that I would not report on anything I witnessed outside of the AODTC.

Gaining the trust of participants, and getting them to tell their stories, was a challenge in itself. In the midst of such challenges I took on the role of 'involved outsider', assuring interviewees that I was an academic and not part of the AODTC, nor that I was a Ministry of Justice evaluator (Unluer, 2012). Many of the participants had learning disabilities, had experienced violence and criminal justice process errors; it became difficult for me not to be affected by the conveyed stress and emotions. Therefore, recognising the importance of balancing a focus on participants' health and wellbeing, and managing emotions in research, became important for me in order to foreground the participants' experiences (Crewe, 2009).

\section{Managing emotions}

Managing emotions involves the researcher's willingness to engage with a self-conscious examination of the emotional dimensions of fieldwork, which allows for the avoidance of 
biases (Jewkes, 2011). Acknowledging emotion by sharing accounts of emotional experiences in research can also deepen understanding of methodological issues in qualitative research (Hedican, 2006). This is poignant for those researching vulnerable and marginalised people such as offenders and addicts. Renzetti and Lee (1993) suggest that researchers caught in emotionally laden research are vulnerable to harm as much as the participants. They point to research involving deviance and social control, and research that intrudes into the private lives of research participants, as areas that make research sensitive, and create vulnerability during the research process (ibid).

In the cases of the symbolic power and arbitrariness of the AODTC, conducting research became emotionally and physically challenging. I felt tired for days at a time, and this returned during the process of analysing my notes and the data. Some criminologists have written about dealing with vulnerability during fieldwork with victims of violence and torture (Armstrong, 2012; Stanley, 2009). However, few authors have documented the effects of conducting research into court processes (Wakeman, 2014), and even fewer have documented emotions arising from fieldwork with people involved in DTCs (Lyons, 2011).

My experiences in the field often left me feeling confused, bemused, shocked, and withdrawn, even potentially risking my findings. For instance, during observations I witnessed an AODTC participant who had suffered violence on remand that, in my view, raised concerns over her safety, and wellbeing and the potential for further harm. As a matter of principle, this incident challenged me on a personal level, and in my understanding of human ethics in research. In the interests of protecting this participant's wellbeing, I considered breaching my ethical agreement of confidentiality in order to disclose these events. Instead, after having a confidential discussion with my supervisor, and seeking counselling to deal with the situation, I decided to write the events up as findings, which are a component of Chapter 7.

Halfway through the fieldwork I found myself exhausted. Part of this arose from regular return flights to Auckland from Wellington, and then the inner-city bus and train travel to Waitakere, which would take up to 4 hours from my home in Wellington to the Waitakere court. There was further travel after court back into Auckland city for court the following day. This process occurred for two to three days at a time. My goal was to fit in as much fieldwork as I could.

Recruiting interviewees entailed time sitting outside of court, as well as networking with various community services and non-governmental organisations and individuals. This was in addition to managing future interviews from afar with people who did not always have access 
to a phone, to transport, or who were homeless or living in transient accommodation. Accordingly, the interviews required a great degree of pre-planning, communication, and flexibility, however, sometimes the process was not entirely straightforward, meaning that on some occasions I would arrive in Auckland to conduct an interview, only to find out that the person I had arranged to meet was either in custody, or had absconded from the programme.

I found that engaging with self, and in research, assisted in managing my emotions and tiredness, and upon reflection created a richer analysis of the research (Anderson, 1989; Wakeman, 2014). It also re-engaged my focus on the participant community, making me conscious of the need to continually question my account of the impact of research into court processes.

Since researchers are expected to minimize the risks of further harm for participants, I adopted a strategy whereby I maintained a level of concern that promoted the health and wellbeing of participants (Israel and Hay, 2006) by offering empathy and practical support to help in gaining access to relevant agencies, such as the court community worker or community law. This also involved managing my emotions as researcher, a challenge that I encountered during the course of recruiting and interviewing people who have suffered marginalisation. For instance, one participant with whom I had built a connection during observations in 2013 contacted me to be interviewed after completing a prison sentence in 2014. I arranged to meet him at a cafe in an Auckland suburb and then go to a park for the interview. However, unbeknown to me he had sustained injuries from a fight two days prior. Before the interview, I queried whether he had received medical attention for his injuries, and had the ability to understand informed consent, because this formed part of the interview process. Once I determined that he had received medical and victim support, and that he understood voluntary consent and was comfortable, then I proceeded with some caution.

Managing emotions through reflexivity became critical to ensuring that participants' voices were prioritised over mine (Wakeman, 2014). While I struggled with conflicting feelings throughout the research process, I learned the value of managing my position throughout the out-of-court interactions, because emotive situations regularly arose due to court day. For instance, I witnessed case managers and lawyers publicly challenge and belittle participants, and was aware that some participants, frustrated and disappointed by AODTC processes, walked from court, and engaged in alcohol and drug use. In other instances, I witnessed the forcible removal of parents from babies and young children for periods in custody, and other 
parents forced to wait to appear at the end of the court day. I also witnessed a confrontation between family members and court workers over the AODTC treatment process and became aware of the deaths a young man and of two former participants from overdose.

Thus, managing emotions became the key to dealing with the challenges of conducting research in the AODTC. To address such challenges, Guillemin and Gillam argued, 'ethical dilemmas and concerns are part of the everyday practice of doing research —all kinds of research' (2004: 26). There were many instances where I engaged in ethics while interacting with participants, in a caring, nonexploitative way yet still being mindful of my role as a researcher (Guillemin \& Gillam 2004). Overall, the decisions I made required a good balance between understanding and empathy as an involved researcher, and a focus on participant health and wellbeing.

\section{Conclusion}

In this chapter, I have presented and explained the theoretical and methodological framework that supports this research, as well as the methods that were used to gather and analyse data gained from in and out of court observations, semi-structured interviews with AODTC participants, declined and exited participants, informal interactions, and documents.

Legal consciousness allows for an examination of AODTC policies and practices, besides the legal processes that constitute addiction, documents, and experiences of law. A history of the present is useful for understanding how knowledge of addiction and treatment are constituted historically and contemporaneously in the AODTC. It also helps to situate the AODTC within an historical, and socio-political context. Combined with critical ethnography, these concepts support an analysis of the role of the AODTC in governing the treatment of addiction, contributing to how the AODTC is located within social and political responses to AOD related offending. They also contribute to socio-legal scholarship by offering an analysis of the court programme, and offenders' understanding of and experiences with the AODTC practices.

Conducting research in the AODTC was a privilege. Spending seven months in the field meant that at times I became immersed in the AODTC practices and the participants' experiences. While I expected that I would need to change my position to accommodate the needs of both the court and the participants, I did not expect to experience a subsequent changing of my legal consciousness. The challenges of gaining access through the Ministry of Justice, and gaining trust with the AODTC's team members, building relationships with court staff, community treatment providers and peer support workers, and conducting fieldwork where judges have largely unrestricted and unregulated discretionary power, have provided powerful insight into 
how ethics in practice evolves during fieldwork. Reflexivity thus provided the tool for managing the blurring of the distinction between the involved researcher and staying neutral in the court (Lavanchy, 2013). 


\section{Chapter 3: A Brief History of Addiction \& Penal Treatment in New Zealand}

\section{Introduction}

In this chapter, I demonstrate how, in New Zealand, the institutional structures of health and justice have largely dominated the field of addiction and treatment throughout the past century and a half (Bunkle, 1980; Webb, 2001). 'Addiction' has crept into the law through a combination of competing moral discourses involving prohibition, descriptions of disease, coercion, curative treatment and punishment (McCaffrey, 2009; Tulloch, 1997; Webb, 2001). Taking in these competing processes, there are concerns that the DTC legitimises punitive forms of treatment aimed at punishing people 'for their disease' (Nolan, 2003:1553), leading to the claim that 'treatment' represents:

.... many aspects of $19^{\text {th }}$ century temperance ideology of addiction... characterizing the DTC as a 21 st-century version of a 'neo-temperance asylum' for drug addiction (Fischer, 2003:236).

The AODTC, in principle and in practice, is reliant on the US DTC model, the view that the causes of AOD related crime originate in addiction as a disease (Ministry of Justice, 2014). Within this frame, 'treatment' operates through an abstinence agenda driven by criminal justice (Boldt, 2009). As confirmed by Judge Tremewan, 'the criminal justice system is the only realistic way in which [offenders] may ever undergo the treatment they need' (2013:3). I argue that treatment on these grounds can become particularly troublesome, because the effects of the targeting addiction related offending through a disease-abstinence agenda can legitimise punitive treatment.

In this chapter, I examine the socio-political, legal and cultural structures comprising historical knowledge of addiction and penal treatment in New Zealand. The chapter does not aim to document the complete history of the ways in which addiction and AOD offending have been conceived and understood in New Zealand. Rather, it seeks to develop a better and informed understanding of the present by considering historical evidence of subjective understandings of addiction and the tensions between health and criminal justice responses to AOD addiction related offending (Yeomans, 2018).

The chapter describes how addiction came to be regarded as a problem, dependent upon a range of social, economic and political influences that generated tensions between addiction as a disease, offender pathology, alcohol, and ethnicity (Garland, 2014; Vrecko, 2016). I provide a 
brief historical overview of the ways in which state power, institutional, ideological and social practices combined to underpin the understanding of addiction as a disease and of penal treatment in New Zealand. Colonisation is briefly considered because the AODTC is built on the view that AOD addiction is a driving factor behind some Māori offending (Ministry of Justice, 2014), and many of the problems identified in the findings are associated with the ongoing effects of colonisation (Durie, 2001; Fergusson, Horwood and Swain-Campbell, 2003).

I illustrate how key government reports have contributed to tensions in the constitution of addiction as perceived criminal behaviour and curative treatment. In addition, the chapter briefly outlines New Zealand laws and responsibilities with respect to the right to health, because these processes are important to the protection of participants' rights to addiction treatment free from coercion and punishment. In this context, I demonstrate how, apart from legal analysis concerning the reduction of harm in the public interest (Law Commission, 2010), there is very little New Zealand research analysing the role of legal coercion in the treatment of AOD addiction (Ministry of Health, 2016).

Finally, I consider the current New Zealand National Drug Policy (NDP). The discussion is limited to outlining the NDP as a government policy that reinforces the tensions between health, crime prevention and law enforcement, and contributes to the AODTC as a criminal justice response to the treatment of addiction.

\section{A brief history of the constitution of AOD addiction and compulsion}

This section provides an overview of key historical milestones in the understanding of, and constitution of, addiction and the treatment of addiction in New Zealand. New Zealand is a small country, colonised by the British during the early 1800s, and it was not until after 1840 that addiction was recognised in law (Mancall, Robertson and Huriwai, 2000). This recognition was in response to the role that alcohol played in criminal and anti-social behaviour, and in generating tension between the indigenous and settler populations.

As Webb (2001) points out, there is no written history of the constitution of addiction and treatment in New Zealand. A fully comprehensive discussion of the various explanations of addiction are beyond the scope of this thesis, because this would require a thesis in itself, as it is a long and complex history. My aim is to highlight the most salient features of that history and their implications, because the AODTC has adopted the view that AOD offending is driven 
by addiction as a disease. Essentially, I provide valuable insight into the key historical efforts to construct and treat the perceived problem of addiction as a disease within criminal justice in New Zealand.

In brief, the international experience that addiction is a disease is contentious, with roots in 18th century metaphysics and morality (Peele, 1987). The latter forms the foundation for contemporary disease theory of alcoholism and drug abuse as wilful misconduct (Valverde, 1998). Opium use in $19^{\text {th }}$ century Britain was influenced by professional, social, and geopolitical interests, illustrating how socio-political factors shaped opinion about addiction (Berridge and Edwards, 1982). In the United States, discourses of addiction shifted between portraying addicted individuals as morally bankrupt criminals, to perceiving them as victims of biology and environment (Murphy, 2011).

In New Zealand, contemporary views on addiction have their roots in the history of alcohol use, opium use, colonisation, prohibition, disease, volition (Hutt, 1999; Tulloch, 1997), and 'negative stereotypical perceptions of native inferiority' (Mancall, Robertson and Huriwai, 2000:133). New Zealand scholars analysing the effect of discourses of addiction upon the health and wellbeing of Māori, highlight the importance of understanding the impact of colonisation on health as well the impact of socioeconomics on wellbeing (Durie, 2001; Hughes, 2007; Mancall, Robertson and Huriwai, 2000). Durie for example claims that,

While socio-economic circumstances and modern health lifestyles have more obvious and immediate effects, the health status of indigenous peoples has been strongly influenced by the experience of colonisation' ... 'When there is a loss of the resources necessary to sustain wellbeing and a loss of standing in terms of full participation in society and the economy, health too is threatened' (2001:48).

Durie's words speak not only to the impact of colonisation, but to the importance of selfdetermination in contemporary society. He added that these processes have been a key 'influence of alcohol and other drugs upon the health and wellbeing of Māori' (in Hughes, 2007:9). Indeed, one way of understanding a brief history of addiction in New Zealand is to examine the forms of power in which it arose and constituted the regulation of people as a pathological risk (Vrecko, 2016). This notion of power encompasses the political rationalities through which the nation and individual citizens are entangled into a web of regulation, and control (Dean, 2010). 
Incorporating the role of government in problematising addiction. I now describe how early conceptualisations of addiction as a disease are historically contingent and dependent upon a range of social, economic and political influences (Vrecko, 2016). All of these influences have played a role in generating tensions between addiction as a problem and disease, the pathologisation of AOD use, offending, and ethnicity.

\section{Early conceptualisations of addiction and penal treatment in New Zealand}

In New Zealand, the earliest descriptions of addiction were focussed on alcohol, and were hugely influenced by moral order, racism and developments in science (Eldred-Grigg, 1984). Hutt's (1999) history of alcohol use in New Zealand makes it clear that when Pākehā introduced alcohol, Māori drank water. In fact, Māori had an aversion to alcohol, calling it 'waipiro' (stinking water). Early reports reveal that from 1830-1840 there was a demand for alcohol by some, but not all, Māori groups. Thus, historical accounts testify to greater alcohol abuse among Pākehā, with documented cases of delirium tremens. No such records exist for Māori (Mancall, Robertson and Huriwai, 2000), because Māori were omitted from most 19th century records.

In 1840, the Treaty of Waitangi provided the New Zealand Government with a means to debase Māori from their tribal lands, and led to the regulation of Māori founded upon the pathologising view that drunkenness is an illness afflicted by race (Mancall, Robertson and Huriwai, 2000). Fear of social disorder driven by alcohol consumption moved Parliament to establish laws specifically targeting Māori (Bollinger, 1967; Tulloch, 1997), such as the Sale of Spirits Ordinance 1847. The legislation, and subsequent alcohol legislation, gave the colonial government exclusive control over the distribution of alcohol, and provided a way to cut Māori out of the economic benefits of its sale. This limited their ability to develop effective strategies with which to manage the social impact of alcohol harm (Mancall, Robertson and Huriwai, 2000). The legal restrictions on the supply of alcohol to Māori also hindered the development of racial equality in New Zealand by removing the responsibility for the behaviour of Māori from the people themselves, to the colonial laws and regulations. By the1860s, alcohol and prohibition policy was used by Pākehā as a means of debasing Māori chiefs of their tribal lands (Bollinger, 1967), constructing Māori as a threat to moral order and purity (McIntosh, 2005) and as a danger to themselves, and culminated in economic and political control over their land (Mancall, Robertson and Huriwai, 2000). 
Early developments in science gave way to a juxtaposing of moral descriptions of addiction and deviancy, whereby people could be held responsible for their condition (Berridge and Edwards, 1982). Indeed, by international standards New Zealand is an early example of legislation that described addicts and the criminally insane as among the first conditions listed in this way. The first official record of 'addiction' is contained in the Lunatics Act 1868, which defined people as 'addicted', and legislated for the compulsory committal of people addicted to alcohol for curative treatment ${ }^{17}$. Early reports indicate that, once confined under the Act, patients were treated as being on 'moral probation' and were required to take 'moral control...to ensure good recovery', in order that they may 'have power of self-control'18.

In the 1880s and early 1900s, anti-Chinese sentiments, and perceptions of Chinese men as 'totally addicted to drugs' (Ferguson, 2005:220), fuelled opium drug laws and social control. Industrialisation had created a world 'out of kilter' and 'beyond personal control', and 'addiction', Bunkle (1980:69) argued, 'was a potent metaphor for this contradiction'. She argued that, to control these forces through moral claims linked to prohibition and penal responses, was to restore order and make the world predictable again (ibid). While Bunkle (1980) was writing about feminist and prohibitionist views of alcohol, the point can be made about 'addictions' in general. In spite of the effects of these laws and regulations, there was no effort to set up addiction treatment beyond committal and the control of Māori, and later the Chinese, through criminalisation and the establishment of dry areas, segregation, and imprisonment (Fergusson, 2005).

Bolstered by the temperance movement, moral purity and the idea of abstinence (Eldred-Grigg, 1984) in 1903 the New Zealand government legislated that drunkenness was a disease of volition. By doing so they perceived that the best method of control was to enforce abstinence as a means of curative treatment, as described in the Inebriates Report (1904):

.. Drunkenness is a disease of volition, and can only be cured by the exercise of the subject's will. To aid and foster this - to make the exercise of the volition a possibility-the best means at our disposal is to enforce abstinence... (p.1).

Given these early connections between the notions of drunkenness as a disease, volition, and abstinence-based treatment, each subsequent piece of legislation during this early period added

\footnotetext{
${ }^{17}$ Section 21 of the Act permitted judges to declare 'any person addicted to the habitual excessive use of intoxicating drinks' to 'curative treatment in order that he may be cured of such habit' (Lunatics Act, 1868:67). ${ }^{18}$ Report of the Joint Committee on Lunatics Asylums, Wellington 1871 pp 2-4.
} 
to and reinforced the classification of addiction as a disease and a moral failing, and led to compulsory treatment policy ${ }^{19}$. The contemporary AODTC conception of addiction and volition echoes this seemingly contradictory juxtaposition between disease and responsibility.

The connections between addiction, individual pathology, and deviant behaviour also meant that certain 'criminal types' became fixed within moral and political discourses in governance and treatment. For example, in 1910 the Minister of Justice re-organised the penal system, classifying eleven different criminal types, including drunkards, for the purposes of identifying the cause of crime and curative treatment (Tulloch, 1997). Thus framed as a criminal problem, 'addiction' emerged as the property of an evolving, dominant, and intricate enforcement network. This cemented treatment as part of penal policy, and led to the institution of penal treatment programmes ${ }^{20}$ in the criminal justice system as an appropriate institutional setting for responses to the problems associated with alcohol and drugs.

Following the historical constructions of addiction, prohibition, compulsion, deviancy, and penal responses, the 1960s and 1970s continued the linking of AOD addiction treatment with the criminal justice system (Board of Health Report, 1973). Increased Māori urban drift, a reported increase in drug use and misuse, and alcohol related offending among Māori (O’Malley, 1973), precipitated a government investigation into why: (i) Māori appeared disproportionally in court records (Hill, 2012), and, (ii) the perceived problem of drug abuse (Board of Health Report, 1973). In 1961, the Hunn Report linked Māori migration from rural ancestral homelands to urban spaces to an increase in Māori 'drinking' and Māori offending rates (Webb, 2012). Derived from colonial biases of alcohol and Māori deviancy, the Report argued that Māori crime rates were the result of Māori failure to assimilate with Pākehā, and recommended the integration of Pākehā and Māori as one (Hill, 2012) ${ }^{21}$. However, by its descriptions of the causes of drinking, the Report used the moral language associated with racial discrimination and alcohol law enforcement in New Zealand

\footnotetext{
${ }^{19}$ The notion of addiction as a disease and as a choice was later contained in the Habitual Drunkards Act, 1906 and the Reformatory Institutions Act 1909 which established the compulsory treatment of people 'addicted to drink' and convicted of drunkenness.

${ }^{20}$ This vision is contained in the Offenders Probation Act Report (1922).

${ }^{21}$ Given the descriptions of pathology, risk and deviancy, further testimonies given by the National Council of Churches before the Royal Commission of Inquiry into the Sale of Liquor in New Zealand 1974 characterised 'Māori drinking', as 'a largely unfavourable factor in the so-called Polynesian adjustment problem' (1974:195).
} 


\section{The Board of Health Committee Reports}

In 1968, the Board of Health Committee was established to review the problem of drug abuse and drug treatment in New Zealand. At the time, policy makers were concerned about the therapeutic value of drugs such as thalidomide and amphetamines and other public health issues related to drug use and misuse. The Committee drew up two Reports: the Board of Health Committee on Drug Dependency and Drug Abuse in New Zealand First Report (1970) and the second and final Board of Health Committee on Drug Dependency and Drug Abuse in New Zealand Second Report (1973). The second Report established that drug abuse in New Zealand reflected a broader global drug problem related to drug misuse and trafficking, and despite the prevailing pathologising view of 'Māori drinking' and deviance, it found that the majority of people criminalised for drug use were European cannabis users (Board of Health Report, 1973).

The $2^{\text {nd }}$ Report found that, while 'the distinction between the legal and illegal use of drugs is a clear-cut one in terms of the current legislation', the boundaries between drug use and misuse were not as well defined and were clouded due to moral values and judgments of people misusing drugs (Board of Health Report, 1973:15). In the context of treatment, the Report cast doubt over the effectiveness of compulsory and coercive treatment (Board of Health, 1973:214), and recommended that:

.... Until the indications and methods of this form of management are clearer, priority should be given to provision of adequate facilities for voluntary treatment.

The Committee recommended that New Zealand update its laws to improve treatment options and to provide support for addicted drug users, because 'sanctions interfered seriously with drug users seeking help from treatment centres' (1973:198). With regard to the efficacy of treatment, the Committee (1973:97) found that:

...the attack on the problem of drug misuse in New Zealand has... been more obviously directed at treating the symptoms and outward manifestations. This is understandable in terms of meeting the immediate situation but it will prove increasingly inadequate unless...more attention is paid to research and action, which attacks and, as far as possible, eradicates the underlying causes.

Attempting to reform descriptions of addiction as a disease and compulsory treatment, the Report recommended that officials recognise the tension between addiction as a disease and drug dependence proclaiming that (1973:216): 
Essentially, drug dependence is a symptom or a complication and not a disease or a cause of a disease.

The Report's rejection of drug dependence as a disease lead to the conclusion that there was a need for greater participation by health professionals in treatment. Thus, rather than the incorporating the management and treatment of addiction exclusively within criminal justice, it recommended that treatment should become a part of public policy as an alternative to justice (Board of Health, 1973). It is noted that the tension between the health view and criminal justice responses to problematic drug use identified in the Report, continues to contribute to confusion that is still evident in current cannabis reform debates in New Zealand ${ }^{22}$.

Fundamentally, the historical penal approaches to addiction made it difficult to generate a political discussion about addiction that did not impose a set of penal imperatives directed toward treating addicts as criminals. Consequently, and despite the findings of the 1973 Report, in the ensuing Misuse of Drugs Act (MODA) 1975 the government focussed on the punitive regulation of certain drugs and deterrence of drug use, (McCaffrey, 2009). Any mention in the MODA of treatment for people with a dependence is limited to the control and regulation of prescribed drugs. Arguably, the MODA was the most influential and leading force in the design of New Zealand's present drug policy, and also in the identification of the principle of harm minimisation, despite the imposition of a punitive regime which I discuss briefly in the section on the National Drug Policy.

Consideration of the brief socio-political context of addiction and penal treatment in New Zealand reveals tensions between public health policies describing addiction as a disease, curative treatment underpinned by prohibition and a focus on a person's moral character and penal responses as a means of social, economic and cultural control. The moral claims of deviancy advanced during the 1960s as explanations of Māori drinking may be viewed as based on colonial thinking. That is, in theory and in practice the colonialism that Māori experienced following the 1840 signing of the Treaty of Waitangi, and the subsequent shaping of their rights to land and economic benefits, have had a detrimental impact on Māori health and wellbeing (Durie, 2001; Jackson, 1988; Mancall, Robertson and Huriwai, 2000; McIntosh, 2005; Mihaere, 2015; Tauri, 1999).

In this section, I argued that 'addiction' within the context of penal treatment has involved moral descriptions of disease, volition, cure, and deviancy, and that a key element to treatment

${ }^{22}$ https://www.radionz.co.nz/news/in-depth/377347/flying-the-flag-for-cannabis-law-reform 
is coercion. I have also shown that historical penal approaches to treatment have made it difficult for the state to consider alternative approaches to addressing and managing AOD related offending. As will be shown in the following chapters, these tensions have contributed to the foundations and acceptance that the AODTC is an appropriate site for treatment.

In the next section, I analyse the concept and practice of legal coercion in AOD treatment, because, as I discuss in Chapter 4, coercion is a key component of DTC procedure. With this point in mind, I outline the obligations of the New Zealand state in facilitating the right to health and treatment, together with the ethical implications of legal coercion in treatment. Accordingly, the section will show that when health meets justice, the use of coercive legal practices can dominate treatment (Valverde, 2010), undermining people's rights, health and wellbeing.

\section{Legal coercion and AOD addiction treatment}

...There are offenders for whom nothing has worked before, they have been to prison, they've had every other type of sentence that there is including therapeutic sentences, but they're really needing a higher level of coercion to deal with that addiction issue....

AODTC Judge Tremewan, October 2013

International human rights law provides that all people, including those with an addiction, have a right to health care that is available, physically and economically accessible without discrimination, and that is gender appropriate. Treatment should also be culturally and ethically acceptable, designed to respect confidentiality, scientifically and medically appropriate, and of good quality (United Nations, 2000). Despite these legal conditions, there is evidence which shows that DTC treatment components 'frequently falls short of these international standards', and 'in some cases, it might be so deficient that it violates protections against torture or ill treatment' (SSRC, 2018:26). Legal coercion is a key component of the AODTC treatment. While the AODTC is organised to facilitate addiction treatment, and to support participants' health, and wellbeing, it also adopts the belief that legal coercion is necessary as addiction as a disease drives AOD offending (Ministry of Justice, 2014; Tremewan, 2013). Taking in these factors, I argue that AODTC legal coercion has the potential to undermine offenders' rights to treatment.

In general, coerced treatment within the context of criminal justice and the DTC revolves around a broad range of legal processes comprising plea bargains, diversion programs, and 
punishment to address AOD offending (Seddon, 2007; Tiger, 2011). Coerced treatment also incorporates knowledge of the AOD user and addiction, and legal pressure to enter and stay in treatment (Kleinig, 2008). In the context of the AODTC, legal pressure is manifested in the programme as the participants are given the choice of a prison sentence, or the AODTC programme. In this section I explore how coercion is used and justified, because while coercion is central to the goals of the DTC and the AODTC (Tiger, 2013; Tremewan, 2013; UNODC, 2009), so too is the New Zealand Government promotion of health, and the protection of AOD offenders in treatment (Human Rights Commission, 2010).

At present, coerced treatment is practiced in the fields of mental health and psychiatry in New Zealand, although the New Zealand Mental Health Foundation (2016) has argued that coerced addiction treatment deviates from medical best practice. In New Zealand law, no express right to health is included in the New Zealand Bill of Rights Act 1990. However, rights to health and treatment are fundamental human rights, referred to in a number of international treaties to which New Zealand is signatory (Human Rights Commission, 2010). The most significant of these are the International Covenant on Economic Social and Cultural Rights (ICESCR), and the International Covenant on Civil and Political Rights (ICCPR). These United Nations Conventions are incorporated by government into laws that include human rights standards, and are linked to health and disability standards and the New Zealand National Drug Policy (Human Rights Commission, 2010; Ministry of Health, 2015). The state therefore has an obligation to ensure access to treatment in the community, and in places of detention. In particular, the court must have regard for the health and wellbeing of the detained person.

Limits on disproportionately severe treatment or punishment are contained in the Bill of Rights Act 1990, and limits on coerced treatment are contained in the New Zealand Code of Health, and the Disability Services Consumers' Rights 1996. Further, the humane treatment of offenders is acknowledged within the United Nations Protection of Prisoners and Detainees against Torture and Other Cruel, Inhuman or Degrading Treatment or Punishment (United Nations, 1992). New Zealand is signatory to the Optional Protocol to the Convention against Torture and other Cruel, Inhuman or Degrading Treatment or Punishment (OPCAT). ${ }^{23}$

The failure to apply international standards to prison drug treatment and health-care settings has been criticised by the UN Committee Against Torture and the UN Special Rapporteur on

\footnotetext{
${ }^{23}$ OPCAT is incorporated into New Zealand law through the Crimes of Torture Act 1989, and is primarily concerned with preventing human rights violations; strengthening protections against ill treatment and improving conditions of detention, taking into account international human rights standards.
} 
Torture. Specifically, the failure to provide adequate health services to inmates and the denial of evidence based opioid substitution treatment for drug dependence are tantamount to cruel, inhuman or degrading treatment or punishment (United Nations, 2013). The UN Special Rapporteur Report signalled how health and justice policies and practices can lead to discrimination and violence in the health care setting, including coerced compulsory treatment and the neglect of people with cognitive disabilities (United Nations, 2013). Briefly, the Report demonstrated how states commit violations of the prohibition on torture or other cruel, inhuman or degrading treatment by mediating treatment through the criminal justice and health-care settings. Thus, as an overall frame for which to examine the AODTC, we should consider the fact that court participants should not be punished for their addiction or health condition, nor should the court be allowed to 'rely on the criminal justice system for access to treatment' (SSRC, 2018:115).

In New Zealand there is a growing body of official reports regarding addiction treatment in prison and the detention of people with a substance use and mental disorder in police custody (IPCA, 2015; Smith, 2007; Tinsley and Young, 2017; Wakem and McGee, 2012). These Reports indicate that limitations imposed by international and domestic law are not enough to ensure the health, social, cultural, and economic rights of the criminal justice population. This is because there are departments with different aims and purposes involved in managing offender health, namely the Ministry of Health, the Department of Corrections, and the Police. As such, the smooth provision of care and deciding which agency has responsibility poses challenges for treatment (IPCA, 2015; Smith, 2007; Tinsley and Young, 2017; Wakem and McGee, 2012). Because AODTC involves the merging of justice with health, it may mean that legally coerced treatment comes to resemble rehabilitative punishment (Boldt, 1998).

In consideration of the fact that coerced treatment deviates from medical best practice (United Nations, 2013), and that there is no express right to health in New Zealand, I argue that AODTC coerced treatment raises the question as to whether treatment provided through the court is appropriate. There are also questions as to the AODTC use of 'addciton as a disease' to describe related offending, because of the potential for the criminal justice process to interfere with clinical treatment. As will be seen in the following chapters, AODTC coercion underpins the court's and community treatment providers' approach to treatment. Therefore, I examine the extent to which the AODTC is cast as a panacea for treating AOD offending, in more detail, in the following chapter. 


\section{Ethical considerations of coerced treatment}

Drawing from a consensus view prepared for the World Health Organization, Porter, Arif and Curran (1986) established that legally coerced treatment should be provided in a way that allows for individuals to be protected by due process, and for humane and effective treatment to be upheld. In the absence of humane and effective treatment, coerced treatment may well become a cost-cutting exercise, designed primarily to reduce reoffending and incarceration rates. Given that the rights to health and treatment and the role of AODTC in merging health with justice, I argue that coerced treatment raises ethical considerations, especially when the court's focus is on treating offending as driven by addiction as a disease, and when punishment forms part of the treatment (von Hirsch and Maher, 1992). To address some of these concerns, this section provides a critical perspective on coercion, and coerced treatment.

The World Health Organisation (WHO) and the United Nations Office on Drugs and Crime (UNODC) have found that coerced addiction treatment is an acceptable alternative to imprisonment if the state provides a legal framework that recognises the right to health and evidence based treatment and care (Hathaway, 2002; UNODC, 2013; 2017). Given that the DTC is both an agent of treatment and deterrence through sanctions, ethical issues arise in the use of coercion (Tiger, 2011). This is important when considering the evidence as to whether or not coerced addiction treatment is ethical in the treatment of offenders.

Policy makers attempting to address public safety, while also attempting to reduce the costs associated with reoffending, have been enticed by the idea that legally coerced treatment is efficacious in treating AOD related crime (Kleinig, 2008). However, the danger of putting this process into action is that it tends to focus on the goal of crime prevention at the expense of treatment (Kleinig, 2008). One effect is the amplification of the legal status of the addict as both irresponsible and responsible (Cohen, 1985; Stevens, 2012). Undeniably, the legality of coercion should not supplant civil rights either in the aims of reducing harms, or in the interests of public safety (Kleinig, 2004), and a person's autonomy requires safeguarding because the perception of free will has therapeutic benefits in treatment (Hodson, 1983).

Critics have suggested that the DTC mandate of crime as related to disease is used to bolster coerced abstinence based treatment (Hall, 1997), however, the risk is that the disease-crimeabstinence mandate may constitute any form of AOD use or behaviour as a breach of treatment, and thus undermine participants' autonomy and ability to remain in treatment (Miller, 2009). The belief that coerced treatment and the criminal justice system are compatible models 
potentially ignores legal threats to get drug users to enter or remain in treatment (Clancey and Howard, 2006; Seddon, 2007) which, may at some point involve punishment for noncompliance (Kleinig, 2008; Wild, Roberts, and Cooper, 2002). Simply speaking, coercing people through threats of punishment to enter or to remain in treatment (Clancey \& Howard, 2006), conflates treatment with punishment (Gross, 2010). In terms of AODTC mandated treatment and given the evident tensions between the merging of health with justice, there are questions around the court's acceptance of 'disease', coercion and voluntary treatment (Boldt, 2009).

Unfortunately, there is a dearth of research on the effects of coerced treatment in New Zealand. There is however evidence in New Zealand legislation that the Alcoholism and Drug Addiction Act (ADA) 1966 played a generative role in the framing of punitive coercive treatment responses. This research found that the origins of the ADA 1966 lie in the systematic expansion of state control of AOD use and addiction, under the provisions of compulsory treatment and punishment. At the time, the argument was that forcing alcoholics and addicts into treatment provided for a greater chance of successful treatment (Webb, 2001). However, doubt was cast over compulsion, as the people who entered treatment involuntarily were less successful than those who entered treatment voluntarily (Webb, 2001).

The international research suggests that voluntary treatment is more likely than coerced treatment to reduce AOD related crime (Bean, 2002; Hunt and Stevens, 2004; Stevens, Berto, Kerschl, Steffan, Heckmann, Oeuvray and Ooyen, 2003; Webb, 2001). However, in spite of this, an extensive DTC study conducted by Belenko (2001), found that the overall effects of treatment on drug use, related crime and health were unclear. The AODTC employs coercion in treatment despite the absence of clear evidence of its effectiveness. The thesis therefore undertakes a critical analysis of legal coercion in the context of the AODTC structure in Chapter 4, and its effects in Chapter's, 5, 6, 7 and 8.

When considering AOD addiction treatment there are concerns that drug policy potentially reinforces the legitimacy of prohibition based abstinence policy (Fischer, 2003). Ethically, one of the ways that AOD policy is theorised and justified by the state, is through harm minimisation or harm reduction. (Measham, 2006). According to Bean (2010:30), harm reduction within the context of the criminal justice is used to justify penalties that involve harm to others as being more blameworthy than harm to self. A troubling effect of this approach is that targeted law enforcement built upon the image of the addict as bad and in need of treatment 
is 'fundamentally at odds with the premise of blameworthy' (Boldt, 1992:2322). Therefore, if the purpose of treatment is to minimise harm, then the question is whether harm minimisation should override the autonomy and rights of individuals in the criminal justice system. This point is important, because criminal justice policy can support punitive rehabilitative sentences, resulting in a diversion of attention away treatment (Hunt and Stevens, 2004; von Hirsch and Maher, 1992). International examples of these policies and practices include UK drug testing treatment orders (DTTOs), which are, in part, informed by the United States DTC model and the US DTCs (Bean, 2002; Hoffman, 2000; Nolan, 1998).

I argue that one manifestation of reducing harm through the criminal justice system is through TJ, because broadly speaking, TJ, like harm reduction, brings together the law and legal processes to promote the wellbeing of the offender. While the AODTC draws on TJ as an innovative approach to reduce the harms arising from AOD offending (Ministry of Justice, 2012a), there is however, a contradiction concerning the abstinence policy and the policy of reducing AOD use as AODTC Judge Tremewan's statement indicates 'there is no other option than to lead a sober life' (2013:4). Therefore, it is questionable as to what extent, if any; the AODTC is seen as a therapeutic and effective treatment intervention that does not undermine participants' rights to treatment targeting offender accountability.

In the next section, I briefly outline the New Zealand National Drug Policy (NDP), a government health policy that recognises that social, economic, and health harms emanate from AOD use and misuse (Ministry of Health, 2015). Yet, there is tension between the NDP as a health-based policy and the promotion of prevention and enforcement responses that rest squarely within criminal justice. Accordingly, I discuss the NDP because it recognises the AODTC pilot as 'Getting the legal balance right' (Ministry of Health, 2015). However, as discussed above, there are questions as to what extent people will receive treatment free of coercion and punishment. For the purposes of this thesis, it is also noted that the AODTC was not incorporated into the NDP until 3 years' post-establishment. Nevertheless, the NDP description of the AODTC as a penal treatment priority is relevant to the discussion so far.

\section{New Zealand National Drug Policy}

The New Zealand National Drug Policy (NDP) recognises that AOD problems are primarily a health issue and it provides for 'evidence based strategies' (Ministry of Health, 2015:1). However, there is no working definition of addiction in the policy, rather addiction treatment is a recognised part of a 'problem limitation' approach. Broadly speaking, problem limitation 
involves using criminal justice as a point of contact for treatment. However, 'prevention' and 'enforcement' are incorporated as coexisting priorities aimed at deterrence. The idea of deterring AOD use and misuse in the NDP is set alongside the balancing of 'social, economic cultural and health harms' to the individual and society, through treatment (Ministry of Health, 2015:17). In this context, deterrence is seen as a gateway to abstinence based treatment, but the prevention and enforcement aspects of the policy justify punishment. With respect to an individual's right to treatment free from coercion and punishment, I argue that together these policies put to question the role of addiction treatment in the NDP.

\section{Getting the legal balance right: the AODTC pilot}

The argument presented is that the NDP approach to social, economic, cultural and health harms is an approach that relates more to punitive criminal justice responses targeting deterrence, enforcement and punishment, than to evidence based health based responses encompassing a person's wellbeing. It is therefore unclear as to what extent humane, evidence based treatment practice is adopted in the policy. This is particularly so in light of the evidence that, under the shared value system of judicial leadership and coercion in practice, 'deterrence' and 'desert values' are mixed with treatment (Goldkamp, 2000:930).

When considering the NDP description of the AODTC as 'getting the legal balance right', in line with the subjective understandings of disease and a retributive focus on accountability, there are questions as to whether the deterrent and crime prevention aims of the health policy (Boldt, 1998; von Hirsch and Maher, 1992) will suppress the participants' rights to treatment.

Considering that there is no recognised right to health, the limitations of addiction treatment in New Zealand, the gaps in research examining the treatment of women and Māori (Gibson, 2016; Mancall et al, 2000), and treatment experiences in the criminal justice system (Bentley, 2014). I argue that there needs to be a firm understanding of the social, cultural and health circumstances that influence the treatment of women and Māori. In addition, to the understanding of AODTC treatment. Because, the incorporating the AODTC into the NDP as getting the legal balance right, in my view, appears to be an attempt to compel people into treatment. The AODTC as it stands is dependent upon an ambiguous understanding of addiction as a disease using the criminal justice system as a point of contact to deter use, in the interests of public safety. When the NDP approach to treatment puts a large emphasis on deterrence and treatment including punishment, it is essentially presenting the AODTC as a 
mix of past and present interpretations of offender pathology and curative treatment (Fischer, 2003).

Moreover, as the AODTC is an apparatus of law reform, it is therefore important to consider the impact of the services provided on the participant community. Because, in my view, the reform of law and legal process is no easy task, yet it seems clear that there needs to be a wellgrounded understanding of the ways in which the criminal justice process may affect mandated treatment. As will be shown in the following chapters, the rhetoric of the AODTC as 'getting the legal balance right' is, in principle and practice, an extremely complex process.

To this point, I have argued that the NDP aimed to deter AOD use and misuse, and that its description of addiction and the scope of treatment is ambiguous. The following section extends this discussion by exploring the availability of prison based AOD treatment in New Zealand. While the AODTC is seen as an alternative to imprisonment, imprisonment is regularly used as a sanction for non-compliance by the court. Unfortunately, there is very little known about the impact of imprisonment on the AODTC treatment programme. Therefore, I consider how AOD addiction is treated in prison, and in keeping with the goal of the chapter to examine addiction and penal treatment, I discuss the Corrections Opioid Treatment policy, as an example of the tensions involved in bringing together the goals of justice and health in addiction treatment.

\section{Prison treatment}

The Corrections (2014) AOD treatment policy 'Breaking the Cycle; Our Drugs and Alcohol Strategy', promotes evidence-based treatment aimed at reducing reoffending. To facilitate this, evidence-based treatment is practiced in drug treatment units (DTUs) in nine New Zealand prisons (Corrections, 2016). Eligibility depends upon the IOMS, a risk-screening tool that matches sentence type, individualistic criminogenic needs and the potential for harm to treatment (Corrections, 2014). Similar to the AODTC, the underlying philosophy is that the person's addiction somehow facilitates their criminality and harm to others. Here, the purpose of treatment is to 'reduce reoffending' through a combination of risk responsive interventions, evidence based 'treatment' including a comprehensive assessment, the monitoring of use, rewards, and sanctions, mental health treatment and medication assisted treatment such as methadone (Corrections, 2016).

Scholars have argued that criminal justice risk responsive interventions aimed at facilitating treatment (O'Malley, 2002; Spivakovsky, 2013) overlook the 'social, historical and cultural 
realities of those less privileged' (Maurutto \& Hannah-Moffatt, 2007:486). In New Zealand, there is empirical evidence to show that Corrections treatment policies and practices have undermined Māori cultural identity through the process of co-opting bicultural therapy ${ }^{24}$ (Mihaere, 2015; Tauri, 1999). Furthermore, it has been found that women are framed according to perceived risk, meaning that their social, economic, and cultural needs are either undermined or ignored (Bentley, 2014). This in spite of the fact that Māori women constitute over $60 \%$ of the female prison population (George et al, 2014). This raises questions about the role of treatment for these offenders, who are more likely to face hardship, discrimination, and punitive practices, as part of AODTC treatment.

Apart from population health studies, there is very little research in New Zealand on the impact of addiction treatment policy in the criminal justice system (Sellman, Hannifin, Deering, and Borren, 1996). However, my investigations reveal that the Corrections Opioid Substitution (Methadone) Treatment Policy is an example of a penal drug treatment policy that draws from the NDP (2015) and Ministry of Health (2010) treatment guidelines. I draw on the Corrections methadone treatment policy as an example that helps us to understand the tensions involved in merging a New Zealand health policy with criminal justice in the governing of opioid addiction treatment for those offenders on a bona fide programme prior to imprisonment (Corrections, $2013)^{25}$. I argue that, as an example, the Corrections treatment policy undermines offenders' rights to treatment because the involuntary withdrawal of methadone is used to enforce compliance, with no room for clinical support. The criteria for involuntary withdrawal is:

... a confirmed breach of the consent and agreement process, or, there is a strong suspicion of a breach based on the balance of probabilities (Corrections, 2013:7).

While the Corrections (MMT) policy is concerning, it is not surprising given the evidence that international and domestic instruments are not enough to safeguard offenders' rights to treatment, health and wellbeing (UNODC, 2017). Similar tensions have also been found in

\footnotetext{
${ }^{24}$ Bicultural therapy refers to the responsive components of cognitive behavioural therapy programmes integrated with tikanga Māori in the criminal justice system. The therapeutic aim is to enable Māori access to treatment programmes delivered in manner that is compatible with their health, social, and cultural needs (Mihaere, 2015).

${ }^{25}$ The Corrections Methadone Policy contained in the Prison Services and Health Services Manual, draws authority from the: Corrections Act 2004, Corrections Regulations 2005, Misuse of Drugs Act 1975, Prison Opioid Substitution and Managed Withdrawal Protocol (Department of Corrections, 2007); Practice Guidelines for Opioid Substitution Treatment in New Zealand 2008 (Ministry of Health, 2008), the Medicines Act 1981, and the National Drug Policy (NDP).
} 
other DTC studies (Csete and Catania, 2013), as well as in studies of community MMT programmes (Bourgois, 2000; Garcia, 2008; Gibson, 2016).

The imposition of treatment in the above context however cannot be justified on the basis that it makes offenders punishable. It is also questionable as to what extent, if any, is the difference between the health setting and criminal justice setting in the treatment context, and is concerning given the fact that the AODTC readily accepts coerced abstinence-based treatment. I investigate therefore whether AODTC treatment policies and practices actually address the social, cultural, and health realities of the participants.

In summary, the descriptions of addiction treatment in the criminal justice system tend toward a coercive context focussed on deterring use and risk responsiveness, ignoring social, economic and cultural and health contexts (Bentley, 2014; Mihaere, 2015). Rather than depart from historical constructions of addiction and deviance, the contemporary treatment, as outlined in the NDP, and prison based drug treatment, form part of the ongoing cycle of dominant norms of punishment and the social control of AOD related offending. Therefore, the historical constructions of addiction, and the historical tensions between curative treatment and punishment in the criminal justice system, are still exerting powerful influences over present day treatment.

\section{Conclusion}

In this chapter, I have briefly described how historical tensions between health and justice have constructed 'addiction' predominantly on moral grounds as a disease and as a criminal justice problem to be treated through coercion and enforcement. As will be discussed in the following chapters, the AODTC reflects past and present beliefs of addiction, offender pathology, responsibility, coercion and curative treatment (Boldt, 2009; Fischer, 2003; Yeomans, 2018). These points are important because, as will be demonstrated, there has been no attempt by the AODTC to refute the controversial claim that addiction is a brain disease (Hart, 2017), despite the reality that this belief and the practice derived from it, has the potential to undermine participant's rights to treatment.

The analysis of legally coerced treatment has shown that there is no actual right to health, and that access to addiction treatment is limited. There are also ethical implications for the use of coercion in the criminal justice system in that the merging of health and criminal justice is 
incompatible with maintaining health and safety standards in treatment in the New Zealand criminal justice system (Smith, 2007; Wakem and McGee, 2012).

I have demonstrated that the underpinning of coercion in the criminal justice system is a combination of deterrence, control, and abstinence based treatment and this is arranged in ways to resemble conventional justice, putting to question the role of treatment and the potential for harm (Gross, 2010; Tiger, 2013; Colyer, 2007; UNODC, 2009). I have also exposed how AODTC Judge Tremewan (2013) does not believe in a harm reduction approach to addiction, rather the AODTC is about focussing on reducing AOD offending. As will be shown in Chapters 5, 6, 7 and 8, there are tensions in the merging of health with justice in the AODTC programme, all which have consequences, both intended and unintended for the participants' health, wellbeing and safety, and for the court treatment programme in general.

In the chapter I have also shown that the aim of the AODTC is briefly described in the NDP as 'getting the legal balance right'. Yet, there are questions as to how the court will balance intensive treatment with offender responsibility and punishment, using sanctions as a form of therapy. The constitution of addiction, AOD offending, the NDP, and prison treatment policies, each form part of the dominant norms of deterrence and punishment of AOD addiction, as opposed to treatment.

Overall, the chapter has demonstrated how addiction in New Zealand is subject to the various socio-political understandings of disease, offender pathology, race, abstinence, coercive treatment and criminal justice responses built on risk responsiveness. While there is very little research documenting the use of legal coercion, and its application in the criminal justice system in New Zealand, I argue that without research there is no 'evidence base'. Without evidence, the AODTC programme invites wide discretion, inconsistency, and uncertainty in legal process, thereby leading to potential violations of participants' rights.

In the next chapter, I detail the genesis of the New Zealand AODTC model. I describe the language and strategies used in establishing the pilot as reflecting historical punitive and rehabilitation approaches to the problem of AOD related offending. I show that these processes have led to law reform assertions that addiction is a disease and curative treatment, and also that the criminal justice system is an appropriate site in which to adopt the US DTC model in order to govern the treatment of AOD related offending. 


\section{Chapter 4: The New Zealand Alcohol and Other Drug Treatment Court}

Dissatisfied with what was currently being done and had always been done, Drug Courts pushed through the envelope and redesigned the criminal justice system.

- $\quad$ US National Association of Drug Professionals ${ }^{26}$

\section{Introduction}

This chapter traces the development of the AODTC as a new approach to AOD offending, representative of a transformation of the traditional court process to offender treatment. This is important because as discussed, the US DTC model provides the template for which the AODTC has been justified on the basis that it effectively 'treats' addiction related offending, and is defended on the grounds of reduced recidivism and cost effectiveness (Hora, Schema and Rosenthal, 1999; Tremewan, 2013).

Nielsen (2000) suggested that institutional and political values shape peoples' legal consciousness about what is acceptable governing practice. This chapter draws attention to several driving factors, rationales and policymaking processes involved in the genesis and development of the AODTC (Garland, 2014).

The chapter is divided into two parts. The first begins with a brief outline of the AODTC principles. I then outline several rationales behind three key policy developments that supplied the case for the grounds for establishing a different way of dealing with AOD offending. The Effective Interventions Cabinet paper entitled 'Preventing Reoffending,27, the multiagency 'Drivers of Crime'28 strategy aimed at identifying the underlying causes of offending, and the Law Commission Review of the Misuse of Drugs Act (2011), each contributed to and made arguments in support of the AODTC. In this context, I outline the development of the AODTC as an official response to the desire to reduce AOD offending and recidivism rates. This involves an examination of the institutional and political context that connects the promotion of US DTC as a basis for the AODTC Pilot and as an alternative to imprisonment by diverting offenders into treatment.

\footnotetext{
${ }^{26}$ US Adult Drug Court Best Practice Standards Volume I (NADCP, 2013:3).

${ }^{27}$ Effective Interventions is the title given to a suite of Cabinet papers put before and approved by the New Zealand government in July 2006, they were designed to enable the government to "stay tough and be smarter" about crime and punishment (Smith, 2007:87).

28 The Drivers of Crime' refers to government's response to addressing the underlying causes of criminal offending and victims' experiences of crime (Ministry of Justice, 2015).
} 
I draw particular attention to the role of law reform (Garland, 2014) in advancing claims targeting AOD related offending (Silbey, 2005), through the promotion of an agenda by which the Law Commission and the AODTC judges have pursued establishing a US style DTC in New Zealand. Importantly, I emphasise the role of the Law Commission in making contradictory treatment recommendations and demonstrate how the law was utilised to advance 'interests', 'beliefs' and 'values' (Harding (2010:22). This led to the judges becoming 'problem-solving activists', promoting the adoption of policies aimed at the treatment of offending (Hoffman, 2002:2097).

In the second Part, I highlight how the AODTC is based on the US DTC model by pointing out the similar features of both. I then identify the key features of the AODTC and present a description of how the court operates and its routine practices, from eligibility through to exit or graduation. This leads to the final section of the chapter where I question the effectiveness of DTCs and the findings of the New Zealand Formative, Interim Process and Final Process Evaluations (Litmus, 2014; 2015; 2016).

\section{The AODTC}

The AODTC borrows from the DTC principles and best practices in its aims of 'reducing AOD reoffending' and 'reducing AOD use', by targeting addiction and offender accountability. For example, similar to the US DTC, the AODTC Handbook describes the court as putting nonviolent $^{29}$ offenders who have an AOD addiction, through intensive judicially monitored treatment (Ministry of Justice, 2012a; 2014). Judicially monitored treatment in the AODTC involves decision-making around bail conditions, weighing up evidence of programme eligibility, programme engagement, evidence of abstinence, and evidence of housing and employment or vocational training (Ministry of Justice, 2012a; 2014).

However, DTC practices have been criticised on the basis that treatment can be tougher and more intrusive than traditional criminal justice processes (Boldt, 1998; Nolan, 2003) because the problem-solving court mandate permits the judge unprecedented discretion, making the programme longer and more onerous than the common sentence (Hoffman, 2002). I argue that the AODTC focus on AOD addiction as driving offending, and the adoption of the US model

\footnotetext{
${ }^{29}$ The Ministry of Justice AODTC Handbooks (2012a; 2014) outline non-violent offenders as those facing a term of imprisonment of up to 3 years. In other countries, eligibility for Drug Court varies according to jurisdiction and the type of Drug Court model. For instance, in the US and Canada, most Drug Courts do not consider violent offenders (NADCP, 2016).
} 
as innovative policy, has the potential to undermine participants' treatment, health and wellbeing.

\section{Reducing re-offending and improving public safety}

In 2006, a cabinet Paper entitled 'Preventing Reoffending', recommended a Drug Court pilot programme for New Zealand on the basis that 'Similar programmes in the United States, Canada, the United Kingdom, and Australia are significantly reducing re-offending' (Preventing Reoffending, 2006). The Paper stated that drug courts 'provide a bridge between the justice and wider health and social services' (2006:17). At the same time, however, the paper also proposed that the effects of a drug court pilot for New Zealand would be dependent on the quality of the programme, and on reducing the potential for net widening (Preventing Reoffending, 2006).

On $3^{\text {rd }}$ of April 2009, the then Ministers of Justice, and Māori Affairs hosted a Ministerial meeting with a wide range of stakeholders which was convened to identify and discuss the 'drivers' of crime. The meeting picked up on, among other things, the proposition that alcohol and drug use is one of the underlying causes (drivers) of crime. The meeting determined that the causes of crime are complex, and that interventions are required which consider 'the individual, family, community and justice sector factors that contribute to crime' (Ministry of Justice, 2009:1). The Ministry of Justice established that, when addressing the drivers of crime, judicial oversight of alcohol and drug treatment of offenders required strengthening if judges were to divert offenders into treatment programmes and away from imprisonment (Ministry of Justice, 2009).

On the $2^{\text {nd }}$ of November 2009 Cabinet agreed that the Addressing the Drivers of Crime package be established as a new whole of government approach to: (1) reduce the harm from alcohol and improve the availability and accessibility of alcohol and drug treatment services; and, (2) identify alternative approaches to manage low-level offenders and offer pathways out of offending. Overall, Cabinet recommended a range of programmes and services aimed at achieving better individual, family, and community outcomes, including the required action for addressing harm from alcohol by 'improving justice sector clients' access to health sector services' (Ministry of Justice, 2009:9).

Following the May 2011 release of the 'Drivers of Crime' strategy, the New Zealand Law Commission released a separate report entitled, Controlling and Regulating Drugs - A Review of the Misuse of Drugs Act 1975 (Law Commission, 2011). Elements of the Review were 
derived from earlier Law Commission documents, Issues Paper 15: Alcohol in Our Lives: An Issues Paper on the Reform of New Zealand's Liquor Laws (NZLC IP15, 2009), and Issues Paper 16: Controlling and Regulating Drugs (NZLC IP16, 2010). Drawing on these Papers, the Commission called for 'greater emphasis to be given to treatment, both in response to offending and more generally' in the community (2011:318). The Law Commission review also considered submissions, surveys, and reports from the New Zealand health sector, Corrections and the judiciary, and the international literature on treating addiction. The review found that tensions existed between alcohol and drug treatment in New Zealand, and questioned the overall effectiveness of treatment (Law Commission, 2011). The Commission specifically rejected the historical view that offenders needed to be cured of AOD dependence. Instead, they stated:

The effectiveness of alcohol and drug treatment is measured in terms of its ability to reduce the harms associated with alcohol and drug dependence rather than its ability to "cure" participants.

The Commission suggested that 'more weight ought to be placed on treatment as a harm minimisation strategy, particularly in the criminal justice sector' (Law Commission, 2011:322). Among the key recommendations contained in the document was the proposal for a drug court pilot.

In arriving at this recommendation, the Commission cited 'robust evidence' collected from the New South Wales Drug Court in Australia ${ }^{30}$, that 'drug courts can be more effective at reducing recidivism' (2011: 334). The Commission was also encouraged by the view that international DTC evaluations showed that they can potentially reduce the risk of reoffending compared with 'alternative options' (ibid). The Commission also identified the potential for risks such as the disproportionate punishment of those offenders who do not successfully complete the programme, and who end up with greater sanctions than their offending would otherwise have attracted. In these instances, the Commission argued:

Offenders should not be exposed to a disproportionate response to their offending, with the inevitable element of coercion that this entails notwithstanding any requirement for their consent, merely because the response is perceived to be beneficial to them (2011: 336).

\footnotetext{
${ }^{30}$ I discuss the New South Wales drug court evaluation further in the section on questioning the effectiveness of DTCs.
} 
In considering the potential for a disproportionate justice response, the Commission suggested robust eligibility criteria for drug court participation, which 'should include both justice and health criteria', that 'the threshold for dependence should be defined', and that 'the justice criteria should focus on the sentence that the offender might otherwise receive' (Law Commission, 2011:342). Crucially, the Commission recognised that addiction treatment is not something that can be achieved alone within the justice/court environment because offenders require ongoing support.

In light of the international research and DTC Key Components and evidence of drug court effectiveness, the Law Commission (2011:342-343) recommended the following key features of the drug court model $^{31}$ :

- A guilty plea;

- The requirement of a social and cultural needs assessment of offenders meeting the criteria. Issues such as accommodation needs are flagged and, to ensure that the treatment programme was appropriate to the needs of the offender. This would be incorporated into the treatment plan;

- Three programme phases including the provisions of parenting courses, safe driving programmes and the encouragement of participant to engage in community service;

- Immediate sentence post decline or post exit;

- A professional team, inclusive of a judge, legal counsel, a clinician and a case worker;

- Participation of community AOD addiction treatment agencies and the encouragement of family/whānau in the participants' recovery;

- Objectives to be to reduce AOD dependence and reduce the risk of reoffending;

- Testing for abstinence from AODs throughout the programme, with the clear aim of sobriety;

- Programme length of a minimum of 12 months. Absolute abstinence $e^{32}$ might take some time to achieve, the failure of participants to satisfy the court that they are clearly demonstrating their commitment to abstinence would result in an exit hearing being convened by the court with a view to their exclusion from the programme.

The last point is a contradiction. In spite of the Law Commission's opinion that addiction is a chronic relapsing condition ${ }^{33}$, and that treatment should not be based on a 'cure' for addiction,

\footnotetext{
${ }^{31}$ In making these recommendations the Law Commission acknowledged the 'substantial input from Judges Tremewan and Aitken from the Waitakere and Auckland District Courts' (Law Commission, 2011:342). I discuss the judges input further in the section on judicial activism in this chapter.

${ }^{32}$ My italics. I return to this point and the Law Commission key features in Chapter 8.

33 The Commission recognised that that dependence is a chronic relapsing condition and 'fewer than 10 percent of people with an alcohol or opioid dependence experience continuous abstinence following treatment' (Law Commission, 2011:321).
} 
the Commission recommended a drug court pilot with objectives that reduce dependence but simultaneously test for absolute abstinence as a measure of success (Law Commission, 2011). Such thinking is clearly informed by the DTC ethos that places blame on the offender for any perceived lack of commitment, potentially leading to the disproportionate punishment of people the AODTC is unable to cure (von Hirsch and Maher, 1992).

Following the Commission's recommendation, the Minister of Justice and the Minister of Courts, announced on the 19 October 2011 that:

Establishing a Drug court delivers on priorities under the Government's Drivers of Crime work programme, which includes reducing alcohol-related harm .... Although Drug Courts are a resource-intensive option, international research shows they can reduce recidivism by an average of 8 per cent (Beehive, 2011).

The government allocated $\$ 10$ million to the Drivers of Crime investment package for alcohol and other drug assessments and interventions allocated \$1.93 million annually over five years for the AODTC pilot in Auckland. The recommended target group comprised offenders with an AOD addiction, facing sentences of up to three years to imprisonment for offences where AODs had been a contributing factor (Ministry of Justice, 2014).

In terms of reform, the contemporary AODTC, shares with the past a bias in the cultural production of law (Garland, 2014; Silbey, 2005), in that the court is established to target AOD addiction as the driver of offending, Māori offending and offender pathology, all under the guise of curative treatment. Given the background of the Pilot, the establishment of the court was also heavily influenced by the 'substantial input' (Law Commission, 2011) of judicial activism in the adoption of the US model and treatment policy, which I now turn to.

\section{Judicial activism and AODTC policy}

Nolan (2001) provides a description of judicial activism in the development of problem-solving courts based on three processes: (i) the development of the DTC programme; (ii) developing awareness of the courts objectives; (iii) and arranging community support in order to sustain a viable treatment program. Nolan reasoned that the judiciary drew on these processes in order to justify their involvement in the establishment of the DTC, and to make 'the necessary arrangements and adjustments for the court', because the judiciary provides the 'authority, leadership and management' for the court (2001:96).

Judicial involvement in the development of the DTC programme has received numerous criticisms. Nolan (2003) Hoffman (2002) and Boldt (1998) have each critically described how 
judicial efforts justifying treatment on the basis that they are best, resemble the problematic aspects of the rehabilitative ideal. In short, there are concerns that the judiciary, in claiming that crime is a result of individual pathology, is influencing the adoption of court procedures that focus on changing people in conjunction with punishment, representing a return to the rehabilitative ideal (Boldt, 1998; Hoffman, 2002). Judicial activism as being involved in influencing and promoting reforms involving health policy is concerning, and remains an issue that warrants further critical interrogation by scholars (Wexler, 2002).

King (2010) argued that judges directing the form of treatment or directing the executive to provide resources to a court programme, would clearly conflict with judicial independence. In New Zealand, traditional court systems separate the roles and functions of judges from other branches of the criminal justice process and government, and the traditional power of the judge is constrained within their own court. New Zealand judges traditionally are not responsible for probation, treatment, or the hiring of treatment providers. In saying this, it is unclear as to the extent of the role of the Ministry of Justice in judicial activism and whether the Ministry is, or has been, involved in supporting or constraining judicial activism within the AODTC. What is evident however is that the two New Zealand Judges, Tremewan and Aitken, were instrumental in identifying the need for, and pursuing support for, the US model. Judge Tremewan claimed to have worked on the project for more than two years prior to its establishment in 2012 (Forbes, 2011). Judge Aitken claimed at an Auckland District Law Society conference that the US model is one that neither requires a change in the delivery of justice, nor in treatment, in New Zealand:

...the Americans offer us a model that has been proven to work. It's not a model that will require a fundamental change in how we deliver justice, deliver treatment to offenders. It doesn't require a fundamental change in how we perceive offenders in this country (as cited in ADLS, 2012:3).

At a criminal justice conference, AODTC Judge Tremewan (2013:10) justified the US model as a proper criminal justice option fit for New Zealand, further claiming that:

.... I have had the privilege of attending the annual conference of the US National Association of Drug Courts Professionals (NADCP)... There was no talk at these conferences about whether to have these courts; that is a given. Rather, the delegates jointly scrutinise the latest best practices ensuring ever-improved courts.... I found observing the first drug court I visited (in Orange County, LA) a profound experience. I spent about three days with a 
growing realisation that this was a fit and proper criminal justice response to the types of cases at hand.

Based on the judges' comments and the uncritical acceptance of the fit and appropriateness of the US model in general, there are questions as to how the court will provide for the protections of participants' rights in New Zealand.

Further to the above justificatory comments, the judicial experience of engaging with drug dependent or mental health offenders is also provided as sufficient evidence of AOD related crime and the need for a specialist drug court (Hoffman, 2002; Miller, 2009). Judge Tremewan's speech confirms this view (2013:5):

...The cases in our criminal courts that do not involve alcohol or other drug misuse are in fact the exception. If you add mental health, (MH) illness as a defining factor of those charged with criminal offences, the number of offenders who do not have either AOD or MH issues is miniscule.

Judicial involvement in promoting the adoption of the US model, also involved influencing the court emphasis on abstinence, this is evidenced in a Ministry of Health AODTC directive to treatment providers which states: 'Judges insist on total abstinence, which will require very regular drug testing of the individuals' (Ministry of Health, 2012). On the basis of this statement it can be concluded that, by insisting on incorporating an abstinence-based model into the AODTC model, the judges have demonstrated involvement in public policy practices (Valverde, 2003). Based on the judges' involvement in public policy, I argue that, in addition to unfettered judicial power, the court has the potential to undermine the humane treatment of people with a severe addiction and/or a mental illness (Des Rosiers, 2015; von Hirsch and Maher, 1992).

The judicial involvement in the adoption of public policy also tests King's (2010) theory that a judge directing a form of treatment evidently conflicts with judicial independence. In addition to driving the adoption of the US model and treatment policy, there is evidence of Judge Tremewan's and Judge Aitken's involvement in the establishment of the AODTC community advisory group (CAG), and court fund raising. Their involvement included providing input to the raising of funds in order to provide financial incentives to participants, over and above government funding (Litmus, 2015; 2016). By arguing for the importance of the judicial role, and by articulating the US DTC as the preferred model together with abstinence-based 
treatment, and by participating in raising funds for the court, Judge Tremewan and Judge Aitken have constructed a bespoke treatment model for them to monitor.

The AODTC model, being informed as it is by judicial activism and based on the US DTC model, is backed by the conglomerate National Association of Drug Court Professionals (NADCP) and National Drug Court Institute (NCDI) ${ }^{34}$. This means that the US DTC Ten Key Components and Adult Drug Court Best Practice Standards (NDCI, 1997; NADCP, 2013; 2015) are articulated and reinforced within the AODTC approach to treatment and punishment. ${ }^{35}$ However, a major limitation with the NADCP and NDCI is that there is no international guarantee of a commitment to a particular drug court model, which may result in unintended consequences such as participants not receiving evidence based treatment (Gallagher, Nordberg and Lefebvre, 2017). Indeed, a general overview of the NADCP Key Components (see Appendix C) found that even if DTCs follow these standards they can 'fall short of providing the necessary medical care and health and human rights protections to participants' in treatment (SSRC, 2018:114). I analyse below claims that the DTC model is cost-effective, reduces AOD recidivism, and, that mandated treatment is effective, as well as discussing the unintended consequences of the treatment that is provided.

So far, I have demonstrated that the principles guiding New Zealand's AODTC practices are established on the presumption that the US DTC model is an effective way to treat AOD related offending in New Zealand. I have argued that the AODTC treatment based on abstinence, as a matter of judicially acclaimed policy, are not evidence-based approaches to addiction treatment. Despite this lack of evidence, the activist judges in New Zealand pursued the adoption of the US DTC model as an approach to treating AOD addiction related offending. My analysis of the AODTC in Chapters 5, 6 and 7, is contextualised within the problem of the justice system responding to AOD related offending in terms of treatment and punishment. In this context, I investigate how the AODTC 'is sustained as a legitimate and governing institution' (Silbey, 2005:337), under the contradictory nexus of offenders having a disease while also requiring them to be accountable for their recovery (Boldt, 1998). My analysis helps demonstrate the ways in which court practices can serve to reinforce a criminal justice agenda,

\footnotetext{
34 The NADCP and NDCl are DTC professional branches, supported by the US Office of National Drug Control Policy, in addition to the U.S. Department of Justice and the US Office of Justice Programs. All documents published by NADCP and NDCI are available through their website. See the related Appendix for a summary of the US DTC ten key components and the adult DTC best practice standards.

${ }^{35}$ To help launch the AODTCs, several NADCP trainers presented at the first AODTC Conference sponsored by the Auckland District Law Society in March 2012 (NCDC, 2012).
} 
which treats and punishes people for having an 'addiction'. This mode of praxis serves to simultaneously 'treat' but in doing so legitimises new forms of punishment within a so-called therapeutic regime (Silbey, 2005).

In the next section, I discuss the DTC features, therapeutic jurisprudence, legal coercion and abstinence. This is useful because I consider the implications of these DTC features for AODTC procedure, judicial authority and participants' rights to evidence based treatment each of which are intended to positively affect offenders' health and wellbeing (Ministry of Justice, 2014).

\section{DTC features}

DTC intervention processes appear ethically salient because they are set under the appearance of law (Kleinig, 2008). In this section, I focus on the main principles of DTCs ${ }^{36}$ : therapeutic jurisprudence, abstinence, and legal coercion, each of which are incorporated into the AODTC therapeutic model.

\section{Therapeutic Jurisprudence}

Therapeutic jurisprudence (TJ) is a perspective that brings together the social sciences, law and legal practice in order to address the health and wellbeing of people in the criminal justice system (Winick, 2002). The principle underlying TJ is that the law and legal process can "enhance the psychological and/or physical well-being of individuals without subordinating other core values of the justice system" (Hora, 2002:1472). While DTCs developed independently to TJ, they are seen as adopting TJ through procedural informality (Boldt, 2009), which has been criticised for allowing the court to 'extend its authority into the lives of drug court clients in unprecedented ways' (Nolan, 2003:1562). These unprecedented extensions have been through the performative functions of ongoing judicial intervention, the close monitoring of behaviour, the integration of treatment services with judicial case processing, and collaboration with community-based and government organisations (Winick and Wexler, 2002), subject to dispute in that $\mathrm{TJ}$ is alleged to be utilised in coercive and punitive ways, amounting to punishment (Fischer, 2003). For example, TJ has been criticised for not being evidence-based (Wexler, 2014) and for its vague definition of what constitutes 'therapeutic' (Birgden, 2002), lending to the bending or ignoring of rules or ethics, and pushing out the

\footnotetext{
36 DTC practices may vary between jurisdictions. However, the majority of DTCs utilise therapeutic jurisprudence, abstinence based treatment and legal coercion as the primary intervention practices.
} 
boundaries of law (Boldt, 2009; Hoffman, 2000). In essence, TJ has faced criticism for its inherent malleability in terms of procedural justice under the guise of 'therapy'.

In her role as a DTC expert, retired US Judge Hora claimed that to apply TJ in the DTC requires judges to 'accept their changing role from neutral, uninvolved arbiter to 'problem solvers who look at cases holistically' (2002:1481). According to Hoffman, 'these ideas emanate from the idea that the judiciary can be a powerful force for social change' not by just applying the law in the traditional sense, but, by 'pushing the existing law to new enlightened boundaries' in a variety of 'non-traditional ways' ways (2000:1479). Hoffman described how it is this aspect of the DTC which 'makes TJ so dangerous and so utterly unacceptable' (2002:2085), as it leads judges' to believe that 'they can play amateur psychiatrist' 2088).

Indeed, Miller has described how, in its TJ form, DTC judges 'endorse a disease model of addiction focussed upon understanding the addict's pathological behaviour as thoughtindependent' (2009:131). Such understanding suggests 'that the addict has a pathological character' for which they are 'amenable to treatment'. This approach, he argued:

...reconstitutes the "therapeutic" ... as physical regulation or discipline imposed by an expert in various forms of surveillance and constraint: the judge. The court gains its authority as better able to engage in discipline and surveillance necessary to treat the offender's addictive disease than the other experts, in large part because the court is able to engage in discipline... (ibid).

The disciplinary aspect of the DTC programme thus seeks to make great use of the therapeutic processes of autonomy and behaviour modification. However, these processes have been criticised for subjecting participants to disproportionately severe treatment (Nolan (2003), undermining autonomy, and embedding the logics of efficacy and crime prevention into treatment (Boldt, 1998; Freiberg, 2002; Hoffman, 2000; Miller, 2004, 2009; Murphy, 2015; Nolan, 2003; Tiger, 2013).

As I discuss below, and in the following chapters the AODTC judges actively pursued the adoption of the DTC model and abstinence as a treatment policy, and, AODTC Judge Tremewan makes no secret of the fact that in her view addiction is a disease, and a responsibility of the offender. I argue that, from a procedural point of view, TJ has practical importance for the AODTC programme, because the judiciary use their power and the power of the criminal justice system to coerce participants through the disease-responsibility mandate to enforce abstinence, and punish those participants that do not comply (Hoffman, 2002). 
From a socio-cultural perspective, Gallagher and Nordberg (2016) found that the DTC TJ mandate undermined African American participants' experiences of the programme. They found that 'treatment was not treatment' because the court created addict label produced 'barriers to evidence based' and 'culturally competent addiction treatment' (p.117). In contrast, Thom and Black (2017:4) have described the cultural setting of the AODTC metaphorically as, 'weaving strands of Law, U.S. Best Practice, recovery and Lore to produce the therapeutic framework' including abstinence-based treatment. These strands are suggested to actualise the TJ, the DTC model and the Treaty of Waitangi, by weaving 'lore' (tikanga Māori) into the legal process. In these ways, they reasoned the court to be 'a holistic and healing approach' for Māori (2017:32), through the collaborative team approach, traditional rules and Māori customs, and the merging of health with justice. For example, the Pou Oranga is purported to ensure that the court is culturally responsive for Māori participants in alignment with US DTC Best Practice standards (Thom, 2017).Yet, western legal principles and processes regarded as 'healing' are considered to bear little resemblance to tikanga Māori (Quince as cited in Brookbanks, 2013).

Indeed, from a socio-cultural perspective, the Māori offender, interpreted within the rhetoric and practices of the western based AODTC, reflects a thought-provoking mix of past and present descriptions of Māori deviance as related to pathology and addiction (Garland, 2014). In this way of thinking, Māori culture is pathologised and transformed to fit in with the US standards and principles, meaning that there is nothing to stop the power of the court and judiciary from undermining Māori autonomy (Mihaere, 2015).

The co-optation of cultural practices and, the role of the Pou Oranga in supporting the diseaseabstinence mandate have in my view, negative implications for the treatment of Māori. Given the limits of culturally-conscious knowledge, the acceptance of Māori offending as driven by addiction, the selective influence of the US model and the potential for TJ to undermine the dignity of participants, to accept the AODTC as 'healing' without investigating the consequences for Māori participants is, I argue, detrimental to treatment, health and wellbeing.

As discussed, the AODTC has been defended on the grounds that it is a fit and proper response to AOD related offending though the delivery of addiction treatment. Accordingly, this thesis considers whether the court is an appropriate therapeutic alternative to justice. In doing so, I examine the appropriateness of the mandated disease-abstinence-based treatment programme 
and identify the treatment for the participants. including the cultural appropriateness of treatment for Māori participants, and the implications in Chapters, 5, 6, 7 and 8.

\section{Abstinence}

A fundamental treatment principle of the DTC model is abstinence (Hora and Stalcup, 2008; NADCP, 2013). The majority of DTCs in the US, Latin America, and Canada perceive addiction as a disease, and thus maintain an insistence on total abstinence, requiring that participants remain AOD free in order to graduate (Boldt, 2010; Fischer, 2003; Lyons, 2011; Murphy, 2011; Nolan, 2010; SSRC, 2018). However, the focus on abstinence has caused individuals characterised with severe drug dependence to be at the highest risk of failing the programme.

According to Miller (2004), DTC programmes adopting the disease model are structured around 'coercive incapacitation' or 'enforcement of abstinence', because 'addicts' are unable to control themselves (p.1533). Put simply, under the DTC regime, abstinence is a form of incapacitation. There is empirical evidence that the majority of US DTCs have rejected the use of methadone maintenance treatment (MMT) and other substitute therapies, on the grounds that a pharmacological approach would replace one drug with another (Boldt, 2014; Csete and Catania, 2013; Nolan, 2010). It has also been suggested that DTC practices such as these may create a barrier to treatment (Csete and Catania, 2013). There is some evidence from the UK and Canada $^{37}$ to show that DTCs are flexible in accommodating participants' partial compliance with program rules during the programme (Nolan, 2010). And there is a noticeable contrast in treatment perspectives between the US and the UK toward the use of pharmacotherapies such as methadone for the treatment of addiction (McIvor, 2006; Nolan, 2010).

Paradoxically, the AODTC Handbook (2012a; 2014) recognises that 'addiction is a chronic, relapsing condition' yet, abstinence is the desired goal of the court (Ministry of Justice, 2012a; 2014). As such, under the criminal justice framework, the expectation is that an overall 180 consecutive days over 12-18 months from entry to exit will result in abstinence and graduation. This is in spite of clinical evidence that suggests 'fewer than $10 \%$ of people with drug addiction [and dependence] will have continuous abstinence following treatment when followed long term' (Sellman, 2009:8). I argue that merely recognising that relapsing occurs does not qualify

\footnotetext{
${ }^{37}$ According to Lyons (2011), the Toronto DTC is not abstinence based, although dirty tests are sanctioned, and all participants are expected to drug free by the end of the programme. Presumably, the Toronto DTC is abstinence based.
} 
as evidence-based, therapeutic, or humane treatment practice, without including treatment processes to assist those who do relapse. For these reasons, I argue that the AODTC goal of abstinence and the court's inability to accommodate relapsing is questionable, and requires further investigation in Chapters 5, 6, 7 and 8.

\section{Legal coercion}

...coercion is employed in the drug treatment court system it does not involve forcing the defendant to receive treatment against his or her will. In this context, it is the careful leverage of judicial authority to encourage the offender to choose the most statistically probable opportunity for rehabilitation and a better life (Hora and Stalcup, 2008: 753).

Coercion is a principle of the DTC whereby the power of the court considers that offenders are not without choice. Therefore, judicial discretion is mixed with voluntary participation and incentives with sanctions to enforce compliance (Belenko, 1998; Burns and Peyrot, 2003; Miller, 2004). DTCs rest their therapeutic legitimacy on the best practice of the carrot and stick approach to offender accountability, which is presented as essential to the process of behaviour modification (Marlowe, Festinger, Dugosh and Benasutti 2006). Accordingly, the DTC is an example of coerced treatment because the offender is given the choice of treatment or imprisonment, although a somewhat constrained choice (Seddon, 2007). Critics of DTC coerced treatment have challenged, that legal coercion speaks to the punitive and deterrent purposes of criminal justice, reinforcing power dynamics, forcing people to a guilty plea putting individual's rights at risk, exposing people to punitive treatment (Boldt, 2010; Fischer, 2003; Seddon, 2007; Tiger, 2011).

In the previous chapter I discussed how legally coerced treatment in New Zealand has involved the use of law and legal process alongside the major goals of social adjustment and curative treatment, law enforcement, and deterrence in New Zealand. I have shown how there is no express right to health, however, the merging of the health with justice has contributed to ongoing tensions between coercion, the risk associated with addiction and offender accountability, crime prevention and deterrence in treatment (Boland, 2008). Given that the AODTC is reliant on 'addiction as a disease' and the coercive power of the law in treatment, it is therefore important to consider to what extent court decision making will act in the best interests of participants' treatment. Because when speaking about coercing and enforcing treatment AODTC Judge Tremewan conflates disease with addiction, offending and the choice to enter the programme (2013:3): 
...it is exhausting to suffer from the disease of addiction where the whole day can be spent committing offences for the income to source and then use ....although we talk of coercing or enforcing treatment, offenders have always had a choice as to whether they enter these courts.

Critics have argued that the validity of such a view hinges on whether offenders targeted for this type of legal coercion are genuinely able to give informed consent to treatment (Seddon, 2007). This is also salient given that the AODTC participant is required to enter a guilty plea in order to enter the court, that the judges utilise TJ in mandating the court eligibility criteria, upholding abstinence as a goal and impose sanctions as part of treatment.

Unfortunately, beyond the underlying DTC framework of merging treatment with justice, there is little known about the conceptual foundations of treatment and treatment services offered in the DTC environment, (Boldt, 1998; Nolan, 2003; Taxman and Bouffard, 2005). Some scholars have however addressed the issue of DTC treatment and cognitive behaviour therapy, and have suggested that DTC participants were not always receiving treatment consistent with evidence based practice (Bouffard and Taxman, 2004; Taxman and Bouffard, 2005).

In the AODTC, coerced treatment involves the judges' role and occurs using various programmes, including a cognitive behavioural therapy programme called Moral Reconation Therapy (MRT), and the belief that criminal behaviour is the responsibility of the participant (Litmus, 2016). Accordingly, MRT is utilised by the court to ensure responsibility for abstinence and relapse prevention including regular and random drug testing, and electronic bracelets to monitor and reinforce recovery (Ministry of Justice, 2014). On top of these processes, there are other treatment measures such as residential treatment, intensive day programmes, drink driving programmes, and AOD treatment community based support services (Ministry of Justice, 2014). Most of these mechanisms are taken from the US model and have been found to be under-researched. Therefore, the degree by which the DTC 'effectively incorporates treatment as a tool' (Taxman and Bouffard, 2002:1685) is unknown.

Considering that the AODTC emerged from a political desire to bridge health with justice in addressing AOD offending, there are questions about the Law Commission recommendations for a threshold for AOD dependence and abstinence, TJ mandate and coercion (Ministry of Justice, 2014) the adoption of the US model and procedural compatibility (Boldt, 2009). Taking in the discussion so far, I have also called into question the constructs of addiction as a disease, offender pathology, behavioural modification, and how the AODTC will balance treatment with punishment. I argue that these points are important when considering whether the AODTC 
will actually be able to balance the rights of offenders to treatment when using the coercive power of law.

I now turn to consider the key features of the AODTC programme, the roles of the AODTC team, the AODTC process, and the programme requirements.

\section{Key features of the Alcohol and Other Drug Treatment Court}

The programme will focus not only on abstinence from drugs and alcohol it will help offenders develop positive life skills that will help them stay away from crime and instead make a positive contribution to their community.

- Minister of Justice Hon Judith Collins 2012, at the opening of the AODTC

AODTC participants are required to become, and remain, abstinent from AODs, and reestablish themselves as crime free citizens. Accordingly, the AODTC goal is to change participants' behaviour by way of treatment and isolation from negative social influences (Miller, 2004).

The Ministry of Justice Interim Process and Final evaluations (Litmus, 2014; 2015; 2016) identified the following features as distinctive to the New Zealand context: the incorporation of Māori cultural practices, and support to meet the needs of Māori participants; mandating attendance at the 12-step Alcoholics Anonymous (AA) and Narcotics Anonymous (NA) meetings ${ }^{38}$; and; the inclusion of peer support workers from the health sector. With the exception of 'Māori cultural practices 'these are also features listed in the US as key principles and best practices of DTCs ${ }^{39}$, and are used in Canada, Ireland, and Australia (NADCP, 2013; 2015, NDCI, 1997; 2016, Nolan, 2002). In addition to these policies and practices, Thom and Black (2017) also identified the roles of the judge and legal counsel as contributing to the unique therapeutic ethos of the AODTC. However, beyond the Litmus evaluations very little is known about how participants experience the court programme. That is, while there has been some attention paid to the AODTC (Thom and Black, 2017), none has focussed on the experiences and perceptions of AODTC participants.

\footnotetext{
${ }^{38}$ During observations, treatment readiness groups including the 12 steps were introduced in Mt Eden Remand, for prisoners coming into the AODTC and those participants held on remand. There are also one on one sessions run for female AODTC participants on remand in the Auckland Region Women's Prison.

${ }^{39}$ The NADCP Best Practice Volume II (2015) recognises that historically disadvantaged groups are more likely to be discriminated against through DTC practices. Thus, according to the best practice document, DTCs have an obligation to determine whether racial and ethnic minority individuals are being disproportionately burdened or excluded from their programs; and if so, take reasonable measures to rectify the problem.
} 


\section{The AODTC Team}

Each AODTC has its own treatment team consisting of a judge, police prosecutor, legal counsel, case manager, and the court co-ordinator (Ministry of Justice, 2012a; 2014). Once a person is accepted into the court, they are assigned to AODTC legal counsel. Critics argue that the effects of the DTC model on the role of legal counsel must take on a role that facilitates the goals of court in meeting recovery (Boldt, 1998; Nolan, 2003).

\section{Judge}

In addition to the problem-solving mandate, the US NADCP Best Practice Standards (2013; 2015) formalise the role of the judge in the close monitoring of treatment and punishment (Marlowe, 2010; Marlowe and Meyer, 2011). However, the flexibility of the judicial role means that the judge is not acting as a neutral arbiter. Rather, the non-adversarial nature of the DTC combined with the informality of the judicial role, carry with it the "potential for real harm' (Boldt, 2010:25). Because, unlike other criminal justice system processes where procedural safeguards check the discretion of authority, in the DTC judicial discretion is relatively difficult to check (Colyer, 2000). The consequences are that the court eligibility process is subjectively defined, meaning that the selection process is biased and helps to account for relatively low levels of participation in the programme (Boldt, 2010; Colyer, 2000).

The AODTC similarly permits the judge wide discretion to determine eligibility, monitor treatment compliance, provide specific directives to undertake AOD assessments, and to determine whether a participant's 'relapse' requires a sanction (Ministry of Justice, 2012a; 2014). As discussed in Chapter 1, at best the AODTC judge adopts the belief that treatment involves a combination of 'carrots and sticks', targeting 'openness and honesty' to get the participant to meet the 'goal of abstinence which will require nothing short of them becoming a wholly different person' (Tremewan, 2013:9). By adopting the carrot and stick approach to abstinence-based treatment the role of the judge has the potential to blur treatment with punishment (Murphy, 2014), potentially doing more harm than good in the AODTC.

\section{Community treatment providers}

Another important characteristic of the DTC environment is the collaboration with community treatment providers. Studies of specialist problem solving courts reveal how the courts' relationships with community organisations are shifting the parameters of punishment (Lyons, 2011; Quirouette, Hannah-Moffat \& Maurutto, 2015; Singh, 2012). These studies illustrate concerns about mandated housing, community providers performing a watchdog role for the 
court to ensure compliance, and providers exerting a considerable amount of authority in encouraging the punishment of participants. Barriers to treatment can include a lack of genderspecific services, stigma, and discrimination by abstinence-based treatment (Marlowe, Hardin and Fox, 2016).

The AODTC has created new opportunities for collaboration with community treatment providers in the governing of addiction. Each evaluation of the AODTC has consistently identified the need for role clarification between the AODTC and the registered community service providers (Odyssey House ${ }^{40}$, Higher Ground, and the Salvation Army) to ensure the scope of responsive treatment practice (Litmus, 2014; 2015; 2016). Of note too are the lack of specific treatment providers for women and for Māori, which I discuss further in Chapters 5 and 8. More broadly, beyond the membership information contained in the Addiction Practitioners' Association Aotearoa New Zealand (DAPPANZ), and AODTC Community Alcohol and Drug Services (CADS), ${ }^{41}$ there is limited information on the qualifications of providers staff, case managers and the peer support workers in the AODTC.

\section{The Alcohol and Other Drug Treatment Court process}

As discussed, the AODTC is a pre-sentence programme, meaning that either a lawyer, a judge, or the police identify individuals who meet the eligibility criteria at arraignment. A judge makes the final referral decision. Once a person is identified as being eligible for the AODTC, a determination hearing is held, and the judge sets out the commitment required. Each AODTC is guided by the same processes comprising eligibility and descriptions of the roles of the team members as outlined in AODTC policy and AODTC Handbook (2012a; 2014). If the individual decides to enter the treatment programme, he/she enters a plea of guilty. Those who participate in the AODTC enter into a contract by which they agree to treatment and to be monitored on a regular basis (Participant Agreement, n.d).

As part of the eligibility process, the AODTC excludes persons if they have a youth court notation, or have been convicted or charged with sexual violence or arson (Ministry of Justice, 2014). However, this is at the discretion of the judges. If individuals accepted into the court have previous convictions for sexual offences or arson, treatment providers are informed.

\footnotetext{
${ }^{40}$ Odyssey House is the main contract holder, responsible for ensuring culturally responsive treatment.

${ }^{41}$ CADS provide the AOD assessments for the AODTC. CADS are included in the pre-court meetings; their role is to contribute to the eligibility criteria and selection of suitable participants.
} 
Sequentially, treatment providers may decline a residential place for participants if they do not meet their safety or insurance criteria (Ministry of Justice, 2014).

As stated, there are two AODTC courts in New Zealand, located in Waitakere and Auckland City. AODTC participants are required to attend court on Wednesday and Friday afternoons in each court respectively, in addition to attending regular treatment ${ }^{42}$ sessions. These include residential treatment, counselling, and intensive day programmes carried out by the above treatment providers. In addition, there are peer support groups, drink drive groups, and the Man Alive stopping violence programmes. Participants are required to adhere to a list of bail conditions, to be available to give regular and random urine samples and have a SCRAM alcohol bracelet fitted. Upon completion of the treatment programme, the participant is sentenced according to the New Zealand Sentencing Act 2002.

\section{AODTC eligibility criteria}

The AODTC Handbook details the following eligibility criteria as:

- aged 17 years and over

- have been charged with offending and that is being driven by AOD dependency, including recidivist drink drivers

- at high risk of reoffending, a risk to themselves, their family, and the community

- have a moderate-severe substance-related dependency (as per the DSM IV or DSM V) ) $^{43}$

- be facing charges for which the sentencing starting point is imprisonment (of up to three years) but the completion of the AOD Court programme will mean that a non-custodial sentence can properly be imposed on a principled sentencing basis.

- Are charged with their third or subsequent drink driving offence in the aggravated form, and /or have a medium- high $\mathrm{RoC}^{*} \mathrm{RoI}^{44}$ score where there is a history with Corrections.

\footnotetext{
42 According to the AODTC Handbooks (Ministry of Justice, 2012a; 2014) a range of treatment programmes are made available to all participants, these involve: detoxification (medical, inpatient or community-based, depending on clinical judgment); pharmacotherapies; residential treatment; intensive outpatient day programmes, specialist drink driving programmes and community outpatient counselling services, stopping violence programmes; the 12-Steps Alcoholics Anonymous and Narcotics Anonymous programmes.

${ }^{43}$ Durrant and Thakker (2003) discuss how many of the aspects contained in the DSM IV for alcohol abuse and dependence are understood in different ways by different cultural groups. Hence, any evaluation process would need to be conducted in a culturally sensitive way.

${ }^{44}$ According to the AODTC Handbook (2014) the RoC*Rol is not used for recidivist drink drivers as their scores are considered to be consistently too low to meet the criteria. Otherwise for drug related offending, eligibility criteria for acceptance into the court is a RoC*Rol score between 0.5 and 0.9.
} 
In addition to the above criteria, the AODTC may request an AOD assessment ${ }^{45}$ to be carried out by Auckland Community Alcohol \& Other Drug Services (CADS). Such assessments are required to be undertaken by clinicians funded by the AODTC (Ministry of Justice, 2012a; 2014). However, the final decision regarding acceptance is that of the judge, as detailed in the AODTC Handbook (2014:14):

The presiding AODT Court judge makes the final decision as to participant eligibility. This determination is informed by the information and assessments collated by parties. This includes the AOD assessment, and involves input from Police Prosecution, defence counsel and Case Managers. Participant eligibility is first discussed in the AODT Court pre-court team meeting; which defendants do not attend (but where they are represented by defence counsel).

Beyond these more formal criteria, and due to the procedural informality and the therapeutic mandate, other more subjective tools are available to the judge when deciding whether the offender is a potential candidate for the AODTC. These include the judges' values, beliefs and understanding of the participant's ability to be open and honest and to be compliant. As pointed out by AODTC Judge Tremewan (2013):

Openness and honesty helps the court team to ensure that we are tailoring individualised treatment programmes to the best effect, as well as encouraging participants towards new behavioural responses from those previously well-worn neural pathways of deceit and manipulation. Of course, with testing being carried out, we are well placed to know if they are using anyway (p.9).

Considering Judge Tremewans knowledge of individualised treatment and behavioural modification, there are questions as to the level of discretion made available to the judges, and the legitimacy of their power to legally mandate 'treatment'. I discuss these tools, the court eligibility criteria, and judicial decision-making practices in depth in Chapters, 5 and 6, 7 and 8 .

\footnotetext{
45 The AOD assessment contains information about participants AOD use and history, dependency status, treatment history, other behavioural addictions (e.g. gambling) and their relevance in relation to offending. There is also information regarding risk, mental health issues, medical history, whānau and social support (e.g. psychological functioning, education and employment, potential support persons and barriers to change), their motivational readiness to change, and recommendations as to potential treatment requirements and options (Ministry of Justice, 2014).
} 


\section{AODTC Handbook, AODTC Participant Agreement and Participant Handbook}

Upon entry into the programme, the AODTC participants consent to treatment by signing the AODTC Participant Agreement (n.d) and are given the Participant Handbook (2013). According to the AODTC Handbooks (2012a; 2014:14), participants are 'expected to understand' the seventeen conditions listed within the Agreement document (Appendix D), and to acknowledge that failure to comply with the agreement, or to make unsatisfactory progress to complete the programme, may involve an expulsion from the AODTC.

The AODTC Participant Handbook (2013) broadly outlines the AODTC programme and its associated requirements such as AOD testing, the three programme phases [identified as milestones], the meaning of incentives and sanctions, and the process of exiting the court. The Participant Handbook encourages obligation through honesty and responsibility on the basis that 'there will always be a consequence for a breach of rules and compliance as participants 'go through the programme, consequences for use become more severe' (AODTC Participant Handbook, 2013). To encourage honesty, abstinence, and accountability AODTC participants are subjected to regular and random testing throughout the programme (AODTC Handbook, 2012a; 2014). The range of drugs tested for include cannabis, opiates, cocaine, benzodiazepines, amphetamines, alcohol, synthetic cannabinoids, and barbiturates, as well as drug substitutes methadone and diazepam (Ministry of Justice, 2012a; 2014). Therefore, the non-disclosure of these drugs incurs a greater sanction than admitted use.

DTCs, including the AODTC, are built on a system of graduated incentives and sanctions. These are designed to govern, motivate, and keep participants focussed on the treatment programme. Individuals doing well in the AODTC can be rewarded by being positioned in the 'A team', recognition of clean time by receiving a tag or medal, verbal praise in court, graduation to the next phase with a certificate, or receiving additional assistance with personal development, cultural, educational, or work-related opportunities (Ministry of Justice, 2012a; 2014).

Those that fail to meet the court's requirements receive a sanction. These can include increased attendance in court, being called last in the court day (which means much longer waiting times), a verbal warning in court, the imposition of curfews, more frequent and random AOD tests, increased attendance at a treatment agency, increased reporting to the case manager and being moved back in advancement, a stand-down or where behaviours raise the risk of reoffending a short remand in custody, or an exit from the Court. (Ministry of Justice, 2014). These incentives 
and sanctions are used by the AODTC in order to accomplish the DTC requirement to transform the drug-using offender into drug-abstinent, non-criminal citizen (Mackinem and Higgins, 2007).

Closed pre-court team meetings are held prior to the weekly court session. These are led by the judges, attended by the court coordinator, legal counsel, the Police, the Pou Oranga, ${ }^{46}$ and treatment case managers (Ministry of Justice, 2012a; 2014). The meeting usually lasts around four hours, and unlike traditional court hearings, the participants are excluded. During these meetings, the judge and team members discuss impending applications, eligibility criteria and make decisions about who should receive incentives and sanctions.

Crucial to these meetings are the assessments and reports provided by the case managers ${ }^{47}$. The AODTC Handbook makes clear that the case manager is responsible for ensuring that a needs assessment for each participant contains:

...information about the defendant's AOD use patterns and history, dependency status (diagnosis), history of previous treatment, other behavioural addictions (e.g. gambling) and their relevance in relation to offending. There is also information regarding risk, mental health issues, medical history, whānau and social support (Ministry of Justice, 2012a; 2014:13).

Overall, the assessment and reports contribute to determining eligibility, progress, and determining whether participants deserve sanctions for failing to meet the court's requirement of abstinence.

The AODTC Handbook (Ministry of Justice, 2012a; 2014) recognises the role of victims in the court process. However, of concern is that the AODTC model itself potentially undermines this process, as Judge Tremewan makes clear that in her view, making amends involves more than restorative justice meetings:

Where relevant, victims will be encouraged to engage in restorative justice meetings while the participant is still before the Court. Those many participants who will be actively engaged with 12-Step programmes, such as AA and NA, will also be working towards making amends

\footnotetext{
${ }^{46}$ The AODTC Māori Pou Oranga is not a formal member of the team (Ministry of Justice, 2014); rather he is an employee of Higher Ground. However, the responsibilities of the Pou Oranga are outlined in the Handbook to: undertake cultural assessments to facilitate the matching of such services and client and whanau needs; establish rapport with clients and their whanau to encourage their engagement in appropriate services; to collaborate with appropriate Kaupapa Māori agencies and other community services; to grow relationships with each of the main marae within the rohe of the AODTC through the Runanga established to support, advise and guide on appropriate issues including tikanga (Ministry of Justice, 2014).

${ }^{47}$ The case manager has a contractual responsibility to Odyssey House and the Ministry of Health (Ministry of Justice, 2012a; 2014).
} 
for harm with the guidance of their sponsors as per Step 9. To put it another way, they will be expected whenever possible to "clean up what they messed up" (2013:10).

As will be shown in the following chapters it is not unusual for the judges to utilise the 12 Steps instrumentally to uphold accountability in the court. In the context of Judge Tremewans' comments, the Ministry of Justice Formative Evaluation (Litmus, 2014), Process Evaluation (Litmus, 2015), and Final Process Evaluation (Litmus, 2016), have all identified that victim engagement in the AODTC is not working. According to the evaluations, this was due to a lack of clarity and scope in the roles of the police and victim advisors, the victim advisors' caseload commitments, poor communication, and the length of the AODTC process (Litmus, 2016).

AODTC participants can exit the court through either a self-exit, termination, or graduation. The Handbook outlines five ways in which a participant can be terminated from the AODTC: (i) further offending ${ }^{48}$; (ii) deliberate and persistent failure to comply with treatment and/or testing; (iii) violent or threatening behaviour within the AODTC or treatment setting; (iv) be exited by a treatment provider due to breaches of a treatment plan; and, (v) acting in a manner which causes the AODTC to conclude that continued participation is untenable (Ministry of Justice, 2012a; 2014). Additionally, during my in-court observations, the structure and length of the programme changed as the AODTC judges started to use their discretion to auto-exit participants at day 14 after a breach of bail and for non-compliance such as absconding from residential treatment. Thus, wide judicial discretion adds to the complexity and uncertainty of the complicated court process. As such, participants may find that treatment lasts longer than the agreed term (Boldt, 2010), or, as indicated by the Final Process evaluation (Litmus, 2016) the AODTC judges exercise their discretion by auto-exiting participants.

In order to graduate from the AODTC, participants are required to fulfil the requirements of three phases based on the following expectations ${ }^{49}$ :

- Attendance at, participation in, and completion or near completion of agreed treatment plan

- No positive AOD tests for 180 days

- Comply with bail conditions

- No unexcused absences

\footnotetext{
${ }^{48}$ Based on type of offending, relative seriousness of the situation and danger to the community (Ministry of Justice, 2014)

${ }^{49}$ The AODTC Handbooks outline that, each phase is expected to take 4-6 months, and that during phase one, it is unlikely that participants will be permitted to work to engage in employment (Ministry of Justice, 2012a; 2014).
} 
- Documentation verifying satisfactory treatment attendance

- Evidence of achievement towards personal goals

- Submission of written phase advancement or graduation request

(Ministry of Justice, 2012a; 2014)

Each requirement is divided into expectations and court required advancement criteria, and is outlined in the AODTC Handbook (2012a; 2014). However, there are inconsistencies between the desired outcomes of 'reduction' of alcohol and drug dependency, and abstinence as a treatment goal. For example, the AODTC Handbook states that the overall goal of the AODTC is to:

- Reduce reoffending

- Reduce drug and alcohol consumption and dependency

- Reduce use of imprisonment

- A positive impact on health and wellbeing, and

- To be cost-effective

(Ministry of Justice, 2012a; 2014)

The inconsistency between the AODTC treatment reduction policy and the abstinence criteria is confusing and concerning. I argue that these criteria raise ethical questions around the graduation criteria and the court's goal of positively affecting health and wellbeing.

I argue that tensions in the development of the AODTC, the Law Commission's contradictory recommendations, and judicial activism have resulted in the adoption of a US DTC model which is insufficiently focussed on evidence based treatment policy, and a focus on health and wellbeing. I develop this argument further in the following chapters, by looking at questions raised over the ambiguous and inconsistent goals of reducing AOD addiction, in conjunction with the goal of abstinence as recommended in the AODTC Handbook (Ministry of Justice, 2012a; 2014).

\section{Questioning DTC effectiveness}

It is not the aim of this thesis to evaluate the effectiveness of the AODTC in reducing reoffending or reducing AOD consumption. However, I believe that it is important to consider the findings of the international research in general and the New Zealand AODTC Formative, Interim Process, and Final Process evaluations (Litmus, 2014; 2015; 2016) in order to contextualise my research. 
According to the United Nations Office on Drugs and Crime, 'Drug Treatment Courts Work!' (UNODC, 2005:1). Yet, existing international DTC evaluations research offer mixed results on the appropriateness and effectiveness of these courts in treating addiction (Belenko, 2002; Csete and Tomasini-Joshi, 2016; SSRC, 2018). The evidence suggests that much of the DTC research has been criticised for having poorly defined comparison groups, omitting data on people who fail, and an over reliance on self-reported data during the treatment programme (Belenko, 2002; Fischer, 2003; GAO, 2011; SSRC, 2018). Moreover, various scholars have claimed that DTC evaluations rarely assess any unintended side effects (Hall and Lucke, 2010) of treatment, such as exposing participants to intrusive treatment and disproportionate punishment (Clancey and Howard, 2006; Gross, 2010; Klag, O’Callaghan and Creed, 2005; Miller, 2004).

In this section, the AODTC graduation rates are reviewed, with particular attention paid to Māori and women. It will be shown that DTC research is inconsistent, and that the majority of research contains methodological flaws that further challenge the claims that DTCs are successful.

\section{Low graduation rates}

There is relatively limited data on the US DTC treatment of ethnicity and gender, despite the disproportionate arrest rates of African Americans in the US (SSRC, 2018). US DTC research suggests that white participants are more likely to succeed than African American participants are. Gallagher and Nordberg (2016) found that culturally incompetent treatment contributed to lower graduation rates for African American participants. Similarly, Dannerbeck et al (2006) in analysing data from 10 DTCs, found significant differences in participation and graduation rates between Caucasian and African American participants. Their data suggests that African American participants are more likely to be exited from the DTC programme than Caucasians and thus less likely to graduate (Dannerbeck et al, 2006). Gallagher (2013) analysed the records of 376 participants in a Texas DTC, finding that Caucasian participants were 4 more times likely to graduate than Hispanic and African American counterparts. O'Hear concluded that DTCs tend to 'exacerbate' 'overall racial disparities' (2009: 477).

The international DTC research examining the experiences of women identified that women are less likely to participate and thus graduate from the DTC programme than men (Fischer and Geiger, 2011). Fischer and Geiger (2011) interviewed 11 women participants in a California DTC to capture their experiences of treatment. They found that the reasons behind 
low graduation rates include a lack of female focussed treatment services and a lack of support for women with children in general (Fischer and Geiger, 2011). So conceivably an absence of evidence based treatment, or cultural insensitivity, are contributing factors to racial and gender disparities in DTC graduation rates (Gallagher, 2013).

The New Zealand AODTC has also achieved low graduation rates. The Final Process Evaluation (Litmus, 2016) found that, for the period November 2012 to April 2016, of the 282 cases accepted into each AODTC, 108 exited, and just 79 graduated. The Final Process evaluation identified that Māori made up $45 \%$ of the AODTC population and $44 \%$ of those exited from the AODTC (Litmus, 2016). Women are less likely to appear in the AODTC, making up just $12 \%$ of the AODTC population, $13 \%$ of graduations and $9 \%$ of exits (Litmus, 2016). The evaluation data on women's experiences in the AODTC is too limited to accurately determine treatment effectiveness. However, the fact that the court targets Māori offending needs to be addressed because each evaluation has identified limited treatment options for both Māori and women (Litmus, 2014; 2015; 2016).

\section{Cost effectiveness and reducing reoffending}

There is limited evidence documenting DTC cost effectiveness (Drugs Policy Alliance, 2011; 2014; SSRC, 2018). A close look at existing DTC evaluation research in the US, Ireland, Latin America, Canada, Australia, and the UK, however, reveals that they do not reduce reoffending rates and, it is unclear as to what extent DTCs actually reduce imprisonment. (Belenko, 2002; Csete et al, 2016; Fischer, 2003; Hall and Lucke, 2010; Hoffman, 2002; Lyons, 2011; SSRC, 2018).

Even if DTCs achieve some savings by reducing reoffending, those savings are likely to disappear when all programme costs are accounted for (Csete et al, 2016; Fischer, 2003; SSRC, 2018). These include the costs involved in professional AOD testing, the use of community treatment services, the use of imprisonment for detoxification and sanctions, and the costs of sentencing participants to imprisonment (Csete et al, 2016; Drugs Policy Alliance, 2011). Critics claim that the DTC strict programme requirements (Gross, 2010), may mean that many participants face failure, incur punishment and ultimately face harsher sentences which in turn generates further costs (Csete and Catania, 2013; Matusow, Dickman, Fong, Dumont, Hardin, Marlowe and Rosenblum, 2013). Csete and Tomasini-Joshi (2016) note that this finding is not surprising in that treatment 'failure' may be frequent because, relapse is a normal part of ceasing drug use. 
Given the AODTC low graduation rate, and that there is little data on whether those that do graduate reoffend and at what rate, it is not possible to conclude that AODTC is more costeffective than the District court, and that it reduces related offending.

\section{Methodological issues with DTC evaluations}

According to the literature, there are various methodological challenges associated with DTC evaluations including the absence of comparison groups and that they do not include people who are declined or exited from the programme (Belenko, 2002; Fischer 2003; Freeman, 2003). Moreover, research has found that DTCs tend to cherry-pick 'treatable' people (Fischer, 2003; Goldkamp, 2000), which allows DTCs to 'report high rates of success as they purposefully target people most likely to complete the programme' (Csete et al, 2016:8). There are also questions as to whether all participants selected for the DTC are in need of treatment for addiction at all. In short, having surveyed the data, the Social Science Research Council (SSRC, 2018) reported that the "political importance of achieving high success rates, coupled with the need to do so to gain access to funding' 'creates incentives to choose participants who do not need treatment' (p.114). Each of these issues can lead to weak evaluation data and bias.

Biased outcome measures can also occur because effectiveness evaluations tend to be conducted by government organisations or interested parties. In the US, Canada and Australia, evaluations are conducted by government departments, treatment providers, or contracted DTC parties (Fischer, 2003; Gallagher, 2013; Hall and Lucke, 2010). With researchers uncovering insufficient statistical controls in evaluations conducted by these groups (Miethe, Lu \& Reese 2000; Payne, 2005).

Researchers have also raised questions about evaluations of the effectiveness of DTCs in reducing recidivism. The foremost concerns include a lack of appropriate control groups and small sample sizes the limited time periods over which recidivism is measured, with follow-up periods overlapping in part or altogether with treatment periods (Belenko, 2002). In light of the methodological issues identified, Gutierrez and Bourgon, (2009:1) conducted a quantitative review of DTC treatment and identified that 'the least biased estimate of the effectiveness of drug courts in reducing recidivism was found to be approximately $8 \%$ '.

The New Zealand Ministry of Justice commissioned the AODTC Formative (2014), Interim (2015) and Final Process evaluations (2016). The evaluations include interviews with court staff, community services, and participants who have voluntarily exited or graduated. To date, there is no evidence of interviews with declined applicants, or follow-up of graduates. Overall, 
the New Zealand evaluations have focussed on the operation of the AODTC, and draw most of their comparisons from the NDCI top ten practices and international effectiveness data (Belenko, 2001). The New Zealand AODTC evaluators conceded the potential for selection bias because 'AODT Court participants interviewed were identified by case managers, peer support workers and Te Pou Oranga' (Litmus, 2016:10). Although, they argued that in terms of appearance at least, the court has positively affected health and wellbeing in that:

...pre-and-post photographs of participants clearly demonstrate the health and wellbeing benefits from being in the AODT Court through their improved appearance (Litmus, 2016:110).

When taking in the above claimed benefits, the AODTC exit rates, and the lack of treatment facilities for Māori and women (Litmus, 2016), it is difficult to determine how the AODTC is recognising participants' right to treatment. It appears that the AODTC evaluations may have overlooked the net-widening effects and unintended consequences of treatment, which are judicial bias and the channelling in of low-level offenders into the court and a lack of evidence based treatment and health care (Miller, 2004). To this end, the majority of evaluations are seen as methodologically problematic and the DTC research casts doubt on cost effectiveness and reductions in offending rates. Despite the weak design and process of the evaluations, the AODTC has received considerable support among policy makers, with the government announcing the programme a success and proposing to continue the AODTC pilot at its two locations until June 2020 (Ministry of Justice, 2018).

\section{Conclusion}

In this chapter, I have outlined the emergence of the AODTC within the context of law reform, and political concerns related to addressing the causes of AOD offending, Māori offending, recidivism rates, and the cost effectiveness of dealing with AOD offenders in the conventional court. In detailing the emergence of the AODTC model, I have highlighted the roles of the Law Commission (2011), and the activism of the AODTC judges.

Influenced by their visits to a United States NADCP conference and DTCs, the judges performed a crucial role in the adoption of the US model and policy. Even though the AODTC is promoted as having distinctive features (Litmus, 2015; 2016), the court has, in fact, adopted features from the NADCP and NDCI DTC principles and best practices. The AODTC claimed to be innovative, but is shown to utilise the US DTC key features of therapeutic jurisprudence, abstinence, and legal coercion to treat addiction as a disease. This is in spite of the international 
literature providing inconclusive evidence on the capacity of DTCs to be effective, to effectively reduce AOD offending, and be more cost effective than incarceration (Csete et al, 2016).

I argue that the development of the AODTC is problematic because, even though the court is based upon the US DTC model, it sustains and reinforces punitive individualistic criminal justice policies, and institutional practices that have historically pathologised addiction and related offending (Marshall, and Barclay, 2003). The implications are that offenders are required to take responsibility and thus be accountable for their offending through their recovery. The risks, in my view, are that the political understandings of AOD related offending, addiction as a disease and curative treatment have created tensions, to the extent that the recommended policies are blurring treatment with punishment. This means that 'recovery' may give way to the understanding of punishment as treatment.

How the AODTC defines and defends addiction as a disease, how it applies coerced treatment, defines and monitors recovery, and ensures accountability and programme compliance will be discussed in the following chapters. My research will demonstrate the effects of AODTC treatment and punishment upon the participants. 


\section{Chapter 5: Addiction and Treatment in the Alcohol and Other Drug Treatment Court}

\section{Introduction}

It is clear from the previous chapters that the Alcohol and Other Drug Treatment Court (AODTC) is highly individualistic, and that it targets addiction as driving AOD related offending. The court accepts that, in order to treat addiction and reduce AOD offending, abstinence is necessary for the participants to demonstrate recovery. 'Abstinence' and 'recovery' are the desired goals of the court. However, there are tensions between the goal of abstinence, addiction as a disease and a chronic relapsing condition, individual accountability, and the goal to 'reduce drug use' through treatment. For these reasons, it is questionable as to what extent, if any, legal coercion, behaviour modification, and punishment will 'positively impact' on participants 'health and wellbeing' (Boldt, 2009; Ministry of Justice, 2012a).

As discussed in Chapter 2, legal consciousness is useful for examining court policies, procedures and practices that assign meaning in the AODTC. It can help inform how addiction treatment is conceptualised through the formal policies and informal rules of the court, including the knowledge and power of those that enforce the requirements of the programme (Levine and Mellema, 2001; Silbey, 2005; Young, 2009). In this regard, I examine the AODTC knowledge of addiction related offending and treatment. In doing so, connections are made between the instrumental role of law, court procedure, and the therapeutic structure in the cultural production of law (Silbey, 2005). This helps facilitate a better understanding of the ways in which the AODTC addiction-disease-abstinence mandate is conceptualised to justify a treatment ethos involving punishment.

In this chapter, I investigate the role of law-making and legal process in the largely unregulated AODTC, and the processes that determine the participants' experiences of treatment and punishment (Merry, 2001). I present the findings from my research to illustrate that the AODTC governing of addiction involving a therapeutic mandate, blurs the boundaries of treatment and punishment (Boldt, 1998; Hoffman, 2002). To do so I draw on data derived from:

- AODTC Handbooks (Ministry of Justice, 2012a; 2014).

- AODTC Participant Agreement and Participant Handbook.

- Ministry of Justice Formative, Interim Process and Final Process evaluations (Litmus, 2014; 2015; 2016).

- In court and out of court participant observations. 
- Informal conversations with legal counsel, a policy advisor, AODTC team members, community court workers and participants' families.

- Semi-structured in-depth interviews with AODTC participants declined and exited participants.

This chapter will show how, structurally, the AODTC understanding of 'addiction' related offending is supported by individualistic, normative understandings of disease, offender pathology and responsibility, that requires prevention and change, including treatment (Boldt, 2010).

The chapter is divided into two parts. The first Part involves an examination of the AODTC eligibility criteria, used as a checklist to identify AOD addiction and related offending. It reveals that these eligibility criteria are the products of ambiguous policy, judicial discretion, and team decision-making based on subjective and inconsistent understandings of honesty, accountability and compliance, risk management, disease, a willingness to be abstinent and perceived programme success. I establish that the AODTC revives historical connections between offender pathology and curative treatment by conceptualising addiction as disease, as the judges and team members engage in the moral regulation of treatment (Garland, 2014; Whetstone and Gowan, 2011). When combined with the procedural informality of the court, and tensions between the court's knowledge of addiction as a disease and abstinence as goal, these processes give way to inconsistencies in decision-making, obscure definitions of substances and the moralising of participants' behaviours as risky, according to the dangers they pose to programme success.

I illustrate the impact of the AODTCs' legal decision-making on the constitution of addiction according to a hypocritical understanding of disease, choice, and accountability for the programme (Marshall, 2016). The court, whilst designed to measure recovery and success, will be shown to utilise the voluntary nature of the court process to frame participants as choosing to opt into the programme on the basis that they choose to take responsibility for the disease of addiction. In this context, the court targets participants' accountability. Accordingly, AODTC legal decision-making constitutes a powerful set of policies and everyday practices that shape legal procedure, culture and addiction treatment (Marshall, 2016).

In the second Part, I focus on the resultant AODTC construct the criminal addict identity, with a description of the three key features: homogenous; both criminal and treatable; and, dishonest. I describe how by taking an individualistic approach to addiction related offending 
and treatment the AODTC reinforces the power and structure of the criminal justice system, undermining the role of social and cultural factors in the treatment of addiction.

\section{Conceptualising addiction in the Alcohol and Other Drug Treatment Court}

While DTCs vary across jurisdictions, there has been considerable debate about the effects of merging criminal justice with health criteria on limited participation and court eligibility. For example, there is robust evidence that DTC eligibility requirements exclude people on the basis of criminal history, the severity of their addiction, prior treatment history, a lack of motivation, medical conditions or mental disorders, and gang membership (Csete and Catania, 2013; Csete and Tomasini-Joshi, 2016; Murphy, 2015; Miller, 2009; SSRN, 2018; Taxman and Bouffard, 2002). As discussed in the previous chapter, international research confirms that it is common practice for DTC programmes to cherry-pick offenders more likely to complete treatment (Belenko, 1998; Fischer, 2003; Goldkamp, 2000). In this Part of the chapter, I focus on how the AODTC conceptualises addiction. In doing so I demonstrate how the court governs eligibility, conceptualises addiction as a choice, and abstinence as an enforceable condition. I also demonstrate how the governing of addiction treatment involves moral values and judgements, as well as the formal rules and enforceable obligations. I argue that these processes have created ambiguity and inconsistency in defining a threshold for addiction, court participation and court conditions.

At this point, it is important to consider whether the AODTC meets the Law Commission (2011) recommendation for a 'robust eligibility criteria' both on paper and in practice. Accordingly, it is important to identify how the judges and team members conceptualise addiction, related offending, and the requirement for treatment in their decision-making.

\section{AODTC eligibility criteria}

The AODTC judges and team members make eligibility decisions about potential participants according to the criteria in the AODTC Handbooks (2012a; 2014). AODTC eligibility is thus based on meeting a combination of risk, criminogenic needs, and health criteria, comprising a moderate to severe dependency and an understanding that addiction is a disease. However, decisions made on whether or not a person meets the court requirements are also based on judicial perceptions of risk management, participant motivation to be compliant, gang membership, accountability, and consideration of programme success. Given that there is so much scope for interpretation, the application of the eligibility criteria invites more inconsistency than it should (Boldt, 1998). 
The key criteria for an individual to be placed in the programme, aside from the fact that they must have an addiction, is that they have an 'at risk' measurement within the medium range, and a willingness to engage in the programme (Ministry of Justice, 2012a). While this process is based on clearly defined AODTC Handbook procedures, my observations of in-court and pre-court meetings reveal that the eligibility process is one that is frequently inconsistent, and is managed in a non-clinical manner. In that, the court requires 'a reasonable belief that AOD dependency is likely':

If all criteria are met, including a reasonable belief that AOD dependency is likely, the judicial officer may direct that the matter be adjourned for approximately three weeks to allow for the full AOD assessment, assignment of counsel and disclosure (AODTC Handbook, 2012a; 2014). My observations suggest that even when cases are adjourned for an AOD assessment, there are still competing views of addiction and the eligibility criteria amongst the judges and team members, which leads to the 'cherry picking' of participants according to the individual values of the judges and team members, their subjective assessment of risk, perceived compliance, and programme success.

During observations, it became clear that the AODTC assessment of addiction in deciding eligibility is the result of individual beliefs leading to inconsistency, well beyond the AODTC instruments and AOD assessments. This is evident in the judges' decisions to target medium to high-risk offenders with a mandatory RoC*RoI score of between $0.5-0.9$, the screening out of participants with coexisting disorders, mental health needs, and the targeting of Māori participants.

According to my observations, tension, confusion, and disagreement over the AODTC assessment criteria, the RoC*RoI tool, and the US DTC model criteria were not unusual in the selection process in the precourt meetings. In fact, disagreement between the judges, team members, and counsel over the implementation of the target criteria was common. As illustrated by the following examples, defence counsel would sometimes challenge the judges' interpretation of the $\mathrm{RoC} * \mathrm{RoI}$ as a tool for determining exclusion:

Judge: The RoC*RoI is a mandatory exclusion instrument. 
Counsel: The RoC*RoI is an instrument that isn't used in the US drug court model, further I would point out the parliamentary decisions around binding judges and the executive decisions on the RoC*RoI tool ${ }^{50}$.

During informal conversations, legal counsel for one applicant conveyed to me that he had a 'number of issues' with the court process. The dominant issue however, was the inconsistent 'administrative decision-making and the tacked on use of the RoC*RoI, despite the supposed evidence based principles of the US model' ${ }^{51}$ That is, the risk management process served as a shallow and inconsistent facade in the screening out of offenders. Similar inconsistencies are identified in US DTC research, suggesting that while the court goal is to emphasise the treatment of addiction related offending, 'in reality a person's criminal record determines eligibility for the program much more often than his/her clinical evaluation' (Murphy, 2008:146).

I regularly observed how tensions between the sentencing process and treatment contribute to some offenders with an addiction and who were within the target population of medium to high-risk, thereby not meeting the court criteria. Comments made by a declined participant during an interview illustrate the point:

My $\mathrm{RoC}^{*}$ RoI score was too low for the drug courts it was 0.5.76. My lawyer said, what does he have to do, kill somebody to get into the drug court? And yeah they said no, he tried getting me into the drug court out at Waitakere too, they said no too. I'm HIV positive, their decision to decline me took away 18 months of my life. I think being under the drug courts umbrella would have, I think, helped in some ways. Because you're under them for 2 years or something but yeah, I was just really disappointed that something as silly as a $\mathrm{RoC} * \mathrm{RoI}$ score declined me. Especially with my offending history and my addiction history, I've struggled with addiction all my life and it would have taken just one look at a computer screen to tell them that I would have been a perfect candidate, but they just didn't even bother.

It appeared to me that there was no preferred measure determining AODTC eligibility because I witnessed the courts using other information, such as a person's ability to be compliant and accountable when designating which preferred risk tool to use.

The judges play a key part in the power and structure of the court and a significant means by which subjectivity is exercised in determining eligibility. During precourt meetings, I often observed wide discretion and inconsistent decision-making over what constitutes the AODTC

\footnotetext{
${ }^{50}$ AODTC observation December, 2013

${ }^{51}$ Informal conversation September, 2014
} 
target criteria of offending driven by a 'moderate to severe addiction' and the RoC*RoI tool as the determining factor According to my observations, this inconsistency has two outcomes. The first is the subjective and inappropriate use of the addict label for the purposes of identifying 'successful' applicants, which means that the court admits some people into the programme that may not necessarily have an addiction. The second is, that those that actually have an addiction are either not considered appropriate for the programme because their addiction is considered too severe, or their history renders them too risky for the treatment programme, and therefore endangers programme success.

For instance, declined applicant Manu (with a RoC*RoI .6.2) meets most of the target criteria. He has a history of addiction, treatment, and offending, which is proven to be attributed to AOD use. In his case, the judge and team's decision to decline was the result of their interpretation of the risks associated with his history of family violence, his family bonds, dishonesty, coexisting mental health needs, and addiction:

Judge: ...Manu has a history of punishment in the youth court of corrective training, deported from Australia for a minor offence, breaches of protection orders, and a term of imprisonment May 2007, since release there has been a significant reduction in offending. Manu has been assessed as a regular drinker, drinking 3-4 times week and uses cannabis tinnies 4-5 times a week, he was diagnosed with depression 10 years ago, and is on regular anti-depressants and he has Hepatitis B and C and cirrhosis - it ticks all the boxes team. Family violence perpetrator, public safety issue, kids, Maori, a long time between offending and outside the 50-day guiding principle- in terms of his treatment history, he received treatment in Odyssey House for 6 months in 2000

Police: We wouldn't support the application, we're not sure how truthful he is about seeing his children because there are several protection orders... we don't believe he sees his kids...he's a bad man that does bad things - sounds terrible- but these issues go beyond the AODTC.

Case manager: We're going towards against him coming into the AODTC we think if he doesn't make Odyssey House he wouldn't be suitable for Higher Ground because of the meds he's on and his history of offending... he's on psych drugs for depression, Higher Ground wouldn't take him because of this. 
Counsel: We're concerned with the Bridge 90 day programme, about him being on antidepressants the mental health concern is worrying that it could come back onto us - his mental health is more prominent than his addictions... ${ }^{52}$

Conversely, Matiu (with a RoC*RoI .7.5) has a history of AOD use, and an offending history inclusive of indecent assault and detainment into Forensic Psychiatric care under the Mental Health Act for 8 months. He too has coexisting mental health and addiction needs that mean, technically, exclusion from the programme. In this case, the judge notes similarities with Manu's case, except that Matiu is accepted into the programme, not on the basis of a clinical AOD assessment, but because of the perceived motivation to be abstinent:

Judge: Matiu has been a regular drinker since 17, he was abstinent from 2003-2006 and claims to be abstinent for the last 5 months. He has Hepatitis B, is a smoker and has issues with mental health and has a history of suicide attempts in 1997 . He has a treatment history of 3 months in residential, 2 weeks at Odyssey where he was discharged because of a suicide attempt, in 2011 he was discharged from the Bridge programme for a relapse. I note the similarity between him and Manu's past, he's now on a sickness benefit for alcohol dependence and he wants to be abstinent...

Police... there's no gang connections, he's considered transient for a number of years and doesn't have any real close associates other than his wino friends.

Case manager: I'm concerned about his inability to maintain abstinence; the fact is that he used meth in August although he has remained abstinent from alcohol.

Counsel: He is going to AA 3 nights a week... and he recognises the triggers, issues around access to his kids.

Judge: A stable address is going to affect treatment, but for me he wants to be abstinent. ${ }^{53}$

The judicial understanding of the motivating factors of honesty leads them to inappropriately construct honesty as a measure of AODTC eligibility:

Judge: ... He has a treatment history of Hanmer Springs, Rotoroa Island and other venues, he meets the criteria of high risk, ticks all the boxes team. For me however, the motivating factors of honesty are very important in accepting him ... ${ }^{54}$

This observation suggests that the judges' decision-making is not aligned with the Handbook (2012a; 2014) selection process, nor with an evidence based clinical assessment of dependence

\footnotetext{
52 AODTC observation October, 2013

53 AODTC observation October, 2013

${ }^{54}$ AODTC observation September, 2013
} 
(Sellman, 2009). Indeed, the observations revealed that the AODTC conceptualisation of addiction is manipulated through judicial beliefs and perceptions of compliance and programme success, running parallel to the Handbook definition of 'a moderate-severe substance-related dependency' (Ministry of Justice 2012a; 2014). Accordingly, the threshold for an addiction is made up according to individual judgements and differed between cases. Consequently, team members' practice the eligibility criteria in a non-clinical way. As demonstrated in the observation below, a case manager used a participant's age as a key factor in judging his likelihood of having an addiction while the judge's response focussed on immaturity and engagement:

Case manager: Isn't he too young to call him an addict?

Judge: I have to say that I think he needs to grow up. I don't know what to do, the AODTC is one option away from imprisonment, it could be that prison is for him. ${ }^{55}$

The above observation is disturbing considering that it is the case manager's role to inform the AODTC 'about the defendant's AOD use patterns and history, dependency status, history of previous treatment, and other behavioural addictions' (Ministry of Justice, 2012a; 2014:13). A further illustration of a non-clinical assessment of addiction came during another observation where I witnessed a Higher Ground employee and the judge agree that a prospective participant 'is not intellectual enough for court', in the sense of being unable to take responsibility. ${ }^{56}$

Essentially these observations show how the individual values and beliefs of the judges and providers manipulate the court process and override the Handbook criteria that 'offending must be driven by an AOD dependency at the moderate to severe end of the addiction/dependency spectrum' (2014:5). As a result, through this extension of their authority, the judges and team members target people who may not have an addiction, which means people whose offending was not driven by AOD dependency and therefore should not be eligible. During observations, it became obvious to me that within each AODTC, the understanding of the eligibility criteria was more often than not based on the judges being convinced of a participant's motivation and inclination to become responsible for the goal of abstinence. These findings expose the tensions between the 'highly individualistic' criminal justice and treatment aspects of the court (Boldt, 1998:1218). They also demonstrate how the AODTC establishes offender pathology and responsibility for recovery.

\footnotetext{
${ }^{55}$ AODTC observation November, 2013.

${ }^{56}$ AODTC observation December, 2013
} 
During observations, it was typical to hear the judges and team legal consciousness of the court criteria focus solely on offending histories such as drunk driving, driving while disqualified, aggravated assault, burglary, dishonesty offences, threatening to kill, intimidating behaviour, and multiple breaches of bail.

Unfortunately, discussion centred on clinical criteria rarely occurred, and on those occasions when it did the discussion usually involved the team assessing risk management according to programme success. For these reasons, the court paved the way for 'personal responsibility' as an eligibility requirement to become dominant:

Judge: Let's focus on personal responsibility, and seeking to know why he might want to participate in the AODTC... 57

The observations, and the interview with a declined applicant, suggest that the AODTC selects participants who do not always meet the officially stated eligibility criteria for an AOD addiction. Rather, AODTC team decision-making created unpredictability and as documented above, a disconnect between the threshold for addiction and evidence-based treatment.

My informal conversations with legal counsel about declined applicants reveal evidence of frequent disagreements, and numerous challenges to the AODTC over the eligibility process, the qualifications of court team members and, whether the court understands what addiction is and how it should be treated. Their accounts revealed how the judges and teams regularly 'pick up on a small aspect of an individual's file and reframe it' according to how the judges and teams perceived the threshold for offending driven by addiction and 'on poorly justified grounds. ${ }^{58}$ This includes not recognising the health needs of participants by the reframing of methamphetamine withdrawal symptoms as a mental health issue, rather than as addiction related. For example, in one case defence counsel conveyed frustration because his client was 'declined on the basis of hallucinations symptomatic of methamphetamine withdrawal, even in the face of corroborating evidence from my client's G.P. of his addiction and withdrawal treatment $^{59}$. Here the judge and team chose to decline this applicant on the basis that his hallucinations were not addiction related.

Similarly, during observations representatives of the AODTC treatment providers also expressed concern about the application of the AODTC eligibility criteria. They saw the judges

\footnotetext{
${ }^{57}$ AODTC observation November, 2013

58 Informal conversation December, 2014

59 Informal conversation September, 2014
} 
as being 'out of touch ${ }^{60}$ when it comes to identifying participants' needs, and expressed doubt as to the judges' capacity to preside over assessing addiction and treatment in the AODTC. For instance, a senior AODTC treatment provider claimed that 'the judges don't know anything about addiction', and expressed concerns around the use of punishment for 'behaviours which are typical of people with an addiction' ${ }^{61}$

Despite the fact that the AODTC Handbook contained set eligibility criteria, the observations and interviews demonstrate that the process of deciding eligibility created tensions between the court's 'therapeutic paradigm', that envisions AOD offending driven by a 'moderate to severe addiction', and the judicial understandings of individual responsibility, risk, compliance and motivation (Miller, 2009; Ministry of Justice, 2012a; 2014). As a result, the AODTC threshold of AOD addiction is subjectively conceptualised through the individual values and beliefs of the judges and team members, and in most cases, there is neither a need for, nor interest in, addressing offenders' health and wellbeing. This results in participants being cherry-picked according to judicial and team perceptions of participant honesty, responsibility, and perceived programme success, rather than in accordance with the Handbook criteria or evidence based AOD assessments of an addiction. As I discuss below and in Chapters, 6, 7 and 8, this process has a powerful effect on the participants' rights to treatment free from coercion and punishment.

\section{Abstinence}

AODTC constituted 'absolute abstinence' is a recommendation made by the Law Commission (2011) a result of judicial activism and the adoption of the US DTC model as a template for the court. As a result, abstinence is the desired goal of the AODTC programme (Ministry of Justice, 2014). Accordingly, the participants' ability to take responsibility for their abstinence is a measure of eligibility and programme success [in addition to honesty and motivation]. Abstinence is also the product of NA and AA programmes, which adopt the disease model of addiction that considers treatment as 'a cure' (Miller, 2004:1533). Thus, it can be said that absolute abstinence is the product of legality, that is, the policy of abstinence as a goal is used to construct understandings of offender pathology, accountability and curative treatment in recovery (Garland, 2014; Nielsen, 2000).

In this section, I highlight one of the major limitations of the AODTC, that is, the contradiction of simultaneously accepting addiction as a 'disease' while holding participants responsible for

\footnotetext{
${ }^{60}$ AODTC observation November, 2014

${ }^{61}$ AODTC observation September, 2014
} 
their addiction. I discuss this issue in depth here, and in the following chapters illustrate this issue in practice.

While New Zealand addiction literature reveals that periods of abstinence post-treatment are rare (Sellman, 2009), the AODTC is not alone in favouring abstinence. Recovery literature shows how abstinence remains the key focus of many of New Zealand's alcohol and drug treatment centres, including the AODTC provider CADS (Community Alcohol and Drug Services, 2016; Sellman, 2009; Smith, 2012). The AODTC abstinence policy provides a mechanism through which the court the court can measure and enforce compliance with the participant contract. To begin, the AODTC Participant Agreement (n.d) makes it clear that a commitment to abstinence is a programme requirement:

I agree to... not to use or possess any legal or illegal mind altering and/or synthetic drug; not to take any substances that may result in a false test....

In order to graduate, the AODTC requires 'a minimum of 180 consecutive days of demonstrated sobriety' ${ }^{62}$, and evidence of 'a commitment to live an alcohol and drug free life'. This is in spite of the AODTC Handbook acknowledgment that 'addiction is a chronic, relapsing condition' (2012a; 2014:15). To be sure, the AODTC Participant Handbook (2013) connects the clear goal of abstinence and the disease of addiction to foster compliant behaviour:

The clear goal of the Court is for you to become abstinent. The reason why the word treatment is in the name of the Court is because the focus is on your treatment in order to manage the disease of addiction.

Given the above policy, and the procedural informality of the court, the judges and team members tell participants that the court is about abstinence, therefore, they must abstain from AODs, because addiction is a cunning disease. Accordingly, the court utilises bail conditions to tie the goal of abstinence to addiction as a disease. These contradictory concepts form the foundation of enforceable treatment.

The comments below, from the judges during the determination hearing, reiterate a series of key bail conditions in order to cultivate compliance: that abstinence is the goal, that participant

\footnotetext{
62 Alongside: the completion of a treatment plan, satisfactory attendance at recovery based supports (such as 12 step fellowship, peer support meeting groups); appropriate progress made with other personal/educational/vocational goals (e.g. obtaining driver's licence); evidence of clear commitment to living an alcohol and drug free lifestyle; engagement in fulltime work or study or suitable community-based activity; no unexcused absences from scheduled services or Court-required appointments for at least 14 consecutive days (Ministry of Justice 2014:18).
} 
honesty, commitment, motivation and the capacity to comply with testing are necessarily compulsory, the 12 steps meetings and SCRAM monitoring are requirements, that addiction is a cunning disease, and that there are sanctions for noncompliance:

Judge: This court is about abstinence, that is abstinence from alcohol and other drugs, the treatment team will set the goals for you, your short-term goals, testing, and long-term goals towards being abstinent. Are you committed to your recovery, to your abstinence, to be honest, do you understand the agreement $?^{63}$

Judge: This is not an easy journey, this is a court about abstinence, you will be signing up to a life away from alcohol and drugs, you will have to be open and honest, you will have to do what the treatment team set you to do. Do you think this is something you are capable of doing? There will be consequences, sanctions if you're caught out. Is that something you are willing to do? This court is about being sober, this is a cunning disease that we are dealing with and we do not want it in the driving seat. Is this something you are willing to do ?64 Judge: The fact that you've applied means that you are interested in recovery.... do you understand the agreement, the testing, the scram bracelet, treatment and bells and whistles? I know that you know that it is this, or prison. ${ }^{65}$

Judge: This is a cunning disease that we are dealing with so we don't want it in the driving seat...no alcohol, illicit drugs or synthetic cannabis... ${ }^{66}$

Judge: ... you must obey the rules of the treatment plan, obey the treatment provider, no driving vehicles, no alcohol and other drugs, stay away from licenced premises, submit to breathe screening tests, you are going to get a SCRAM on and have friends in court from the 12-step fellowship because this is a cunning disease. ${ }^{67}$

As the AODTC judges decide that the participant has a 'disease' of a 'cunning' nature, the participants are instructed to abstain not only from certain AODs, but also from behaviours that go beyond the written remit of the court. The instructions then move beyond AOD use into personality traits, in particular honesty. Such individualised treatment creates the opportunity for the judges to impose their personal values and beliefs in deciding on what level of 'disease' the offender has and whether 'punishment should be imposed' (Hoffman, 2000:2096), which in turn signals unfettered discretion. The danger of this process is the fusion of treatment with

\footnotetext{
${ }^{63}$ AODTC observation October, 2013

${ }^{64}$ AODTC observation September, 2013

${ }^{65}$ AODTC observation, October, 2013

${ }^{66}$ AODTC observation September, 2013

${ }^{67}$ AODTC observation December, 2013
} 
punishment, alongside the potential of the court to dehumanise people through the unrealistic, non-evidence-based abstinence mandate (Boldt, 2009; Sellman 2009).

As illustrated below, during interviews many of the participants conveyed to me their experiences of a chronic relapsing condition, which raises questions about the courts targeting abstinence, accountability and expectation of a cure:

Morgan: ... About 15 years ago, I started drinking heavily and using drugs, meth arrived, then I just got into it. Got done for drink driving a couple of times, went to jail and then got out, turned my life around... got married to a girl, and we got into meth quite heavily about 10 years ago we came to Auckland, I got into treatment straight away she didn't, she went back home.... I was in Wings Trust, they told me to get out and go to work I hoped things would get better.... went out and got a job and got back into addiction, then a few years later hit rock bottom, went into the Bridge Programme got three quarters of the way through that and got arrested for drinking and drugs..

Despite the relapsing nature of addiction, as indicated by the interview extracts below, the participants' fate in the programme is dependent upon the contractual concept of 'total' abstinence. The judges and team members are telling them that they have a disease, therefore they should abstain. Here the accounts of the participants highlight the oppressive nature of this process, and the punitive aspects of criminal justice in responding to addiction treatment:

Miro: The court definitely sees it like we have a disease and should abstain. I think purely the reason they see it like that is just the whole law; drug possession is against the law, so if it's against the law then you shouldn't be doing it.

Manu: My perception is that they perceive it rightly so as a disease from a public safety point of view...

Morris: They require abstinence while we're in this drug court programme, they require total abstinence. They abuse it with power; they abuse it with telling you what to do instead of letting you feel comfortable where you know you can succeed at something. Instead, they put you in a position where they can overwhelm you, and stretch you to the point to see how far you can take it. Like it's a game and I don't like it, because we're all recovering addicts with a disease, with a problem that we need to give attention to but they're adding to it with more, and more complications and technicalities, they say it's better than jail you know, but if you can't comply with these rules you're off. 
Marama: I know the court sees addiction as a disease because they send us to NA, AA meetings and these meetings address the disease and we're all given tools and ways and strategies to cope with this disease otherwise we go to jail.

Maru: It's meant to be a disease, but they don't see it as a disease where people are sick you know, what I mean is, it's like if you had cancer and got sick you went to hospital. With us if we use then we go to jail.

Beyond the uncertainty of attributing disease to offending, the judges and team members are engaging in decision-making practices that indicate they have not fully understood the implications of targeting abstinence. That is, if addiction is a truly a disease, then it is highly likely that the AODTC attempts to enforce abstinence-based treatment will fail. And even more troubling are the consequences for those participants with a cognitive impairment, ${ }^{68}$ some of whom did not understand the meaning of abstinence:

Maru: What do you mean by abstinence? Is abstinence staying off drugs?

Toni: Yes, that is what abstinence is.

Toni: Do you know what abstinence means?

Manu: No.

Toni: It means that you are not allowed to take drugs or alcohol at all.

Mahaka: Yeah well, they want to see if you're man or woman enough to handle it.

Participants had confused interpretations of the strict requirement for abstinence and most of the participants observed were found to be in breach of their bail conditions, meaning that they would lose their clean time, were put back a phase in the programme, or, were kicked out of treatment. For instance, Maddox explained to me how his misunderstanding of the abstinence requirement was treated as a full relapse:

I don't normally drink alcohol I'm a methamphetamine user. But I did on this occasion, so the drug court wiped my clean time for drinking the alcohol, so since they wiped my clean time I was pretty bummed about that, so I ended up using my drug of choice methamphetamine, which then led to me getting kicked out of my treatment programme, they call it a full relapse. The participant experiences were a practical illustration of the assumption that addiction is a disease, and an individual 'moral failing' or 'individual pathology', and the narrow focus that those who relapse are blamed (Boldt, 1998:1218). That is, the court assumes one relapse will

\footnotetext{
${ }^{68}$ In Chapter 7, I discuss the implications of the court programme on people with coexisting health conditions and a brain/head injury.
} 
result in a full relapse and attract sanctions (Tiger, 2013), despite the AODTC Handbook (Ministry of Justice, 2012a; 2014) acknowledgement that addiction is a chronic, relapsing condition. Given this finding, it is therefore unreasonable of the judges to tell the participants they have a disease, all the while utilising bail to attribute blame when they do not respond to treatment. In order to enforce responsibility, these processes make it easier to cross the boundary of treatment with punishment, as demonstrated below, and allow the court to designate legal behaviours and substances as illegal.

It is clear that the AODTC acknowledgment that addiction is a disease, abstinence is the desired goal, and addiction as a chronic relapsing condition are in tension with each other (Ministry of Justice, 2012a; 2014). These policies are further complicated through the therapeutic paradigm and individualised treatment that permit the judges to engage in practices that enforce the addiction is a disease-abstinence standard, and to closely monitor behaviours and compliance. When we consider the moralising language and procedures of the AODTC therapeutic approach to addiction related offending, the participants' interviews highlight the repressive power of the court concerning their accessibility to treatment free from punishment. I argue that these processes have profound implications for participants' treatment, health, and wellbeing in recovery, as I discuss further in Chapters 6, 7 and 8.

If the judges uphold addiction as a disease, and enforced abstinence is the focus, then the next step is to shift the gaze to how the court defines substances and behaviours as addictive and illegal.

\section{Defining substances and behaviours as addictive, illegal and dangerous}

We have referred to 'alcohol and other drugs' in the name of the Court because those who appear in this Court should not use either alcohol or other drugs. It does not matter what was your 'drug of choice'. ${ }^{69}$

Miller claimed that the DTC preoccupation with disease and offender responsibility has a net widening effect that operates 'at the fringes' of the state (Miller, 2009:110). It means that the possibilities are never-ending when defining what is and what is not addictive, what is illegal and dangerous to recovery, and what culminates in the 'blameworthiness of conduct' (von Hirsch and Maher, 1992). Indeed, there is American research that indicates that, through targeting 'addiction' related offending, DTCs routinely ignore and violate treatment guidelines of 'clinical norms and ethics' (Csete and Catania, 2013:6).

69 'The meaning of our court name', AODTC Participant Handbook (n.d). 
In New Zealand, there is criminological research that underlines the need for better knowledge amongst treatment providers, and greater access to treatment options for people with an addiction (Conroy, 2018; Gibson, 2016). As discussed in Chapter 3, tensions exist between justice, health, and the right to treatment free from coercion and discrimination. In this research, it is clear that the AODTC's goal of abstinence is based on the conjecture that addiction is a disease, and includes the naming of certain substances and behaviours as dangerous to recovery. Here the court is employing the moral power of the law in relation to clinical issues and treatment (Silbey, 2005). Accordingly, court naming and blaming are the evaluative processes that make it easier to cherry pick offenders, in order to make them fit into ambiguous eligibility criterion, decline people, and render abstinence as enforceable.

In this section, I show how the goal of abstinence presents an irreconcilable approach with AODTC pharmacological support and treatment. Treatment continues to take on a form of deterrence, in the form of involuntary withdrawal and punishment, which is outside the confines of 'support' and 'treatment'. I illustrate how the power of the court is utilised by the judges and team members to deter participants from continuing with the safer, alternative medications such as diazepam, naltrexone and methadone.

The AODTC Handbooks point out that pharmacotherapies can 'replace the substance of choice', and are described as 'safer alternatives to ongoing substance use in that they are prescribed to be used in a safer way' (Ministry of Justice, 2012a; 2014:22). Specifically, the Handbook outlines:

Substitute medications are safer alternatives to ongoing substance use in that they are prescribed to be used in a safer way (e.g. not injected), are often longer acting, and they provide more stable, consistent supply in terms of both quality and quantity, allowing clients to make other lifestyle changes (2014:22).

However, my observations reveal that, in practice, the judges and treatment providers utilise the goal of abstinence to discourage participants from continuing with the safer, alternative medications diazepam ${ }^{70}$ and methadone, because each of these medications are paradoxically listed amongst the schedule of 'other drugs' tested for in the AODTC Handbook (Ministry of Justice, 2012a; 2014). This may be the result of law reform as discussed above, or even the policies of the contracted treatment providers.

\footnotetext{
70 In New Zealand, Diazepam (generic name Benzodiazepine) is a controlled drug used to treat anxiety disorders, alcohol withdrawal symptoms and has been proven as effective in treating opioid dependency (OST) and withdrawal.
} 
However, the uncritical adoption of the abstinence policy, and the embrace of individual accountability for the moral good inform the formal and informal court rules governing the treatment of people on substitute medication. Here we can see the constitutive role of the abstinence policy on the procedural decision-making in treatment (Boldt, 2009; Silbey, 2005). I regularly witnessed decisions during the eligibility and treatment processes that involved nonrecognition of the purposes of pharmacological treatment and, the denial of proper treatment and practices through the forced reduction of opioid substitute medication methadone and diazepam. In these contexts, it became obvious to me that the goals of the AODTC overrode the rights of participants to clinical and humane treatment:

Case manager: I am concerned that Matiu is still on Diazepam, the aim is to reduce the mgs over the next two weeks and get his testing clean...this is relapsing and is related to his anxiety... I'm concerned, he uses his anxiety as a justification for using Diazepam. ${ }^{71}$

The results are that participants on alternative medicines are constituted as both challenging for the programme and difficult to treat:

Case manager: Higher Ground wouldn't take her on diazepam and we're also concerned around her use of methadone... we see these behaviour's as having the potential to impact on her treatment...

Judge: ...my key concern is the self-withdrawal from the methadone programme we might be looking at some significant compliance issues... she is quite a complex, quite a challenging individual.

Case manager: Yes, they see her behaviours as having the potential to impact on her treatment; it's about reducing barriers into getting treatment. ${ }^{72}$

In light of the above, it is important to reflect on the fact that in New Zealand, diazepam, naltrexone and methadone are readily accepted as safe and effective alternatives in the treatment of opioid, other drugs and alcohol dependence (Ministry of Health, 2010; 2014) ${ }^{73}$. Certainly, decades of medical research and practice have established that opioid dependence can be treated successfully and cost-effectively. Moreover, international research finds that methadone is the 'most evaluated form of treatment in the field of drug abuse treatment'

\footnotetext{
${ }^{71}$ AODTC observation October, 2013

72 AODTC observation December, 2013

${ }^{73}$ Even though New Zealand 'compared with the rest of the world has not had a large heroin problem for many years' (Ministry of Health, 2010:3).
} 
(Farrell et al in Stone, 2015). Both methadone and diazepam are included for their therapeutic use on the WHO Model List of Essential Medicines (WHO, 2013).

Despite the Handbook (2012a; 2014) provisions, and the robust evidence of the effectiveness of diazepam and methadone therapy, my observations reveal that there is a reluctance by the AODTC to have people on naltrexone, a clinically prescribed medicine to help people maintain abstinence after they have successfully come off opiates:

Case manager: We're kind of going against him coming into the court. We think if he doesn't make it into Odyssey house, he wouldn't he suitable for Higher Ground because of the naltrexone. Te Ara Hou could have him but there's no contract with them, and he's on a psychoactive substance for depression. Higher ground just would not take him because of his treatment. $^{74}$

Methadone:

Case manager: Odyssey is reluctant to take her back; apparently, they tried to reduce her methadone. She talks about methadone like it's her medicine, she's been on it ten years in the UK they come off it quickly...she's addicted to methadone and there is no known treatment programme and what doesn't help is that her G.P keeps giving it to her, there's no point... ${ }^{75}$

The above quotes illustrate the issues of providing these participants with access to, or continued pharmacological treatment. Because the AODTC tests for these drugs, it is my view that the AODTC abstinence mandate leads to ignoring clinical treatment and evidence-based specialised knowledge of treatment efficacy and safety. While at first glance the court's reluctance to treat these participants reflects the goal of abstinence, we must question why the court case manager describes naltrexone as a psychoactive substance, when it is a prescribed medicine for withdrawal support. After all, the power given to the case managers and treatment providers to supply and control treatment is in part informed by the court as an alternative option to criminal justice.

Another inconsistency to emerge out of AODTC definitions of problematic substances is that tobacco is not a prohibited drug, nor is it tested for. This is clearly evident in both in the AODTC Handbooks and the Participant Handbook. However, in the AODTC (and within Odyssey House and Higher Ground) tobacco is still constructed as a dangerous substance, and nicotine patches are prescribed for withdrawal. Therefore, unlike the treatment of participants

\footnotetext{
${ }^{74}$ AODTC observation October, 2013

${ }^{75}$ AODTC observation October, 2013
} 
being prescribed diazepam, naltrexone and methadone, tobacco 'clean time' is acknowledged positively as signalling a participant's progress:

Case manager: He's also 29 days of no tobacco today

Judge: I am just wanting to acknowledge 29 days without cigarettes, it's a challenging step and its 66 days today clean and sober. ${ }^{76}$

Conversely, the AODTC constructed status of tobacco means that there are also strict consequences for tobacco use:

Morgan: ...I got to a year clean and yet they are still not like happy with me because of my behaviours you know, breaking the rules like having a cigarette when I'm not allowed to...

Essentially the AODTC's vague, non-clinical constitution of dangerous substances and behaviours means that treatment instead revolves around the court's ambiguous interpretation of addictive substances and behaviours. Nolan called this position the "postmodern moral order', where human conditions and behaviour such as AOD use are pathologised to 'share an addictive moral equivalence' to other behaviours such as 'gambling' and the 'consumption of chocolate' (in Hoffman, 2002:2084). Evidence of other ambiguities or the pathologisation of behaviours in the court, include legal behaviours such as gambling and sex work. These are among the proliferation of risky or dangerous behaviours that the AODTC views as posing a threat to recovery and causing possible recidivism. For instance, during a pre-court meeting, the Salvation Army Bridge programme case manager advised the Court that some of the participants are gambling ${ }^{77}$ :

Judge: Gambling is considered a no go in the AODTC, it's a matter of law as a starting point, we'll need to put something in the handbook about it.

Counsel: You're pushing it, what type of gambling, buying a lotto ticket, betting on an All Blacks game?

Judge: I'm going to make it a blanket condition. ${ }^{78}$

The observations above demonstrate how unconstrained legal decision-making operates in ways that uphold a moral understanding of addiction, providing for significant tensions between the punitive goals of the court, and treatment (Boldt, 1998). I regularly witnessed the judges and team members define what is morally right, consistent with their identification of

\footnotetext{
${ }^{76}$ AODTC observation December, 2013

77 AODTC observation October, 2013

${ }^{78}$ AODTC observation September, 2013
} 
behaviours deemed to risk programme success. This process is also evidenced by the following observation. Here sex work is subjected to moral judgements when discussing an email alerting the AODTC to the fact that 'Molly was seen out on Saturday night'.

Judge: She's not allowed to work while she's in the AODTC... [Laughing] I wonder what she was wearing, actually the Police can get video footage, if need be we can use this to tell her this is the time to spit it out.

Case manager: Molly says she was waiting for a friend to pick her up.

Police: Doesn't she need to make an application for work [laughing].

Judge: We need to articulate to her that this is not the life for her.

Counsel: This is linked to her using.

Police: It'll be good for the court to say it's prohibited as this is a community court.

Judge: It's [sex work] a no-go, we need to make it clear that it's prohibited - if she admits it she gets discharged. It's up to Counsel to convey this shouldn't happen, and that this is behaviour on notice. ${ }^{79}$

Even if the court is intended to be therapeutic, there is nothing to stop the judges and team members conceptualising sex work as risky and suspect, which also echoes the stigma in wider society and maintains that stigma. Importantly, the moralising that occurs as part of the AODTC decision-making process illustrates how the court understanding of prohibited behaviours is constituted in an ad hoc fashion in line with the individual beliefs and values of the judges and the team members. As a result, the judges and team members are attributing blame to non-criminal behaviours, creating problems of fairness and certainty in the court process.

Throughout my fieldwork, I witnessed court decision making that sustained inequality and powerlessness (Ewick and Silbey, 1998). It appeared to me that the AODTC judges and team members viewed the law as a mechanism for enforcing a particular social order, aligned with the norms and values of the judges and team members. I observed numerous references to social behaviours as being prohibited or dangerous to participants' recovery that are otherwise legal or safe, that were not in the Handbook, and that would not warrant punishment or exclusion according to the stated criteria. In addition to these references I also observed decision-making that defined the consumption of sweets, consensual sex between partners, and

\footnotetext{
${ }^{79}$ AODTC observation October, 2013
} 
sleeping in the same bed with a partner, as sharing an addictive moral equivalence to dangerous and prohibited behaviours (which I discuss in Chapter 7). These references to, and prohibition of, legal substances and behaviours, are the direct result of the judges' and team members' understanding of the goal of abstinence, and the belief that addiction is a brain disease. Since there appears to be no agreed definition as to what constitutes offending driven by addiction, or the threshold for addiction, the outcomes are that the retributive and deterrent aspects of the court programme override the stated aim of addressing the health and wellbeing of participants. Given the ambiguity surrounding the AODTC's knowledge of risk and dangerousness, Chapters 6, 7 and 8 take up on these points and weave them through discussions involving the court's recovery practices, barriers encountered by the participants, and the AODTC's practices of inconsistent judicial intervention, therapeutic surveillance, and using remand in custody as therapeutic punishment.

\section{Addiction as a choice}

Addiction as a choice, as articulated in the AODTC, begins with the understanding that addiction is a disease and a responsibility, abstinence, and a focus on accountability (Ministry of Justice, 2014). Pursuant to this contradictory approach is the belief that addiction drives criminal offending, although addiction is also a 'chronic relapsing disease' (Ministry of Justice, 2009; Tremewan, 2013). In this context, the therapeutic value of 'choice' is utilised by the court to ensure compliance, through carrots and sticks (Bowers, 2007). However, attempts to reduce reoffending through this approach to treatment have been criticised as a misdirection of therapeutic values, undermining the premise that participants voluntarily enter the DTC (Bowers, 2007; Chriss, 2002; Goldkamp, 2000; Miller, 2004).

Few scholars have considered the contradictions between the DTC disease-choiceresponsibility dichotomy; they have either raised them 'in passing only' or 'as anecdotal support for their intuitions' (Bowers, 2007:7). Of concern is that DTCs uphold the moral view of addiction as 'wilful choice', made by the offender as 'capable of choosing between right and wrong' (ibid). In this section, I locate the AODTC assumption of addiction as a choice as contributing to the court construct of individual responsibility. Here I argue that the AODTC builds on the notion of addiction as a choice by evaluating criminal responsibility and guilt that is consistent with traditional justifications of blame and punishment (von Hirsch and Maher, 1992), which then leads the judges to interpret their own understanding of accountability and non-compliance. In these respects, I argue that the AODTC does not depart from antiquated understandings of addiction, criminal behaviour and punishment. 
The AODTC operates on the basis that addiction is both a disease and a choice. Both the AODTC Participant Agreement (n.d), and the AODTC Participant Handbook (2013), outline choice and participation as voluntary. At the determination hearing the participants are required to enter a guilty plea, demonstrate that they choose to commit to the programme, and thus choose to abstain from AODs. This is illustrated in the following observation of the judge offering the choice of a position in the court:

Judge: We have assessed you and you certainly meet the criteria, I can assume you choose to come into this court, therefore you choose to confront your addiction... If you choose to come into the court then you need a lasting commitment, an enduring commitment to abstain from alcohol and drugs, you are signing up for intensive supervision and regular testing. It is a term of imprisonment if you don't come into the court...80

During interviews, most of the participants conveyed how their choice to commit the programme was instead a constrained one. The following interviews demonstrating how the offer of the AODTC acted as an incentive potentially undermining informed consent:

Mary: I had two options, drug court or prison.

Matiu: When I first signed up it was to a get out of jail card you know...

Marama: Judge Tremewan was already dealing with my case in the District Court, and when I appeared, she suggested that I'm perfect for the AODT court and would I like to, and I'm like, hell yeah, I don't want to go to jail.

Miro: Basically I just finished a 5 year lag, and then I moved down to [XXXX]. I relocated geographically to get away from old associates and tried to start a new life, things didn't work out, so I ended back in the criminal arena again, then I ended up being caught. The judge pretty much asked what happened, and I said well for me it is when I was in jail, I couldn't get to a minimum classification because of my previous history. I couldn't get reintegration or work to release or anything like that, so I just stayed in medium category prisoner and then I done my 4 years and they kicked me out, pretty much 350 dollars. Although I had the desire to change, I didn't have the support in place, well I thought I had the support in place, but the support that was meant to be there wasn't there. So I ended up back in jail again, and then a judge was talking to me and started to talk to me about the drug court and would I be interested and I said absolutely and she goes yeah, that's how I got in here.

Morris: I got a couple of hundred convictions... I'd been up for burglary, but I just finished four years prior you know. I asked for it in my case in the normal court and they offered me

\footnotetext{
${ }^{80}$ AODTC observation November, 2013
} 
five years starting point so I tried drug court and the judge said she could give me 3 years, so they let me in...

Mahaka: I didn't want to leave my family...

Michael: ...I was sort of pushed into the drug court by my lawyer; I guess doing this is like an initiative you know....

Matt: The last part of my life I been in jail 15 years at different times... I was approached in the cells with this idea that they have the drug court and they said it might be an option, and at that time, I was just wanting to get out of jail.

However, incentivising participants to enter the court manipulates the entry criteria and challenges the idea of the court as a voluntary process (Ministry of Justice 2012a; 2014).

As discussed above and in Chapter 4, the AODTC operates on the idea of internal motivation, where carrots and sticks are hung over the participants during proceedings (Tremewan, 2013). As demonstrated, during the eligibility process the judges utilise the carrot and stick approach to isolate potential participants and in other instances, to weed out those participants who 'choose' to let their addictions drive their choices, in order to coerce commitment and compliance:

Judge: ...You made a promise to commit to the court programme but instead you have let yourself down... by choosing to put yourself in a situation to use is just not on let's not put yourself in that position again alright, some smart thinking is needed.

Judge: You made a promise to the court to commit 100 per cent, we are not going to exit you today, but you need to promise to step it up or else.

Therefore, by simultaneously treating addiction as a disease and a choice, the AODTC relies heavily on the idea that addiction is a weakness of the will and individual responsibility. For these reasons, 'sticks' are necessary to enforce the participants to internalise addiction, making the participant governable:

Judge... your addiction has been driving this, we know that you can have a better future so; I am sending you back into custody to think about your choices...

This confidence of the AODTC to force participants to find reason in custody not only runs counter to addiction treatment literature (Sellman, 2008), but creates a blame conveying response justifying the decision for punitive interventions (von Hirsch and Maher, 1992). Here, the court power resembles a type of 'medieval trial by ordeal' (Bowers, 2007:6), running counter to the understanding that participants choose to commit to the programme and lays 
bare the punitive manner in which the court treats participants. This is evident in the following AODTC observation of Maurice, who has been in the AODTC 5 weeks:

Counsel: Maurice is committed to the court and would very much like to remain he has been frank in his admission of use of methamphetamine on Friday last week and possibly on Monday

Judge: That's a long time to have a positive test Maurice - you tell me.

Maurice: I got an opportunity on Thursday and used, I didn't enjoy it. I went to Higher Ground on Monday morning and my urine tested positive I still tried to lie to them.

Judge: The main thing that's a bit gutting is all the bullshit stories... We are not planning to do all the work for you, a lot of people are working for you and at the end of the day you have to do it. It has been said that Maurice is a big-time crim.

Maurice: Your honour I'm trying, I'm at Higher Ground now.

Judge: You've got some serious thinking to do down there [Maurice is sent to custody]. ${ }^{81}$

According to the above observation, AODTC constituted choice not only works to make participants solely responsible for their addiction, it also works to obscure the reality of the causes of addiction, and the relationship between addiction, AOD offending, and accountability (Measham, 2002; Miller, 2004). Ultimately, when the AODTC imprisons someone for relapsing or failing, the court is not punishing participants for criminal behaviour, they are punishing them for not complying with the programme.

During my observations, the judges did not discuss with counsel or the other team members whether a sanction is proportionate to the level of risk posed, or is punitive, unfair, or disproportionate. The observations above suggest that the AODTC decision-making creates inconsistency in case processing, inconsistency in treatment decision-making, and the use of punishment under the guise of treatment. All of which I discuss further in the following chapters.

In this section, I have argued that AODTC constituted 'choice' changes criminal justice, by creating criminal responsibility for addiction. As a central ambiguity of the AODTC, the uncritical acceptance of the disease-choice-responsibility dichotomy lays bare the court's authoritarian and hypocritical approach to treatment, and highlights an individualistic approach to AOD offending. The issue with these approaches is that, if addiction is a disease, and if

\footnotetext{
${ }^{81}$ AODTC observation October, 2013
} 
relapse is an integral part of addiction, then why is it that addiction is framed as a choice, and why are participants punished for a relapse. According to Bowers (2007:6), the cause of this contradiction is the lack of theoretical coherence in drug courts'. Certainly, these contradictions have been a common finding of other DTC research (Boldt, 2010; Csete and Catania, 2013; Mackinem and Higgins, 2007; Murphy; 2011; SSRC, 2018; Tiger, 2013).

So far in this chapter, I have demonstrated how the AODTC uses an ambiguous and inconsistent standard of eligibility. Rather than drawing from evidence-based criteria and treatment policies to address health and wellbeing, the judges, team members and treatment providers constitute certain substances and behaviours according to their individual values, the risk posed to programme success, and perceptions of dangerousness. The individual values of the AODTC judges, team members, and providers, clearly deviate from Ministry of Health clinical and ethical best practice and WHO international treatment standards, by coercing and forcing involuntary withdrawal without consultation with the participant, without consultation with a Doctor, and without the necessary social support for relapse prevention (Ministry of Health, 2014).

I have also established that the AODTC's construct of addiction and choice blurs the distinction between disease and criminal responsibility. While the AODTC's constitution of voluntary participation and choice is contradictory to addiction as a disease, I argue that together these processes impose an unreasonable and disproportionate standard of accountability for abstinence and programme success. In this context, accountability for choices are then used to measure motivation, and to convey blame for the purposes of ensuring compliance and recovery, which I discuss below.

While the chapter has shown that the AODTC requires the constitution of an addicted subject in order to carry out its function, it is apparent that this is a problematic process underpinned by a disease-abstinence-responsibility mandate. In such instances, the construct and governance of the participant is similar to the moral governance of the $19^{\text {th }}$ century lunatic confined for curative treatment (as discussed in Chapter 3). In this regard, the AODTC conceptions of addiction and treatment hold moral value inherent in the normative understanding of individual pathology and deviant behaviour (Garland, 2014; Young, 1999). The very fact that this population is already stigmatised (Wilson, 2014) should, in my view, urgently speak to the need for further investigation, which I discuss in Chapter 8. 
In the next part of the chapter, I examine the consequences of the AODTC model, and the construct of the criminal addict identity, which form the axis of ambiguous and inconsistent treatment practices in the court.

\section{The Criminal Addict Identity}

This section outlines the characteristics of the AODTC criminal addict identity. I demonstrate how tensions between the court's 'therapeutic' policies and practices are intertwined with the contradictory disease-criminal responsibility paradigm, resulting in the AODTC's construct of the criminal addict identity. The processes underpinning the criminal addict are presented in three sections: (i) homogenous, where race and gender are repressed and manipulated as leverage for taking responsibility; (ii) criminal and treatable, a dual process whereby the treatable addict identity is identified on the basis of risk and the potential for programme success; and, (iii) dishonest, which is grounded in the 12 Steps of AA and NA recovery that assumes addiction is a disease and that denial is part of the disease.

\section{Homogenous}

According to the disease model of addiction, individuals are simultaneously aligned with responsibility and irresponsibility (Reinarman, 2005). Moore and Hirai (2014), claim that the DTC mantra of taking responsibility is the process that the offender is positioned as a singular homogenous identity in recovery. I have shown that, in the AODTC, this process occurs through the belief that addiction is both a disease and a choice for which individuals need to be held accountable through abstinence.

In order to treat, the AODTC constitutes a homogenous addict identity through the diseaseabstinence-responsibility paradigm and the NA and AA 12 steps programmes (Miller, 2009). Under this approach, 'addiction as a disease' and the 12 steps permit the AODTC to neutralise participants' identity for the purposes of monitoring behaviour and progress in treatment. Establishing the homogenous identity, is thus a levelling process whereby ethnicity and gender are absorbed within and rendered invisible, by the criminal addict identity (Rafalovich, 1999; Reinarman, 2005).

The 12 Steps programme reaffirms that participants have a disease of addiction that unites all as addicts, and that ethnicity and gender make no difference to recovery at all (Reinarman, 2005). The AODTC Formative (2014), Interim (2015) and Final (Litmus, 2016) evaluations have each identified a lack of specific programmes for women and Māori. This research suggests that, in an environment that purports to be sensitive to cultural and gender differences, 
the attempts to recognise and incorporate difference into court decision-making practices are marginalising women and Māori (Hannah-Moffat, 2005; Mihaere, 2015).

The abstinence-responsibility mandate means that there is nothing to stop the court from undermining Māori autonomy through the homogenous addict identity. The AODTC's embracing of the homogenous addict identity is particularly problematic when we also consider the tensions between the colonial and contemporary criminal justice attempts to treat Māori offending under the guise of pathology and, bicultural therapeutic programmes (Mihaere, 2015; Tauri, 1999). For instance, the AODTC Handbook requires 'cultural assessments to facilitate the matching of such services and client and whanau needs'(2012a; 2014:5), the observations and interviews confirm however that the AODTC has allowed the dominant western therapeutic approach to homogenise cultural identity for the purposes of treatment, ignoring the needs of Māori participants. This is a view evidenced in interviews with Māori participants:

Matiu: I'm Māori, so I thought I'd try Te Ara Hou, but what I thought was best for me didn't work, what the Court thought would be best for me has been the plan, that's been the best environment...

Mary: I'm Māori and European, but I was brought up in a Māori family, and now I have this European family looking after me with all this professional care and all this professional knowledge and wisdom of how to better my Māori life [pause] it doesn't make sense...

In many respects, some Māori participants see the AODTC process as patronising:

Mahaka: I'm Māori and Rarotongan... they're supposed to break you down, rebuild you or some shit like that, I couldn't do it, it's just fucken bullshit it's not for me, easier in jail.

The participants' accounts are important, because they reveal the tensions involved in the 'individualised programme' and, by the court homogenising Māori cultural identity in both treatment and criminal justice decision-making. New Zealand criminal justice treatment programmes have been found, in other research, Mihaere (2015:143), to be patronising by emphasising individual solutions to 'larger social, cultural, political and structural problems'. In this research it is clear that, procedurally, the AODTC treatment of Māori participants is patronising, effectively ignoring the structural disadvantages and discrimination that occurs in the New Zealand criminal justice system. Ultimately, the court homogenisation process goes towards legitimising treatment that undermines Māori cultural identity, which I discuss further in the following chapter. 
The homogenisation of gender is similarly problematic. Measham (2002) argues that women do drugs differently to men, and as a result, their drug addiction and treatment is often a hidden gendered process. Previous studies have found that women in DTC treatment tend to experience stigma, shame and social dislocation because addiction is assumed a disease (Lyons, 2011). As argued in Chapter 4 there is a lack of attention given to gender in the AODTC (Litmus, 2014; 2015; 2016). The failure to address the gender gap in the AODTC does not mean that these factors have no impact on crime. It may be that treating women as a homogeneous group, and expecting to see shifts in the rate of offending of this group compared to all males, is unrealistic. Alternatively, it could be that the differential treatment of women ignores gender identity and gender roles, which can have an impact on treatment decision making, as discussed in the next chapter.

The AODTC's adoption of the homogenous addict is particularly problematic when we consider the evidence of a link between female imprisonment, histories of abuse, addiction, socio-political deprivation and oppression when accessing treatment (Adamson, Schroder \& Sheridan, 2007; Bentley, 2014; Conroy, 2018; Gibson, 2016). These factors have been found to influence the treatment of female offenders and redefined their 'welfare needs as risks' (Bentley, 2014:5). Indeed, the ways in which women are seen as mad and bad, has been found to prompt judges to use remand as an opportunity to pathologise and infantilise women as mentally unstable (Walklate, 1995). Of concern, is that Māori women tend to experience oppression and discrimination in the criminal justice system, based on stereotypical constructions of drug use and ethnicity (George, Ngamu, Sidwell, Hauraki, Martin- Fletcher, Ripia, Davis, Ratima, Wihongi, 2014). Taking in these social, political, and cultural issues, Chapters 6, and 7 demonstrate the impact of the AODTC adoption of the homogenous mandate on the treatment of women, transgender and Māori, and the implications in Chapter 8.

\section{Criminal and treatable}

As discussed in Chapters 3 and 4, the addict can be socio-politically located in New Zealand penal treatment, and the NDP crime prevention and enforcement responses to AOD use and misuse. Underpinning treatment are tensions involving the disease-criminal responsibility paradigm, compulsion, and moral language associated with recovery and cure. The AODTC therapeutic mandate stems in many ways from these tensions, as evidenced in the Law Commission (2011) recommendation of addressing the tensions between health and justice through the DTC model. The consequences are that the adoption of the model has given way 
to the contradictory addiction is a disease-abstinence policy, buttressing the AODTC paradigm of the addict as criminal and treatable.

The AODTC is accessible only to those offenders identified as having committed an AOD related crime, and to those that the judges perceive as likely to be compliant and thus successful in the abstinence-based programme. While the bail is a defining feature of the AODTC treatment programme, the interviews and observations show that, in practice, the bail conditions are utilised to combine treatment with punishment-based responses through wideranging conditions and interventions intended to enforce the programme:

Judge: There are treatment programme expectations, you are to have a SCRAM fitted, are you capable of doing IOP and daily testing? Because the primary focus for me is that, I don't get any more excuses, such as, a lack of money, you have got support, you're going to get a hop [bus] card, you need to get yourself a benefit, and you need to help your mother. Your relationship from now on will be straight.... But, if you put a foot wrong, you are back into prison, this court will not become part of this process if you put a foot wrong. ${ }^{82}$

The above observation demonstrates how, unlike the regular court process, there is nothing to limit the judges' discretion, in the pre-adjudication stage, to impose unrealistic expectations while monitoring participants' progress. In fact, the observations and interviews so far, confirm the judges construct bail conditions inclusive of non-treatment commitments, surveillance, and individual accountability. Thus, the monitoring of addiction treatment comprises tensions between the formal legal system and informal rules, as the judges impose bail according to their individual understanding of participants' motivation to become abstinent and accountable for poor choices:

Michael: There's probably times that I could have used and I thought no, better not, because you know that accountability thing, you know that's hanging over my shoulder all the time...

According to my observations the judges often perceived negative 'treatment' reports such as 'his attitude comes over as gangster like' or 'he's charming but manipulative' as participants not taking responsibility for their recovery. In many cases, such reports are translated as noncompliance meaning that non-criminal behaviours or poor attitudes were heavily reprimanded, with participants either remanded in custody or exited, as demonstrated in the following observation of Makareta.

${ }^{82}$ AODTC observation November, 2013 
Makareta has not attended her Intensive Outpatient (IOP) meeting due to a clash with a Work and Income New Zealand ${ }^{83}$ appointment. The judge and team exercise discretion during the discussion about her lack of commitment to the AODTC:

Judge: I need to take in her history of offending and lifestyle, 33 charges in total...18 burglaries, 1 assault, a Prostitute on K' road, these are difficult entrenched behaviours, I wonder whether Makareta wants to be exited team?

Counsel: I've discussed whether she wants to be exited today because she has to repeat phase 1 again, she said that she doesn't want to exit.

Case manager: Higher Ground see her as manipulating, she's too hard to work with, and they want to know why she is still in the AODTC.

Judge: She missed an IOP; she may well have been excused.

Case manager: Another participant told me that Makareta wanted to take lollies to Higher Ground meetings to wind them up.

Judge: Right, she needs to be reminded that it's time to get rid of her.

Case manager: Yes, it is, she's been here a year and she's still on Phase 1.

Judge: She hasn't attended a meeting a day and she's been undermining this court for a long time...I said to her no excuses, it's going to be an exit hearing, it's up to counsel to take instruction. There's a question about whether she gets bail or not, but it could come down to home detention in terms of a sentence. 1. She's missed an IOP appointment, 2. She's missed 12 step meetings and 3. We don't accept the WINZ excuse. Makareta does best at manipulation, she's undermining the AODTC it's a foregone conclusion. She will be exited into custody today. ${ }^{84}$

Unfortunately, one of the concerning consequences of the AODTC rendering the participants as criminal and treatable is that the process is also supported by the construct of the homogenous addict.

Myles: I'm on my 12th DIC and it's never helped me going into prison. It's never done anything, it just makes you worse mentally, stuffs you up, because being behind bars for an addict you know, you know you're an addict not a convict. To be a criminal, you go out there and do it deliberately under the influence of an addiction you know. I'm an addict, not a criminal. If I wasn't an addict I wouldn't be a criminal, and my whole record wreaks of alcohol,

\footnotetext{
${ }^{83}$ Work and Income New Zealand (WINZ) provide financial assistance to AODTC participants.

${ }^{84}$ AODTC observation December, 2013
} 
so you know maybe I do deserve prison and they should slam the gates on me but then you know, I'm just going to be worse than them. Mentally unfit and what, looking at 4 walls, I'm not getting anything done with my problem. Now that I'm getting something done with it they're just piling more and more and more where you're set up to fail...I got to see a Doctor soon, I haven't had a relapse but it's driving me to relapse.

Despite the claims of a humane criminal justice response to addiction related offending, the courts practice an archaic, vindictive logic whereby for those that do not meet the many requirements or, breach bail conditions, are sanctioned and remanded in custody. My observations reveal that, the reasons include not attending an appointment, turning up to court late, being perceived as manipulative, perceived as unmotivated and dishonest, failure to take responsibility for treatment expectations, and not satisfying the residential providers' expectations. I argue that these processes are full of complex governing dynamics, which I discuss at greater length in Chapters 6, 7 and 8.

\section{Dishonest}

In the AODTC, all participants are constituted as criminal and thus dishonest. This view is also supported by the abstinence policy, responsibility, and by testing to determine honesty (Ministry of Justice, 2012a; 2014). The AODTC honesty mandate, which, DTCs pride themselves upon (Mackinem and Higgins, 2007; Tiger, 2013), is echoed in the AODTC as the 'number one priority', 'number one expectation', and a 'minimum requirement':

Judge: Honesty is our number one priority, we expect people to be ready willing and able, we expect people to commit to the court, as recovery can be a rocky road so what we expect straight away is 100 percent honesty. ${ }^{85}$

Judge: ...the number one expectation is honesty, so you are going to be fitted with the alcohol SCRAM bracelet on Tuesday because while you are in the community, its protection. Protection for us, protection for them, protection for you... ${ }^{86}$

Judge: Honesty is a minimum requirement, if you are dishonest there will be a sanction and you will lose your previous clean time... ${ }^{87}$

The underlying rationale for this mandate is that denial and deception are part of the disease of addiction. In therapeutic terms, incarceration is justified to 'shock' participants out of their denial (Boldt, 2010). The court's mandate on honesty also creates standards for the judges and

\footnotetext{
${ }^{85}$ AODTC observation October, 2013

${ }^{86}$ AODTC observation December, 2013

${ }^{87}$ AODTC observation December, 2013
} 
treatment providers to challenge participants by accusing them of lying, not only about AOD use, but also about not being responsible and respectful:

Judge: ...we say honesty in this court that involves turning up on time, doing all the things you're meant to be doing, the biggest issue for us is you're lying about use... ${ }^{88}$

Judge: You seriously need to step this up, what I'm hearing overall is that you're not putting first things first, start being responsible and stop wasting time. You need to be more respectful; this is a court of honesty you need to be open and honest. ${ }^{89}$

AODTC participants confirm the court approach to honesty:

Marama: They take honesty really seriously that's one of the golden things in this court, if you're not honest and you're found out, you'll be heavily reprimanded. Depending on how bad you keep lying, you can be exited from the court because it's telling the court you're not being honest to yourself you know.

Manu: You have to be 100 percent honest if you weren't, you would get a sanction of some sort, you get held back to the end of the day, the first time my clean time got wiped...

Matt: When I made an application to have the SCRAM taken off my case manager was hindering it because she kept telling them that I'm dishonest, so yeah, they're guided by how the case managers see your honesty.

With honesty such a priority, AODTC participants encounter intense and intrusive, regular, and random testing and surveillance strategies. These involve urine testing, breath testing, SCRAM alcohol monitoring, and breath alcohol ignition devices. Furthermore, participants are also required to provide evidence of attendance at 12 Steps meetings, and sometimes, for those who have employment, evidence from their employer that they are not consuming alcohol in the workplace. The net widening effects of the 12 Steps meetings, and the court surveillance strategies, are discussed further in the following chapters.

Since participants are considered dishonest, they are given a colour code and card for testing. They are required to call the testing venue Monday to Friday to see if their colour has been selected. They are then given a time, and are required to transport themselves to the testing venue. Testing is a standard that guarantees whether or not the participants are not lying about AOD use.

\footnotetext{
${ }^{88}$ AODTC observation October, 2013

${ }^{89}$ AODTC observation September, 2013
} 
Observed testing is carried out by an employee of the company contracted to ensure that the participant is passing their own urine. Participants cannot refuse to be tested, however testing staff can decline to test participants on the basis of suspicion of AOD use:

Morris: In my first test they turned me away because they said that I looked like I was currently using, I wasn't, I'd run there...

If there is any level of doubt, participants are confronted by testing staff, and tests are sent on for further technical screening:

Matt: I've signed every test I've been to, I've kept every piece of paper, cos there was one time when there was all this stuff going on with my SCRAM, they said why didn't you go to testing, I said I went to testing - no, it's been marked down here that you didn't go to testing. I said I went to testing and, I've got the proof, and they went, we'll call you back and I never did get that phone call back to apologise that they were wrong.

Miro: Because I looked like I had been using even when my test came up clear they still sent it off to the ESR... when it came back clear I said, I bloody told you so.

The AODTC atmosphere of suspicion is reflected in the justification of insensitive testing practices carried out by the courts and treatment providers. During interviews, participants described humiliating experiences of testing, involving the deliberate use of cultural insensitivity [such as taking hair samples]; on the spot and observed testing [such as watching participants urinate]; forcing participants with chronic health needs to submit to random urine samples and breathalysers; and forcing participants to pay for breath alcohol ignition devices. The following descriptions were not uncommon:

Murray: ... physically, I'm finding it pretty hard as an old fella, got emphysema, they have one of those blow in machines in my vehicle and I don't have the oxygen for it...

Marama: They keep dropping new things on us like the testing, apparently, the judge thought that it was already observed testing, but we only signed to do testing. The agreement was, we agreed to do testing, they said nothing about we agreed to do observed testing, then all of a sudden, it all changed. We have to do observed testing, I took it really, really, badly, it was the way I found out, they didn't tell us, they just changed things instead of sitting in a group with all of us and discussing how do we feel you know, when in the end the courts going to get their way anyway...

Makareta: At one stage they wanted to take a hair follicle, I said no, they said but this is part of the agreement of being part of this Court. I went fuck off, this is a part of me you know, and as you know, that's culturally disrespectful. Cos to us Māori, giving you that hair follicle is 
tapu, we are not allowed to do things like that... they said that from now on we just got to accept it and if we have any resentments against it we can't challenge it...

Mel: I went and sat in my car and sat outside [of testing] for about an hour because it's the fear, you know, that they're going to be watching me mimi into a fucking cup you know. It's so fucking small... my wairua [spirituality/wellbeing] was hurt and I just couldn't, it was my wairua that was hurting and I haven't had a chance to really let that out because I'm too busy panicking about Court...

Morgan: ...I've got a breathalyser in my car to make it go, cost me 300 bucks last week to get it installed...

Beyond compounding an environment of suspicion and insensitivity, these accounts of the AODTC testing requirements contradict the AODTC therapeutic mandate of having a positive effect on participants' health and wellbeing. As summed up in an interview with Maru:

Maru: It's a funnel affect if you're not of the mind-set and struggling with a physical problem doing detoxing etc. coupled with a mental obsession over your drug of choice then you are going to struggle like hell. I've already been asked to give 3 samples of urine to people you know, these are the people who are still wilful and they are still at that stage which is O.K. that's the stage you're at and I believe the court see that and why they have a set punishment system for that.

A fundamental principle of the AODTCs is the requirement of honesty, yet, at the same time the constitutive effect is that, participants are presumed to be in denial and dishonest, unless proven honest through an array of punitive bail conditions and testing methods aimed at enforcing abstinence. Since the bail conditions are subject to the courts' and testing staffs' demands, these processes mean that the participants were subject to challenges over treatment issues that were not entirely their responsibility:

Murray: I don't see in any of the courses including the 90 day programme and other programmes explaining to the punter what is happening to them. I mean, if they have a mental issue coupled with a physical reaction so that they can get their heads around what is happening to them. Why is this happening to me, why do I need to fight it, how do I fight it.

Matiu: They got a lot of support workers and stuff like that but yeah, I think they can do a bit more, the support workers themselves you know, like following through with what they say. They say you know, we will come and check on you, or fucken follow up on things you want to do you know, but they don't you know, quite fucken slack. Like I've gotten in trouble for things I'm supposed to do you, because they've forgotten about those meetings you know, they can't be fucked, you know what I mean, like if they stayed on their toes, or stayed on our toes 
you'd probably get a few more people going through you know, like not fucking up to you, you know.

During observations, it was not unusual for the case managers and legal counsel to openly challenge participants outside the courtroom, and for the judges and treatment providers to make further demands upon bail conditions, such as changing treatment requirements, changes in court procedure, and graduation criteria at a moment's notice ${ }^{90}$. In practice, each of these AODTC governing processes worked to reinforce participants as inherently dishonest.

In summary, the observations and interviews demonstrate how judicial and team decision making blurs the distinction between the instrumental and constitutive role of the law in accounting for the participants' rights to humane effective treatment. Ultimately, this makes the court procedurally unfair (Seron and Silbey, 2004). Because the identity of the criminal addict is legally constructed in the AODTC, the criminal justice structures of power and authority, I argue, are reducible to the discretion and values of the judges and team members, and their influences in the programme.

\section{Conclusion}

This chapter has provided evidence of the AODTC constitution of addiction treatment. It has been shown that the AODTC therapeutic mandate is underpinned by contradictory policies aimed at reducing use, abstinence-based treatment, and deterrence (Law Commission, 2011; Ministry of Health, 2012, 2015; Ministry of Justice, 2012a, 2012b). The chapter has presented evidence of the contradictory logic in the AODTC's eligibility criteria and the inconsistent application of these criteria, and abstinence as a goal, justified on the basis that the offender has the disease of addiction.

The chapter has demonstrated that the AODTC conceptualises the threshold for addiction simultaneously as a disease, choice, and a responsibility. Within these contexts, the AODTC then harnesses 'choice', which implies responsibility, to justify punitive 'treatment' interventions such as involuntary withdrawal. The AODTC's treatment interventions also simultaneously construct the criminal addict identity as homogenous, criminal and treatable, and dishonest in order to justify intensive, inhumane, and disproportionate treatment practices. All of these approaches have given way to, and help facilitate vague descriptions of addiction

\footnotetext{
90 These legal processes are discussed in more detail in the following chapters, in particular Chapter 7.
} 
in the court through the unregulated judges and team members' positioning of non-criminal behaviours and substances as risky, criminal, and dangerous.

As I demonstrate in the next chapter, the AODTC recovery process involves an array of ambiguous processes and coercive practices that revive the historical connection between offender pathology and curative treatment (Allen, 1981; Whetstone and Gowan, 2011). 


\title{
Chapter 6: Recovery in the Alcohol and Other Drug Treatment Court
}

\author{
"It's about taking responsibility for their lives"
}

- $\quad$ Minister of Justice Judith Collins during a visit to the Auckland AODTC September $2013^{91}$

\section{Introduction}

Recovery in the AODTC is determined according to the extent to which participants take responsibility for their addiction and abstinence. As with the court's knowledge of addiction, there is no standard definition of AODTC recovery beyond the requirement of abstinence, and the ambiguous milestones contained in the Handbook (Ministry of Justice, 2012a; 2014). Effectively, recovery is a subjective process.

In this chapter, I examine how recovery is conceptualised and measured in the AODTC, and the effects of this process. The chapter is divided into two parts. The first part describes how the AODTC facilitates recovery by utilising the following: (i) legal coercion, which encompasses the court's understanding of addiction as a disease, choice, and accountability; (ii) the 12 steps of AA and NA, which endorses the disease model of addiction, individual responsibility, and abstinence; (iii) the tools of the court, which include conditions to be honest and commitment to the goal of abstinence; and (iv) the broad goals of abstinence, honesty and accountability to measure progress.

Focussing on Māori, women, and transgender participants, the second part of the chapter describes the barriers to treatment, family/whanau, employment and financial stability, and support in securing appropriate housing. It argues that the AODTC is failing to positively affect participants' health and wellbeing, because court therapeutic practices are fixated on the abstract concept that addiction is a disease for which participants need to be held responsible through the goal of abstinence, I argue that legal coercion and accountability play a large part in creating these barriers.

I conclude that the AODTC's vague concept of recovery produces a range of ambiguous treatment policies and practices built on a criminal justice response to the addict identity. I demonstrate that the court frames the participants as responsible for their recovery but, at the same time, as irresponsible. In this framework, the judges determine what the treatment will be and whether the participant is compliant or not. Consequently, the AODTC is not guided by

\footnotetext{
${ }^{91}$ AODTC observation September 2013
} 
proven addiction treatment, and clinical best practice does not predominate, instead the court deploys the authority and coercive power of criminal justice when governing recovery. The AODTC may be well intentioned, but I argue that the courts have legitimised governing practices that undermine effective treatment and thus, the health and wellbeing of participants.

\section{Legal Coercion}

Research indicates that DTCs embrace a coercive form of justice based on the addicted offender as one that is rational and responsible-despite having the disease of addiction (Miller, 2009). AODTC Judge Tremewan makes clear that, "participants do choose to be coerced in the treatment court' because it is 'exhausting to suffer from the disease of addiction where the whole day is committing offences' (2013:3). Ultimately, in the AODTC, there is nothing to stop the judges from using the power of the court to conceptualise disease to AOD offending and thus to justify coerced treatment, which raises important questions concerning the uncritical acceptance of the disease-choice-responsibility mandate, the unfettered authority of judges and the DTC model itself.

In this section, I will describe how legal coercion in AODTC mandated recovery comprises: (i) judicial monitoring of accountability and abstinence; and (ii) assumptions of the dishonest participant and accepting responsibility as a measure of recovery. I demonstrate that by utilising the coercive power of the law, the judges undermine participants' capacity to give informed consent, and interfere with their autonomy to take responsibility for their recovery.

That is to say, AODTC legal coercion casts doubt on whether participants have given 'informed consent' to treatment and raises questions about the basic right to participate in treatment.

Boldt argued that procedurally, the practice of using coercion in the DTC is to mediate the tension between the irresponsible addict and the responsible autonomous agent, "held responsible for their choices' (2009:14). In this regard, legal coercion is built on 'deterrent and desert values' (Goldkamp, in Fischer, 2003), as well as the need for swift deterrent effects such as threats and sanctions (Boldt, 2009). The following observations demonstrate that the AODTC judges coerce participants through the requirement of honesty and with threats of sanctions involving a loss of clean time, exiting and imprisonment. As a result, punishment is conflated with treatment through the judicial monitoring of accountability: 
Judge: Seriously, if you don't do this you will be exited, it's about understanding your responsibilities... ${ }^{92}$

Judge: If you're not going to be open and honest we're not going to get too far. In terms of a sanction, you have lost your clean time and you won't be getting home leave, you're very, very lucky you haven't been exited... ${ }^{93}$

Judge: I can tell you without a shadow of doubt, if you don't do something meaningful I will imprison you, we believe that you can do a lot more for yourself on your own... ${ }^{94}$

Judge: ... I think it is disrespectful to not be honest, do you understand. At least you had the good grace to be honest that you lied. So let us be upfront, we are not stupid, you will find that in the fullness of time things normally show themselves, do you agree? ${ }^{95}$

The largely unregulated environment of the AODTC permits the judges to utilise retributive threats to coerce programme compliance. During observations, I regularly witnessed the judges use actual imprisonment to coerce commitment and compliance and respond to non-criminal behaviours, exposing those participants to the punitive and disproportionate effects of criminal justice. As demonstrated in the observation below, Matthew has requested to exit the programme but the judge instead imposes intrusive conditions requiring him to abstain from AODs and to attend 12 steps meetings while in remand on bail:

Matthew: ...it's just too hard I want to go back to doing things like before.

Judge: What would you rather be doing? Would you rather be free of me and the court just going to work and living where you want to be? Would you be free of drink and drugs?

Matthew: Yeah.

Judge: There's been a lot of changes there needs to be a plan in place.

Matthew: I'm not really happy with my case manager.

Judge: Will you talk with counsel and tell him about what it would look like out of court because I will sentence you, that doesn't mean prison but I don't want to set you up to fail that means you need to talk to counsel seeing as you won't talk to the case manager. Did you go to testing today?

\footnotetext{
92 AODTC observation October, 2013

${ }^{93}$ AODTC observation December, 2013

${ }^{94}$ AODTC observation September, 2013

${ }^{95}$ AODTC observation December, 2013
} 
Matthew: No.

Judge: Right, remand for 1 week to think about it. Talk to your case manager

Matthew: Do I get a sentence next week?

Judge: No it's unlikely. In the meantime no alcohol, no drugs, no crime, I would like you to attend 12 step meetings so you're not in breach of bail and I don't want you getting in touch with your old associates. ${ }^{96}$

These interviews confirm that the threats of punishment are regularly utilised by the court for various retributive and deterrent ends:

Matiu: If you can't comply with these rules, you're off so that's a threat you're always threatened...

Myles: They use all these big words, the main word and they minimize it and twist and turn it into a word that means something totally different is a threat. If you don't do it, if you don't comply you're off to jail sweet and simple, they manipulate the word threat they turn it into something else...

Maru: .... I've been told by my lawyers that the judge I'm appearing in front of today is going to be quite upset with me. Because I am one of her statistics and she's worked a long time to get this pilot court going, and it's just going to be a cross on her when she goes to throw the paper work at the other people to try and get it up and running properly, I'll be a cross on that mark.

Ultimately, in the absence of clear regulations (Hull, 2003), the judges are free to deploy threats to coerce and to manipulate the participants to be compliant. As evidenced above, the process depends upon the judge's decisions to target responsibility and their assumptions about what addiction treatment should be. One of the consequences is that, while emphasising the various goals and conditions of the court, the judges' infantilise participants as not knowing, or not being able to commit to recovery:

Judge: I have to put things in concrete, there is team concern, we want to be watchful of the risks involved, you need to spend more time with your peer support worker putting together a plan. Looking forward in your life, work out your recovery commitments. Life is full of

\footnotetext{
${ }^{96}$ AODTC observation September, 2013
} 
competing pressures, these are dangerous times for people in recovery, you need to factor in the 12 steps meetings, testing too, and you need to keep the goals of the court in mind. ${ }^{97}$

It is clear from my in-court observations, the interviews above and in Chapter 5, that court participants are not partaking in treatment as a process involving informed consent. Neither are they participating in treatment free from threats, the conveying of blame, the application of punishment and imprisonment. The effects are that, in addition to monitoring treatment, the judges are engaging in unfair coercion. They are justifying the preventive aims of the court by permitting the court to speak of forced punishment as addiction treatment. The results are that there is no ambiguity about the role of coercion, at least not from the judges. Rather there is ambiguity over what role treatment has beyond the disease-responsibility mandate and 'rehabilitative punishment' (Boldt, 1998). As will be shown below, coercion and discretion underpin much of AODTC treatment through the 12 Steps programme, and the processes of enforcing the various punitive tools of the court. And in Chapter's 7 and 8, I show how wide judicial discretion underpins the merging of treatment with punishment and harms in the AODTC.

\section{The 12 Steps of Alcoholics Anonymous and Narcotics Anonymous}

"One of the things I appreciate about you is that you realised early on that you had the serenity to surrender, you surrendered to the recovery journey" AODTC judge ${ }^{98}$

Among the more contentious components of AODTC (treatment) is the requirement for attendance at the 12 Steps AA and NA meetings. The AA and NA meetings also place abstinence as a primary goal of recovery from alcohol and drug addiction. The AODTC Handbook (Ministry of Justice, 2012a; 2014), the Participant Agreement (n.d), and the Participant Handbook (2013), are the instruments by which the court mandates the 12 Steps to foster abstinence compliance. The Participant Agreement serves as the official contract between the AODTC and participants, and outlines the rules and conditions of treatment. The Agreement is also the key document formalising the relationship between the court and community treatment providers (see Appendix D).

Attending the AA and NA meetings and completing the 12 Steps programme is used by the court to measure clean time and compliance. The Participant Handbook (2013) makes it clear

\footnotetext{
${ }^{97}$ AODTC observation September, 2013

${ }^{98}$ AODTC observation December 2013
} 
the participants that attending AA and NA and doing the 12 Steps is a key part of treatment and a priority of the court:

Recovery is ongoing and you need to keep working at it-remember it works if you work at it! You are likely to be attending other support meetings [such as AA and NA meetings]. If so, the Court will give you a card to take with you to those meetings to record your attendance. You should hand your card in at the beginning of the meeting....so it can be 'marked off' at the end of the meeting. Bring the card back to court to show the judge.

Underlining its importance as a tool of the AODTC, the 12 steps Serenity Prayer is incorporated into the Participant Handbook (2013):

God, grant me the serenity to accept the things I cannot change, the courage to change the things I can, and the wisdom to know the difference.

E te Atua, homai ki a au te wairua marie ki ngā mea ekore e teaea e ahau te whakarereke. Homai te manawanui ki ngā mea e taea ana e au te whakarereke. Homai te maramatanga kia matau ai ahau ko tehea, tehea. ${ }^{99}$

In court, the Serenity Prayer is leveraged through three culturally significant Triptych panels hung in each AODTC titled: 'Serenity', 'Courage' and 'Wisdom', 'for those suffering from the disease of addiction' (Participant Handbook, 2013). During observations, it was commonplace for these panels to be upheld by the judges in order to coerce participants to commit to the 12 Steps. Accordingly, mandating the 12 Steps meetings as part of treatment results in the judges becoming active participants in the governance of addiction treatment.

I regularly witnessed the judges utilise the 12 Steps language to coerce commitment to recovery. This is evidenced in the following observation:

Judge: I rather like the notion of the higher power, whatever that means to that particular person in recovery.

Major: The main reason for the AA meeting is being abstinent and the higher power, the higher power is on the walls all around this place... ${ }^{100}$

The public AA and NA meetings are utilised by the judges to measure compliance through 12 steps meeting attendance cards, and as an opportunity to engage in infantilising language:

Judge: Do you know what your sobriety date is?

\footnotetext{
${ }^{99}$ As copied from the AODTC Participant Handbook (2013).

${ }^{100}$ AODTC observation December, 2013
} 
Max: 123 days I think.

Judge: You're right! [Clapping] have you got your purple card for me? [The judge addresses the court]. Our purple cards are where our participants write out their AA and NA meetings. I like to put a star on it, I'll give you a nice blue one today, a kahurangi blue one, the next time you come back with a full card you will have done 100 meetings we will give you a reward. ${ }^{101}$

Judge: Just so that we are aware, recovery comes first. That is our number one priority.... recovery is the foundation of which all of these things are laid, it's about staying connected, keeping your meetings up, it's important for us to keep the message going. ${ }^{102}$

The above observations are common examples of how the pervasive use of the one-size fits all 12 Steps model involves 'therapeutic paternalism' (Hoffman, 2002:2083), and a moral grounding for the judge to stipulate recovery as the court's number one priority. Essentially, this process means that the participants must take on the addict identity and put their recovery above all else. The interviews below confirm the paternalistic stance utilised by the AODTC through the abstinence mandate and AA and NA meetings.

During the interviews, it was common for the participants to convey feelings of frustration and exclusion as an AODTC participant in the public 12 Steps meetings:

Mahaka: When you go to AA and NA meetings, it's only a small percentage of people from the drug court. Sharing the drug court experience with people from outside and a lot of our experiences are similar, but they haven't got the added pressure of court pressure we have. We got drug court pressure, which is a long process it's all abstinence based where you know; we've got a lot more baggage.

Myles: I've been to some of these AA meetings where some of the people that are working in the court are attending.... One of them that sits there, the Māori one [Pou Oranga] he sits there with his eyes shut and just looks like he's asleep and he's talking all this rubbish with his eyes closed, the guy can't even look us in the eye.... I'm not going to AA meetings you know where a guy just shuts his eyes and he's talking rubbish, I can't even make up that shit you know, I'd get a better conversation with myself you know, rehabilitating myself, that sort of thing.

Besides the morally infused 12 Steps of AA and NA, the AODTC depends on the values and beliefs of the judges and team members to uphold abstinence, and to anchor participants'

${ }^{101}$ AODTC observation October, 2013

${ }^{102}$ AODTC observation September, 2013 
responsibility for recovery. AODTC Judge Tremewan makes clear that the 'goal of abstinence, which will require nothing short of them becoming a wholly different person - changing the people with whom they mix, the places they go and the things they do' (2013:9) I regularly witnessed both judges engage in monitoring compliance through coercive threats of 'places you go' and 'people you see' and 'certain people' and often without context.

Judge: The journey is about changing the way you do things, places you go, people you hang out with, I think the last one will be the hardest for you. ${ }^{103}$

Judge....if you go to certain places, if you see certain people and if certain stuff is going to go down... ${ }^{104}$

As I discuss in the section on barriers encountered in recovery, the above monitoring of compliance is completely hostile to the idea of 'supporting' the participants' health and wellbeing. Throughout the programme, even after a long period of abstinence, I witnessed the judges repeatedly re-emphasise to participants, 'places' 'people' and 'certain people' and 'things'. Thus if it is people, places and things that lead to a relapse, then these phrases imply that addiction may not be a brain disease at all, that social, cultural and environmental factors play a larger part in constituting recovery. Indeed, taking in the confusion and disagreement over what constitutes the threshold for addiction during the eligibility process, the observations and interviews have cast doubt over what addiction recovery actually is. Nevertheless, the participants are taught that they have the disease of addiction, abstinence is the number one priority of the court and compliance with the 12 Steps are mandatory. In this way, the court conveys responsibility for the disease to the individual and thus their recovery:

Morgan: ...I've submitted to the fact that I have a disease and the programme is for the better.

Manu: ...going to the NA meetings, you know, that's my connectedness being connected to something greater than I am, you know... it's the same as the drug court I learnt I have a disease, a disease of addiction.

The interview and observation data makes clear that the authority afforded to the court to mandate attendance at public 12 Steps and AA meetings is utilised by the judges as a moral and paternalistic mechanism of control. The assumption is that, when mobilised, the law 'carries with it the 'moral authority' (Marshall and Barclay, 2003:623) to uphold the 12 Steps language in order to manipulate participants, and to make them governable. It is clear that, by

${ }^{103}$ AODTC observation September, 2013

${ }^{104}$ AODTC observation December, 2013 
the legal authority of the court, and the 12 Steps, the judges do not respect participants' rights to autonomy, which would not otherwise appear legitimate without the authority of the court (Kleinig, 2008). Even though the AODTC Handbook (2012a; 2014) details that the programme provides a variety of treatment and rehabilitation services, procedurally, the legal decisionmaking prioritises the 12 steps of AA and NA and abstinence in order to govern compliance.

Thus far, I have demonstrated that the coercive power of the AODTC involves judicial threats and punishment to govern abstinence and enforce programme compliance. Even though the participants are required to take responsibility for their addiction, the judges employ ambiguous strategies to justify intrusive involvement in the participants' lives thereby raising questions about the extent of the court's authority and the limits to that authority.

\section{Using the AODTC tools}

"Using the tools" of the court refers to two AODTC constructs: (i) honesty, and (ii) commitment to the goal of abstinence. As shown in the previous chapter, these tools reflect the judges' individual values and beliefs as criteria for AODTC eligibility and as rules to measure of success. In this sense, the judges' values and beliefs constitute the formal and informal rules of the court (Levine and Mellema, 2001). They thus provide the mechanisms for coercing participants to transform themselves from being dishonest and in denial, to becoming a better, responsible citizen (Valverde, 2010) through 'collaborative co-telling' (Burns and Peyrot, 2003: 432).

Instrumentally the AODTC Handbook (2012a; 2014) assumes that all offenders, irrespective of cognitive ability, will use the tools of the court and commit to being 'prosocial' people. The Participant Agreement (n.d) makes clear that this process involves the participants being 'honest'. In-court, the judges engage in telling the participants that 'honesty' is the 'most important tool' in recovery, and is the tool that transforms the participant into one that is recovered:

Judge: What is the most important tool?

Mattie: Just be completely honest with what's going on.

Judge: Because it's important to be honest about mixing with people that are in recovery. ${ }^{105}$

${ }^{105}$ AODTC observation September, 2013 
Therefore, for the court to recognise success, it is the duty of participants to choose to use the tools to become better by demonstrating that they are putting their addictions first and foremost:

Judge: I really appreciate the way you're getting better...You are putting your addictions first now, it would be good to test the water this weekend, I'm going to relax bail rules for this weekend however bail is to be retained on a needs basis... ${ }^{106}$

Those participants who demonstrate commitment to the court by putting their addictions first, are perceived to be taking responsibility for their recovery. However, there are dangers to the co-telling process as it not only constitutes participants according to how they perceive the courts' requirements, but it is also utilised by the judges for diverse ends such as coerced participation and enforced recovery:

Judge: Tell the court what it's been like for you.

Moana: This drug and alcohol court is making me a better person, a better father... ${ }^{107}$

Judge: Have you looked in the mirror Malcolm, what do you see?

Malcolm: An old man.

Judges: You are looking well; you are looking better, healthier, a much better person. Your job is to keep making gains, making tools.

Malcolm: Even if it is positive, knowing the limitations of every decision I make is the right the decision, is hard.

Judge: So we are going to vary bail, we are not going to put you in custody; I'm not going to say that we don't have concerns about you ok. We need to look at the most suitable strategy for you. No alcohol and other drugs, no driving, you must submit to breathe screening and fully comply with orders, the SCRAM bracelet will go back on, so no swimming with the SCRAM on o.k., you keep up the clean time ok. ${ }^{108}$

As a sign of their progress, the judges expect participants to demonstrate compliance in court through collaborative co-telling:

Judge: Today is a special day do you want to tell us? It has something to do with how long you have been sober for

\footnotetext{
${ }^{106}$ AODTC observation September, 2013

107 AODTC observation October, 2013

${ }^{108}$ AODTC observation, October, 2013
} 
Max: 6 months.

Judge: How does that feel?

Max: I'm getting there.

Judge: Yes, but how are you feeling about things?

Max: I have been sober 6 months and 3 days today, I know I have a long way to go, I fully admit that I do have an alcohol problem... it has made me learn to be comfortable with others. At the beginning of the programme I was in denial it took me a while to be abstinent, I can say that alcohol is my enemy, I want to become a better person, I want to get involved in church, I am willing to go through whatever process to better myself to become better. ${ }^{109}$

During interviews, when asked if their experiences with the AODTC changed how they viewed themselves, some of the participants mirrored the courts' narrative of taking responsibility toward becoming a better person:

Mikaere: I see myself today as a better person, a responsible person and honest person and thinking about relapse is something I don't want to think about...

Mary: As long as I have that knowledge that I am an addict that I am going to be responsible for myself as an addict because you know my behaviours are unsafe for myself and the community until I get better...

These interviews demonstrate the constitutive role of law in the AODTC. That is, through their involvement in the programme the participants are interpreting their recovery in line with the AODTC's dogma of individual responsibility and knowledge of becoming a better, honest citizen. In this context, the law is neither neutral nor passive. Rather, the power of the law is utilised by the court to coerce, rendering the participants helpless and powerless (Marshall and Barclay, 2003). The consequences are that treatment for those that do not mirror the court's requirements, treatment is translated into punishment (Tiger, 2013).

During the interviews, most of the participants conveyed to me that the court's focus on compliance in recovery, blurred punishment with treatment. They felt that 'recovery' meant demonstrating compliance with the court's narrative of responsibility, underpinned by 'ultimatums' and threats, as summed up in the following interview with Matt:

${ }^{109}$ AODTC observation October, 2013 
Matt: Punishment and treatment, they're put together, it all depends on how you speak to the judge, how your present yourself. It's the same as case managers, if you get in the bad books with the case manager or certain case managers, like if you chat back to them, then they just won't bother giving you anything light you know what I mean, it's just too bad. You're out sort of thing, they give you ultimatums, a lot of ultimatums.

The observations and participants accounts show that 'using the tools' of the court in recovery is an uncertain process. The judges assume that any failure to use the tools of the AODTC will lessen a participant's chances of recovery. Therefore, it can be concluded that the tools of recovery are not necessarily determined by the severity of a person's addiction or their particular treatment needs. Instead, it is about displaying honesty and compliance by taking responsibility for addiction and thus recovery, which ultimately means that treatment, is constituted as justice (Nolan, 2003).

\section{Measuring progress}

As discussed above, the AODTC's informal structure and the broad goals of abstinence and accountability, permit the judges great freedom to exercise their discretion to measure and determine treatment progress. Accordingly, progress in recovery depends upon judicial understanding of honesty and compliance with 'clean time', in addition to the AODTC Handbook ambiguous definition of three 'advancement milestones' (Ministry of Justice, 2012a; 2014), which are measured where an overall:

...review of a defendant's progress signals advancement within the AODT Court. These milestones are not necessarily linked to treatment timeframes. In deciding whether a participant should bring an application to advance a phase, the team will take into account their progress with treatment and other goals, their compliance with other obligations, and sobriety time (p.16).

The Participant Handbook (2013) confirms that progress is subject to the phase advancement milestones, and the expectations of being clean, sober, and compliant with the court's conditions. It also outlines that 'progress' from one phase to another 'will probably take between 4 and 6 months', and to graduate participants are required to be abstinent from AODs for 'at least 180 consecutive days'. The Participant Agreement however gives no certainty as to what participants must do to graduate successfully. Instead, it situates 'honesty', 'compliance', and 'accountability' for recovery and outlines sanctions for any failing to comply with treatment conditions. 
Considering the descriptions of progress in the Handbook (Ministry of Justice 2012a; 2014), the Participant Handbook (2013) and the Participant Agreement (n.d) and combined with the findings so far, the AODTC's prescription for progress is based on vague milestones, coerced treatment, abstinence from all substances, and avoidance of behaviours judged to be risky and dangerous. It also entails avoiding 'people', 'places,' and 'things', achieving and internalising the criminal addict identity, and continually using the tools of the courts toward becoming a better, responsible citizen. Accurate and evidence-based measurements of recovery, or even moderated AOD use as an acceptable measure of progress (Lyons, 2011; Sellman, 2009), are simply not considered, denied or ignored. The data indicates that AODTC progress is not clearly defined according to evidence-based clinical treatment practices. Rather, progress is determined according to judicial and team member discretion to evaluate progress based on the ambiguous goals of the court, the subjective understanding of individual responsibility and risk to programme success.

The observations and the interviews show that this process is undermined by judicial bias (Nielsen, 2000). That is, the procedural informality underpinning the court's therapeutic mandate provides the judges with added opportunities to apply their subjective knowledge of a participant's risk (Miller, 2009). In such instances, there are no formal rules to restrain the judges from personal bias. Rather, the informal values and rules that constitute the court process and the judicial role influence a participant's progress. As a result, the court therapeutic approach promotes confusion over the process of fact-finding. For instance, during a precourt meeting I witnessed the judge deliberate on a participant's progress according to the judge's previous history with the same participant in a different court:

Judge: Marama appeared before me at [XX district court] for drunk driving, she has a history of dishonesty and she gave me a flat out lie about driving drunk, she's a liar, she can't be trusted...

The unregulated judicial role also facilitates subjective judicial descriptions of AODTC progress including, 'staying on track' 'back on track,' and 'not getting too comfortable' with the programme. These vague descriptions are used by the judges collectively to govern and measure compliance towards recovery: 
Judge: The way I see it is that things are going very nicely and we want you to stay on track. That means, not getting too comfortable, not getting too comfy, that old habits come creeping up...don't do anything, to jeopardise anything. ${ }^{110}$

The imperative of working oneself by using the tools of the AODTC connotes working towards recovery, in the sense of building moral character:

Judge: ... you have to think what is driving your journey, whether it is your addiction or those irresponsible antics... so you can work towards a recovery... It remains to be seen where you get to...11

During interviews, it was not unusual for the participants to express confusion about the court's assessments of progress, as conveyed by Monty:

Monty: One drawback is that it's a very long process, very long, 18 months, 20 months, 24 months, I'm not sure.

Toni: Have they given you an indication of time?

Monty: No, they said and its written in the prospectus booklet that phase 1 is 4-6 months you know, phase 2 about 6 months' phase 3 about the same, so about 18 months. I'm in my 7th month now I'm sort of starting again in the phase 1 because of my relapse. This treatment I'm going to on Monday will last for 8 weeks so I'm hoping at the end of that 8 weeks they'll invite me because they invite you to go to the next level, hopefully they'll invite me to go to the next level as long as I graduate you know. If I get discharged for some reason it's not going to be good, not many options left for me.

The above observations and interviews reveal subjective understandings of progress. The AODTC milestones are not linked to the specific timeframes as stipulated in the Handbooks. Instead, phase advancement is inevitably shaped according to the judges' and teams' perceptions of the individual participant's honesty and commitment. The participants interviewed saw these tools as focussed on 'choice', and as an opportunity for the court to intervene with punishment:

Mahaka: It's just the tools that they use. If you choose not to use those tools, then you choose no. They're flaky, they're extremely flaky on a lot of things, but not punishment...

${ }^{110}$ AODTC observation October, 2013

${ }^{111}$ AODTC observation December, 2013 
The results are that, in practice, the court's understanding of progress adds to uncertainty for the participants, constituting a type of psychological harm in their recovery. During observations it became clear that the duration of clean time does not matter in most instances, because the focus of the court is on the dangers to recovery:

Judge: .... 258 days of clean time, I want you to remember that life is full of competing pressures, and these are very dangerous times for people in recovery, I shouldn't have to remind you to be safe, let's keep the goals of the court in mind, this is an alternative to imprisonment, you should be giving back... ${ }^{112}$

Irrespective of the AODTC Handbook phase advancement criteria, the judges were observed to frequently remind the participants that in order to take responsibility for sobriety, they need to keep safe and thus should not get ahead of themselves:

Judge: 90 meetings in 90 days. I am going to give you a purple star and one more as an encouragement star. We know you have had challenges and that you are just doing recovery that is just how it is- today I'm going to acknowledge that you know how to keep yourself safe and make good decisions ${ }^{113}$

Judge: ... today we acknowledge your sobriety time is 346 days, in fact, very soon we'll be handing out a special medal, but we won't be getting ahead of ourselves...I'm asking you to think about what sort of life you are going to make. Your recovery is going to be a fundamental aspect of this... take one day at a time because the minute you stop working on your recovery your addiction is back in the driving seat. ${ }^{114}$

I also witnessed the judges' focus on the participants booking photo as a coercive governing logic:

Judge: Obviously, you have a bit of the programme to go... things will keep moving forward... do the things that are required so we see your progress. When was the last time we looked at your booking photo? You know I'm going to get you to look at the photo [the judge holds the booking photo up in front of the open court]

Matt: Pretty dark [in tears]

Judge: It's written all over your face, you're changing... this person is not well. ${ }^{115}$

${ }^{112}$ AODTC observation November, 2013

${ }^{113}$ AODTC observation, December 2013

${ }^{114}$ AODTC observation November, 2013

${ }^{115}$ AODTC observation November 2013 
It can be argued that the judge's manipulative use of the booking photo, and the phrase 'this person is not well', attributes Matt's criminal behaviour to addiction, putting into question the extent to which the measurement of AODTC progress is determined by clinical treatment. The observations and interviews show that the AODTC expects participants to use ambiguous tools in their journey toward recovery. The result goes beyond treating addiction; it is about placing the onus of choosing to become a better citizen onto the participant. The courts' expectations are clouded, a result of the ambiguity in the AODTC Handbook milestone criteria. As shown in Chapter 5, abstinence is the standard imposed by the AODTC. However, measuring abstinence involves the judges and team members determining ambiguous descriptions of substance and behaviours as dangerous to recovery.

AODTC progress is complicated by the fact that a participant's stay in the programme is dictated by coercion, the judge's understanding of total abstinence, clean time, and uncertain knowledge of relapse prevention. These processes result in an emphasis on participants' responsibility as a measure of progress. According to the data, these processes can lead to arbitrary outcomes, including determining progress according to a participant's ability to be honest, the extent to which participants use the ambiguous tools of the court, and punishing participants for minor infractions. These problems are discussed at greater length in the next section and in the following chapters.

Up until now, the chapter has shown that recovery in the AODTC is underpinned by judicial assumptions that addiction is a disease, and coerced treatment is necessary. The evidence demonstrates the effects are that participants are infantilised as not knowing, while also being held accountable for relapses. Likewise, the morally and spiritually infused 12 Steps of AA and NA are utilised to coerce participants, all the while maintaining the idea that addiction is a disease. Therefore, the participants are confused by the court's view that they have a disease of addiction, and are subjected to threats and punishment but are also required to take responsibility.

I have demonstrated how the AODTC belief that addicts are inherently dishonest provides the justification for insisting that participants use the tools of the courts for becoming a better citizen. Here the judges draw upon a subjective interpretation of honesty and commitment, placing the onus on participants to provide evidence of their compliance to the programme. As a result, to become better, participants are required to negotiate uncertain and inconsistent standards of progress. 
Essentially, the legal decisions made in the programme sustain the powerful influence that the criminal justice system has over addiction treatment, health and wellbeing. To highlight the significance of the uncertainty surrounding AODTC progress, judicial understanding of addiction, treatment and relapse prevention, the following section illustrates the consequences of coercing recovery in the AODTC.

\section{Barriers to Achieving Progress in Recovery}

As discussed in Chapter 4, the Law Commission recommended a pilot built on solving the health/criminal divide through 'treatment' that recognises the social and cultural needs of participants (Law Commission, 2011). However, there is little evidence to suggest that the AODTC governing of addiction 'treatment' solves the divide between health and justice. Rather, the data so far indicates that the legally mandated programme comprising coercion, a focus on individual responsibility and programme success excludes participants from evidencebased treatment (Csete et al, 2016; Dannerbeck, Harris, Sundet and Lloyd, 2008; Gallagher and Nordberg, 2016; Miller, 2004; Moore and Hirai, 2014; SSRC, 2018; Tiger, 2013). The observations and interviews confirm that the court knowledge of addiction as a disease, and the homogenous addict identity, replace the social and cultural factors that support recovery, thus underemphasising the participants' economic, social, and cultural needs in treatment. To illustrate this point, the following is an observation of the AODTC judge coercing a participant to place treatment over his job:

I am very concerned that your job is distracting you from your recovery. Treatment is at the heart of Phase 1 it is about attending AA and NA meetings, you should be attending at least one 12 steps meeting a day and attending drug testing... ${ }^{116}$

In this next part of the chapter, I illustrate how the AODTC treatment practices are undermining participants' treatment, health, and wellbeing. Specifically, the data demonstrates that court decision-making practices produce four negative outcomes, each of which create barriers to or undermine the health and wellbeing of the participants: (i) A lack of recognition of cultural services for Māori participants'; (ii) a lack of provisions for women and transgender participants; (iii) reducing the prospects of employment and financial stability for participants; and, (iv) treating participants' housing needs and their continuing contact with family/whānau as risks to recovery.

${ }^{116}$ AODTC observation November, 2013 


\section{Māori}

The AODTC was given impetus by the belief that Māori offending, and reoffending is driven to some extent by AOD addiction. My observations reveal that, during the eligibility process, the courts give weight to applicants identified as Māori, Māori represented approximately 70\% of the participants observed, and 14 of the 18 participants interviewed identified themselves as Māori. Between November 2012 and April 2016, the Ministry of Justice evaluations identified that Māori comprised $45 \%$ of the AODTC participant population, and $44 \%$ of the AODTC terminations (Litmus, 2016).

As discussed in Chapter 3, Māori have been historically disadvantaged by government policies and practices based on the stereotype of Māori deviancy, Māori as a threat to moral order, and as a danger to themselves (Mancall et al, 2000; McIntosh, 2005). Research confirms the importance of culturally based care, because the experiences of Māori are different to Pākehā (Durie, 2011; Huriwai, Robertson, Armstrong and Huata, 2001; Mihaere, 2015). Thus, reducing health inequality between Māori and non-Māori and working with the Treaty of Waitangi has been a longstanding aim of the Ministry of Health and Ministry of Justice (Durie, 2011; Mihaere, 2015). The Ministry of Health and District Health Boards have processes in place to ensure health inequity is addressed for Māori (National Committee for Addiction Treatment, 2012). In this regard, Mancall, et al (2000) argued that addiction treatment should emphasise tino rangatiratanga (self-determination), which is a useful way of encouraging Māori to take greater control for their treatment. However, as demonstrated in the previous chapter in the AODTC, Māori cultural identity is homogenised for the purposes of treatment, putting to question the role of self-determination in treatment.

When addressing the rights of Māori in the criminal justice system, Māori criminologists Mihaere (2015) and Tauri (2005) have demonstrated how the following processes have undermined Māori self-determination in the Pākehā criminal justice process:

- The Pākehā use of Māori cultural identity as an explanation for Māori offending.

- A lack of Māori involvement in the design of policy and the development of programmes.

- Māori providers are placed in a position of having to weaken their cultural approach to fit in with the dominant aims of the criminal justice system.

- Limited funding from the Crown towards Māori treatment providers.

- A tendency to incorporate tikanga within cognitive based therapeutic interventions, which in turn reduces the potency of Māori approaches to rehabilitation. 
Notably, Mihaere (2015) found that criminal justice rehabilitation programmes focussed on Māori are often developed under conditions that 'are not open to Māori peer review' (p.169). Rather, rehabilitative programmes are worked to address western principles and procedures, resulting in Māori culture being 'undermined and subjugated' (ibid). In this regard, individualised criminal justice rehabilitative programmes tend to overlook the impact of colonialism and racism on Māori offending, instead choosing to target Māori criminality and pathologising Māori offending. Given the AODTC construct of individualised treatment, AODTC Judge Tremewan claimed that 'cultural factors', 'are critical and will form a central part of the individualised treatment plan among the other supports offered' (2013:9-10). Presumably, one would then expect that the supports on offer encourage Māori providers and thus Māori cultural identity in treatment.

During fieldwork, the Te Ara Hou Alcohol \& Other Drug Residential Services ${ }^{117}$ programme was observed to provide limited support to some of the Māori participants. The Ministry of Health funding contract at the time of fieldwork (which I discuss below) however, does not cover nor describe the role of Te Ara Hou as an AODTC provider. Their involvement in the court is briefly described in the Formative Evaluation, as helping participants 'develop a strong sense of identity to replace negative criminal behaviour' (Litmus, 2014:78). In this context, the AODTC focus on Māori cultural identity is supported by the idea that Māori are more prone to criminal offending, supporting the pathologising of Māori offending (Mihaere, 2015).

Given the state's recognition of the Treaty of Waitangi, and its application in health care (as discussed above and in Chapter, 3), it is therefore questionable as to how the AODTC views the role of Te Ara Hou in the delivery of culturally based health care. Moreover, taking in the AODTC structure, it is questionable as to the extent in which the AODTC is intended to support the treatment of Māori in ways that uphold and address their social and cultural rights. Indeed, both the Process Evaluation and the Final Process Evaluation (Litmus, 2015; 2016) describe Te Ara Hou as not having a contract to provide services to the AODTC. Instead, Odyssey House is the contracted treatment service provider, with services subcontracted to Higher Ground and the Salvation Army Bridge Programme (Litmus, 2016. As such, any support for

\footnotetext{
117 Te Ara Hou is a Kaupapa Māori residential service that approaches treatment, recovery and rehabilitation from Te Toi o Matariki, known as an 'Awakening' therapeutic model. The model works on the concept that, one must understand who they are as individuals, then as Māori, then their cultural value base. Ownership of behaviours are realigned with the traditional Mãori philosophy of wellbeing.

According to Durie (2011), Māori wellbeing involves the individual taha wairua (spiritual health), whānau (family) hapu (sub-tribe) and taha hinengaro (mental health).
} 
addressing the social and cultural needs of Māori is subject to the standard conditions contained in the Odyssey House contract with the Ministry of Health, which to all intents and purposes, resembles the US DTC model (Ministry of Health, 2012).

My examination of the Odyssey House contract revealed that the service comprises an overarching aim to improve Māori health outcomes, and to reduce Māori health inequalities in consultation with Māori (Ministry of Health, 2012). Accordingly, the contract contains provisions and objectives to be met, such as removing barriers for Māori accessing treatment services, facilitating the involvement of whānau, the integration of Māori values, beliefs and cultural practices, the availability of Māori staff, and education and training of staff in Māori values, beliefs and cultural practices. However the AODTC Final Evaluation (2016) reported 'that not all AODT Court treatment providers have an in-house Māori cultural advisor', with one treatment provider 'using staff who identify as Māori on an as-needed basis' in order to ensure that 'the cultural needs to Māori are being met'(p.65).

As demonstrated in the previous chapter, the effects of the AODTC model are that Māori participants are forced to take on the values and beliefs of the court, the homogenous identity, and the abstinence-disease mandate. In this regard, Māori participants are not encouraged to take control of their treatment; instead, Māori participants are forced to internalise the western programme, adopt the 12 steps language, 'I have the disease of addiction' and take individual responsibility, which acts as a levelling process. The interviewees reveal that Māori participants are subject to discriminatory and culturally insensitive testing practices such as the taking of a hair follicle and observed urine samples. Those participants have conveyed how these court practices are intrusive and culturally disrespectful, resulting in them feeling challenged about their rights to autonomy, equality, and cultural identity. The observations and interviews with Māori court workers and court participants also indicate that the AODTC policy and decision-making practices undermine Māori health and wellbeing in a number of ways. Cultural identity has been co-opted into the AODTC mandate of individual responsibility, meaning that the court is counterproductive to self-determination for Māori (Mancall et al, 2000).

As discussed, as a matter of policy and practice, the court alienates Māori from their culture (Mihaere, 2015). During observations, a court worker told me that 'a karakia is essential because Màori are the reason as to why they opened this court up'. ${ }^{118}$ I felt concerned about

${ }^{118}$ AODTC observation, September 2013 
this approach to Māori culture because I witnessed the court open with a karakia on only two occasions over the seven months of fieldwork. The idea of addressing Māori criminality in this context means that Māori cultural values are cast as something for particular occasions only (Mihaere, 2015).

It also became clear to me that the court approach to Māori culture is primarily reliant on the opinions of the judiciary. To illustrate this point, on the occasion when I observed the Minster of Justice visit, the judge declined to allow a karakia. After court, the Māori representative pulled me aside to convey their disappointment:

My request to perform a karakia for the Minister was met by the judge's admonishment. I was very upset...I took my mokopuna up to Bastion Point and cried, and cried, my heart was aching because this court is about us, it is for us, they should be allowing us to have input into it. ${ }^{119}$

During observations, the customary and celebratory practices of a haka and waiata appeared to me to be utilised at the discretion of the judges, to give the impression that the court is facilitating the integration of Māori culture. An informal conversation with a Māori member of the court revealed that these approaches came across as suffocating for Māori, as conveyed by a community court worker:

The haka and waiata are tacked on, when you've got people in blue and in red it's almost as if you've got another gang arriving. We are still in the criminal court, this is an addition to New Zealand, it's got to come from our people, I don't think they're helping you know, please don't do this to our beautiful culture, I get very upset about this because we could do a much better job, it's not even tokenistic, it's gone beyond that. It leaves you with a heavy heart, people are leaving on a cloud that they are indestructible; half don't know what the meaning of haka [participants and judges] are saying. We need to come back to the land of New Zealand, not from the land of the USA, we do not need to be dictated to by white fellas. You can't critique it [the model], if you do, you get slammed, when practices are imported and placed over us, we often feel suffocated... ${ }^{120}$

\footnotetext{
${ }^{119}$ AODTC informal conversation, October 2013

${ }^{120}$ AODTC observation, December 2014
} 
Moreover, in order to make the AODTC culturally responsive, the 'Pou Oranga and judges' roles are seen as 'critical in normalising tikanga Māori in the court' (Litmus, 2016:70). Thom (2017) suggested that the incorporation of tikanga means the Pou Oranga provides therapeutic 'cultural expertise in a treatment setting, as well as extensive knowledge of addiction recovery' (p. 183). However, and in contrast, my observations reveal that the Pou Oranga role involves performing as an adjunct to the court by monitoring accountability and programme compliance.

Within the structural context, according to the AODTC Handbook, the Pou Oranga is responsible only for collaboration with Māori agencies and community services, matching services to participants' needs (Ministry of Justice, 2012a; 2014). A great degree of status is placed on the Pou Oranga when collaborating with the courts in managing Māori participants' treatment and recovery. During observations, the judge introduced the Pou Oranga to the court as 'the healing post', and both judges consulted with him on matters not related to the prescribed role. The following observations show that, as part of the healing process, the Pou Oranga instead acts as an agent of the court, monitoring participants' compliance and responsibility. In this context, the Pou Oranga does not act as a neutral arbiter when matching service to participants needs. I regularly witnessed the Pou Oranga engage in practices such as collaborating with the court to attribute blame and shame to the participants:

Pou Oranga: She'll admit it if you put it to her that she has shamed her whanau regardless of whether she did it or not....

The dangers of shaming the participants is that it could potentially lead to a false admission and imprisonment. During a court session, the Pou Oranga justifies a participant's status in remand in custody as treatment readiness:

Pou Oranga: I think you are in the best place at the moment leading up to your treatment; you are in the best place.

Judge: Right, we will see you in two weeks.

In another observation, the Pou Oranga issues a sanction of written work for a participant who has missed testing:

Pou Oranga: He's had a relationship breakdown and missed testing on Saturday, so I've asked him for a written account.

My observations reveal that the role of the Pou Oranga is opening the door for a new set of 'therapeutic' practices governing Māori as at risk, and the introduction of punishment as 
healing. The Pou Oranga is provided with oversight in meeting the aims of the court as underpinned by the AODTC knowledge of the homogenous addicted offender. This means that Māori participants are left with few options in order to meet the demands of the programme.

As discussed, Māori feel the burden of the court's homogenising processes. Those participants stated that they have had to endure patronising and culturally insensitive practices, which demonstrates how testing undermines their spiritual and psychological wellbeing despite the court's and providers' recognition of Māori health and wellbeing as a core priority. Thus, while Māori participants were willing to give the programme a go, they indicated that the court and treatment providers too often framed them as irresponsible and as criminal:

Marama: I wanted to do anything and everything to be in this court, and to recognise that I was an alcoholic. Well then, that was what I thought I needed to do, I accepted it in the beginning that I needed to do to be in this [the court], I have hated it heaps of times... I've always tried to turn it around to keep me on track, but they are always trying to make me an example to my whānau...

Manu: they [Odyssey House] don't see us as Māori, for us Māori they see us as criminals. Because we're in the courts, so they treat us differently.

The evidence above, and in the previous chapter, demonstrates how the AODTC treatment policy is inconsistent with the Ministry of Health promotion of improving Māori health outcomes, the reduction of Māori health inequalities in consultation with Māori and the removal of barriers for Māori in accessing treatment. The AODTC deployment of cultural identity is at the caprice of the judges and the Odyssey House agreement. The observations and interviews confirm that the facilitating of the involvement of whānau, the integration of Māori values, beliefs and cultural practices, are subject to the AODTC values and beliefs. It is clear that the dominant legal decision-making and court monitoring practices take precedence over the rights of Māori to self-determination in treatment and recovery. Compounding these issues is the problematic identification of Māori cultural identity through the Pākehā judicial lens, judicial values, an obsessive focus on Māori participants as at risk, and a lack of recognition of the ongoing effects of colonisation.

To summarise, the evidence is that the AODTC is disempowering Māori by undermining their social and cultural needs through the lack of Māori treatment services, and court practices dominated by a Pākehā understanding of the homogenous identity (Mikaere, 1990). In this way, the court structure hides the socio-cultural disadvantages experienced by Māori. 
The observations and interviews indicate that the barriers encountered by Māori are the result of the AODTC drafting a criminal justice process to 'treat' the pathology of Māori offending. In this context, the incorporation of Māori cultural practices are co-opted into the dominant US model in order to make the AODTC structure appear culturally appropriate (Tauri, 2005). There is also evidence that customary and celebratory cultural practices are undermined by every day court practices, and the involvement of the contracted treatment providers. Thus, the appropriation of elements of Māori cultural practice for the purposes of rehabilitation merely ensures that the AODTC is, on the face of it, seen as 'healing'. These findings suggest that incorporating tikanga into the dominant western therapeutic intervention represents a therapeutic approach based on an expansion of state power on Māori, reducing the effectiveness of Māori approaches to rehabilitation (Foucault in von Hirsch and Maher, 1992).

\section{Gender}

Barriers to treatment are evident in the gender-biased treatment of AODTC participants, who are situated within the dominant view of the good woman/mother, and prosocial man/father (Moore and Lyons, 2007). According to my observations, the governing of gender indicates that women in the AODTC are perceived as not conforming to the ideal good woman/mother stereotype and are therefore situated as doubly deviant and unfit. As discussed above, this is particularly evident for Māori women in particular. Men on the other hand are encouraged to focus on improving their prosocial skills for the sake of themselves and/or their families. An outcome of this process is that the AODTC 'therapeutic' decision-making process shifts the attention from a person's offending to their gender, thereby perpetuating gendered stereotypes of female offending, inequality, and exclusion from the programme (von Hirsch and Maher, 1992). An informal conversation with legal counsel confirms these issues:

Women in the court have a big battle... women in violent relationships are not for the court, they're considered too hard. Male participants don't get treated like this, there's a different standard for men in the court and I get bullied when I identify these issues. Women with a history of a number of partners are scrutinized, their relationship history is seen as a significant barrier to treatment, it doesn't happen to men, there's a different standard for $\operatorname{men}^{121}$.

The above comment also reflects how the court's underlying therapeutic ethos presumes that women require closer monitoring because they are not rational (von Hirsch and Maher, 1992);

${ }^{121}$ AODTC observation, December 2014 
accordingly, women are situated as risky to programme success. These double standards survive despite significant progress in recent years in identifying gender inequalities and differences in criminal justice policies, sentencing procedures, and treatment (Bentley, 2014; Carlen and Tombs, 2006; Kingi, 2009; Stanley, 2011).

Most of the women involved in the AODTC are typical of women imprisoned in New Zealand (Kingi, 2009). According to my observations, they tend to be poor, are single parents, and have extensive histories of mental health problems, sexual abuse, and repeat victimisation. In spite of this, the AODTC judges, treatment teams, and service providers regularly attribute women's behaviour to inadequate self-understanding of their addiction. As a result, women are subjected to pathologising and infantilising language, and are treated as being at risk to recovery. To illustrate this point, the following is an observation of the AODTC judge when measuring a female participant's potential for success in the programme:

Judge: She is extraordinarily damaged, history of neglect, violence and sex abuse... she says that she has been running her own 12 steps meetings in prison, therefore she should put her money where her mouth is, let us give her the chance that she's been looking for. These are my expectations, she actually has to prove that she can make it; she is released on the condition that the SCRAM is available, and, if she fails to turn up for the SCRAM then she has breached, she is exited. ${ }^{122}$

This position is upheld in court through the authoritarian and ambiguous framing of women as at risk (Hannah-Moffatt, 1999), whereby they cannot be 'distracted' by their relationships, mothering, and as shown in the previous chapter, through sex work.

My observations highlight a concern that women in the AODTC are judged as doubly deviant, especially those who have children. Because of their offending, these women are presumed to be putting their children at risk irrespective of whether they are in recovery or not. For example, if they have not lost custody of their children, they are expected to hand them over to their partner or relatives, reducing the importance of family/whānau engagement in and as support to recovery (which is discussed in more context below). The pregnant women observed are monitored closely by the court, and depending upon the level of risk the baby poses to their progress, these women are permitted to keep their babies once born, but only while under the care of residential treatment. However, it became apparent to me that regaining or maintaining access to their children is a common issue for women in the AODTC.

${ }^{122}$ AODTC observation, September, 2013 
The observations and the interviews reveal that motherhood provides an opportunity for the court to infantilise women, situating them as unfit, but potentially salvageable for the purposes of ensuring compliance in recovery. The following observation is typical of the court leveraging compliance through motherhood:

Judge: It is lovely to call this matter first, today Mabel you are 319 days sober and clean just remarkable.... A day out was not what you hoped for, what has come out of it for you?

Mabel: Just to be careful next time, in the early days I probably would have relapsed, it did not even cross my mind.

Judge: And Milo was with you?

Mabel: Yes, he was, but next time I'll call for support.

Judge: Did you have a phone with you; are you surprised you did not think about drinking and using?

Mabel: My little boy is keeping me clean.

Judge: I love the fact that you are so uncomplaining.... ${ }^{123}$

The AODTC's therapeutic paradigm, while viewing women as unfit, assumes that women can be coerced and punished through their children. This is a process that Chesney-Lind identifies as 'vengeful equity' (2006:17), whereby legal practices legitimise the oppression of gender identity. My observations and the interviews support this view and show that, in the AODTC, women perceived to be stepping outside the norm are seen as being out of control and a threat to the programme success. These findings are also in line with those found by Bentley (2014), Boyd (1999) and Gibson (2016) each of which discussed the dehumanising effects of treatment programmes involving coercion, and the differences in treatment care between men and women. I discuss the positioning of motherhood further in the section 'family/whānau', and present interview data demonstrating the barriers women encounter in maintaining contact with their children.

The AODTC's dominant interaction with male participants reveals that the courts support men to be 'prosocial' fathers and role models. This is illustrated in the following observations:

${ }^{123}$ AODTC observation November, 2013 
Judge: As you move into phase 3, it is about us supporting you to be the good father that you are... ${ }^{124}$

Judge: ... it is about making good relationships with your kids, having a father is very important. $^{125}$

However, the court focus on the men as taking responsibility through being a prosocial father means that some of the men felt it affected their treatment:

Monty:...I've just walked into my 2 youngest ones lives, my 12 and my 13 year old, they're going through a lot, my daughter was abused and my son, well they were both bought up in a dysfunctional family, so it's just compounded more, more pressure you know. One of the rewards of recovery is having my children you know, in their lives you know, but at the same time I'm dealing with all their stuff you know at the same time, and a couple of times its nearly taken my focus off recovery because of what's going on you know...

The AODTC's interpretation of risk to recovery also means that male participants in heterosexual relationships regularly find that their treatment is constituted according to the paternalistic view that women pose a threat to their male partner's autonomous care and recovery. That is, the onus for their treatment is informed by their partner's behaviour. Evidence of this process is illustrated in the following observation of a pre-court meeting where the judge and team members discuss a participant's progress in the context of his partner posing a risk to his recovery:

Counsel: It's difficult for his family he's confused, and she feels left out of his recovery, she's feeling isolated, I've suggested couples counselling, she's doing two jobs and is the main caregiver.

Judge: Wouldn't it be great if they could have a weekend without the kids.

Case manager: She's working two jobs and they have 3 kids we need to be mindful of her, she could sabotage his treatment recovery....

Counsel: She said she's feeling useless.

Case manager: I would really like Mara to build some resources because he is in recovery. ${ }^{126}$

${ }^{124}$ AODTC observation December, 2013

${ }^{125}$ AODTC observation October, 2013

${ }^{126}$ AODTC observation, December, 2013 
In another case, the judge is concerned that a participant's partner and family are going to jeopardise his phase application:

Judge: Melissa and her dad and those undesirables are keeping Marco busy. It is a very long time for him to be sober around Melissa, and we need to remind him of his priorities to the court, keeping up five meetings, a week... the biggest thing for him is to walk the talk and move forward to phase three. ${ }^{127}$

Thus, in a co-ordinated way, the court extends the scope of law and risk to include family relationships, and those not intended for treatment intervention and accountability. This process is particularly evident in the treatment of the transgender participants interviewed, despite the progress made in New Zealand law recognising the rights to freedom from discrimination (Human Rights Commission, 2008).

To date, there is no known current research on the treatment of transgender participants in DTCs. Further, there is very little known about the treatment experiences of transgender people who use drugs or use addiction treatment services (Lyons, Shannon, Pierre, Small, Krusi and Kerr, 2015). Often this is because transgender people are excluded from, or grouped with, sexual minority groups in research (ibid).

My observations of the treatment of transgender participants in the AODTC reveal that this group are more likely to encounter discrimination due to bias in the exercise of judicial discretion, and treatment practices constructed on subjective assessments of risk to programme success. During observations, the judges and treatment providers took a narrow-minded view toward transgender participants' status by frequently, and forcefully imposing the homogenous addict identity on these participants. For example, transwoman Mary's hair extensions are framed by the case manager as transferring her addiction, and the judge rationalises this as a treatment challenge:

Case manager: Anna at Higher Ground has issues with Mary's hair extensions and is going to ask to cut them off, she sees them as transferring Mary's addiction. Apparently, Mary remarked that she is fixated on her hair during a self-report, Jillian at Higher Ground is also concerned that she's fixated on them.

Judge: It's a treatment issue, I can see that Higher Ground is going to be a challenge for her... ${ }^{128}$

${ }^{127}$ AODTC observation, December, 2013

${ }^{128}$ AODTC observation December, 2013 
The case manager's view elevates Mary's gender status as being different and dangerous to the process of recovery, and the judge's response supports coercive threats and punishment in treatment. Essentially, the above observation confirms the production of transgender as doubly deviant, allowing transphobia and stigma to occur for transgender people in treatment (Lyons, et al, 2015).

When I interviewed Mary, she described how the court enforced the addict identity, in so doing undermining her transwoman identity:

Mary...they all know that I'm transwoman and they all know that through my relapsing... well they wanted to cut my hair extensions off because you know they saw my hair extensions as causing my relapsing

Toni: Who wanted to cut your hair?

Mary: The court and Higher Ground. I say if they're going to make a drug court then expect trans people to come in here you know, they got to be accepting than punishing...

Another transwoman 'Mel' revealed transphobia in treatment, also known as felt stigma (Lyons et al, 2015), by the treatment providers conveying the belief that her presence was a disturbance to the success of the programme. In making the following comment, Mel identified themes of rejection and stigma as barriers to her treatment:

Mel: When I heard that I was going to Odyssey I was really, really worried, just around the whole acceptance of being transgender and how people were going to take me and that, I was really quite shocked at how well they treated me at first, but, I don't think that they catered for me.... I don't think they accepted me...I warned them of my anger issues and tendencies when I arrived, I don't think they catered for those, it's a big thing for transgender girls to go into treatment or to seek help and kind of be put under the spotlight.

Unfortunately, the fear of treatment, and of differential treatment, resulted in Mel self-exiting the programme. The experiences of Mel and Mary reveal that procedurally the law is uncontested in treatment. That is, there is an evident lack of understanding between the court and treatment providers on the legal recognition for transgender people (Hull, 2016). Here, it can be said that the institutional power of the law in safeguarding these participants' rights is for the most, invisible (Silbey, 2005). These findings essentially illustrate transgender discrimination in the court (which I discuss further in the following chapter). 
According to my observations and interviews, women and transgender participants are treated as risky, lacking agency and responsibility, which suggests that, despite evidence-based policies and regardless of the fact that the judges involved are women themselves, and, despite the pronounced heterogeneity of participants, the AODTC oppresses gender through reductionist understandings of their lives (Chesney-Lind, 2006), rendering these participants as powerless. Accordingly, gender identity and participation in the treatment programme are shaped by legal and moral values of the judges and team members (Carlen and Tombs, 2006; Marshall and Barclay, 2003). For these reasons, rather than acting as an alternative to punishment, the AODTC transforms treatment into punishment.

\section{Employment and financial stability}

"Let me tell you that your job is to keep making gains, making tools because this court is like a full time job, for us your number one work priority is recovery...you don't get to work in prison either." AODTC judge ${ }^{129}$

Employment is identified in the AODTC Handbook as a requirement for successful graduation (Ministry of Justice, 2012a; 2014). In practice however, employment is regarded as something the participants are not ready for until they have gained a therapeutic self-understanding (McKim, 2008). Employment during mandated treatment is seen as undermining the court's goals of responsibilisation, recovery and self-care. Many of the participants are required to forgo employment for the purposes of treatment. This means giving up or losing a job due to the constraints imposed by the AODTC:

Mahaka: I'm a tradesman, I have to leave my job every week to come to court, they expect me to leave my job, by the time courts finished it's too late to head back...

Matt: I've had to put my job on hold to do the 90 day programme, I'm hoping that my boss will be willing to keep it for me...

Morgan: I worked when I first came in [to the court] but I lost my job because of this mainly because I was not there doing what I'm supposed to be doing you know...

Murray: Once again I've had to leave my tools on the job site today to come to court...it's been 3 hours, if my tools go missing I'm going to bill the court...

Miro: Apparently, I'm allowed back to work in phase 2, but they keep changing the goal posts, so who knows...

${ }^{129}$ AODTC observation December, 2013 
The prioritising of treatment over employment suggests that participants' employment status is subordinated to the court's concept of dangerousness to success. Therefore, any hope of positive engagement in employment is at the discretion of the AODTC. The participants interviewed relayed that leaving the security of their jobs to go onto a benefit contributes to financial insecurity:

Mikaere: They wanted me to go on a benefit so I could go into treatment, but instead of you know going yes I'll do it, I thought hang on, I'm going to go and find out about this. If I went on a benefit, I had to have a stand down period you know, so the information they gave me was not correct. So I had an argument with my case manager at the time, and I said you can't tell me to quit my job to do this you know, if you want me to do things you got to look at things around, so that I'm able to be at work, and be able to pay my bills. You just can't do it, you can't make me do this, you're making me go backwards a lot financially, but it's done that anyway...

Maru: ...they asked me to go on a benefit so I can go into to treatment, why should somebody who is working go onto a sickness benefit.

Matiu: ...you can't live on a fucken sickness benefit, I've never lived on a fucken sickness benefit or the dole you know and that turns you back to crime you know, what I mean is easy money you know, yeah the financial side, it's fucked. I've never ever lived on the fucken benefit you know, well that's just me I suppose, but I mean even out of this, not in recovery or anything you know, it's fucked, I couldn't give a fuck about the benefit you know...

Morris: I get 73.00 a week from the WINZ office, I am not allowed to work, so out of that 73.00 every month the bank takes 20.00 for bank charges so fundamentally it halved the house income...

Myles:... at the end of the week, once the department of courts has taken my fines out, I'm left with about 70 cents, and I'm supposed to catch buses and everything and the court has come back to me and said give us a budget. I said a budget of what, what am I going to give you a budget of, I can't even buy a bag of lollies with that....

Participants related how the treatment providers withheld their benefit while they were in residential treatment:

Monty: ... when we are in residential treatment they take our benefit but when we're out you know in the real world; we get our benefit.

Matt: In residential they allow you 60.00 a week, still that's not much at all. I spend over 30.00 on Tuesday getting to testing and one meeting out of my own pocket and I'm on the 
benefit. I'm not rich, and they've got their testing on Dominion road, we're a west Auckland based thing, and I mean it's all the way in central and for us to be living in west Auckland in the Waitakere court and have to travel all the way into central, it takes up a good few hours of my day, just on public transport, let alone the money and everything else...

Participants who exited the court programme repeatedly cited the prioritising of recovery over employment and financial hardship as the reasons for exiting. This is particularly problematic given the generalised view that finding employment is something that may reduce the risk of reoffending (Ministry of Justice, 2014), and highlights an issue with the fit of the AODTC in the criminal justice process:

Mahaka: I was in the drug court for 11 months. I got a letter from my boss saying that I was going to be getting a supervisory role in my job, you know that's a big step, that's a big income rise but no, they wouldn't allow me to take the position. So I exited, because the pressure was too much. I couldn't do everything you know, there's not enough time in the day, and your employment is what keeps your family going and they don't get it.

Miro: ...I had a relapse and during that relapse, they put me back into detox for a week, and while I was there, I was offered a job. I come to court, and they said no you can't work, because you know the times not right and I said you know, the best thing for me is to go to work. That's what I feel, but they think they know better you know, I don't understand it, I think if someone is working, fuck, if someone can get a fucking job which is hard to get, cos the things I slip back on are financially you know...

The interviews illustrate how the AODTC approach to relapse prevention forces the participants to place recovery before employment, leaving many of them to deal with the daily reality of economic hardship on top of meeting the many programme requirements.

The approach by the court does not appear to factor in that employment is a protective factor to the risk of reoffending. The interviews in fact demonstrate that there is very little fairness in the court (Boldt, 2009), because the legal decision-making processes are focussed on the goal of abstinence over and above the participants' employment and financial stability. As a result, the systematic difficulties faced by participants in maintaining employment are exacerbated by their involvement in the AODTC.

\section{Mandated housing}

The AODTC mandated housing is problematic, yet unsurprising given that bail conditions allocate participants to a specific residential address or remand for the purposes of treatment. 
As shown in the previous chapter, this is a process informed by the judges' understanding of the AODTC eligibility criteria:

Judge: A stable address is going to affect treatment; entry is subject to accommodation Counsel could you present it to him that there is a place subject to finding an address. ${ }^{130}$

Those participants accepted into the AODTC programme are regularly compelled into mandated housing. Those participants who are homeless, or do not have suitable housing are required to find one, unaided. For them, mandated housing represents a loss in income, and a reduced capacity to pay rent because they are required to enter residential treatment, it encourages relapse, and when suitable mandated housing is not available, lengthy periods in remand on bail. I discuss this further in the next chapter.

My in-court and out of court observations reveal that housing is undermined by ineffective judicial decision-making. For instance, an AODTC judge, knowing the potential risks to a participant's wellbeing, considers the impact of placing this participant in a transient lodge: 'Matthew does well in treatment, but the danger time is in Sandringham lodge'131. Whilst the judge acknowledges the dangers involved in AODTC lodging, it is the participant who is held responsible for their own care, and where irresponsibility is met with punishment.

Evidence of the dangers associated with mandated lodging was revealed through observations and informal conversations with legal counsel and a policy analyst, and interviews with participants. These highlight the precarious nature of court mandated, substandard lodging, and the extent to which it is failing participants. For instance, during observations I was approached by Counsel who suggested that I 'go and take a look at Epsom Lodge'. Counsel pointed out

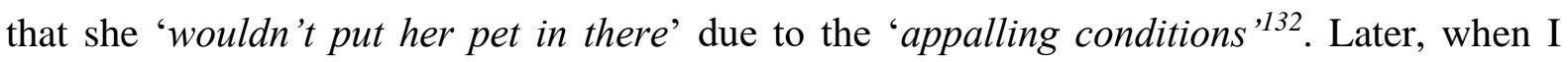
discussed the AODTC's use of transient accommodation with a policy analyst, the response was that they knew about the 'Epsom Lodge use, but it is not being used now'. Contradicting this claim, participants interviewed 9 months later confirmed the AODTC's continued use of Epsom Lodge and other transient housing.

The participants relayed stories of substandard conditions affecting their dignity, health, mental wellbeing, finances, and their ability to maintain the courts' requirement of staying clean and in recovery:

\footnotetext{
${ }^{130}$ AODTC observation October, 2013

${ }^{131}$ AODTC observation September, 2013

${ }^{132}$ AODTC observation October, 2013
} 
Morgan: ... I'm going into residential treatment really cos as dangerous as the place is for an alcoholic and drug addict its substandard living wise. The conditions are quite grubby, communal kitchen, communal bathrooms. The people there are into drugs or alcohol, there's young pregnant mothers you know, it's not a very comfortable place to live. I just go there to watch t.v. and go to bed basically.

Murray: I've been staying in a boarding lodge which is an old house in Western Springs you'd be hard pressed to put a dog in there and they're charging me over 200.00 out of my benefit, I only get 230.00 a week. I'm now going to Ewington Ave next week where I'll get a cot and 3 pots and a clean room to sleep in which will be a lot more conducive to my recovery. What I'm talking about is, allow me to hold onto a little bit of dignity cos even in prison I would have a cleaner and better room albeit with bars on it...

Monty: The first Lodge [Epsom] I went into was absolutely shocking like the people there, they weren't willing to help like too caught up in their own shit to help...

Because of the problematic nature of the mandated housing, many of the participants felt excluded from fair and safe treatment. They expressed feelings of confusion as to why the onus for accommodation rested upon them, why the AODTC is reluctant to support their accommodation needs. The following interviews are common examples of complaints conveyed to me of the court's inability to provide accommodation that supports their recovery:

Myles: I'm staying at Epsom Lodge at the moment... they take all my subsidies. I was better off at my girlfriend's place, but they [the judge and team] say to me, you know you're safer at Epsom Lodge it's better there, and yet, there's a lot of drinking of alcohol and dope smokers there. So I leave there in the morning and go do my programmes and come back late at night so I don't have to face it...

Maru: I chose to go to Te Ara Hou to face my addictions to get to know more about my Māori identity you know, in fact, my case manager encouraged me to do it, and I thought it would help me. But no, they took me out and put me into custody and then the Bridge programme, because the judge didn't think I was in touch with her programme you know...

The participants' experiences of the AODTC approach to housing confirms that this process entails decision-making prescribed as part of court bail conditions (Cowan, 2004). However, in practice, the mandating of housing results in a loss of financial security, substandard and inappropriate accommodation, psychological isolation, punishment, and the undermining of cultural connections. All of these factors escalate the risk of relapse for participants. Essentially, these AODTC practices are an example of legal decisions and governing practices 
that are undermining the participants' rights to dignity, wellbeing, and humane conditions in treatment (all of which I discuss this further in the following chapters).

\section{Family/whānau}

'There is also a focus on family/whanau in these courts. Participants come from a familial context and that must be taken into account. There are significant benefits in a family feeling included. In some cases, bridges have previously been burnt and can be rebuilt. In other cases, partners or other family members have their own AOD issues and can be encouraged to address these too' (AODTC Judge Tremewan, 2013:10).

Instrumentally, the AODTC Handbook outlines how a participant's 'family/whānau' has 'an important role to play' in the programme (Ministry of Justice, 2012a; 2014). Yet, my data indicates that the role of family/whānau in the court is subject to the judges and treatment team members' values and beliefs around gender, risk, and accountability in that, participants' relationships are frequently seen as jeopardising treatment success. Rather than focussing on family as a means of encouraging participation, supporting and addressing participants' wellbeing, (as described above by Judge Tremewan, 2013), the court decision-making practices instead coerce participants to prioritise treatment over family. This is illustrated in the following observation:

Judge: Tell us how your first few days have been at Higher Ground?

Matthew: I'm taking it one day at a time, I've got to learn to take it slowly because it's tough being away from my family. I only get to see them on the weekend.

Judge: Well the truth is, people do not get to see their family that much when they are in prison.

Matthew: They're constantly on my mind...

Judge: O.k. what are the challenges for you? ${ }^{133}$

The judge's attitude towards participants with children supports the belief that these participants are irresponsible, thus they require coercion to ensure that they take responsibility above all else, even when it is evident that families are dependent on participants for their own wellbeing. In these instances, many of the male participants are financially and emotionally responsible for children, but have experienced hopelessness, revealing that their involvement in the AODTC has negatively impacted on their wellbeing and that of their families:

${ }^{133}$ AODTC observation September, 2013 
Maru: ...they put you through all this treatment, but they don't acknowledge the stress it puts the family on you know, and this is meant to be a family oriented court...

Mikaere: I can't change coming into this court...I did what I thought was right for me and my family, but I don't think the court sees it like that you know...

Mahaka: ...the only problem is my family are struggling while I'm doing it. But they'd be struggling anyway if I was in prison, so you know...

Monty: I put the court first for so long, and that sort of now it's got to be them [family] you know ... I should have just gone to jail and done the nine months or the year in jail. I would have been out by now you know, I wouldn't have seen my son I probably would have lost contact with him, but I've pretty much have done that anyway you know, that's the way I think, cos at the end of the day, the drug court is just putting another strain on my relationship.

Myles: What stresses me is making me drag my partner through the court, even though she's only been here 4 times. But it's all the stuff I've had to do, and I go to AA meetings and that didn't help me, and not looking after my son, and not being able to go to family meeting because I got drug testing...

Miro: ...the hard parts are the pressures of how to survive the court and how much it has affected my family you know, especially my missus and my daughter you know, they're the main ones you know, I fucken turned their worlds upside down you know...

Morgan: I think the courts are a good idea, but I actually think that they need to put it on hold and rethink it you know, I really do. I think they've probably destroyed more than one relationship out of this you know, mines one to think of, which many times been past the point of breaking you know, 3 or 4 times you know, so till they actually say that this is to keep the family together, this is what they said it was for, they should stop and rethink it, and come up with better ideas you know. Better solutions they're doing something, but they're doing more damage than good.

Similarly, the women interviewed spoke about how the courts prioritise treatment over familial responsibilities and connection, mostly because the women were perceived as deviant and thus not to be trusted to care for themselves and their families. The interviews below confirm how the court's treatment processes force many of the women to internalise marginalisation and stigma (Lyons et al, 2015), which then manifests in feelings of futility and disconnection with their family: 
Makareta: I came into the drug court so I could get my son back, but I got exited from Higher Ground into remand, they [judge and team] wouldn't let me see him until they could find me another treatment place then it was up to them when I could see him after that...

Marama: In Odyssey, there's a lot of pressure to be a good mother, on top of everything else in the court I couldn't do it I had to exit...

Maggie: They [the judge and team] made it that I can't have baby without my partner or a family member present, when I go into Odyssey they'll supervise baby's visits I was sort of hoping to have him in there cos I'll be living there...

The AODTC assessment of participants' responsibility is a subjective process, supported by the court construct of the homogenous addict identity. The observations and interviews reveal that the greater a participant's commitment to their family, the more barriers the courts impose. Despite the AODTC Handbook (Ministry of Justice, 2012a; 2014) recognition of family involvement in the programme, the participants' accounts reveal that maintaining positive contact with family is a burdensome task. This process is particularly difficult for those participants with children, in particular women, because as detailed above they are treated at greater risk of relapse.

In the interviews in this chapter and Chapter 5, the participants conveyed that it is the judges who hold the power in treatment. Accordingly, the participants' perceptions of powerlessness in treatment are compounded by procedural uncertainty and the court's inability to provide evidence based treatment (Harding, 2010). The discrimination that the participants encounter as part of their treatment is credited to the AODTC abstinence-disease policy, the judges' and teams' values and decision-making reinforced by the responsibility mandate. This form of mandated treatment is, at best, described as providing a culture of contradiction and failure, rather than an investment in the governing of addiction treatment.

More importantly, the environment within which the AODTC emerged (as discussed in Chapter 4), and the targeting the treatment of AOD related offending through abstinence as a goal, reinforces the court's focus on the conflation of treatment with punishment (Garland, 2014; Harding, 2010; Silbey, 2005). It has been shown through the observations, document analysis and interviews that the court decision-making practices are overwhelmingly focussed on upholding the belief that the participants have a disease, all the while focussing on enforcing accountability for abstinence and their recovery. 
The participants' stories illustrate how the AODTC fails to provide treatment free from coercion and discrimination. In this context, the evidence speaks of the court as influencing and reframing the treatment of addiction. Many of the participants conveyed the basic desire to survive in the court programme. In this respect, they felt that the court provisions of mandated housing, testing, family connections, and employment created barriers and undermined their right to safety and security in treatment. In these respects, the law is not present in maintaining their autonomy and rights. Rather, they questioned the coercive use of the law and the punitive practices that encompassed their treatment. Their experiences convey how the court therapeutic process is hypocritical and contradictory, constituting them as having a disease, but also as dishonest and holding them accountable for not using the ambiguous tools of the court. All of these processes are creating barriers by excluding the participants from treatment and thus perpetuating further injustice. These findings raise important questions around the legal recognition of Māori, gender equality, relationships, and employment in treatment.

As discussed in Chapter 3, the rights of the participants to treatment free from coercion are recognised under international human rights law and other domestic legal instruments (Human Rights Commission, 2008; 2010). When taken together, I argue there is a strong case for an inquiry into the nature and extent of discrimination in the AODTC setting.

\section{Conclusion}

This chapter has demonstrated that the AODTC approach to recovery involves an array of contradictory and inconsistent practices stemming from the courts' focus on the responsible, but irresponsible participant. The implications are that the court overlooks a host of structural factors that result from an uncritical acceptance of the idea that addiction is a disease and a choice, and from the elevation of abstinence as the goal of recovery over important protective factors including employment and family. In combination, these assumptions and practices undermine the chances of recovery and programme success.

In order for participants to complete the AODTC programme and to become better citizens, the AODTC employs the subjective 12 Steps model of AA and NA based on the assumption that addiction is a disease, a requirement, and is a measurement of abstinence and success. These processes further invoke responsibility upon the participants to use the AODTC tools of treatment. However, court constituted responsibility does not transform the addict from criminal to responsible citizen, lead to success, or even progress in recovery. Success and 
progress in AODTC recovery are ambiguously and uncertainly defined, and are subject to judicial coercion.

There are serious questions as to what extent AODTC progress is determined by clinical treatment, the role of informed consent in treatment, and participants' autonomy in the programme. My observations of AODTC practices, along with interviews with court participants highlight an element of doubt, and very little convergence between the AODTC Handbook (Ministry of Justice, 2012a; 2014) and actual court practices on the meaning of participants' treatment, health and wellbeing. The participants' interviews confirm this.

The interviews make clear that the participants' experiences are based upon the courts formal and informal rules that target individual responsibility and accountability in governing 'treatment' (Levine and Mellema, 2001). Accordingly, their experiences of the programme are determined by a court understanding of law that prefers a punitive, incapacitating approach to treatment (Young, 2009). In all cases, participation in the programme is so entwined with the AODTC's understanding of addiction being a disease and participants as inherently dishonest, that the participants' status was further devalued. The inability of the AODTC to recognise the wider impact has been identified by Ministry of Justice evaluators in various treatment areas, such as 'community-based treatments with accommodation options', 'residential treatment options for participants with children, and treatment programmes dedicated to women and of specific cultural groups (Litmus, 2014; Litmus, 2016).

AODTC recovery built on abstinence and accountability means that the courts have undermined opportunities for the participants to engage in clinical treatment and support. Without evidence-based healthcare, the right support for wellbeing, employment, or housing, many of the AODTC participants suffer a terrible breakdown in the social and cultural networks that could support their recovery. These findings support Miller's (2009) characterisation of the DTC model as encompassing:

... a political decision to promote a treatment model that requires the drug offender to take personal responsibility for circumstances the state has, if not created, then deliberately exacerbated (p.116).

I argue that AODTC recovery, as governed through coercion and threats of imprisonment, abstinence, ambiguous tools, and standards of progress, results in 'treatment' practices having a direct and detrimental effect on the participants. In the following chapter, I build on the 
problematic features of the court in order to describe how the AODTC punishes under the guise of treatment, by merging treatment with punishment. 


\section{Chapter 7: Punishment under the Guise of Treatment in the Alcohol and Other Drug Treatment Court}

\section{Introduction}

In this chapter, I demonstrate how the AODTC merges treatment with punishment (Boldt, 2009). In the previous chapters, I have shown that there are tensions in the AODTC assumptions of addiction related offending, disease, choice, and offender accountability. Underpinning these tensions are the judges and team members applying their subjective understandings of addiction related offending and individual risk to treatment and recovery. As a result, the AODTC participants encounter coerced treatment that is burdensome and does not protect their rights.

The chapter is divided into two Parts. The first outlines how the AODTC provides the context for the transformation of the judicial role from an objective one to a subjective one (Burns and Peyrot, 2008). I show how as heads of the treatment teams, the judges are not constrained in their power and decision-making in treatment. In this context, I demonstrate that the judges act as 'amateur psychiatrists' through unfettered discretion and in so doing use ambiguous tools to enforce treatment (Hoffman, 2002:2088). As a result, the programme has been made inconsistent and unsafe for participants.

I demonstrate how the power of AODTC treatment providers extends well beyond treatment and healthcare to include the administration of AODTC punishment. These practices have caused the participants to be subject to punitive punishment while in residential treatment. Importantly, this part of the chapter illustrates how the participants cope with receiving treatment that is not consistent with clinical evidence-based practice.

In the second Part, I describe the AODTC's application of 'therapeutic punishment', which includes mandated AOD testing and SCRAM monitoring as mechanisms of 'therapeutic surveillance'. I describe how, in practice, these procedures and mechanisms are used in a punitive fashion to monitor, coerce and motivate participants towards the courts' goals of recovery. Because of this punitive approach to treatment, I argue that the AODTC is imposing unjustifiable punishment and is causing harm for the participants through the inappropriate and disproportionate use of sanctions, which are utilised to enforce compliance. 


\section{Transforming judicial authority}

The institutionalisation of the DTC transforms the role of the judge from an independent arbiter to that of a 'hands-on judiciary' (Goldkamp, 2000:927) who is actively involved in the 'therapeutic management' of participants (Hoffman, 2000). That is, through their authority, the judges can make decisions on a participant's treatment and punishment as they pursue the reduction of AOD related offending (Burns and Peyrot, 2008). However, the informality of the DTC problem-solving undermines judicial impartiality, due process and procedural fairness in the 'cultural practice' of TJ (Castellano, 2011:962; Hoffman, 2000; Miller, 2004; Nolan, 2003).

As illustrated in the previous chapters, the AODTC practices supported by TJ and 'therapeutic' interventions have changed the judicial role in a way that is unprecedented in the adult criminal courts. In such instances, the informal values and rules that constitute the AODTC structure and the judicial role, influence eligibility and progress and promote confusion over the requirements of the treatment programme. As a result, the judges have become self-styled therapists perceiving AOD related offending as a symptom of disease while targeting offender accountability, casting doubt on the judicial role in monitoring addiction treatment.

In this section, I describe how the judges understanding of the DTC model is undermining procedural fairness and protections for the participants (Boldt, 2009; von Hirsch and Maher, 1992), which raises important questions about the wisdom of using the US model as a guide for the AODTC. I argue that the participants' rights to treatment are being undermined.

The AODTC Handbook (2012a, 2014) makes it clear that the judges' role involves "presiding over the court sitting to deliver the co-ordinated response to the participant in the court room in a manner that demonstrates appropriate therapeutic techniques" (p.6). Important points emerging from my research are that, the role the judges enjoy provides them with numerous opportunities to become actively involved in the treatment, to interpret eligibility, to impose punishment conditions according to their individual beliefs of addiction related offending, and their biased view of a participant's moral character.

During observations, it was apparent that the judges' values and beliefs influence what information comes before the court. The judges also controlled legal counsel, limiting counsel's advice to their client as to the requirements and consequences of the court programme. Defence counsel communicated to me out of court that: 'I want to make it clear 
that my level of independence in the court is confined by what Lisa [the judge] says' ${ }^{134}$ The consequences as indicated in Chapter's 5 and 6 are that legal counsel are constrained in representing their clients' interests, and in limiting the coercive power of the law (Boldt, 1998). Indeed, the judge made problem-solving element of the court means that the judges have unconstrained power to use the coercive power of the law to transform the participants' lives (Boldt, 2009; Colyer, 2000). The observations and interviews demonstrate that the judges tend to search for, and focus on, participants' character, and either disregard or downplay clinical evidence of an addiction and clinical treatment that challenges their beliefs of participant responsibility. I argue that these dynamics are dangerously selective of the DTC diseasechoice-responsibility mandate (Miller, 2009).

As revealed in Chapters 5 and 6, at the forefront of their authority the judges utilise various ambiguous tools to coerce participation, to monitor compliance, and to deter participants from engaging in risky behaviours. The observations and interviews confirm that the accountability policy has created numerous opportunities for the judges to exercise their individual beliefs of the dishonest criminal addict and abstinence in order to ensure that participants and their families are held responsible for recovery. As demonstrated in an interview with Matiu (who had been in the programme for 19 months), the judicial role is far from therapeutic, and it involves coercion, blame, and burden:

Matiu: Fuck, I hate to say it, but I never fucken talk to judges like the way I talk to her you know, and they fucken know it. She tells me you know that I keep on shitting on them, and it makes me feel bad you know what I mean. I'm trying. I'm trying to fucken put things right you know, and for me, I started this whole fucken thing just to get out of jail and then I thought about you know my kids and shit like that, so I made that a goal and then other things get piled on top you know...

The judges are not health professionals and health professionals are not judges (Nolan, 2003). However, the conflation of 'therapeutic interventions' with punishment permits the judges to apply the 'disease-abstinence-accountability' mandate to bail conditions and treatment, permitting them to speak of treatment as punishment (Hoffman, 2002). As illustrated in Chapters 5 and 6 , the effects of the personal input of the judges, is that they are altering the eligibility criteria on paper and in practice. They are deciding whether a participant has an addiction or not, in some cases accepting people into the programme that do not have an

${ }^{134}$ AODTC informal conversation, September 2013 
addiction. They are attributing disease to choice, sending people to prison for minor programme infractions and keeping people in custody for being dishonest, leading to repeated contact with the criminal justice system. Thus through their authority, the judges are actively transforming their role through individual values, beliefs, likes, and dislikes (Hoffman, 2002). I argue that these processes reinforce the extent to which the AODTC is predicated on its US equivalent, and the archaic idea of AOD offending as driven by disease.

Of concern is that the AODTC receives the regular guidance of US DTC retired Judge Peggy Hora (Litmus, 2014). Judge Hora uses the court proceedings to further advance the DTC model and the moral language associated with the disease-crime-responsibility dichotomy. The effect of her guidance is the reinforcement of an antiquated view of addicts as 'sick' and of offending as symptomatic of disease. This process is demonstrated during an observation of Judge Hora's fifth visit to the AODTC in December 2013:

AODTC Judge: Judge Hora is there anything you would like to add?

Judge Hora: There are some universal truths you are only as sick as your secrets.

AODTC Judge: Perfect, thank you Judge Hora you are only as sick as your secret.

Judge Hora's involvement changes the way the court perceives addiction related offending:

Judge Hora: I see before me a nice family guy, but what I see in the booking photo, I see whoa a mass murderer...

The above observations also demonstrate how the courtroom is transformed according to dubious legal beliefs that pathologise offending to disease (Nolan, 2003, von Hirsch and Maher, 1992).

In addition to Judge Hora's visits, the AODTC judges extend their knowledge of US best practices and principles through regular guidance involving Skype and email contact with the leading doyens of the US National Association of Drug Court Professionals, Douglas Marlowe, and Shannon Carey. According to my observations, in those instances when the AODTC judges are challenged on the grounds of proportionality and fairmindedness, they justify their decisions on the basis that they operate in accordance with the US best practices and principles. The consequences are that the participants felt humiliated because there was no opportunity for them to seek redress over court procedures. The quote from Makareta, confirms the AODTC justifies its legitimacy on the basis that the over-simplified defence that US DTCs are effective: 
Makareta...I wanted a defended hearing over the SCRAM because it was spiking when I wasn't actually drinking... but they were saying, we've had people over in America doing all these things so if you're going to go ahead with it then well, all the drug court professionals are going to come over from America for the hearing...

Supported by a largely unchecked environment, the judges, in determining responsibility have often made the programme unfair and oppressive.

Even though the purpose of treatment is to address reoffending, the requirement to comply with honesty is the 'number one priority' of the court, which means the accountability mandate takes preference in decision-making. So if participants are perceived by the judges' to be dishonest, then custody is used as a form of shock treatment to enforce the programme requirements. For example, 'Mac' has been in the programme for 43 days, but has been remanded into custody for 'two relapses'. The first is methamphetamine use, and the second involves consensual sexual intercourse with another participant while at Higher Ground residential treatment. During the pre-court meeting, the judge weighs up how Mac is 'all smoke and mirrors', but because he has breached the honesty policy and clean time, she will need' to go hard on that':

Judge: ...Well this is a breach of honesty and I need to go hard on that, it's important to be open and honest and he needs to test clean, Mac needs to be fronted on the honesty issue. ${ }^{135}$

In court, the judge weighs up his release from custody according to his ability to be honest:

Judge: ...the way I look at it is I still think custody for another two weeks.

Mac: I did mess up, I did learn from it.

Judge: Are you wanting to make a bail application now, because my recollection is what happened last time is that we held you in custody until your weekend out promise to go to activities we thought this looks really good.... Well you just went out and used, it was the opposite... I'm not trying to rub your face in it... I respect the way you took it when we gave it to you... I'm actually feeling really positive... it's not actually about Mac it's about Mac's addiction... so in terms of the application what's your bail proposal?

Mac: I'm happy to go on 24 hrs bail.

Judge: I can tell you without any shadow of doubt that there's absolutely no way that I'm going to bail you. ${ }^{136}$

${ }^{135}$ AODTC observation October, 2013

${ }^{136}$ AODTC observation, October, 2013 
Three weeks later, I observed Mac was still in custody.

According to my observations, the judges' are motivated by a participants ability to be honest and compliant with the programme, thus, judicial discretion determined the level of treatment and punishment participants received. For those participants perceived to be dishonest or noncompliant, the deterrent and retributive approaches determined treatment (This process I discuss further below in the sections 'therapeutic punishment' and 'therapeutic remands').

Influenced by the DTC model the AODTC judges are introducing a problem-solving mandate targeting AOD offending and new punishment techniques masquerading as treatment. The power afforded to the judges has allowed them to take on treatment decisions and utilise the power of the criminal justice system to impose punishments for acts that would not normally be punishable in a court, when potentially no criminal offence has been committed. Put simply, when it comes to following procedure, a little knowledge of addiction and treatment is a dangerous thing in the hands of the judiciary (Young, 2009).

\section{Judicial discretion}

According to Boldt, a consequence of the informality of the DTC process is that it legitimises an 'ungovernable discretion' resembling 'rehabilitative punishment' (1998:1263). Accordingly, the degree of discretion that characterises the judicial decision-making in the DTC adds to the programme's 'procedural and substantive risks' (Boldt, 2009:24). As illustrated, the AODTC judges enjoy wide discretion to make crucial decisions with respect to participants' treatment and punishment. As a result, the judges make normative assessments hanging addiction onto responsibility and accountability and, because of their wide discretion in treatment, there is disconnect between court procedure and participants rights. Through their authority and influence, the judges are responsible for the cultural production of law in the AODTC (Silbey, 2005; Young, 2009).

According to my research, if a participant commits an offence whilst on the programme, the judges' decisions tend to be subjective, based upon their understanding of participant motivation to become abstinent, rather than on the programme requirements or legal standards. The consequences are that, under the discretion made available to them, the judges bring a more coercive power to the AODTC. Therefore, unlike the traditional courts' process, the judges are involving themselves in the rehabilitative arena in ways that provide the opportunity for punitive governance that is subjective (von Hirsch and Maher, 1992). 
I observed how through the therapeutic mandate, the judges operate and make decisions not always according to the rules and programme requirements, but use their discretion to make decisions on the basis of their individual beliefs and perceptions of the US DTC model. This leads to inconsistency, a great degree of unpredictability, and unfairness for participants who have committed further offending. It is within this context that I argue the effect of AODTC judicial discretion raises issues around certainty and consistency. Illustrating the very uncertainty of the AODTC judges' decision-making, the following observations are of participants who have committed further offending whilst on the programme. Each participant has been charged with male assaults female, and both have entered guilty pleas. In the second case, the participant also threatened to kill his partner. In each case, each AODTC judge considers the role of motivation in the treatment programme when weighing up the process of accountability.

Manzo is 10 months into the AODTC programme and is charged with two counts of male assaults female. The judge addresses his offending according to her knowledge of risk and his success in the programme, rather than on the required treatment:

Counsel: His partner is pregnant and due in December, I request the AODTC to help break the cycle, where does the balance lie in the wider public interest factor. The key point is that Mr M get help, he's been on intensive supervision in the court since November 2012 and he hasn't had the right treatment and is under extreme financial hardship.

Judge: Manzo you need treatment; however, it is not appropriate to remain in this court. You need help. There are two concerning issues: the first is the nature of the offending. I know that you were drunk when you assaulted another person. The second is the evidence is that it is getting more serious, offending on bail is very serious, because of the serious nature and as to why, it is not appropriate for you to stay. I am concerned the effect of your offending has on treatment. I am very sorry I have had to make that decision, the AODTC is not the end you can get treatment in prison. ${ }^{137}$

Miro is 29 weeks into the AODTC programme and is charged with two counts of male assaults female and threatening to kill. The judge addresses his offending according to her understanding of information received from his response to treatment, weighing up whether he remains in the court:

${ }^{137}$ AODTC observation September, 2013 
Judge: We need to go over a similar process to the Family Violence Court, so today is going to be treated as an exit hearing, although we're not going to exit him today. He's going to stay in the court, we're going to continue working with him and work around his partner.

Police: We're uncomfortable with him having contact with her as she is the victim.

Counsel: ...He's going to apply for an amendment to bail conditions and with consent not to go near the home address. Although I'm wondering if it's entirely necessary if he's invited there.

Judge: ...I acknowledge significant progress and good reports that he's going well, but clearly you're not doing that well.... The court has to consider whether you should be exited today because of new charges in making that decision we're taking into account your progress... try to put right what you can... for a better future we understand that there's been a lot of pressure on you but that's not an excuse, it's important not to feel sorry for yourself it's easy to go on the pity pot the poor me's... There will be accountability... It's actually not just about you... so it has to be sorted simple as that O.K.:

Miro... To be honest the curfew has hindered my ability to go to meetings.

Judge: We'll also allow you contact with your wife if she allows that. What would you like to say?

Miro: I appreciate the opportunity once again. I consider myself very lucky considering the charges.

Judge: There is a lesson here to take on board, just be mindful of the bail conditions. ${ }^{138}$

The above examples reveal that the judges are problematising the behaviours of these men, on their intuitive understanding of motivation, commitment, and treatment success. Thereby determining the participant's progress (Burns and Peyrot, 2003). These forms of decisionmaking are also troubling, because in the context of providing procedural safeguards and upholding the rights of the participants (Boldt, 2009), the AODTC approach illustrates a lack of certainty in the programme requirements, and a lack of consistency in judicial decisionmaking in the application of those requirements. The above observations illustrate how the judges are extending the boundaries of the court jurisdiction through their discretionary judgements and the imposition of punishment (Colyer, 2007; Tiger, 2011).

${ }^{138}$ AODTC observation November, 2013 
The AODTC judges' discretion is accommodated by the new roles the judges occupy. The legitimacy of this process rests upon the adoption of the DTC model. My findings show that the judges' individual interpretations of 'addiction' and their interference in treatment decisionmaking have created inconsistency and the foundation for treatment based on punitive goals and failure for many of the participants. I argue that, with no template other than the US DTC model, and the guidance of a retired US judge and US DTC doyens, the AODTC threatens to undermine the legitimacy of the New Zealand judiciary through a very different set of judicial values and standards.

The AODTC confers on the judges an ungovernable discretion and power to coerce that frequently masquerades as an enlightened approach to treatment, but which creates unfairness, inconsistency and uncertainty. These processes undermine safeguards and the rights of participants to treatment free from punishment (Boldt, 1998; von Hirsch and Ashworth, 2005).

\section{"Is she more deserving than someone else?"139 Inconsistent judicial intervention}

The largely unchecked authority given to the AODTC judges, as illustrated above, has created a court that exerts substantial power over the participants through their ability to hold them accountable for their offending, and through the management of treatment and recovery. These processes, as demonstrated in the earlier chapters, have given the judges extensive discretion to engage in a profound mix of well-intentioned treatment, and disparaging punitive punishment, which generates inequality and creates barriers to treatment, thereby putting the participants', health and wellbeing at risk.

According to WHO and UNODC, "the main goal of detoxification programmes is to achieve withdrawal in as safe and as comfortable a manner as possible" (UNODC, 2003: iv.2). As discussed in Chapters 3 and 4, various socio-political and cultural factors have generated tensions between criminal justice approaches, and health approaches to addiction treatment in New Zealand. In this regard, I have demonstrated how, for example, the Corrections MMT punitive involuntary withdrawal policy is cloaked in the rhetoric of 'health' (Corrections, 2013). Given the AODTC's abstinence treatment policy, preoccupation with defining injecting drug users, people on methadone, buprenorphine, and opioid substitutes as dangerous and doubly difficult, these people tend to be either forced to withdraw or are subjected to intensive judicial monitoring and judicial intervention (as discussed in Chapter 5). Related to these issues

${ }^{139}$ AODTC observation October, 2013 
are that the judges have also made unbalanced decisions to decline participants on the basis that these participants are on a withdrawal programme.

Despite the evidence that this population should be given realistic goals in treatment (UNODC, 2003; Ministry of Health, 2014), my observations show that, when compared to other participants, injecting drug users and people on methadone are more likely than others to face barriers to treatment through repeat sanctions or exits, resulting in their exclusion from the programme. The data illustrates that these sanctions and subsequent exits are generally the result of the judges using their discretionary power to decide who stays and who goes, not based on clinical judgements about treatment, but on the basis of their personal preferences and what they see as threats to programme success. As such, there is a resultant lack of understanding of the health needs or other problems among people with an addiction (Matua Raki, 2016). For instance, Mitch, a known injecting drug user, was admitted into the AODTC in December 2012. During my observations in September 2013, I witnessed the Bridge Programme exit him for cigarette smoking and for what the Bridge Programme staff perceived 'difficult behaviours'. The judge and team members made no secret of the fact that they wanted to use the alcohol monitoring SCRAM device to control his behaviours. In the below observation, the judge claims Mitch is consistently struggling with the programme, that Mitch has had an overdose and 2 relapses, and the judges thinks his lack of engagement is down to immaturity:

Judge: ...there is nothing left for him, there's just not been that level of function since his overdose. Odyssey is refusing him treatment; we have really tried...

Case manager: He doesn't do anything significantly bad - but he hasn't moved, he hasn't offended - just 2 relapses, I think it's a shame that when he does mess up he has to start with treatment again, we would support keeping him in.

Judge: He just can't move forward from his immature behaviours, if he doesn't appear a warrant will be issued, otherwise he'll be remanded in custody to make a final decision ${ }^{140}$.

A month later, I observed the judge and team discuss the tragic circumstances that led Mitch being on remand in custody after handing himself into the Police. The situation was that Mitch had absconded from the programme. While at home, he made up a batch of morphine, and

${ }^{140}$ AODTC observation October, 2013 
along with his friend injected half of it. The team members discussed how the friend's son then injected the remaining half of the morphine himself, resulting in the death of the young man.

Police: Whether he is responsible comes down to his actions, the boy died.

Judge: It is devastating circumstances and he was due for an exit hearing, and the fact that he was on the run.

Counsel: I'm concerned for him

Treatment: I sent him a text saying you should hand yourself in

Judge: Right team, what do you think about exiting him?

Counsel: I would like him to stay in the programme.

Case manager: treatment have had the same chat about what are the benefits for him if he comes back

Police: He has caused the death of somebody else, so from our perspective, we want to reduce crime and offending and weighing it up from our point of view, is keeping him in the programme a greater issue than him decamping from treatment.

The judge ponders Mitch's participation according to her understanding of treatment success and a preference for compliance and accountability:

Judge: He needs treatment, but he has been doing this a long time...I am concerned that he is running from treatment and we've done everything except Odyssey. If Odyssey says he is not suitable then there is nothing for him. Smoking got him discharged from Higher Ground and the Bridge programmes, how badly does he want it...I do not know how you live being directly involved in the death of an addict and where did he get a needle from

Counsel: We should be mindful if the press get hold of it, and how would the public see the pilot.

Judge: Have the police followed up with his family?

Police: The father is an active addict, so was the son.

Judge: Do we want to cut him loose because of the publicity?

Counsel; He's a depressive character, I don't know if he's going to be deemed suitable for Odyssey House

Case manager: I would be surprised 
Judge: Let's think about it over the next two weeks while he's in custody. He can stay if Odyssey takes him and the police will need a guilty plea on a charge of possession a Class B drug. ${ }^{141}$

Given the court's responsibility for treatment, it might have been expected that the judge would know that addiction is a chronic and complex relapsing disorder. Why then are they not drawing on this knowledge in their decision-making and in deciding whether sanctions are appropriate or not. Unfortunately, the treatment process is compromised by the court goal of abstinence and by the judge determining that addiction is a compliance issue, meaning that they are putting participant's health and wellbeing at stake. These findings also bring attention to how the treatment providers intersect with the criminal justice process, which I discuss in greater length below.

This one effect of judicial discretion is that the focus on participant risk to programme success often takes precedence over treatment. When I asked the participants how they perceived their treatment in the AODTC, they conveyed how they received punishment for taking responsibility, were confused with the courts focus on 'choices' and were frustrated, that the court places unrealistic demands on them that they have difficulty complying:

Monty: I've had a couple of run ins with the judges, they tried to exit me a couple of times over not going to AA meetings, not doing Harmony Trust, I went there I did half of it but I was crook. I was absolutely sick I just couldn't do a couple of days so I didn't go and that was a last minute thing, they said that I didn't have to go, yet next minute I had to do it, it's the decisions they sort out you know, they're mixed and confusing...

Morris:...the judge punished me for saying that I couldn't drive because I was unwell, and they say any decision you make for yourself, they don't respect you know. At the end of the day you're meant to make decisions every day of your life for you, for your family and whatever you know, so yeah, I just don't get it. It's like it doesn't matter what you do, you get punished for making the right decisions for your family and yourself you know, that's how I see it...

Miro: ... when they said [the judge and team members] to me that I needed to start changing my behaviours and my way of thinking, I said that it's pretty hard to do that overnight you know. I've only been in the court for 7 or 8 months and they reckon that's plenty of time. But I don't know, I find it really hard to just change and that people who do change like that are

${ }^{141}$ AODTC observation November, 2013 
probably faking it that's the way I see it...I know we do make bad choices under the influence but I mean when I've been off the shit I've still made some bad choices you know...

Myles: I know that the judge is mad at me. I'm not in the A team anymore, and I'm spending over a hundred dollars a week to get to all these programmes and meetings and comply with what they want me to do, and it's still not enough for them, they want me to do CADS and yet I'm doing 18 months soon - or could be doing up to 18 months with Odyssey treatment and they want me to do CADS as well as 6 other things that I've got to do. I've drug court, I've got drug testing, I've got to comply with addiction integrating with Odyssey which is once a week on Wednesdays at Mount Eden, then I've got to do CADS another one they want me to do plus the 3 meetings a week. I mean come on...

The above accounts also confirm that what determines the treatment provisions appears to be an unregulated AODTC, and judicial inflexibility. Due to the inflexibility, and in spite of the AODTC Handbook specification that 'an appropriate treatment plan is created based on the individual's assessed treatment needs and requirements' (2012:8), the evidence demonstrates the judges' subjective and non-clinical knowledge of treatment, that they appear to make up the programme requirements case by case depending on their interpretation of the participants honesty and motivation to be compliant. This leads to inconsistency and unfairness, which in turn means that it is hard for the participants to predict what, might happen. All of which points to lack of due process and procedural safeguards. As discussed above, this is particularly so for the treatment of people with co-existing health needs.

As exposed in Chapters 5 and 6, how the judges oversee the level of treatment and punishment involves sweeping claims and vague decision-making. Of concern is that this process is particularly damaging for the participants with a brain injury or traumatic brain injury (TBI) and Post-traumatic Stress Disorder (PTSD). ${ }^{142}$ The judges non-clinical knowledge is illustrated well in the treatment of people with a TBI, and, injecting drug users, despite the evidence of a strong correlation between AOD related offending, TBI, addiction and mental health disorders (Indig, Gear and Wilhelm, 2016; Woolhouse, 2015). In light of this correlation, and despite the stated availability of a "psychologist, two alcohol and drug specialists and a clinical supervisor/co-ordinator' (Litmus, 2014:31), my findings raise a concern that the AODTC handling of participants with a history of injury, trauma and depression is causing harm. What

${ }^{142}$ Which I also discuss in the section below on AODTC therapeutic sanctions. 
follows is an extended discussion of the judicial role in the management of the treatment of participants with a TBI and PTSD. ${ }^{143}$

Managing participants with a Traumatic Brain Injury (TBI) and Post-Traumatic Stress Disorder (PTSD)

As discussed in Chapter 4, DTCs are generally designed to treat AOD related offending through a TJ philosophy, which is also supported by DTC key components and best practices, including intensive monitoring (Lutze and Wormer, 2014). From a TJ perspective, there is research that establishes that ethnic minorities, and people with an addiction and mental health issues, tend to be more susceptible to a brain injury and cognitive disabilities (Woolhouse, 2015). Therefore, responding to the treatment needs of this population is important if they are to be treated humanely and appropriately in sentencing (Indig, Gear and Wilhelm, 2016).

My observations, and the interviews, demonstrate that the AODTC treatment of people with a brain injury/TBI and coexisting health needs involves dubious legal decisions and punitive treatment standards. For example, in the observation below, Mike has a TBI and he is struggling to process the abstinence requirement. Rather than recognising the impact of a TBI upon his cognitive ability to be compliant with the abstinence standard, the judge leverages the goal of testing, according to her subjective knowledge of accountability:

Judge: He is extremely trying.

Counsel: It's his head injury, he's a concrete thinker.

Judge: Well he is wearing a SCRAM bracelet, however, there are ongoing difficulties around testing, so he can't be excused if he fails then if he isn't doing what he should be doing, there's no reason why he can't change his behaviours.

The accountability mandate means that rather than considering and encouraging appropriate treatment over punishment (Winick, 2002), the judges conflate the participant's cognitive disability with irresponsible behaviours, and thus as a compliance issue. Even though these are practices that are supported by the US DTC key components and best practice (Litmus, 2014; Nolan, 2001), I argue that such judicial authority is anti-therapeutic. It generates

\footnotetext{
${ }^{143}$ Brain injury is a general term referring to any injury to the brain. These types of injuries involve stroke and aneurysms, infections from meningitis, hypoxia (lack of oxygen to the brain), brain tumours, and neurotoxic disorders: including drugs and alcohol, pesticides, gases, solvents can all lead to a brain injury. A TBI is an injury to the brain resulting from externally inflicted trauma. There are two types of TBI; 'closed' involves blunt impact without penetration and 'open', when the skull is penetrated (Brain Injury New Zealand).
} 
misunderstanding around the programme requirement for abstinence, and the criteria that addiction is a chronic relapsing condition is denied, which thereby undermines the court policy of supporting participants' health and wellbeing.

The AODTC's focus on responsibility and accountability means that the court also renders depression and anxiety as situational and that it does not require the intervention of Community Alcohol and Drug Services (CADS). For example, the Ministry of Justice Formative evaluation document pointed out:

Most offenders seen in custody screened positive for depression and anxiety. Follow-up diagnostic testing indicated the depression and anxiety was situational and not a long-term disorder. CADS have, therefore, discontinued use of the depression and anxiety screening tools (Litmus, 2014:32).

The participants suffering from PTSD indicated that they were not receiving evidence based clinical support, and they expressed doubt, frustration, and confusion with the court-mandated treatment and support:

Morris: I got diagnosed with trauma. That came from being in the drug court, but there's no support. What I'm saying is, you know, they're only dealing with the drug and the alcohol, they don't help with the counselling, with that you got to go and find it yourself. They only deal with a little square you know, but that little square could be coming off something else and they don't acknowledge that, and they don't want to know about that...

The evidence that depression and anxiety are situational is concerning and suggests that judicial authority is not bound by law or treatment, but is instead focussed on the efficacy of legitimising participant responsibility and programme success (Merry, 2001). For these reasons, the AODTC approach toward treatment has participants with pre-existing health conditions and underlying mental health issues reporting that the court has done little to treat and support them. This was particularly so for Monty, who had suffered feelings of depression after surviving a serious car accident.

Monty: There's a lot of people that have underlying problems like me from a serious accident which had death in it and dealing with guilt and whatever, but they don't want to know...they're not helping our problems and that's costly, it's really costly.

Most described how the refusal of the courts and residential treatment providers to recognise participants' health needs, their histories of abuse, trauma, and depression had a range of negative effects such as anger, greater anxiety and sleep deprivation, avoidance of people in 
residential treatment and during court appearances, humiliation, suicidal thoughts, and fear of being arrested.

The failure to treat other physical, cognitive and mental health needs, I argue are the result of the AODTC rigid conceptualisation of abstinence-based treatment, a judicial focus on programme compliance, and the prioritisation of risk over health and psychological wellbeing. The processes I argue have undermined the intention as clearly stated in the AODTC Handbooks, 'to positively impact on health and wellbeing' (Ministry of Justice, 2012a:6; 2014). My observations show that this is because the judges appear to have lost sight of creating 'the best chance' for participants' health, wellbeing, and success in treatment (Ministry of Justice, 2012b:9; 2014). Moreover, the decision to treat or to exit a participant takes place behind closed doors, and therefore lacks transparency. On that basis, I argue that the court is subjecting participants to inadequate and discriminatory treatment, denying them the right to humane and effective treatment in terms of their health and wellbeing.

\section{“Can you put him in prison for the weekend?"144 The role of AODTC residential treatment providers in punishment}

The AODTC treatment providers Odyssey House, Higher Ground, and the Salvation Army exert a great deal of control over the treatment and punishment of participants, rather than simply supplying appropriate treatment. As discussed in Chapter 4 the treatment providers' and case managers' responsibilities are defined by the Ministry of Health AODTC contract and are prescribed by the AODTC Handbook (Ministry of Health, 2012; Ministry of Justice, 2012a; 2014). My findings in Chapters 5 and 6, however, demonstrate that the level of involvement of the treatment providers and case managers' in the programme have undermined addiction treatment. That their involvement in the programme contribute to the court therapeutic surveillance and punishment of participants.

The case managers have a contractual responsibility to overview participants' treatment programmes, and to report to the court on their progress (Ministry of Justice, 2012a; 2014). The collaborative context of the court means that 'For some case managers from a treatment background, the court environment is a new experience and requires training and time to achieve a level of comfort' (Litmus, 2014:53). As illustrated above and in the previous chapters, my observations conducted at the same time as the Litmus Formative Evaluation (2014) reveal that case managers are given unconstrained powers to pass and enforce

${ }^{144}$ Higher Ground employee, AODTC Observation November, 2013 
judgement on treatment despite not receiving training in that area. Put simply, the findings illustrate how the case managers focus is not health, but as adjuncts employees of the court. Like the judges, the case managers target participants' responsibility and compliance. They influence the eligibility and exit processes, contribute to determining detoxification, gather detailed information on the participants and their families, and use information borne from surveillance. As a result, they inform the court of breaches of bail conditions involving relapsing and participant irresponsibility in terms of failing to maintain recovery. ${ }^{145}$

I regularly witnessed the case managers discuss the withdrawing of a participant's rights to safe evidence based treatment, facilitated by a range of roles and responsibilities not normally afforded counsellors or case managers in a court environment. The observations that follow demonstrate how the case managers align themselves with the courts punitive approach to controlling participants by acting on behalf of the court and the treatment provider, thereby increasing their power to make decisions involving sanctions and punishment (Castellano, 2011).

The following is an observation of a case manager acting on behalf of the treatment provider, who, as a punishment, is preventing a participant from having a gang tattoo removed, something normally viewed as a positive aspect of rehabilitation:

Counsel: The priority is for him to have his gang tattoo removed, Odyssey are refusing to assist him until he is in level 2 of their programme. I've requested 5 times to do this, I felt that they are receiving mixed messages...the tattoo could be contributing toward his low status in Odyssey...

Case manager: We organised for a tattoo removal appointment, but he blew his chance because he was caught smoking in the bushes and was kicked out of the programme.

Judge: What can we do to facilitate this?

Case manager: .... they [Odyssey House] don't want him to be seen getting special treatment compared to the other clients. ${ }^{146}$

\footnotetext{
145 For instance, a typical weekly calendar for a Phase 2 AODTC participant resident in Higher Ground Rehabilitation Trust involves the oversight of: (1) Reporting daily to ESR for testing, (2) Daily attendance at NA and AA meetings (3) Attendance at Man Alive and Higher Ground groups. AODTC participant weekly schedule as provided during an AODTC observation in November 2013.

${ }^{146}$ AODTC observation November, 2013
} 
During the pre-court meetings, I regularly observed disagreements between the treatment providers' rules, and the case managers' beliefs and judicial decision-making, which resulted in the blurring treatment with punishment:

Case manager: His behaviour is outside of the community rules, Odyssey see it as he is part of the therapeutic community... he acknowledges that he is running his own race... his status is his own fault.

Judge: I think 102 days at Odyssey is a great report.

Case manager: He's on this pretence that he can go and do whatever he likes, Odyssey said he is not allowed to attend his partners scan for cancer today - if there is a formal diagnosis then they'll revisit it. Exercise is his addiction as well, he does three 45-minute aerobics sessions a week and he's complaining he can't lift more than $10 \mathrm{kgs} . .$.

Judge: Yes, he's transferring his addiction...

Case manager: He needs to trust the treatment your honour you need to reinforce this. ${ }^{147}$

The above observation is an example of the case manager impugning the judge's unpredictability to follow through with a sanction for behaviours that would not normally warrant punishment, illustrating how the case managers negotiate participants' sanctions.

The treatment provider's authority also provides a new platform for the blacklisting and punishment of participants:

Judge: ... she has been blacklisted. Wings won't take her because her former partner is affiliated with gangs....

Case manager: Well we've referred Molly to a couple of organisations -it's been a week and they have processes to go through... ${ }^{148}$

In the above situation, the participant could not be released from remand in custody. This is a consequence of the court sharing information about the participant's family with the treatment provider, meaning that the treatment providers are not just managing treatment; they are wielding disproportionate power in the court and in the control of participants who are considered risky (Hannah-Moffatt and Maurutto, 2012; Quirouette, Hannah-Moffatt and Maurutto, 2015). Indeed, the relationship between therapeutic interventions, net widening and the responsibility mandate serve as a dangerous mix in case managing the treatment programme

${ }^{147}$ AODTC observation December, 2013

${ }^{148}$ AODTC observation November, 2013 
(which is discussed below and in the section on 'therapeutic punishment'). As demonstrated in the following comment:

...she's [the case manager] stressing me out because she told me that, you're not getting real treatment because AA is nothing. I mean, how dare she say that, maybe she should say that to the judge in front of everyone else...

During my out of court observations, one of the participants interviewed for this research, 'Michael', absconded from Higher Ground residential treatment after just 24 hours in that programme. I was not surprised because during the interview he appeared unprepared for the expectations of the Higher Ground treatment programme:

Toni: So, your bail conditions are for you to be at Higher Ground 7 days a week for 4 and half months.

Michael: All up, 18 months.

Toni: Do you know the rules of Higher Ground?

Michael: Yes and no. Like it's a totally different environment than I'm used to you know, and you know they do a lot of stuff that I won't be used to. You know, like how I've been brought up is totally different, it's going to be like putting me in the queens house you know what I mean, with the queens staff and everything and having to be proper you know what I mean.

I caught up with Michael and his partner outside of the court. Michael told me that he absconded from Higher Ground because he saw an old acquaintance who had a cell phone: The rules in Higher Ground are no cells if you see someone with one you are required to tell on them... I mean I'm not going to nark on my mate. After he absconded, his case manager texted him and then his partner telling them that he will go to prison because he has breached his bail. The following comment from his partner demonstrated the elevated authority of the case manager in collaborating with the court in enforcing compliance and accountability:

He's going to prison... his case manager texted him telling him to hand himself into the police because he's breached his bail but he's refusing to, so she asked me to do it, I told her there's no fucking way that I'm handing him in...

Outside the court, I witnessed the case manager's discussion with Michael, which revolved around her reiterating the accountability mandate: 'if you want to stay in the court you will need to apply to go back into the treatment plan at Higher Ground which would take two weeks, that is 2 weeks in custody as a sanction'. Upon hearing this, his partner questioned the case 
manager: 'Why isn't the treatment programme catered to their individual needs, why do they need to sit around and talk like that, why aren 't Higher Ground doing their job, it's not his job to tell on people'. The case manager's response: The programme is his choice and his responsibility'. Afterward, Michael communicated to me: 'I can't handle it; they're too hard'... 'the pressure in Higher Ground is driving me to do something stupid, it's just too hard'. 149

The observations demonstrate how the case manager and treatment provider's collaborative agreement with the court incentivises the assessment of participants' progress according to the court choice-responsibility mandate. Another unfortunate consequence of their authority is if a participant refused to take on the addict identity, or was perceived to be of bad character or a risk to programme success, the treatment provider can ban or exit without the involvement of an addiction Psychiatrist or a clinical report. Thus, through their involvement in the court, the case managers and providers are also involved in the cultural production of law (Silbey, 2005). As demonstrated above and in the following sections, this process leaves many of the participants unsupported on remand in custody, and facing expulsion from the programme.

Considering the case managers and residential treatment providers' sweeping powers, a number of participants made the following comments when asked about how they coped with the treatment providers' help:

Manu: In Higher Ground it's down to surrender, if you don't surrender then you know you're buggered...

Mike: ... in Higher Ground it's such a tense environment you don't need a SCRAM bracelet there's no chance of you having alcohol and if there was, that person would pay dearly...

Mary: Higher Ground is really strict, they have like a challenge system, if I did something really bad or anything minor bad we all come into this house meeting at 9 o'clock and we all have to challenge each other on our behaviours so if I did something someone would say, Maisy I challenge you for what you did, and you know, say if I had an extra banana at breakfast they can challenge you over that, I mean they know everything about everyone, everything is so controlled everything you do because all the facilitators are watching if you do something wrong it gets challenged...you're not allowed to answer back, you're only allowed to say thank you and if you answer back then you are putting your own treatment in

${ }^{149}$ AODTC observation August 2014 
jeopardy because you're answering back inappropriately and you know, it's just best to sit back so you don't jeopardise your treatment.

The combination of the treatment providers' rules, and the AODTC's ambiguous construction of dangerous substances and behaviours, left many of the participants struggling with the treatment provided:

Maru: I've got a therapeutic discharge from Higher Ground...they got a lot of rules in there, its behavioural stuff really, I called a gay guy a faggot and that's really bad in there, I also had about 3 warnings for other behavioural stuff and that just topped it off. I was still in Phase 1 but I was briefly in Phase 2 I didn't go to a meeting on my first date because I went to a movie instead of sticking to the plan, didn't go to the meeting I got into a lot of serious trouble over that. I didn't realise how bad it was not going to a meeting....they gave me a lot of consequences. They Phase dropped me to level one and Higher Ground have their own set of consequences, sanctions, the court were aware of that. Higher Ground are their own policing unit really, you know, the court has a high regard of Higher Ground cos they're dealing with a lot of different people, a lot of different stages of addiction and Higher Ground is really harsh, I honestly think you know as much I did learn about responsibility and sitting with feelings, not holding resentments, getting the tools for recovery and all that, sometimes I think that Higher Ground put punishment ahead of progress and they discharged me for calling someone a silly name.

Toni: What happened when you got discharged?

Maru: I spent 4 nights in remand then I was released to the Salvation Army, I couldn't go into Wings Trust cos I got discharged from Higher Ground if you get discharged they won't hold a seat for you in Wings it's sort of a stipulation ....so I been out in the community for just over a month now and I've used twice in one week because my willpower is not strong enough and where I'm actually staying there's a lot of addicts and alcoholics there.

Miro: ...I went to Higher Ground and got kicked out for mucking around with one of the girls, when you've got females and males all stuck together like that you know...one of the rules is no sex...

Mikaere: In Higher Ground it's hard, you're allowed to go up to the shops for an hour and a half on a Saturday and then you're only allowed to buy a milkshake, the drink's not allowed to be an energy drink or coke it's very strict ... 
Matiu: When I came out of jail they put me straight into Bridge then I finished and that same day they put me straight into Higher Ground and I only lasted fuck it, a couple of weeks in there, I couldn't do that...

Makareta: ...coming into the drug court is like entering a new relationship you know. At first, it's like I get a chance to sort out my life with support, with proper support, and it's something I've been screaming out for years and something I've been saying to the Parole Board, but it was never there, was never there and you know. It's like entering into this new relationship of recovery... But I'm at the stage now 6 months into it where the novelty has worn off, life is hitting me you know, and man, I'm battling, but this time I'm battling with support you know, every day you know because I'm in Wings Trust...

Many expressed frustration, fear, and confusion about the AODTC's provision of support for their participation in residential treatment, and of the powers afforded to the providers:

Morris: ... being discharged for our treatment and being put back in the community because Wings Trust isn't available to us doesn't help. Pre-treatment and post treatment is not available when we're discharged. There's a couple of other guys in the same boat as me, they're out in the community hopefully they go well you know, they're different situations they got a partner or whatever not sure of the personals of them but it's a lot harder when you haven't got a supportive post treatment place to go to in the community.

Myles: At Higher Ground, I felt like I couldn't open up or talk about anything. Like they'd use it against me, like you'd be challenged for it, I just hated the place, I just feel like it was a breeding ground for narks really...they expect you to be narks on each other but they don't call it that, they say that they'll kick you out for calling it that. They call it challenging. It's supposed to come from a caring place, but what bothers me is like, I got kicked out, like I got challenged cos for not giving somebody enough food, he felt that I was ripping him off because I was giving him dinner, I was serving the dinner and that was his perception of it you know, but they just took his word for it and also another person challenged me cos they thought that they heard me buying a t-shirt off somebody else which is negative contracting and which wasn't the case and so those couple of things all added up and they ended up kicking me out.

Morgan: I was kicked out of Higher Ground for what they call getting too many challenges. I was getting challenged every day you know, like, for the way I swore, for the way I walked, for anything stupid like that. I sort of became their scapegoat you know, cos when you get challenged, you can't challenge them for 24 hours. So like if I said something they could challenge me before I could challenge them, you know what I mean...by the time 24 hours 
come you forgotten about it you know or you're worried about something else, it's quite stupid and everything becomes tit for tat, I don't know I find that programme really hard...

Maru: ...you're not allowed mobile phones in treatment and if you get mail, they check it.

Monty...the court tried to make me go to Higher Ground but they didn't tell me the cost of it, I went there and it was like 3 and a half thousand dollars that you needed to pay for it....they wanted me to go on a benefit so the benefit could pay for it...

Of concern is the evidence that the treatment providers' and the case managers' treatment of transgender participants isolated them, denying them the right to autonomy. As revealed in the previous chapter the experiences of Mel and Mary demonstrate how the AODTC construct of the homogenous addict identity underpinned discrimination in the programme. Of particular concern was Higher Ground's request to cut Mary's hair extensions off. When I interviewed Mary, she described how her current provider Odyssey House would not let her have hair conditioner until she progressed to Level 2 of their programme. Equally concerning was that Odyssey were deliberately withholding most of her benefit as a mechanism of control, making it doubly harder for her to purchase conditioner:

Mary: I'm in Odyssey but sometimes I think I wish the court could send me some hair conditioner or something like that...Odyssey give me allowance out of my benefit, my peer support workers ${ }^{150}$ are coming to the bank afterwards with me to get my benefit out and we're only allowed to spend five dollars on a shop walk at Odyssey but if we need things like conditioner or shampoo we have to wait to get to level 2 then we have to write a proposal...

Toni: Level 2 of the drug court programme?

Mary: Level 2 at Odyssey. I'm looking at level one next week so if everything remains ok, I'll have to wait 2 weeks to get into level 2 for conditioner...

In what can be interpreted as the ill-treatment of Mary, I argue, such treatment cannot justify denying her the right to basic needs and an adequate standard of care in treatment. The above accounts demonstrate how the providers are not treating the AODTC participants with humanity, respect and dignity. Instead, the residential providers are engaging in treatment imposed for the purposes of intimidation, tantamount to psychological harm. Essentially, the

\footnotetext{
${ }^{150}$ Each AODTC participant is allocated a peer support worker [a person with lived history of addiction and criminal justice involvement]. The scope of the peer support workers' role is seen as 'encouraging treatment and retention and encouraging Court required activities such as periodic drug testing and Court attendance' (Ministry of Justice, 2012b:8). Thus, participants are required to report to the peer support workers during each phase of the programme.
} 
residential providers are so preoccupied with upholding the punitive aims of the court that they have overlooked the benefits of treatment upon the participant's health and psychological wellbeing. These findings illustrate how the residential treatment providers' roles are introducing new punitive practices into the New Zealand criminal justice sphere, and in the treatment of addiction.

However, the residential treatment providers, whilst acting for the court are still ethically bound to supply evidence-based clinical treatment and to support the health and wellbeing of the participants (Ministry of Health, 2014; Castellano, 2011; Quirouette, Hannah Moffatt and Maurutto, 2015). The participants interviewed recounted how they were very careful about what to disclose and what not to disclose in residential treatment to their treatment case managers and peer support workers, because it could be used against them. This approach to treatment is inconsistent with New Zealand research on addiction treatment, which finds that trust and positive interactions are fundamental to success. As Sellman states:

Demonstrating the qualities of being a good friend such as being flexible, honest and trustworthy and being interested and warm, as well as having therapeutic skills including exploration, reflection, making accurate interpretations, facilitating expression of affect and being affirming, are the basis for developing strong therapeutic alliances (2009:9).

Power is inescapable in the treatment context (Young, 1994). The observations and interviews demonstrate how severe treatment is exacerbated through the providers' intensive collaboration with the court. Of concern are the empirical findings, which reveal that the various tactics of the residential treatment providers are punitive and inadequate. When it comes to addressing the participants' health and wellbeing through treatment, the providers are coercing through challenges, threats, and treatment standards involving intimidation and harsh punishments. These findings suggest that the treatment providers are in breach of the obligations and health standards contained in the New Zealand Code of Health, and Disability Services Consumers' Rights 1996. In most instances, the treatment providers and case managers are also in breach of the ethical principles and ethical standards recognised in the right to treatment services, and the provisions of health and safety standards (Human Rights Commission, 2010), which I discuss further in the following chapter.

The providers are also in breach of the Code of Ethics of Addiction Practitioners Association Aotearoa New Zealand (DAPAANZ, 2016). This is because they fail to recognise 'a high degree of give and take, compromise and restatement of the aim of treatment' and fail to ensure 
the 'safety, dignity and rights of participants' (DAPAANZ, 2016:7) in their treatment of AODTC participants. The findings show that, by their actions, the treatment providers play a direct role, alongside the judges, in the manipulation of treatment and the deliberate exclusion of participants from meaningful engagement in treatment.

In summary, the collaborative arrangement between case managers and treatment providers in the AODTC upholds the choice-responsibility mandate, resulting in sweeping powers that add to the punishment of participants. The examples given above and in the previous chapters indicate that the case managers have considerable influence in the court's decision making in the court through their involvement in defining participant eligibility, conceptualising addiction as a disease, and upholding the various ambiguous tools of the court.

The distinctive shared value system under the AODTC gives the residential treatment providers opportunities to engage in punitive behaviour modification practices, directing compliance, while giving new opportunities for surveillance and the imposition of sanctions. Taken together, these help legitimise the role of deterrence in addressing AOD related offending. The data indicates that the treatment providers have acted in ways that fly in the face of achieving humane and effective treatment of addiction and in encouraging participation (Sellman, 2009). Ultimately, my findings demonstrate that the treatment providers' involvement in the AODTC opens the door for new 'anti-therapeutic' opportunities to get tough on participants, and which generates an additional set of harms.

Thus far, the chapter has established that the AODTC therapeutic mandate legitimises the authority of the judges to exercise their discretion to make participants accountable through treatment. The empirical data demonstrates that the coercive court practices and the disproportionate use of punishment generates a culture notable for its lack of care for participants' health and wellbeing, and which blurs the boundaries between treatment and punishment (Miller, 2009). Consequently, the law is oppressive, counterproductive, and harmful to treatment (Levine and Mellema, 2001). In the following section, I discuss therapeutic punishment in the AODTC.

\section{Therapeutic punishment: treatment as punishment in the AODTC}

Therapeutic punishment in the AODTC begins with the court's construction of the risky, dishonest addict as being in need of both treatment and punishment. As detailed in the previous sections, once the addict is identified, therapeutic intervention is reinforced through accountability, leaving little distinction between treatment and punishment. 
Murphy (2015) refers to therapeutic punishment as involving a broader set of practices that DTCs and treatment providers can employ in an effort to quell the behaviour of participants after they have violated rules. In this section, I locate therapeutic punishment as a set of AODTC practices that include the denial of treatment: AOD testing and SCRAM electronic monitoring [mechanisms of therapeutic surveillance]; therapeutic sanctions [built on judicially prescribed teachable moments]; and, therapeutic remands [such as coercing recovery and administering punishment]. Each practice has a number of different objectives that are informed by the court's values of establishing honesty and trust, monitoring behaviours and, accountability, and responsibility during treatment. All have punitive effects through the widening of control, elimination of participant protections, and by concealing irregularities in treatment.

\section{Therapeutic Surveillance: AOD testing as establishing honesty and trust}

Therapeutic surveillance in the AODTC begins with the construction of the dishonest addict identity and continues through testing and SCRAM monitoring. According to the Ministry of Justice Formative evaluation document, participants recognise 'testing as a way to establish honesty with oneself and trust with the AODT Court' (Litmus, 2014:89). In practice, AODTC therapeutic surveillance is used for purely punitive means, such as phase applications, compliance in treatment and care, and protection issues around parenting. Therapeutic surveillance requires the collaboration of the AODTC and residential treatment providers to oversee testing as a tool to assess honesty, reliability and motivation towards becoming better.

However, the observations and interviews revealed that it is through the combination of testing and SCRAM monitoring, that the effects of the court's construction of the dishonest criminal addict identity, and the power of the responsibilising process, are laid bare:

Judge: I'm interested in the carrot and stick, the SCRAM is a demonstration of trust and can go a long way, I'll look at strict conditions and curfews, if you put a foot wrong its back into custody... ${ }^{151}$

Interviews with participants revealed testing to be a punitive practice, resulting in unjustifiable punishment:

Morgan: I've been here almost 2 years and missed one piss test. I was supposed to graduate today but now they're not going to let me graduate because I missed one piss test...I told

${ }^{151}$ AODTC observation September, 2013 
them that they're turning into a pack of Nazis you know, that's one hell of a punishment because you miss one piss test...

Moreover, as discussed above, the judges' view of behaviour modification leaves no opportunity for the recognition of the needs of the participants with a brain injury ${ }^{152}$. Even when there is documented evidence of a participant as suffering a brain injury and associated cognitive impairment, procedurally, the AODTC remains focussed on establishing honesty and accountability. Taking in the evidence that the court places the participants beyond legal safeguards and an understanding of their health needs, people who have a brain injury, TBI and through lower levels of physical and social functioning, can encounter trouble with everyday tasks and post trauma headaches ${ }^{153}$. Ultimately, this makes these participants doubly vulnerable to coercion, the choice-responsibility mandate, and misinterpretation of their rights to clinical treatment. This process is evident in an account from 'Mahaka', who suffers the ongoing effects of what he describes as a 'head injury', which in fact is a TBI caused by an axe piercing his skull, requiring brain surgery:

Mahaka: With the testing at Higher Ground, they just turn up, and you got to test within 20 to 30 minutes sometimes you can't, it's really frustrating there's a lot of pressure. I have a head injury you know and for me to try and strain to get it out, I was getting headaches.

The systematic difficulties faced by participants through the testing requirements drove many to despair and suicidal thoughts. Some of the participants felt so desperate that they sought advice from the outside agencies. As Marama lamented, she approached the Human Rights Commission for better protection of her rights to cultural identity and dignity in testing.

\begin{abstract}
Marama: ...they said that they're going to do random testing from now on and we just got to accept it and if we have any resentments against it we can't challenge it, we cannot challenge anything in this court. I tried to challenge it, but the Human Rights Commissioner told me don't talk to the judge, do not talk to your lawyers, do not talk to anybody on the team this is how you go about doing these things, it's just a letter to the judge jurisdiction thing...I felt unjustified, unjustified and disrespected, as a Māori woman. I felt my dignity had been taken
\end{abstract}

\footnotetext{
152 The New Zealand Ministry of Health (2016) provides extensive information on treating people with an addiction and head injury. Attached to the Ministry of Health is the Matua Raki (2012) Substance Withdrawal Management Guidelines for addiction and allied practitioners Matua Raki, Wellington. This document provides information for safe withdrawal management for addiction and allied practitioners. ACC New Zealand (2016) provides a Traumatic Brain Injury (TBI) Strategy as well as an Evidence Based Best Practice Guidelines document outlining the treatment of people with addiction and a traumatic brain injury.

${ }^{153}$ Headache is one of the most common symptoms after a traumatic brain injury (TBI) and affect over $30 \%$ of individuals who have a TBI. Retrieved from: https://www.acc.co.nz/assets/iminjured/34e131ea22/Information-on-headaches-after-a-traumatic-brain-injury.pdf
} 
away, and then the very next day, they expected me to go to testing again and face those same people. I didn't go, I got excused, in the end they said you know, you have to go and get a Doctors certificate and I said oh well that's going to be hard because I want to kill myself.

Many of the participants characterised the testing process as the courts shirking their responsibility to support participants to get clean in order to meet the testing commitment and abstinent requirements:

Mel: Testing is a major commitment cos you got to be clean before you go into residential, it's meant to takes a few weeks before you can go in there, they expect you to be abstinent off drugs on your own you know...

They also characterised the testing process as one involving distrust, as a loss of rights, as no different to jail, mentally hard, and a struggle:

Michael: At testing, they watch you pee so it's pretty desperate. I think it's because they don't trust you, you know, they'd be doing that in jail anyway so you know it doesn't matter how you put it, you're still in the court so you still have to do it...human rights and all that stuff, but it's the same in jail...

Morris: I think that, it's [the drug court] a struggle. Like these programmes are mentally quite hard you know, in jail it's a lot easier to block out the outside world, and time just seems to fly by, you know. It's when you can look up the driveway and think fuck it, I could just take off and it just opens up more memories in your head...

Participants also noted the loss of dignity and financial hardship associated with testing:

Murray:....there's fuck all dignity in testing, you get stripped of that fucken oath, you got to also take into account hey you done the crime you got to do the time if this is the way you decide to do your time then that's all well and good. But I think if you're looking personally for a recovery point of view, then give that guy whose got 70 cents give him an extra 20 bucks a week for his bus fare at least to get to the piss test...

The AODTC expectation that the participants will engage in a reciprocal relationship with the treatment programme, affords the judges and treatment providers unwarranted control over participants (Nolan, 2001). However, the suffering experienced by the participants is credited to the AODTC positioning accountability through mandatory testing and surveillance (Moore and Hirai, 2015). In this regard, the merging of testing as a non-adversarial regulatory mechanism with the justice process and punishment masks the realities faced by the participants. The way testing is administered, and the ramifications of a test a missed or failed 
test, affect participants' abilities to address their recovery. Added to this is the role of the SCRAM electronic monitoring device.

\section{SCRAM monitoring}

The SCRAM bracelet is a profoundly punitive mechanism of therapeutic surveillance, used to monitor, coerce and enforce compliance. I argue that the goal is punishment. The participants drew similarities between punitive AODTC values and unjustifiable punishment:

Mahaka: ...you can't have the SCRAM fully submerged in the water or you'll get penalised for it being submerged in water, they're worth over 800 dollars to buy so if it gets destroyed, you're liable...

Matiu: ...even when I wasn't using, it still came up with a use and tampers, I mean how do you explain that?

Marama: The rules with the SCRAM are you're not allowed to use any alcoholic products which is in lots of moisturisers and stuffs, foods, hand crèmes...

Maru:... my SCRAM would spike...it almost pushed me over the edge cos I couldn't keep always being in the firing line, always having to explain myself every week you know, having meetings with my case manager every week and I was trying to find reasons as to what I was doing you know, what am I using...

As with mandated testing, the SCRAM is dependent more on judicial and team decisionmaking centred on establishing honesty than on care and support. In the event of a SCRAM result revealing a spike, the judge and team consider taking action according to their knowledge of the dishonest addict, and risk:

Case manager: She told us it's her leg crème.

Coordinator: The spike looks like a metabolised one, one that is ingested like Listerine or alcohol although shaving legs, body washing, and touching can make it spike.

Judge... her father is an alcoholic and she's attending ALANON. The AODTC will ask the ESR to do a metabolite urine test to confirm alcohol 48-72 hours after consumption. Team we cannot tell participants that the court will be doing this for a month as a double check on the SCRAMs... ${ }^{154}$

\footnotetext{
${ }^{154}$ AODTC observation December, 2013
} 
One effect of the management of SCRAM results is that once again the judges position their knowledge according to participants' dangerousness. As shown in the previous chapter, this is particularly problematic, especially for those participants with a partner:

Judge: Milo has slept on the sofa for 2 weeks and has a flat line, do we accept that?

Case manager: Totally accept it.... the spikes have been very low level, not a large wave.

Judge: I think his partner is utterly dodgy, she said that he had taken a sip of wine when they were cooking.

Case manager: He's a naïve man.

Judge: Well do we proceed as a team; are the spikes a result of Dawns drinking? Or, do we accept what the SCRAM people are saying? We want to keep this quiet too team from the other participants. Remember Martha and her SCRAM spiking every 15 minutes, it is just not helpful for participants to know that if their partners are drinking the SCRAM will spike. I'm going to ask him to go to ALANON because Dawn is an alcoholic.

Case manager: Well the fact that he slept on the couch means that she couldn't go two weeks without a drink.

Judge: I'm not going to encourage him to sleep apart, but encourage him to affirm and to go to ALANON...I have to say that I notice this SCRAM has actually clouded my engagement with him. ${ }^{155}$

One of the consequences of the focus on the control of participants is that testing and monitoring embeds the view of addiction as a disease, and speaks to the courts construct of responsibilisation in treatment. The above findings illustrate that the judges, when meeting the goals of the court, crudely translate participants' relationships as risks. The justification for this is clearly based on the AODTC construct of the dishonest criminal addict at risk of relapse, deterrence, and programme success.

\section{Therapeutic sanctions: Creating opportunities for a teachable moment}

AODTC therapeutic sanctions function when the judges merge treatment with punishment. Therapeutic sanctions are drawn from the US National Drug Court Institute best practice components (NDCI, 2011), and form part of the therapeutic process of behaviour modification (Litmus, 2014). Therapeutic sanctions fall within the judge's discretion to personalise

${ }^{155}$ AODTC observation November, 2013 
punishment (Burns and Peyrot, 2003). In this context, the judges work to identify who is responding to treatment, and who is not.

The AODTC Handbook identifies therapeutic sanctions as contributing to "the desired goal of abstinence'. For those participants 'not meeting the desired goal of abstinence... then the consequences for that participant will be more severe' (Ministry of Justice, 2012b:18). Left to the judges to calculate participants' motivation, this process requires substantial skill in identifying a particular behaviour as a violation of abstinence-based treatment. As shown above, much of this is based on an interpretation of honesty, and programme compliance.

In practice, AODTC sanctions range from an open admonishment of 'step it up', to a loss of clean time, being put back a Phase, being left until the end of the court day, writing letters and essays which are referred to as 'reflections', and, as the last resort, time spent on remand in custody. Repeat sanctions and general non-compliance commonly result in expulsion.

During observations, an average of 70 percent of the court day was spent on the judges putting into practice their knowledge of identifying and managing participants' relapses. The judges' responses entailed coercion, justification, and blaming and compelling participants to learn from a graduated range of sanctions. The following example of the judge coercing a participant to admit to relapsing demonstrates the judge's role as a therapeutic authority, and how therapeutic sanctions are used to attribute blame and punishment:

Judge: What have you got to tell the court?

Matthew: I admit that I have been using...

Judge: From my point of view you've had a couple of false starts the point is to learn from them, you can reappear in 1 week...have a good think about whether you want to stay in the court. [Matthew is remanded into custody] $]^{156}$

According to the Ministry of Justice Formative Evaluation Report, 'sanctions' are referred to as 'opportunities for learning, by the judge as a teachable moment' (Litmus, 2014: 58). This suggests that participants need to be taught a lesson as part of their treatment, and for not staying on track to recovery.

One of the strongest points to emerge from this part of the research is that the judges' interpretation of responsibility, dishonesty, and blame is used to defend the sanctioning

${ }^{156}$ AODTC observation of a participant in Phase one December, 2013 
practices. This process typically involves the judges emphasising the court's mantra that participants must demonstrate 100 percent commitment to the programme by adhering to bail conditions and being accountable, otherwise participants are at risk of a sanction. Any sanction is tailored according to the degree to which bail and treatment conditions have been breached. In the following sections, I discuss the implications of using sanctions as motivation in the AODTC.

\section{Letters and essays as sanctions}

Letters and essays are used as a therapeutic sanction in order to deter, impose blame, and to ensure accountability. This manifestation of the sanctioning process is described in the AODTC Handbook as 'sanction (3), a suitable piece of work (i.e. written) focussing on behaviour, which gives rise to the sanction' (Ministry of Justice, 2012b:22). By focussing on behaviour modification, this sanction becomes subjective, grounded upon the contradictory diseaseresponsibility mandate, and behaviours considered to be risky to programme success.

During observations, a typical AODTC interpretation of a written sanction involving a 'suitable piece of work' ranges from a single sentence to ten thousand-word essays. Each is defined as a 'teachable moment', aimed at forcing participants to reflect upon their irresponsibility. The main problem with this form of sanctioning however is the overuse of discretionary decisions, and the resulting failure to take into account participants' wellbeing and dignity. As already illustrated, this is particularly evident in the treatment of participants with coexisting health needs, those with a brain injury and cognitive impairment.

Despite the acknowledged availability of evidence based treatment (Ministry of Justice, 2012a, 2014), my observations and the interviews reveal that the letter and essay sanction is punitive and is founded on the behaviour modification aspects of the programme. In this context, the unchecked powers of the court and treatment providers to target the participants' responsibility means that they are subject to disproportionate punishment. In the following observation, Morgan, who has a TBI, is given a sanction of a ten-thousand-word essay by the treatment provider, rather than being offered safe clinical support:

Morgan: Higher Ground gave me a sanction of a 10,000-word essay for pretty much having a bad attitude, when I told my lawyer he just laughed and said that is what they write in a thesis. I had a significant brain injury last year you know and for me to write 10,000 words well I was in no state to do that so I negotiated it down to 5000 words...I opted for that because I would have had to leave with a therapeutic discharge... 
Thus, the sanctioning in this context which was unrelated to a relapse or to criminal offending, is disproportionately severe, and demonstrates a lack of recognition by the AODTC of individual health needs and wellbeing.

In another case I witnessed the AODTC judge and team members laugh loudly at the prospect of a participant writing a 5000 word essay on 'The pain of grandiosity', to which the Higher Ground representative added: 'will help the participant to focus on handling his thoughts' in treatment ${ }^{157}$. In all cases, the decisions surrounding this type of sanctioning lacked clinical reasoning in treating addiction. Instead, these sanctions are constituted on the retributive and deterrent effects of law to convey blame and punishment (Fischer, 2003). The consequences are that the court is failing to treat the participants humanely (von Hirsch and Maher, 1992).

Moreover, according to my observations, most of the letters and essays contained detailed information relating to participants' lives prior to their involvement in the AODTC, descriptions of their offending, descriptions of their familial relationships, and the nature of their addiction and extent of their relapsing. No restrictions were placed on what participants are required to read aloud in front of the open court. I observed many of the participants struggle with the task. I also witnessed members of the public, sitting in the court; appear visibly upset after listening to offending histories, revelations of historical abuse, psychological and physical history, family dynamics, and other personal details.

As discussed, there are questions around the gendered court process and the lack of protections for vulnerable women in the programme. This was clearly evident during my research, in that it was more common for women to be subjected to sanctions that involved reading out their life story than men. In contrast to the women, men were encouraged to write in ways that conveyed how responsible they are becoming for themselves and their families through the 12 Steps meetings. In one case, I witnessed a female participant, prompted by the judge, read aloud a deeply personal account of a horrific and personal attack. This participant's letter contained a detailed description of her 'relationship with my children', offending history prior to her involvement in the AODTC, 'life as a sex worker and surviving being stabbed 152 times... being left for dead in an alleyway', the location of the attack, the extent of her 'horrific injuries', her recovery from the injuries and how the treatment for her injuries contributed to her 'addiction to pain killers'. 158

${ }^{157}$ AODTC observation November, 2013

${ }^{158}$ AODTC observation November, 2013 
When I asked participants about the sanction of written work, many talked of feeling humiliated and of having experiences of heightened states of anxiety and pressure to perform before the court:

Marama: ...my anxiety plays up when I have to read in front of everybody in court. I almost passed out at my 3rd letter, I went all starry eyed but they gave me water...I honestly believe that it should be optional, I think it's because they want to see you - I don't know, rolling through the challenges, but it gets too much sometimes...

Regardless of how participants negotiate the sanction of written work, the judges use this process to coerce and teach the participants a lesson about accountability, which brings attention to the AODTC's persistence that participants take responsibility and how it obscures the role of punishment as the predominant mode of treatment.

The court's and treatment providers' reciprocal agreement, essential components of the programme, is interpreted widely to make participants punishable. This adds to the creation of barriers to health, psychological wellbeing, and success in treatment. For those participants considered therapeutically non-responsive, the most punitive sanction is remand.

\section{Therapeutic remands: Creating new harm}

Judge: I don't want to see you rot in custody...But we know that last time you were out on a weekend it wasn't flash, we need to be in the driving seat not the addiction, we will revisit this in 1 week.... ${ }^{159}$

Finally, punitiveness in the AODTC is further materialised in the use of remand in custody as a treatment sanction. Moore (2007:48) describes such sanctioning as 'therapeutic remands'. As already shown, the judges typically draw upon unfettered discretion and the construction of the criminal and treatable addict in order to merge treatment and punishment. In the context of therapeutic remands, this generates an ethical issue regarding the purpose of remand in treatment, and whether and when remand in custody is appropriate in treatment (Smith, 2007). Issues of fairness, proportionality, protection from harm and penal limits arise in the context of the AODTC's use of therapeutic remand under the guise of treatment (Hannah-Moffat and Maurutto, 2012).

This section exposes how the AODTC combines the goals of responsibility and commitment to abstinence and recovery which produces disproportionate punishment. It shows that the

${ }^{159}$ AODTC observation November, 2013 
AODTC policy of therapeutic sanctions imposed by the judges, supported by unregulated discretionary decision-making, is the cause of the severity of sanctions (Burns et al, 2003).

Observations and interviews reveal that a relapse results in time spent on remand in custody. This generally varies from a three-day weekend to two weeks, and in some circumstances up to three months. This is described by a participant:

Monty: I had about three relapses and in each I went into remand, the first time was two weeks, the second time was a month, the third time I just finished my jail sentence instead of going back to rehab.

Essentially, AODTC use of remand in custody leaves very little room for decisions based on what is best for the participant and what is required to protect them from harm. As demonstrated in Chapters 5 and 6, it is not unusual for the judges to remand participants in custody based on suspicion and non-compliance, such as not turning up on time or for being 'dishonest'. As shown above, this position is profoundly damaging for participants who are willing to embrace their recovery, but find that they are exited, or self-exit from residential treatment for reasons unrelated to the programme requirements of abstinence. These participants are in breach of their bail conditions and are required to hand themselves into the police or the court. For the majority this results in a stint in custody, because the AODTC's collaborative approach to treatment inadvertently escalates participants' level of risk until a placement becomes available:

Judge: I am going to remand you into custody until a place is available in Higher Ground, stay positive and I encourage you to attend those 12 step meetings... ${ }^{160}$

The inability of the AODTC to provide appropriate residential treatment in an all-inclusive way was noted in the Formative Evaluation; 'some participants waiting on remand in custody for several months for an appropriate treatment programme' (Litmus, 2014:82). Two years later, the Final Evaluation confirmed that 'offenders accepted into the court can be remanded in custody and wait up to two months before suitable accommodation becomes available' (Litmus, 2016:4). The fact that participants are being remanded simply because it provides a form of accommodation begs the question as to why remand in custody is being used in the first place (Smith, 2007). It also raises concerns about proportionality in balancing decision

${ }^{160}$ AODTC observation October, 2013 
making around punishment in treatment (Hannah-Moffatt et al, 2012), and the legitimacy of AODTC use of remand for effecting treatment and motivating engagement in treatment:

Makareta: I was already in remand when I put my application in for the drug court so it was a long process... it was two months...they had to see which rehab I was going to and wait for a bed to be available....I was going good for say 3 months [in the programme] things took a turn for the worse and I fell off the wagon...they put me back in remand for a week but they gave me a second chance I tried Odyssey House stayed there for another two months then ran away....I was remanded back into custody for two weeks... [before being sentenced]

During my observations, the AODTC participants held in remand are located alongside other prisoners and prisoners awaiting sentence, further jeopardising their health and wellbeing and increasing the potential for inhumane conditions and harm (Stanley, 2004). The evident lack of regard for participants' health and wellbeing is of concern, because the New Zealand prison health system has come under increasing scrutiny in light of the evidence of high levels of AOD issues, coexisting mental illness, disability, and mortality in inmate populations (Indig, Gear and Wilhelm, 2016; Wakem and McGee, 2012;; Smith, 2007; Tinsley and Young, 2017). Indeed, a recent case prosecuted by the Office of the Health and Disability Commissioner ${ }^{161}$ found that a lack of treatment and the failure to manage and ensure an inmate's medical needs breached Right 4 (1) of the Code of Health and Disability Services Consumers' Rights ${ }^{162}$.

As shown above, it is clear that the AODTC's approach to, and use of, remand in custody leaves participants vulnerable to coercion and violence. The increased vulnerability of participants on remand in custody can be attributed to the judges' and team members' knowledge of the programme and of the purpose of remand. In the following observations, 'Melanie' is to be released from remand in custody into the care of the Higher Ground residential programme. Melanie's participation in the programme is an incentive for her to regain custody of her child:

Counsel: The incentive for her is to get out to care for her 4 year old child who is in the care of his grandmother; the rules of Higher Ground have been discussed as well as those of the court. ${ }^{163}$

\footnotetext{
${ }^{161}$ Decision 14HDC01769, Serco New Zealand Limited, Department of Corrections, June, 2016

162 Right 4(1) of the Code states that every consumer has the right to have services provided with reasonable care and skill.

${ }^{163}$ AODTC observation September, 2013
} 
Two weeks later, the judge and team acknowledge how Melanie is finding Higher Ground challenging, having 'gone straight from custody into care'. Together, the judge and team minimise such challenges with, 'these are early days'. However, Melanie's time in custody involved violence resulting in a broken arm. In light of this, the case manager forewarns the court that, if Melanie is exited from Higher Ground, she runs the risk of encountering further violence in custody:

Case Manager: The gang girls got to her in custody before she went to Higher Ground, so we need to take one step at a time-she's received several warnings for rolling her eyes in Higher Ground and is on her final warning. ${ }^{164}$

Using the threat of an exit, the judge's decision-making takes a coercive position, directed at responsibilising Melanie. This leaves her vulnerable to punishment and further violence if she fails treatment:

Melanie: My attitude is mostly the problem.

Judge: What do you mean?

Melanie: Being sarcastic.

Judge: Being tough?

Melanie: All of the above they call it a mask in there.

Judge: Is there anything we can do?

Melanie: I just got to do it myself.

Judge: It's about stopping and thinking.

Melanie: Before I act

Judge: We are very much helping you, it's a tough time in custody but you've come through it... ${ }^{165}$

Three weeks later, I observed the team discuss how Melanie had been exited from Higher Ground, and is again on remand in custody as the team seek to locate suitable mandated housing, which was complicated by the fact that the treatment provider had blacklisted

${ }^{164}$ AODTC observation October, 2013

${ }^{165}$ AODTC observation November, 2013 
Melanie. Faced with a potential disaster, the judge considers extending her authority to keep another AODTC participant, Mona, on remand in custody for Melanie's protection:

Judge: Melanie has been blacklisted... team I'm concerned for her safety in custody now that Mona is being released on bail today.

Case manager: Mona and Melanie share a cell in remand, they're seen as narks by the gang girls because of their involvement in the AODTC.

Judge: She is going to be vulnerable when Mona leaves, the gang girls chopped her hair off in custody prior to the drug court... then the broken arm in custody and we don't have anywhere for her to live...we could keep Mona in custody till we find a place for Melanie.. ${ }^{166}$

Of concern is that Mona was released from custody on the basis that the judge and team located interim accommodation for Melanie. The above observation is typical of the tensions involved in decision-making in the AODTC. It exposes the paradoxical purpose of using custody and bail conditions as practices of behavioural modification (Smith, 2007). The result is a lack of balance between health care and the control of behaviour. This further magnifies the dangers associated with the use of remanding participants into custody and reveals a lack of judicial investment in the participants' health and wellbeing. For participants, these processes have led to negative and harmful experiences of prison violence and a disregard for safety:

Morris.... I go in for two weeks and get stabbed in the neck and they quickly rip me out of there then put me back in and say Morris can you handle two days, can you handle it, it's only two days and you'll be back with us and you'll be out on Tuesday and the day was Friday. It's not two days that's Friday, Saturday, Sunday, Monday on the 5th day I'm out which is Tuesday. She [the judge] means the weekend not counting the weekend you got two days it's no bloody holiday each day is counted when you're in prison...

It has also resulted in oppression and exclusion from family relationships:

Maggie: ...I had my baby with me when I had to go into custody for a relapse.... I didn't want to [be put into custody] I wasn't prepared, I put up a fight so they got the court security onto me to get me into the cells...

Murray...At the end of the day remand was putting another strain on my relationship that was already strained to the max...

And it often resulted in punitive punishment:

${ }^{166}$ AODTC observation December, 2013 
Mel: When I relapsed I chose to go to the men's prison, because I started going to prison when I was 18 years old, as a transwoman I know the system really well there... I went to prison [remand] 3 times in the last 3 months. The first relapse was within the first month, I went to prison for the weekend, got out, the other month of relapsing I went to prison for a week got out, I had a few uses, they went haywire, I went into prison again, this time it was for 2 weeks...

The above examples demonstrate that the AODTC's use of remand in custody is repeatedly undermining the treatment of addiction. In practice, the participants are held accountable to judges who employ wide discretion, and make subjective decisions on the participants' 'best interests'. The result is the expansion of judicial supervision, monitoring, and control over participants. Based on its own understanding of addiction, health and wellbeing, the AODTC has incorporated treatment into punishment.

Despite the opportunities for treatment offered by the AODTC, the above sections have shown that therapeutic punishments, testing, surveillance, sanctions, and therapeutic remands are the products of ungovernable discretion that is supported by the goals of the courts to enforce accountability. All of the above practices result in new sets of criminal justice harms.

\section{Conclusion}

This chapter has provided an empirical account of the AODTC practices of merging treatment with punishment. While the main symbolic message is that the judges are doing something new and innovative by ascribing disease to AOD related offending (Fischer, 2003; Tremewan, 2013), they are sustaining and reproducing a focus on offender pathology and the interplay between treatment and criminal justice (von Hirsch and Maher, 1992).

There are intended and unintended consequences (Hoffman, 2002). The judges and treatment providers have unrestrained power (Boldt, 1998) to enforce the monitoring of participants' compliance. This presents with two sets of harms. The first is the expanded jurisdiction of the judges that permits them unfettered discretion to coerce treatment through punishment (Boldt, 2009). Guided by the US DTC and best practice components, the disease-crime dichotomy, and the requirement to enforce recovery, the judges' interpretation of 'appropriate therapeutic techniques' (Ministry of Justice, 2014:6) involves various ambiguous tools aimed at deterring and changing the participants through non-clinical interventions, to the detriment of participants' treatment, health and wellbeing. The observations and interviews illustrate that 
these processes impinge upon the participants' rights to autonomy, safety and dignity in treatment.

I have demonstrated that there are differences in the judges' individual understanding of treatment, compliance and programme success, culminating in therapeutic punishment practices built on a punitive system of surveillance and sanctioning. The AODTC's reliance upon the culturally insensitive and punitive practices of regular and random testing, surveillance and sanctions have severely compromised the participants' health and safety. Repeatedly during observations, the judges continued to mandate inappropriate therapeutic practices to the detriment of participants' health and wellbeing. The participant's accounts bear evidence to this.

The second harm is the mandating of residential treatment providers and the expansion of their powers of oversight of punishment through treatment. The treatment providers, like the judges, have a duty of care over the participants (Malloch, 2000). As demonstrated in Chapters 3 and 4 , this duty begins with the fact that the state recognises the basic right to treatment that is fair. However, there are problems and unintended consequences associated with the merging of justice with health through treatment. There is evidence that the roles of case managers and residential providers blur the distinction between treatment and punishment. Evidence of unrestrained power and inadequate care exercised in residential 'treatment' surfaces in all accounts from the participants in this research, who described the treatment providers' roles as administrators of punishment, and which served to perpetuate the AODTC construct of the homogenous, dishonest criminal addict identity. When viewed in relation to the court's therapeutic mandate, the treatment providers' role contributes to the failure of the AODTC programme to take responsibility for how they treat and simultaneously how they make participants governable through punishment.

The findings raise serious questions about the AODTC therapeutic model and the assumption that coercion works to treat crime (Boldt, 1998). Ultimately, they illustrate that the AODTC collaborative approach favours rehabilitative punishment, generally associated with a failure to protect participants' rights (Boldt, 1998; Miller, 2004; von Hirsch and Maher, 1992). Given the harms to participants, it is difficult to detect any justification for using punishment instrumentally as part of treatment, or for their health and psychological wellbeing. This is considered alongside other issues and recommendations in the following discussion chapter. 


\section{Chapter 8: Addressing the Harms Arising from the Alcohol and Other Drug Treatment Court}

Therapeutic courts aim to reduce reoffending, alcohol, drug use, and addiction. They try to help a person's health and well-being so they can move on with their lives.

- Ministry of Justice, 2016

Drug courts perform their duties without manifestation, by word or conduct, of bias or prejudice, including, but not limited to, bias or prejudice based upon race, gender, national origin, disability, age, sexual orientation, language, or socioeconomic status.

- $\quad$ US National Drug Court Institute, 2011

\section{Introduction}

The investigation into the New Zealand AODTC governing of AOD addiction treatment in this thesis has shown that the operations of the AODTC are informed by the following fundamental assumptions: (i) a causal connection between crime as a choice and addiction as a disease, which in turn bestows an understanding of the participants as criminal and treatable; (ii) that judicial authority is necessary to coerce, monitor, intervene and to punish for failing treatment; and (iii) that abstinence is a criminal justice goal, achieved through intrusive monitoring, deterrence and incapacitation.

Kleinig (2008) claimed that the legitimacy of DTC intervention appears ethically salient because it is set under the appearance of law. This thesis has critically examined the AODTC treatment policies and legal decision making practices, taking in documents, observations and the participants' stories and experiences of treatment. It has been shown that the AODTC has uncritically embraced the US DTC principles and practices as a panacea to address AOD offending. Despite appearing ethically salient, this thesis has shown that in practice that the AODTC has created barriers to treatment and inflicted harms on participants. It argues that these result from the notion of individualised justice about addiction and AOD related offending (Hoffman, 2002).

The chapter begins by summarising a range of harms generated by the AODTC. These harms stem from, and are produced by, four key and overlapping DTC features, each of which blur the distinction between treatment and punishment: the integration of treatment with judicial case processing; judicial intervention; the close monitoring of participants' behaviour; and collaboration with community treatment providers (Boldt, 2009, Wexler, 2002). 
I then present a series of recommendations and options for reform designed to address the harms produced by the court. I draw attention to the Law Commission's (2011) problematic recommendations, and the substantial role played by judicial activism in the decision to adopt the DTC model, as key factors underpinning those harms. In this context, I argue that the recommendations and options for reform are essential if the AODTC is to continue to address AOD related offending through treatment whilst supporting the health and wellbeing of participants. However, given the stated political commitment to the AODTC it is doubtful whether these recommendations will lead to action. I recommend an interim return to the traditional criminal justice options of the Sentencing Act 2002, with its provisions for adjournment for treatment and pre-sentence reports. Such a return will ensure that the judges' decisions are regulated and are based on sentence type, rather than on the abstract concepts of disease, offender pathology and programme success. The role of defence counsel is also recommended to be brought into line with acting in the best interests of their client, rather than in line with the abstract court aims of 'abstinence' and 'recovery'. I also put forward options for an alternative approach to AOD offending, and a general move away from punishment.

\section{AODTC harms}

This thesis has found that the AODTC can be harmful. Harm is generated though the court's willingness to use the law as a 'problem solving tool' with the objective of treating AOD offending as both a disease and a choice that carries a responsibility (Boldt, 2009; Merry, 2001). In this context, the court's focus on 'treatment' is the goal of enforcing abstinence. The thesis findings raise serious questions about the AODTC's procedural fairness and the protections of participants' rights to access appropriate treatment (Boldt, 1998, 2009). Overall, the findings have demonstrated how the court's focus on treating AOD related offending often comes at the expenses of social, cultural, and economic rights of the participants, and thus contest the claims that the AODTC is therapeutic, culturally supportive, and healing (Thom and Black, 2017; Tremewan, 2013).

New Zealand laws include limitations that authorities and adjudicators are obliged to consider in order to uphold the rights of people receiving treatment in the criminal justice system. ${ }^{167}$ Accordingly, the state has an obligation to ensure access to treatment in the community and criminal justice system. In particular, the court must have regard for the participants' health and wellbeing. As pointed out, the BORA 1990 and the New Zealand Code of Health, and

${ }^{167}$ A detailed analysis of the Bill of Rights Act 1990 (BORA) is outside the scope of this thesis. 
Disability Services Consumers' Rights 1996 impose rules and limits on coercion, disproportionately severe treatment, and/or punishment. As signatory to OPCAT, there are 'tools' and 'standards' in place to ensure safe detention, and the right to be treated humanely and with dignity and respect in the New Zealand criminal justice system. The UN Convention on the Rights of Persons with Disabilities (CRPD) also extends the protection from torture beyond the state to communities and privately run centres in the case of persons with cognitive disabilities, and those in psychological recovery (ODI, 2018). Yet, AODTC addiction treatment falls short of these domestic and international standards. The data presented in Chapters, 5, 6 and 7 reveals that tensions between the court's therapeutic mandate and justice means, in most cases, that the court is not safeguarding human rights and applying sentencing consistency according to New Zealand laws and its international obligations. In this section, I summarise the harms identified in the AODTC treatment of addiction.

\section{The integration of treatment with judicial case processing}

The data collected for this thesis reveals that the therapeutic functions of the AODTC, informed by judicial coercion and coercive treatment, are undermining treatment. As discussed in chapters 5,6 and 7, the judges cherry-pick participants according to perceived 'honesty' and the potential for programme success. Accordingly, they are labelling some people as addicts when they otherwise would not meet the clinical criteria. Therefore, there is an absence of clear eligibility criteria, inconsistency in the determination of progress, programme violations and exits. These findings raise serious questions about the voluntary nature of participation, the role of informed consent, fairness, determinacy, and access to medications in the programme.

\section{Judicial intervention}

Unfortunately, through the largely unregulated 'therapeutic' setting, there is nothing to stop the judges from participating in treatment decision-making, telling the participants that they have 'the disease of addiction' and intimidating participants in an attempt to uphold accountability. The data shows the 'crime' -'disease' - 'abstinence' mandate, results in the judges conflating disease with criminality and blameworthy conduct, requiring punishment (Miller, 2004). Thus, rather than safeguarding participants' rights to treatment, the judges are making moral judgements constructed on individual beliefs, and are extending the power of the law to interfere in participants clinical treatment. Accordingly, they are presenting ambiguous descriptions of relapsing and progress and using punishment and the threat of punishment to enforce programme compliance. 


\section{The close monitoring of behaviour}

This thesis has shown that harms have occurred as the result of the courts' use of the behavioural modification mandate in place of evidence-based treatment. My observations and interviews with participants show that the court coerces or forces individuals into the programme where they are subject to involuntary withdrawal and punishment for treatment non-compliance. This approach discriminates against people who use AODs, denying them their right to access appropriate health-care services and treatment. I have demonstrated how close monitoring homogenises participants and regards them as inherently dishonest but responsible. In this context, treatment amounts to discrimination. The court discriminates against those with coexisting disorders and, health needs, Māori, women and transgender people. Accordingly, harm is also occurring through the cultural production of law (Silbey, 2005), as the court prescribes legal behaviours as illegal, uses ambiguous tools to monitor clean time, determines relapses and measures behaviours in order to ensure accountability. Sanctions produce harms and cause anguish through public shaming and the imposition of humiliating written exercises. There is also 'therapeutic surveillance' in the form of invasive monitoring, where the power of the court is absolute in measuring participant compliance.

The thesis finds the use of 'therapeutic remand' to be extremely harmful, and that it is administered for retributive and vexatious ends, including retribution for court-constructed relapses, isolation and timeout for making 'bad' choices such as missing tests and other appointments, to coerce participation to incapacitate addiction, and even worse, using remand as a source of housing for participants. As vividly illustrated in Chapter 7, one participant on therapeutic remand received a broken arm, while another was stabbed in the neck. These cases demonstrate that the court is depriving the participants of autonomy and is not only failing in its duty to protect them from harm but is actively producing harm.

\section{Collaboration with community treatment providers}

The observations and interviews demonstrate that the case managers and community providers are given powers to contribute to administrative decision making, to determine eligibility, to coerce, uphold abstinence, and sanction non-addiction behaviours. They have also been shown to manipulate participants' honesty to enforce compliance, take participants money and recommend punishments. Their powers produce harms by applying treatment according to the collaborative arrangement with the court and through the subjective understanding of addiction as a disease and 'criminal responsibility'. Even if their intent is to 'treat', treatment providers facilitate the interference of justice in treatment, defining what problem-solving jurisprudence 
means in practice and in the everyday lives of people in treatment (Ewick and Silbey, 1998; Miller, 2009). Overall, the data suggests that the collaborative arrangement with the court fails to recognise, and does not abide with, established New Zealand health and disability, addiction practitioner, and treatment guidelines (see for example, DAPAANZ, 2016; Matua Raki, 2012; Ministry of Health, 2015).

It is clear that the AODTC is failing to provide sufficient protections from unjustified, punitive and disproportionate punishment. In spite of good intentions, the harms and human rights violations identified in this thesis mirror those identified by Csete and Tomasini-Joshi (2015), who in surveying the DTC data, came to the conclusion that:

...these courts do not represent reform if they undermine health and human rights, if they put health decisions in the hands of judges and prosecutors who reject clinically indicated treatment, or if they impose punishment for relapses that are a normal part of drug dependence (p.16).

They noted that, governments must not ignore human rights and the public health impacts of criminal justice policies (Csete et al, 2016). As documented in this thesis, the lack of participant protection and inadequate regulation of the treatment programme are fundamental failures of the AODTC. I therefore propose a series of recommendations and areas of reform. These include the reduction of judicial intervention, and the removal of the imposition of imprisonment as a form of treatment and for minor infractions. I also suggest a range of measures designed to avoid using the criminal justice system to adjudicate on the provision of essential health services.

\section{Recommendations}

The thesis findings have helped identify the following key areas in which the AODTC is not achieving. These are:

- Providing effective AOD addiction treatment.

- Protecting participants from inhumane and degrading treatment.

- Protecting participants from disproportionate and inappropriate punishment.

- Ensuring that Māori, women, transgender, people with a coexisting disorder and health needs are free from discrimination, oppression and marginalisation.

- Supporting participant's relationships with their families/whanau.

- Supporting participant's engagement in employment.

- Supporting safe and adequate housing. 
The purpose of the AODTC should be to reduce AOD consumption and dependency, reduce offending, reduce the use of imprisonment, and reduce costs, positively affecting the health and wellbeing of participants (Ministry of Justice, 2012a; 2014).

Unfortunately, treatment in the AODTC is based on the DTC model, the Law Commission's (2011) recommendation of 'absolute abstinence' as a measure of progress, and judicial activism in the adoption of the US model and health policy (as discussed in Chapter, 4). In my view, these policies and practices have undermined procedural fairness and humaneness in treatment (Boldt, 2009; von Hirsch and Maher, 1992). Without doubt, the harms identified in this thesis indicate that the law is failing to protect the participants from discrimination, decision-making involving unrealistic and sometimes impossible demands upon participants' autonomy as the court focuses on modifying their behaviour. Because the court has 'unchecked powers' coercion occurs, the judges and team members also have the freedom to the label legal behaviours and substances as criminal and dangerous to programme success. Reflecting a lack of concern and an insensitivity to participants' health and psychological wellbeing, these findings illustrate how the AODTC exhibits some of the more serious concerns related to the rehabilitative ideal (Hoffman, 2002).

\section{Protection of health and treatment}

I argue that the New Zealand BORA 1990, the Human Rights Act 1993, OPCAT, the Code of Health, and Disability Services Consumers' Rights 1996 set standards for treatment and accountability measures to be followed in the criminal justice system and community-based treatment services. These protections have not been afforded to participants, they do not inform the operation of the court, and they are too infrequently considered as part of the AODTC decision-making. I believe that they ought to be incorporated formally into a regulatory framework for the court to ensure effective protection against legally coerced, cruel and degrading treatment or unjust punishment, and to uphold the human rights of people receiving treatment. While the UNODC (2012) has argued that coerced drug treatment is an acceptable alternative to imprisonment, a view that is consistent with international drug control treaties. The UNODC-WHO (2017) consensus is that coercion in the absence of humane and effective treatment cannot be justified. 
In the benchmark case Taunoa $v$ Attorney-General ${ }^{168}$, the New Zealand High Court found that segregation for purposes not related to penalties for misbehaviour meant that prisoners were 'not treated with the humanity and respect to the inherent dignity that they were entitled to as human beings'. In discussing segregation, the court pointed out that treatment 'fell well below standards that befit a human being, including one who is in prison'. The finding that 'unlawful and difficult behaviour by prisoners can never justify unlawful conduct by their jailers'; can be applied to the AODTC. Given that the state is responsible for harms that arise from its institutions, I argue that this decision sets the standard for all parts of the criminal justice system that offer treatment, including the AODTC. However, this thesis contests that a rights framework on its own is simply not enough to protect participants in the AODTC because treatment decisions are subject to the governing logics of the US DTC principles and practices and the largely unfettered discretion enjoyed by the judges.

In consideration of the harms generated by the AODTC, I propose an independent and comprehensive evaluation focussed specifically on the participants' experiences into the punitive treatment practices arising from the court, because this is not ground covered by the evaluations so far. It is my view that an independent evaluation offers the opportunity to examine the discriminatory and disproportionate effects of the court's ambiguous constitution of addiction as a disease and participant responsibility, unfettered judicial discretion, and subjective knowledge affecting the AODTC's governing of addiction treatment.

\section{A departure from individual responses to $A O D$ offending and addiction}

DTC practices put great emphasis on participant accountability for abstinence and becoming a better citizen (Boldt, 2009; Fischer, 2003). The various 'therapeutic tools' of the court provide new scope for conceptualising the criminal addict and individualising coerced treatment and punishment. I have been unable to detect evidence of clear, objective, and consistently applied eligibility criteria in the selection of participants, and clinical knowledge of addiction and treatment is often absent or under-utilised. These findings generate questions about the cherry picking of participants, and whether the benefits of coercion outweigh the costs, harms, and damaging consequences to the person to whom it is applied. I propose specifically that any proposal for reform of the court should consider whether treatment-comprising remand is likely

\footnotetext{
168 Taunoa v Attorney-General (2004) 7 HRNZ 379. A group of prisoners brought an action challenging the lawfulness of behavioural modification and behavioural management regimes to manage prisoners through segregation. They claimed that the segregation system constituted torture and was correspondingly unlawful under the Penal Institutions Regulations 2000 and the New Zealand BORA.
} 
to alleviate harms to the individual, whether it is more cost-effective than punishment for failing treatment, and thus whether it is ever appropriate.

Furthermore, my research has identified how the judges use their expanded powers to coerce participation. It indicates that the 'therapeutic' authority of the judge, the 'disease' designation of the court mandate and the general lack of understanding of social, economic, and cultural wellbeing, undermines appropriate treatment. Few judges have a sophisticated understanding of how ethnicity, collective histories, and gender intersect (Maurutto and Hannah-Moffat, 2016). Even the New Zealand judges who regularly hear cases involving Māori, women, and LGBT offenders in criminal courts, and who may be familiar with the social and cultural realities of these groups, can lack the expertise required to identify and situate social disadvantage and structural discrimination (Jackson, 1988).

The AODTC practices documented by this thesis indicate that the court lacks a full and proper understanding of the adverse effects of colonisation, race relations and gender discrimination. My research indicates that the biggest obstacle for Māori is the AODTC model itself. According to Mihaere (2015) 'Māori cultural identity is important to Māori people and to governmental engagement with Māori people' (p.161). However, this thesis has detailed how the AODTC's treatment of Māori has been detrimental to Māori by relying on knowledge informed by the homogenous criminal addict, the dominant Pākehā legal culture, and rehabilitation practices. An important finding of the document analysis and observations is that the AODTC does not utilise an appropriately qualified Māori health provider. The interviews show that, within the court, the understanding of Māori cultural identity is largely subjective, and that a meaningful interpretation and application of cultural practices is largely absent. As a result, Māori women in particular have internalised the AODTC practice of homogenising their identity according to the criminal addict identity.

To prevent further harms arising from AODTC decision making, I propose that the AODTC policies and practices be critically reviewed with respect to the narrow focus on the crimedisease designation in terms of the perceived danger to programme success. Under my proposal, there should be an evaluation of the current model conducted in collaboration with qualified health professionals, in order to achieve meaningful and evidence-based structural change. Its focus should be on health and human rights so that remedial solutions to treatment are identified and further harms are avoided. 


\section{Constraining judicial leadership}

The AODTC is an embodiment of judicial activism, judge created abstinence treatment policy, and the uncritical adoption of US DTC best practice and principles. Judicial involvement in the development of the court, and in the adoption of treatment policy, calls into question whether the judges should be involved in the deployment of legal decision making beyond the operation of the court. I propose that regulations are put in place to constrain judicial activism in problemsolving court policymaking. Constraints should also be put in place to limit judicial involvement in the identification and setting of the terms or deciding on the nature of treatment.

The most obvious finding of this study is that the various roles performed by AODTC judges pose numerous harms in the governance and treatment of addiction. It is evident from the observations and interviews that the AODTC is struggling to navigate new and uncertain legal ground. The judge is the AODTC team leader and the ultimate treatment decision maker (Ministry of Justice, 2012a; 2014). Therefore, there is an obligation on the judge to adhere to principles and standards when making decisions about treatment. Simply put, treatment decisions should be made by clinical and not administrative or judicial staff.

Informed by the harms identified by this thesis, the AODTC should operate in accordance with the standards of international best practice and ensure the integrity of professional conduct, provide impartiality and consistency, apply the principle of proportionality, promote cultural change, and encourage the reporting of events that may result in actual harm to others. I propose that practice standards should promote and protect the specific rights of participants in accordance with New Zealand law. Appropriate standards would be achieved by removing the largely unfettered discretion from judges and when the might of the criminal justice system is not used to impose punishments when no criminal acts have been committed.

In the absence of specific New Zealand best practice standards for the AODTC developed for New Zealand context, and, compounded by limited volume and scope in the empirical research on the benefits of drug courts (Csete et al, 2016; SSRC, 2018) this thesis recommends that treatment is monitored through a community treatment order. Based on my recommendations, a community treatment order would safeguard informed consent and provide treatment in the best interests of the individual. The success of treatment however would likely depend upon the recommendations. 


\section{Confining community treatment providers to the provision of health-based practice}

This thesis has shown that the AODTC community treatment providers are producing law by performing as an adjunct to criminal justice. As a result, they are engaging in punitive treatment practices. Ministry of Health contracted community providers, Odyssey House, Higher Ground, and the Salvation Army employ registered members of the Addiction Practitioners' Association, Aotearoa-New Zealand (DAPAANZ, 2016). These providers and their employees have an obligation to ensure that participants are treated with respect and dignity in accordance with the DAPAANZ Code of Ethics, and the New Zealand Code of Health and Disability Services Consumers' Rights Regulation 1996. Despite these obligations, it appears that the goal of abstinence, participant accountability, and punishment are often seen as equally important, if not more so than providing addiction treatment.

Previous research has established that DTC treatment collaboration is undermined by a lack of expertise, an uncertain understanding of the causes of addiction, and the structures of privilege and oppression (Gallagher, 2013; Lutze and van Wormer, 2007; Lyons, 2011). The community treatment practices documented in this thesis have legitimised the discrimination of Māori and oppression of gender that appear endemic to the New Zealand criminal justice system and community treatment practices (Conroy, 2018; George et al, 2014; Gibson, 2016; Tauri and Webb, 2012). Based on these findings, I argue that there is a need to investigate the full range of problems that contribute to the discrimination and oppression of the AODTC participants in community treatment, including an investigation into the qualifications of the Pou Oranga, the practitioners, case managers, and peer support workers.

It is important that measures be put in place to prohibit community treatment providers from operating as the agents for criminal justice so that they confine themselves to providing treatment and that their professional decisions are in accordance with the Human Rights Act 1993 and the Code of Health and Disability Services Consumers' Rights Regulation 1996. In order for this to work, the Ministry of Health should monitor community providers, and provide accountability measures as per the New Zealand Health and Disability Services (General) Standards 2008.

\section{Ensuring proper treatment}

The UN Special Rapporteur on Health noted how tensions underpinning criminal justice policy 'fuel the perception that people who use drugs are unproductive criminals or moral degenerates, which in turn allows disciplinary treatment approaches to proliferate" (2010:11). Returning to 
the concepts of power and the cultural production of law, we can see a number of ways in which the AODTC understanding of AOD related offending and the disease-responsibility mandate underpins the harms it generates (Boldt, 2009; Foucault in Garland, 2014; Merry, 2001; Silbey, 2005). The evidence demonstrates that the legitimacy of AODTC functions on overt expressions of state and judicial power under the guise of treatment. Founded on a mix of past and present perspectives of offender pathology and race, 'treatment' has involved misconceptions of disease, the requirement for abstinence, and dubious legal decision making practices targeting accountability over the health needs of participants.

An important point that arises from my research is that more information, health standards and training in Opioid treatment, treatment support of injecting drug use and people with a brain injury and co-existing health needs is clearly required. When understood in this way, WHO and UNODC 'International Standards for the Treatment of Drug Use Disorders' (2017) make clear that it is unreasonable to coerce involuntary withdrawal and to involuntary discharge people as methods for treating non-compliance. Likewise, New Zealand scholars agree that, when treating the criminal justice population who have a brain injury, it is important to consider cognitive changes and ongoing mental health needs (McKinlay, Corrigan, Horwood and Fergusson, 2014; Mitchell, Theadom and Du Preez, 2017, Woolhouse, 2015).

It is therefore important that the government take into account the evidence that challenges the AODTC mandate that participants suffer from a disease and that it reconsider the court's practices of coerced treatment. Thus, identifying the range of health needs, and the degree of physical and cognitive impairment that justifies treatment, requires that we examine carefully the clinical meaning of addiction and the varying degrees of associated health needs. This requires a review of criminal justice and criminal punishment in the context of justifying coercion, deterrence and retribution via random testing, involuntary withdrawal, and severe intrusions into participants' autonomy. (I discuss the consequences of ensuring a review in the section below).

The punitive sanctions evident in the use of punishment under the guise of treatment, require careful attention as to the requirements for accountability, compliance and proportionality (Schopp, 2013). In ideal circumstances, I would recommend that a working model of addiction treatment be developed to address the clinical, social and cultural aspects of AOD use. However, I question whether the criminal justice system is the appropriate site for addiction treatment. 
DTC scholars have suggested that there is a need for researchers and evaluators to focus on racial disparities and other forms of discrimination in DTCs (O'Hear, 2009; Csete et al, 2016). The Treaty of Waitangi principle of partnership requires that Pākehā and Māori act towards each other reasonably and with the utmost good faith to promote and protect Māori (Toki, 2011). I have identified the AODTC's lack of recognition of treatment standards for Māori that result in Māori cultural identity being co-opted into the programme through court decision making. Similar tensions have been identified in legal decision-making practices in Canada's Gladue courts (Milward and Parkes, 2011; Maurutto and Hannah-Moffat, 2016). In order to avoid further institutional discrimination and cultural misappropriation in the treatment of Māori, I argue that it is vital that the court draw on the treatment services of Māori health providers and Māori health professionals.

\section{Gender}

My research indicates that there is a need for treatment services designed specifically for women and the LGBT community. I propose the establishment of a specific AOD treatment framework for women and LGBT participants. Under my proposal, this should include gender advocates and professionals who deal solely with women and queer experiences of addiction. Best practice would involve improving knowledge of the human rights affecting women and LGBT individuals with addiction needs. Yet, treatment programmes alone cannot address the economic and social disenfranchisement of these participants. To improve the health and treatment outcomes of LGBT people, it is important to design policies that seek to support participation in treatment, enable access to healthcare, and supply anti-stigma education and policies for the courts and providers (Lyons, Shannon, Pierre, Small, Krüsi and Kerr, 2015).

In order to avoid further harms arising from the AODTC abstinence approaches, I recommend the introduction of practical health services that align with the international research, are tolerant of relapsing, and which have greater concerns for offenders' health and psychological wellbeing. Based on my research, and looking to an alternative model, I consider that it will be more humane for the state to introduce an evidence-based health target inclusive of reducing harm by taking in co-existing health needs, ethnicity, and gender diversity.

According to Lutze and van Wormer, it is vital that DTCs 'assure that the process and programs that offenders participate in are accessible, relevant, and of quality. If not, then both the court and the defendant are likely to fail' (2007: 230). The changes I have proposed may increase 
the prospect that the participants are better protected through reference to the state's obligations to recognise humane treatment and that non-discriminatory definitions of addiction and treatment are applied. However, I question whether it is realistic to expect that the criminal court process will conform in practice to evidence based 'treatment', especially since research has found that, evidence-based policy in criminal justice is often absent in New Zealand (Goodall, 2016). This is particularly so in New Zealand in the passing of longer and restricted bail and parole conditions, which have ultimately led to longer sentences and an increase of the prison population (ibid).

Unquestionably, the creation of alternatives to the criminal justice system for addressing AOD related offending in New Zealand is needed. However, a close examination of the US DTC model confirms that it is an inappropriate solution for treating AOD related offending in New Zealand. An assessment of its suitability finds that the DTC model conforms more to attaching disease to blameworthiness and accountability to compliance and punishment. The question then is, what of the role of treatment.

Considering the harms identified by this thesis, I suggest an alternative approach that is not based solely upon the US DTC model and approaches to justice, one that does not coerce people nor put treatment decisions in the hands of judges.

\section{An alternative approach}

In this section, I propose an alternative approach that places greater emphasis on regulated health-based responses inclusive of social, cultural, and economic needs for Māori, women, LGBT people, and people with co-existing health needs.

I propose a grounded, proportionate and appropriate health approach to addiction related offending in New Zealand. I call this approach grounded because it involves regulated District Health Board (DHB) evidence-based treatment. As noted above, treatment should follow internationally accepted standards, including the recognition that AOD addiction involves relapsing, and that offenders have the right to medication-assisted treatment such as methadone and buprenorphine. This proposal does not insist that participants should be forced to stop treatment as a condition of entering a programme. It is anticipated that the process would facilitate access to voluntary treatment by removing coercion, humiliating treatment and fear of punishment. As such, any alternative approach should include the removal of punishment for relapsing and a general move away from the punishment contained in the AODTC. In order for it to succeed, I propose that any new treatment model must involve a community-based 
focus that supports people by addressing their right to clinical treatment and health care, supports their rights to housing and employment from the outset, replaces sanctioning with community service conditions, and provides the option of sentencing in the traditional court.

People with an addiction often have a coexisting disorder or a mental health condition as well as a shorter life expectancy, with Māori and women facing the greatest risk (Te Pou o Te Whakaaro Nui, 2014). Therefore, if we are serious about wanting to ameliorate societal conditions that underlie AOD related offending, then we should consider seriously the concerns raised in this thesis about the treatment of these participants.

As discussed in Chapter 3, Māori health and wellbeing are determined by the past as much as the present (Durie, in Hughes, 2007). Taking in the fact that Māori are disproportionately represented in the New Zealand criminal justice system, and in considering the structural problems identified in this thesis, I propose an alternative approach incorporating the rights instruments identified above alongside the Treaty of Waitangi principles and obligations (Toki, 2011). This approach would foreground partnership, participation, and self-determination, facilitate the necessary involvement of Māori and their ownership of reform (Bishop, 2012) to address their health and wellbeing, and change the nature of treatment for Māori (Durie, 2011).

I anticipate that this approach will also ensure recognition that culture affects health and wellbeing for Māori while underlining the importance of incorporating the Treaty in the constitution of health and self-governance in treatment (Te Rau Matatini, 2015). Ideally, this approach would also mean that addressing the underlying causes of Māori offending would occur in the community, in the hands of qualified Māori mental health and addiction treatment practitioners. However, based on the thesis findings, this process would first need to overcome the challenges presented by the dominance of the US DTC model, the co-option of individualised risk-based responses to AOD offending, and a move away from imprisonment.

Women and LGBT people are a minority in the New Zealand criminal justice population and the AOD treatment population. As a result, there are significant gaps in knowledge concerning gender specific treatment options for women and LGBT people. This is further complicated by the poor range of treatment options, poor accessibility, and the dearth of evidence-based treatment for women (Conroy, 2018; Gibson, 2016). As a starting point, I propose a balanced approach that begins with clarifying the protection of gender identity as per the Human Rights Act 1993. Incorporating that protection from discrimination into treatment involves adopting policies and practices that demonstrate a commitment to, and an investment in, supporting 
women and LGBT people in their access to treatment. This new approach would also need to support further education for community providers and, ideally, more funding for gender responsive, safer, and non-stigmatising treatment services in New Zealand.

The above changes and recommendations are based on my findings that the AODTC is causing harms to the participants. If there is no move to make change, I propose in the interim a return to the traditional criminal justice options. I argue that the Sentencing Act 2002 provision of adjournment for treatment, and the ordering of a pre-sentence report will ensure that the judges make evidence-based decisions about sentence type rather than focussing on the abstract concepts of disease and dangerousness. These measures would also ensure that the court decision-making is regulated, and that defence counsel would be acting in the best interests of the offender rather than acting in alliance with the DTC problem-solving mandate (Nolan, 2003).

However, there are other concerns to be dealt with. These include challenging the accepted definition that addiction is a disease, the aims of treatment and punishment, and the availability and types of treatment offered. Questions should be asked as to whether the current focus is on cost-effective goals of crime prevention and public safety rather than addressing the health and wellbeing of participants.

\section{Conducting truly independent evaluation studies and further research}

An additional recommendation is that independent evaluation studies be carried out, and that further research is required to assess the proposals listed above. As discussed in Chapter 4, methodologically, much of the DTC research is problematic and subjective. This has led criminal justice and DTC scholars to suggest that despite a large body of DTC research, 'much of it is suspect because of methodological difficulties' (Csete et al, 2016) and the 'cherrypicking' of participants (Boldt, 2009).

This research has thrown up many questions in need of further investigation. Despite decades of practice, few independent qualitative studies have examined how DTCs govern the treatment of addiction. There are very few studies that have examined the actual experiences of DTC participants and even fewer [if any] that have used that experience to assess the effectiveness of DTC treatment. In addition, there is limited research focussed on the effectiveness of DTC judicial decision-making, eligibility practices, the constitution of addiction treatment, and even fewer studies that have examined the long-term effects of DTC treatment. These are important issues that require the attention of future researchers. 
I propose that genuinely independent qualitative research is required to examine the consequences of the New Zealand AODTC. Based on the findings of this thesis, it is vital to compare AODTC treatment practices to those treatment practices that do not use abstinence as a treatment goal and that do not impose punishment for non-compliance, that do provide safe housing, and facilitate and encourage employment and relationships with whānau. Further investigation into the partnerships between community organisations and the criminal justice system is also essential, because as the findings have demonstrated, the community treatment providers are an important factor in exacerbating intrusive and punitive treatment practices.

As discussed, New Zealand research on female and LGBT offenders, prisoners and exprisoners is limited, and what little has been produced has been largely ignored (Bentley, 2014; Human Rights Commission, 2008). I argue that if positive change is to occur, more research needs to be not only completed, but also recognised and acted upon. Future evaluations should take into consideration current laws that protect gender diversity and assess the extent to which the criminal justice system complies with them. A key goal of any treatment programme should be to ensure that all people receive treatment free from shame and discrimination and that their right to assert citizenship is safeguarded.

In addition, further longitudinal research is required to follow up on the AODTC participants after graduation. This research in my view would test the hypothesis that the court actually reduces reoffending and is cost-effective. This would also yield a more accurate picture as to whether, or the extent to which, the AODTC affects a reduction in AOD related offending over a longer time period.

To develop a fuller picture future investigation should also consider the research outside of DTCs, the AODTC, and criminal justice practices. International research suggests that a number of countries are diverting criminal prosecution or imprisonment for AOD related offending. For instance, in the UK there is the option of community sentencing for drug offenders through supervised treatment by health authorities which amounts to a non-custodial sentence (Csete et al, 2016).

Finally, attention must begin to shift away from the US DTC model and ambiguous assessments of disease. Evidence from psychiatry and public health will give insight into the ways addiction is defined, measured and treated. This would also help to remove some of the ambiguity and inconsistency that currently surrounds definitions of addiction and coerced 
treatment. It is only when the problematic practices of these courts are understood, that treatment can be health based and applied in accordance with participants' rights.

\section{Conclusion}

This New Zealand study, the first of its kind, has investigated the AODTC's governing role in the treatment of addiction. The thesis has presented a genealogical account of the AODTC policy framework and its goal to reduce recidivism and AOD use, emphasising the connections between political rationalities, law reform and judicial activism that supported the adoption of US DTC model (Garland, 2014). The thesis has also investigated both the instrumental policies adopted from the US DTC model and their relationship to AODTC policies and court practices, and participants' experiences of treatment (Harding, 2010; Silbey, 2005). It has shown that the AODTC is based on an uncritical adoption of the US DTC model, and its principles and practices, in developing the infrastructure for delivering abstinence-based treatment. The treatment practices of the AODTC do not correspond to the best practice consensus of the US DTC National Association of Drug Court Professionals (NADCPs) nor do they reflect best practice in New Zealand as enshrined in international and domestic policy. From a law and policy perspective, the AODTC does not take responsibility for the range of harms that participants' experience. Ultimately, my findings raise significant questions as to the value and effectiveness of the AODTC in its current form.

A key finding of this thesis is that procedurally, the AODTC permits unfettered judicial discretion, which in turn allows the judges to conceptualise addiction as a disease while locating accountability within the offender. Essentially, the AODTC merges treatment with punishment as a method of control. The AODTC treatment practices documented in this thesis have been shown to marginalise vulnerable participants and prevent them from accessing the humane and effective treatment to which they are entitled. I argue therefore that it is necessary for the health and justice system to more clearly define addiction, and that all treatment delivered within the context of the AODTC be evidence based and accord to international best practice. If the AODTC continues to rely on a subjective judicial understanding of addiction, primarily defined by the needs of criminal justice and the programme, it is my view that the AODTC will continue to undermine participants' treatment, health, and wellbeing.

This thesis has shown that the AODTC model fluctuates between assumptions of crime and disease, treatment and punishment. Historically, the constitution of addiction and treatment in the New Zealand criminal justice system has led to the moral identification of addiction as a 
disease and to penal treatment. This has, in turn, led to oppression, the use of deterrence, and law enforcement over and above treatment. Therefore, the evidence that Māori, women and transgender, and people with coexisting health needs are being harmed by the AODTC should raise an alarm.

Given the serious nature of alcohol and other drug addiction, Boldt (1998) suggested that if DTCs operate on the basis of the rationale that addicts should get treatment rather than punishment, then the addition of treatment to punishment may be the wrong solution. Rather, the question that ought to be asked is why AOD addicted offenders are being treated in the criminal justice system at all.

The New Zealand AODTC merges treatment with punishment through coercion and wide judicial discretion. This creates the danger that punishment becomes the disproportionate and predominant mode of addiction treatment and control. On this basis, the AODTC is simply reinforcing the way AOD users have always been treated in the criminal justice system. The proposed reform of the AODTC would more effectively protect participants, encourage a change of culture in treating AOD offending, and go some way in mitigating the harms that it currently produces. 


\section{Reference List}

Adamson S, Schroder RN, Sheridan J (Eds) (2012). New Zealand Addiction Treatment Research Monograph. Research Proceedings from the Cutting Edge Conference, 2010.

Adler, P. (1993). Wheeling and Dealing, Second Edition. New York: Columbia University Press.

Agar, M. (2002). How the drug field turned my beard grey. Drug Policy 13:249-258

Alcoholism and Drug Addiction Act, (1966). Retrieved from:

http://www.legislation.govt.nz/act/public/1966/0097/latest/DLM380085.html April, 2014

Allen, F. (1981). The Decline of the Rehabilitative Ideal, Penal Policy and Social Purpose, New Haven, CT, Yale University Press.

Anderson, G. (1989). Critical ethnography in education: Origins, current status, and new directions. Review of Educational Research 59:249-270. DOI:

10.3102/00346543059003249

Anderson, J. (2001). What to do about "much ado" about drug courts? International Journal of Drug Policy 12:469-475

Armstrong, L. (2012). Reflections on a research process: Exploring violence against sex workers from a feminist perspective, Women's Studies, 26, (1):2-10

Arrigo, B. (2004). The Ethics of Therapeutic Jurisprudence: A Critical and Theoretical Enquiry of Law, Psychology and Crime, Psychiatry, Psychology and Law, 11(1):2343

Auckland District Law Society INC (ADLS). (2012). Alcohol and Oher Drug Treatment Courts (AODTCs) Conference. Retrieved: http://www.adls.org.nz/adls-store/cpd/cpdseminar-papers/(2012)-aodtc-conference-paper/ March, 2013

Awatere, D., (1984). Mãori Sovereignty. Auckland: Broadsheet

Bean, P. (2002). Drug Courts the Judge, and the Rehabilitative ideal. Drug Courts in theory and in practice, In J. Nolan (Ed), (pp: 235-255). New York. Aldine De Gruyter.

Becker, H. (1963). Outsiders; studies in the sociology of deviance. London.

Beehive, (2009). Tackling Methamphetamine: An Action Plan, Department of the Prime Minister and Cabinet. Policy Advisory Group. Wellington: New Zealand. Retrieved: https://www.beehive.govt.nz/sites/all/files/ActionPlan.pdf March, 2014

Beehive, (2011). Simon Power and Georgina Te Heuheu release, Drug Court pilot announced for Auckland, 19 October. Retrieved: https://www.beehive.govt.nz/release/drug-court-pilot-announced-auckland August, 2013 
Beehive, (2012). Judith Collins speech Alcohol and Other Drug Treatment Court (AODTC) pilot launch, I November, Retrieved http://www.beehive.govt.nz/speech/alcohol-andother-drug-treatment-court-aodt-pilot-launch December, 2013

Belenko, S. (1998). Research on Drug Courts: A Critical Review. National Drug Court Institute Review, 1(1):1-27.

Belenko, S. (2002). The Challenges of Conducting Research in Drug Treatment Court Settings, Substance Use and Misuse, 37, (12 \& 13): 1635-1664.

Bentley, H. (2014). The Cycle of Female Prisoner(Re)Integration: Pathways, criminal justice and imprisonment. MA Thesis, Victoria University of Wellington.

Berridge and Edwards (1982). Opium and the People: Opiate Use in Nineteenth-Century England. London.

Birgden, A. (2002). Therapeutic Jurisprudence and Good Lives: A Rehabilitation Framework for Corrections, Australian Psychologist, November 2002. DOI:

10.1080/00050060210001706856

Bishop, R. (2012). Pretty difficult: Implementing Kaupapa Māori theory in English-medium secondary schools, New Zealand Journal of Educational Studies, 47, (2), 38-50.

Board of Health Committee Report (1973). DRUG DEPENDENCY AND DRUG ABUSE IN NEW ZEALAND: Second, report (18). New Zealand Committee on Drug Dependency and Drug Abuse in New Zealand. Board of Health, Wellington, New Zealand: Board of Health, 1973.

Boland, P. (2008). British drugs policy: Problematizing the distinction between legal and illegal drugs and the definition of the 'drugs problem', The Journal of Community and Criminal Justice, 55(2): 171-187. DOI: 10.1177/0264550508089120

Boldt, R. (1998). Rehabilitative Punishment and the Drug Treatment Court Movement: Washington University quarterly 76:1205-1306

Boldt, R. (2009). A Circumspect Look at Problem-Solving Courts, Problem-Solving Courts: Justice for the Twenty-first Century? In P. Higgins and M. Mackinem (Eds) (pp. 1332). Santa Barbara, CA, ABC-CLIO.

Boldt, R. (2010). The Tomahawk and Healing Balm: Drug Treatment Courts in Theory and Practice. University of Maryland Law Journal of Race, Religion, Gender and Class, 9, (1).

Boldt, R. (2014). Problem-Solving Courts and Pragmatism, Maryland Law Review, 73(4), 11, 1120-1171.

Bollinger, C. (1967). Grog's Own Country: The Story of Liquor Licensing in New Zealand. Auckland.

Boshears, P, Boeri, M., and Harbry, L. (2011). Addiction and sociality: Perspectives from methamphetamine users in suburban USA, Addiction Research and Theory, 19, (4):289-301. DOI:10.3109/16066359.2011.566654 
Bouffard, J. and Taxman, F. (2004). Looking inside the "Black Box" of Drug Court

Treatment Services Using Direct Observations. Journal of Drug Issues, 34: 195- 219. DOI: $10.1177 / 002204260403400109$

Bourgois, P. (2000). Disciplining addictions: the bio-politics of methadone and heroin in the United States. Culture, Medicine and Psychiatry 24(2): 165-195.

Bowers, J. (2007). Contraindicated Drug Courts. Paper Series: Retrieved: http://www.law.uchicago.edu/academics/publiclaw/index.html

Boyd, S. (2015). From witches to Crack Moms: Women, Drug Law, and Policy, Carolina Academic Press, Durham, North Carolina, United States

Brook, H, \& Stringer, R. (2005). Users, using, used: A beginner's guide to deconstructing drugs discourse, Drug Policy, 16:316-325.

Brookbanks, W. (2015). Therapeutic Jurisprudence: New Zealand Perspectives. Thomson Reuters.

Buchman, D. Skinner, W. and Illes, J. (2010). Negotiating the Relationship between Addiction, Ethics, and Brain Science, AJOB Neurosci, 1(1):36-45.

Bunkle, P. (1980). 'The Origins of the Women's Movement in New Zealand: The Women's Christian Temperance Union 1885-1895', in Bunkle and Hughes (eds), Women in New Zealand Society, George Allen \& Unwin, Sydney, 1980, pp. 52-76

Burns, S and Peyrot, M. (2003). Tough Love: Nurturing and Coercing Responsibility and Recovery in California Drug Courts. Social Problems 50(3): 416-438

Burns, S and Peyrot, M (2008). Reclaiming Discretion: Judicial Sanctioning Strategy in Court-Supervised Drug Treatment. Contemporary Ethnography 37(6):720-744. DOI: $10.1177 / 0891241607310705$

Campbell, N. D. (2007). Discovering Addiction: The Science and Politics of Substance Abuse Research. Ann Arbor: The University of Michigan Press.

Carey, S and Finigan, M. (2004). A Detailed Cost Analysis in a Mature Drug Court Setting:

A Cost-Benefit Evaluation of the Multnomah County Drug Court, Journal of Contemporary Criminal Justice, 20: 315-338. DOI: 10.1177/1043986204266893

Carey, S. Finigan, M. and Pukstas, K (2008). Exploring the Key Components of Drug Courts: A Comparative Study of 18 Adult Drug Courts on Practices, Outcomes, and Costs, NPC Research Report, Oregon, United States

Carlen, P. and Tombs, J. (2006). Reconfigurations of penality: The ongoing case of the women's imprisonment and reintegration industries, Theoretical Criminology, 10(3): $337-360$.

Castellano, U (2011). Courting Compliance: Case Managers as "Double Agents" in the Mental Health Courts, Law \& Social Inquiry, 36 (2): 484-514.

Charmaz, K. (2006). Constructing Grounded Theory: A Practical Guide Through Qualitative Analysis. London: Sage publications 
Chesney-Lind, M. (2006). Patriarchy, Crime, and Justice: Feminist Criminology in an Era of Backlash, Feminist Criminology, 1(1), 6-26. 10.1177/1557085105282893.

Chriss, J. (2002). The Drug Court Movement: An Analysis of Tacit Assumptions. Drug Courts in Theory and in Practice. In J.L. Nolan (pp 189-213). New York: Aldine de Gruyter.

Chua, L., and Engel, D. (2019). Legal Consciousness Reconsidered, Annual Review of Law and Social Science, 15:1.1-1.19

Clancey, G., \& Howard, J. (2006). Diversion and criminal justice drug treatment: mechanism of emancipation or social control? Drug and Alcohol Review, 25, 377-385. DOI: $10.1080 / 09595230600741388$

Cohen, S. (1985). Visions of Social Control: Crime, Punishment and Classification. Cambridge: Polity Press.

Colyer, C. J. (2007). Innovation and Discretion: The drug Court as a People-Processing Institution. Criminal Justice Policy Review, 18: 313-328. DOI: 10.1177/0887403407303199

Conrad, P. (1992). Medicalization and Social Control, Annual Review of Sociology, 18: 209232.

Conroy, J. (2018). A gendered difference? Female experience of drug and alcohol treatment in New Zealand. MA thesis, Victoria University of Wellington, New Zealand.

Cooper, C. (2017). Drug treatment courts and their progeny in the US: Overcoming their winding trajectory to make the concept work for the long term. International Journal for Court Administration, 8(3), 3-12

Corbin, J., and Strauss, A. (2008). Basics of Qualitative Research: Techniques and Procedures for Developing Grounded Theory (third Ed.). Thousand Oaks, CA: Sage.

Corrections (2013). Opioid Substitution (Methadone) Treatment Policy and Procedures. PS Health Services Manual. Wellington: New Zealand. Corrections.

Corrections, (2014). Breaking the Cycle: Our Drug and Alcohol Strategy Through To 2020. Retrieved:

http://www.corrections.govt.nz/ data/assets/pdf_file/0008/839195/COR_15146_Dru g_and_Alchohol_Strat_Doc_v14_lowres.pdf December, 2014

Corrections (2016). Practice: The New Zealand Corrections Journal 4 (2). Retrieved: https://www.corrections.govt.nz/resources/newsletters_and_brochures/journal January 2017.

Cram, F (2009). 'Maintaining Indigenous Voices' in Mertens D and Ginsberg P. The Handbook of Social Research Ethics. Thousand Oaks. Sage Publications.

Crewe, B. (2009) 'Soft Power in Prisons: Implications for Staff-Prisoner Relationships, Liberty and Legitimacy', conference paper presented in 2009, currently under review for European Journal of Criminology 
Csete J, and Catania, H. (2013). Methadone treatment providers' views of drug court policy and practice: a case study of New York State Harm Reduction Journal, 10(35): 2-9

Csete, J, and Tomasini-Joshi, D. (2015). Drug Courts: Equivocal Evidence on a Popular Intervention. Open Society Foundations. Retrieved:

https://www.opensocietyfoundations.org/reports/drug-courts-equivocal-evidencepopular-intervention February, 2019

Dannerbeck, A., Harris, G., and Lloyd, K. (2006). Understanding and Responding to Racial Differences in Drug Court Outcomes, Journal of Ethnicity in Substance Abuse, $5(2): 1-22$

DAPPANZ, (2016). Code of Ethics. Addiction Practitioners' Association Aotearoa New Zealand. Retrieved: http://www.dapaanz.org.nz/ March 2016

Dingel, M, Hammer, J, Ostergren, J and McCormick, J (2012). Chronic Addiction, Compulsion, and the Empirical Evidence, AJOB Neuroscience, 3(2): 58-59, DOI: $10.1080 / 21507740.2012 .665411$

Drug Policy Alliance (2011). Drug Courts Are Not the Answer: Toward a Health-Centred Approach to Drug Use. New York: Drug Policy Alliance. Retrieved:

https://www.drugpolicy.org/docUploads/Drug_Courts_Are_Not the_Answer_Final2. pdf

Drug Policy Alliance, (2014). Moving Away from Drug Courts: Toward a Health-Centred Approach to Drug Use. New York: Drug Policy Alliance. Retrieved: http://www.drugpolicy.org/resource/moving-away-drug-courts-toward-healthcentered-approach-drug-use June, 2014

Duncan, G. (2002). Critical Race Theory and Method: Rendering Race in Urban Ethnographic Research. Qualitative Inquiry 8(1): 85-104. DOI: 10.1177/107780040200800106

Durie, M. (2001). Mauri Ora, The Dynamics of Māori Health. Oxford University Press

Durie, M. (2011). Indigenizing mental health services: New Zealand experience. Transcultural Psychiatry 48(1\&2) 24-36. DOI: 10.1177/1363461510383182

Durrant, R. and Thakker, J. (2003). Substance use and abuse: Cultural and Historical Perspectives. London: Sage.

Effective Interventions, (2006). Cabinet Paper, 9, Preventing re-offending. Retrieved from: http://www.justice.govt.nz/publications/global-publications/e/effective-interventions December, 2013

Eldred-Grigg, S. (1984). Pleasures of the flesh: sex \& drugs in colonial New Zealand, 18401915. A.H. and A.W. Reed, Wellington, New Zealand.

Engel, D. M. (2005). Globalization and the Decline of Legal Consciousness: Torts, Ghosts, and Karma in Thailand, Law and Social Enquiry, 30(3): 469-514.

Engel, D.M. and Munger, F.W. (2003). Rights of Inclusion: Law and Identity in the Life Stories of Americans with Disabilities. Chicago, University of Chicago Press 
Ewick, P. and Silbey, S. (1998). The Common Place of law; Stories from everyday life. The University of Chicago Press, Chicago

Ferguson, P. (2005). The Making of White New Zealand Policy: Nationalism, Citizenship, and the Exclusion of Chinese 1880-1920. Doctoral Thesis, University of Canterbury, New Zealand.

Fergusson, D., Horwood, J and Swain-Campbell, N (2003). Ethnicity and Criminal Convictions: Results of a 21-year Longitudinal Study, THE AUSTRALIAN AND NEW ZEALAND JOURNAL OF CRIMINOLOGY 36(3), 354-367

Fitzgerald, T (2004). Powerful Voices and Powerful Stories: reflections on the challenges and dynamics of intercultural research, Intercultural Studies, 25 (3):233-245.

Fischer, B. (2003). 'Doing good with a vengeance': A critical assessment of the practices, effects and implications of drug treatment courts in North America, Criminal Justice, 3(3): $227-248$

Fonow, M., and Cook, J. (2005). Women in Culture and Society, 30 (4): 2211-2236.

Freeman, K. (2002). NEW SOUTH WALES DRUG COURT EVALUATION: HEALTH, WELL-BEING AND PARTICIPANT SATISFACTION, New South Wales Bureau of Crime Statistics and Research

Freiberg, A. (2002). Specialised Courts and Sentencing, Paper presented at the Probation and Community Corrections: Paper presented at 'Making the Community Safer Conference', the Australian Institute of Criminology and the Probation and Community Corrections Officers' Association, Perth, 23-24 September 2002.

Gallagher, J. (2013). African American Participants' Views on Racial Disparities in Drug Court Outcomes. Journal of Social Work Practice in the Addictions, 13:2, 143-162, DOI: $10.1080 / 1533256 X .2013 .784689$

Gallagher, J., Nordberg, A, and Kennard, T. (2015). A Qualitative Study Assessing the Effectiveness of the Key Components of a Drug Court, Alcoholism Treatment Quarterly, 33:1, 64-81, DOI: 10.1080/07347324.2015.982453

Gallagher, J., and Nordberg, A. (2016). Comparing and contrasting White and African American participants' lived experiences in drug court, Journal of Ethnicity in Criminal Justice, 14:2, 100-119, DOI: 10.1080/15377938.2015.1117999

Garcia-Villegas, M. (2003) SYMBOLIC POWERWITHOUT VIOLENCE? CRITICAL COMMENTS ON LEGAL CONSCIOUSNESS STUDIES. International Journal for the Semiotics of Law, 16: 363-393

Garland, D. (2014). What is a "history of the present"? On Foucault's genealogies and their critical preconditions, Punishment \& Society, 16(4) 365-384. DOI: $10.1177 / 1462474514541711$

George, L., Ngamu, E., Sidwell, M., Hauraki, M., Martin- Fletcher, N., Ripia, Davis, R., Ratima, P., and Wihongi, H. (2014). Narratives of Suffering and Hope: Historical 
trauma and contemporary rebuilding for Māori women with experiences of incarceration, MAI, 3(3) 184-196.

Gibson, K. (2016). Women who inject drugs: barriers to their access of Needle Exchange services and gendered experiences. MA Thesis, Victoria University of Wellington, New Zealand

Goldingay, S. (2007) 'Jail Mums: The Status of Adult Female Prisoners Among Young Female Prisoners in Christchurch Women's Prison'. Social Policy Journal of New Zealand, 31, 56-73

Goldkamp, J. (2000). THE DRUG COURT RESPONSE: ISSUES AND IMPLICATIONS FOR JUSTICE CHANGE, Albany Law Review, 923-961.

Goldkamp, J, White, M., and Robinson, J. (2001). Do Drug Courts Work? Getting Inside the Drug Court Black Box, Journal of Drug Issues, 31(1), 27-72.

Goldsmith, J., and Latessa, E. (2001). Coerced Treatment of Addictions in the Criminal Justice System, Psychiatric Annals, 31(11):657-664.

Goodall, H. L. (2000). Writing the New Ethnography. Cumnor Hill: AltaMira Press

Goodall, W. (2016). The sentenced prisoner population. Practice, 4, 16-22.

Gottfredson, D.C., Najaka, S. \& Kearley B. (2003). Effectiveness of Drug Treatment Court: Evidence from a Randomised Trial. Criminology and Public Policy, 2(2), 171-196. DOI: $10.1111 / \mathrm{j} .1745-9133.2003 . t b 00117 . x$

Gowan, T. and Whetstone, S. (2012). Making the criminal addict: Subjectivity and social control in a strong-arm rehab. Punishment \& Society, 14, (69): 69-93. DOI: $10.1177 / 1462474511424684$

Granfield, R and Reinarman, C (2014). Expanding Addiction: Critical Essays. Routledge

Gross, J. (2010). The Effects of Net-Widening on Minority and Indigent Drug Offenders: A Critique of Drug Courts, Law Journal of Race, Religion, Gender and Class, 10(1), 9:161-178.

Guillemin, M and Gillam, L (2004). Ethics, Reflexivity, and Ethically Important Moments in Research. Qualitative Inquiry 10(2):261-28 DOI: 10.1177/1077800403262360

Gutierrez, L. and Bourgon, G. (2009). Drug Treatment Courts: A Quantitative Review of Study and Treatment Quality, Justice Research and Policy, 14, (2), 47-76.

Habitual Drunkards Act (1906). No. 45. Retrieved from: http://www.enzs.auckland.ac.nz/docs/1906/1906A45.pdf March 2014

Hall, W., and Lucke, J. (2010). Legally coerced treatment for drug using offenders: ethical and policy issues. Contemporary Issues in Crime and Justice, 144, 1-12.

Hallam, C. and Bewley-Taylor, D. (2010). Drug Use Knowledge, Culture and Context, The Beckley Foundation Drug Policy Programme, Briefing Paper Twenty-One. Retrieved from: http://www.emcdda.europa.eu/publications/joint/ndo-handbook/toolbox April, 2014 
Hammersley, M and Atkinson, P. (2007). Ethnography: Principles in Practice. Third edition, Routledge, London: Taylor and Francis.

Hammersley, R. and Reid, M. (2002). Why the pervasive addiction myth is still believed. Addiction Research \& Theory 10(1):7-30. DOI: 10.1080/16066350290001687

Hannah-Moffatt, K. (2000). Prisons that Empower, Neoliberal Governance in Canadian Women's Prisons, British Journal of Criminology, 40, 510-531.

Hannah-Moffatt, K. (2005). Criminogenic needs and the transformative risk subject: Hybridizations of risk/need in penality, Punishment and Society, 7(1): 29-51. DOI : $10.1177 / 1462474505048132$

Hannah-Moffatt, K. and Maurutto, P. (2012). Shifting and targeted forms of penal governance: Bail, punishment and specialized courts. Theoretical Criminology 16: 201-219. DOI: 10.1177/1362480612443302

Harding, S and Norberg, K. (2005). New Feminist Approaches to Social Science Methodologies: An Introduction. Journal of Women in Culture and Society 2005, 30, (4):1-8.

Harding, R. (2010). Regulating Sexuality: Legal Consciousness in Lesbian and Gay Lives, Taylor \& Francis.

Harris, R., Cormack, D., Tobias, M., Ye, L., Talamaivao, T., Minster, J., Timutimu, R., (2012). Self-Reported Experience of Racial Discrimination and Health Care Use in New Zealand: Results from the 2006/07 New Zealand Health Survey, American Journal of Public Health 102(5):1012-1019

Harris, J. and McElrath, K. (2012). Methadone as Social Control: Institutionalized Stigma and the Prospect of Recovery. Qualitative Health Research 22(6): 810-824. DOI: $10.1177 / 1049732311432718$

Hart, K (2017). Viewing addiction as a brain disease promotes social injustice, NATURE HUMAN BEHAVIOUR 1(0055) DOI: 10.1038/s41562-017-0055

Hathaway, A. (2002). From harm reduction to human rights: bringing liberalism back into drug reform debates. Drug and Alcohol Review, 21, 397-404. DOI:

$10.1080 / 095923021000023270$

Healthpoint (2016). NGO Mental Health \& Addictions, Retrieved: http://www.healthpointltd.co.nz/products/healthcare-services-informationdirectory/ngo-mental-health-addictions-1/ September, 2016

Hedican, E. J. (2006). Understanding Emotional Experience in Fieldwork: Responding to Grief in a Northern Aboriginal Village, International Journal of Qualitative Methods $5(1), 1-8$.

Heidensohn, F. (2006). Gender and Justice: New Concepts and Approaches, UK: Willan.

Hill, R. (2012). MAORI URBAN MIGRATION AND THE ASSERTION OF

INDIGENEITY IN AOTEAROA/NEW ZEALAND, 1945-1975, Interventions, 14:2, 256-278, DOI:10.1080/1369801X.2012.687903 
Hodson, J.D. (1983). The Ethics of Legal Coercion. Holland: D. Reidel Publishing Company

Hoffman, M. (2000). THE Drug Court Scandal, North Carolina Law Review, 78, 1437-1534.

Hoffman, M. (2002). THERAPEUTIC JURISPRUDENCE, NEOREHABILITATIONISM, AND JUDICIAL COLLECTIVISM: THE LEAST DANGEROUS BRANCH BECOMES MOST DANGEROUS, Fordham Urban Law Journal, 2063-2098.

Homes for Inebriates (1904). First Report, Appendix to the Journals of the House of Representatives, 1904 Session I, H-22b. Retrieved from: http://atojs.natlib.govt.nz/cgi-bin/atojs?a=d\&d=AJHR1904-I.2.3.2.32\&e=-------10--1-----0-- March, 2014

Hook, G. R. (2009). "Warrior genes” and the disease of being Māori. MAI Review, 2:1-11. Retrieved from: http://www.review.mai.ac.nz May, 2014

Hora, P., Schma, G, and Rosenthal, J. (1999). Therapeutic Jurisprudence and the Drug Treatment Court Movement: Revolutionizing the Criminal Justice System's Response to Drug Abuse and Crime in America. Notre Dame Law Review 74(2): 439-537.

Hora, P. (2002). A Dozen Years of Drug Treatment Courts: Uncovering Our Theoretical Foundation and the Construction of a Mainstream Paradigm. Substance Use \& Misuse 37(12 \& 13): 1469-1488

Hora, P and Stalcup, T (2008). Drug Treatment Courts in the Twenty-First Century: The Evolution of the Revolution in Problem-Solving Courts, Georgia Law Review, 42, (3): 719-743.

Hora, P. (2011). Courting New Solutions Using Problem-Solving Justice: Key Components, Guiding Principles, Strategies, Responses, Models, Approaches, Blueprints and Tool Kits, Chapman Journal of Criminal Justice, 2:7-52.

Hough, M (2002). CONTROLLING/POLICING SUBSTANCE USE (RS): DRUG USER TREATMENT WITHIN A CRIMINAL JUSTICE CONTEXT, Substance Use and Misuse, 37, (8-10):985-996. DOI: 10.1081/JA-120004162

Hudson M, Milne M, Reynolds P, Russell K, and Smith B. (2010). Te Ara Tika: Guidelines for Māori Research Ethics: A Framework for Researchers and Ethics Committee Members. Auckland: Health Research Council of New Zealand.

Hughes, H. (2007). WHAKAOHONGA NA KAHUNGATANGA: AWAKENING FROM ADDICTION. M.A Thesis, Victoria University of Wellington, New Zealand.

Hull, E. (2016). Legal Consciousness in Marginalized Groups: The Case of LGBT People, Law \& Social Inquiry, 41(3), 551-572

Human rights Commission (2008). To Be Who I am: Report into of the Inquiry into Discrimination Experienced by Transgender People, Wellington, New Zealand.

Human Rights Commission (2010). The Right to Health, Economic, Social and Cultural Rights. Retrieved from:

https://www.hrc.co.nz/files/9714/2388/0506/HRNZ_10_Right_to_health.pdf 
Hunt, N, and Stevens, A. (2004). Whose Harm? Harm Reduction and the Shift to Coercion in UK Drug Policy, Social Policy \& Society 3(4): 333-342. DOI:

10.1017/S1474746404001964

Hunter, M. (2002). Rethinking epistemology, methodology, and racism: or, is White sociology really dead?, Race \& Society, 5, 119-138.

Hunter, C. Nixon, J and Blandy, S. (2008). Researching the Judiciary: Exploring the Invisible in Judicial Decision Making, Law and Society 35 (1):76-90.

Huriwai, T., Robertson, P., Armstrong, D., Kingi, T, and Huata, P. (2001). WHANAUNGATANGA - A PROCESS IN THE TREATMENT OF MAORI WITH ALCOHOL- AND DRUG-USE RELATED PROBLEMS, Substance Use \& Misuse, 36(8), 1033-1051. DOI: 10.1081/JA-100104488

Husak, D. (1999). Addiction and Criminal Liability, Law and Philosophy 18, (6): 655-684.

Hutt, M. (1999), Te Iwi Maori me te Inu Waipiro: He Tuhituhinga Hitori Maori \& Alcohol: A History. Alcohol Advisory Council of New Zealand (ALAC), Wellington, New Zealand.

Inciardi, J.A. (1979). Heroin Use and Street Crime, Crime \& Delinquency 25: 335-346. DOI: $10.1177 / 001112877902500304$

Indig, D., Gear, C., and Wilhelm K., (2016). Comorbid substance use disorders and mental health disorders among New Zealand prisoners. New Zealand: Department of Corrections, Wellington.

IPCA, Independent Police Conduct Authority, (2015). Review of Police Custodial Management. Wellington, New Zealand. Retrieved:

https://www.ipca.govt.nz/Site/publications-and-media/Reports-on-places-of-Policedetention.aspx January, 2016

Inebriates Report (1904). Homes for Inebriates, New Zealand. Retrieved: http://www.nzlii.org/nz/legis/hist_act/la186832v1868n16232/June, 2013

Israel, M. and Hay, I. (2006). Research ethics for social scientists: between ethical conduct and regulatory compliance. London. Sage.

Jackson, M. (1988) Maori and the Criminal Justice System: He Whaipaanga Hou: A New Perspective. Department of Justice, Wellington, New Zealand.

Jewkes, Y. (2011). Autoethnography and Emotion as Intellectual Resources: Doing Prison Research Differently, Qualitative Inquiry18 (1) 63-75. DOI: $10.1177 / 1077800411428942$

Justice Policy Institute, (2011). Addicted to the Courts: How a Growing Dependence on Drug Courts Impacts People and Communities, Retrieved from: http://www.justicepolicy.org/research/2217 April 2014

Kaye, K. (2012). Rehabilitating the 'drugs lifestyle': Criminal justice, social control, and the cultivation of agency, Ethnography, 14(2) 207-232. DOI:

$10.1177 / 1466138112457311$ 
Keane, H. (2004). Disorders of Desire: Addiction and Problems of Intimacy. Journal of Medical Humanities 25(3): 189-204. DOI: 1041-3545/04/0900-0189/0

King, M. (2010). Judging, judicial values and judicial conduct in problem-solving courts, Indigenous sentencing courts and mainstream courts, 133-159. Retrieved from: http://sites.thomsonreuters.com.au/journals/files/2010/09/Article-King-2010-19-JJA133.pdf October 2014

Kingi, V. (2009). The Forgotten Victims - the Effects of Imprisonment on Families/Whānau, Paper presented at the Institute of Policy Studies Forum 'Addressing the Underlying Causes of Offending: What is the evidence?' Victoria University of Wellington, 26-27 February 2009

Klag, S., O’Callaghan, F. \& Creed, P. (2005). The Use of Legal Coercion in the Treatment of Substance Abusers: An Overview and Critical Analysis of Thirty Years of Research. Substance Use \& Misuse, 40: 1777-1795. DOI 10.1080/10826080500260891

Kleinig, J. (2004). Ethical Issues in Substance Use Intervention, Substance Use \& Misuse 39 (3):369-398.

Kleinig, J. (2008). The Ethics of Harm Reduction, Substance Use and Misuse, 43, (1), 1-16. DOI: $10.1080 / 10826080701690680$

Knauer, N. (2012). Legal Consciousness and LGBT Research: The Role of the Law in the Everyday Lives of LGBT Individuals, Journal of Homosexuality, 59:5, 748-756, DOI: 10.1080/00918369.2012.673947

Koetzle Shaffer, D., Hartman, J., and, Johnson Listwan, S., (2009). Drug Abusing Women in the Community: The Impact of Drug Court Involvement on Recidivism, Journal of Drug Issues, (9), 803-828.

Kornhauser, R. (2016). The effectiveness of Australia's drug courts, Australian \& New Zealand Journal of Criminology, 0(0) 1-23. DOI: 10.1177/0004865816673412

Lather, P. (1993). Fertile Obsession: Validity after Post structuralism, The Sociological Quarterly, 34 (4), 673-693.

Lavanchy, A. (2013). Dissonant alignments: The ethics and politics of researching state institutions, Current Sociology, 0(0): 1-16. DOI: 10.1177/0011392113486883

Law Commission Report, (2010). Compulsory Treatment for Substance Dependence A Review of the Alcoholism and Drug Addiction Act 1966, Chapter 1: Drug Policy And Treatment pp 16-18. Retrieved from: http://www.lawcom.govt.nz/project/reviewmisuse-drugs-act-1975/publication/report/2010/compulsory-treatment-substancedependent 23 March, 2013

Law Commission Report, (2011). Controlling and Regulating Drugs - A Review of the Misuse of Drugs Act 1975, R122, Part 3, Chapter 12, Drug treatment, 319-344. Retrieved: http://www.lawcom.govt.nz/project/review-misuse-drugs-act1975?quicktabs_23=report\#quicktabs-23 March 2013 
Lenton S. and Single, E. (1998). 'The definition of harm reduction', Drug and Alcohol Review 17:213-220. DOI: 10.1080/09595239800187011

Lind, B., Weatherburn, D., Chen, S., Shanahan, M., Lanscar, E., Haas, M. and De Abreu Lourenco, R. (2002). New South Wales drug court evaluation: Cost-effectiveness. Sydney: NSW Bureau of Crime Statistics and Research.

Liebling, A. (2001). Whose Side Are We On? Theory and Practices in Prison Research, British Journal of Criminology, 41, 472-484.

Lines, R. (2010). Deliver us from evil'? - The Single Convention on Narcotic Drugs, 50 years on. International Journal on Human Rights and Drug Policy 1, 3-14. Retrieved: http://evolvecms.webfreelancersuk.co.uk/sites/default/files/Deliver_us_from_evil.pdf April 2014

Litmus, (2014). Formative Evaluation for the Alcohol and other Drug Treatment Court Pilot, 31 March 2014.

Litmus, (2015). Process Evaluation for the Alcohol and other Drug Treatment Court Te Whare Whakapiki Wairua Interim Report, 18 August 2015.

Litmus, (2016). Final Process Evaluation for the Alcohol and Other Drug Treatment Court, Te Whare Whakapiki Wairua, 17 August 2016

Lunatics Act (1868). (32 Victoriae 1868 No 16), New Zealand Legal Information Institute, Retrieved http://www.nzlii.org/nz/legis/hist_act/la186832v1868n16232/June, 2013

Lutze, F. and van Wormer, J (2007). The Nexus Between Drug and Alcohol Treatment Program Integrity and Drug Court Effectiveness: Policy Recommendations for Pursuing Success, Criminal Justice Policy Review, 18(3): 226-245. DOI: $10.1177 / 0887403406302327$

Lyons, T. (2011). A Critical Ethnography of the Ottawa Drug Treatment Court: Linking Discourses of Addiction, Addicted Subjects \& Treatment Practices. PhD Thesis, Carleton University, Ottawa, Ontario, Canada.

Lyons, T, Shannon K, Pierre, L, Small, W, Krusi, A and Kerr, T. (2015). A qualitative study of transgender individuals' experiences in residential addiction treatment settings: stigma and inclusivity. Substance Abuse Treatment, Prevention, and Policy, 10(17):16. DOI 10.1186/s13011-015-0015-4

Macintosh, T. (2005). Maori identities: Fixed, Fluid, Forced. H, Liu, T, Mc Creanor, T, McIntosh and T, Teaiwa (Eds). New Zealand Identities: Departures and Destinations, pp:38-52, Victoria University Press: Wellington, New Zealand.

Mackinem, M, and Higgins, P. (2007). Tell Me about the Test: The Construction of Truth and Lies in Drug Court. Contemporary Ethnography 36(3):223-251. DOI: $10.1177 / 0891241606287417$

Madison, D (2012). Critical Ethnography: Method, Ethics, and Performance, (2 ${ }^{\text {nd }}$ Ed.) SAGE. 
Makkai, T. \& Veraar, K. (2003). Final Report on the South East Queensland Drug Court, Australian Institute of Criminology Technical and Background Paper Series, no. 6, Australian Institute of Criminology, Canberra.

Malkin, V. (2005). The End of Welfare As We Know It: What Happens When the Judge is in Charge. Critique of Anthropology, 25(4) 361-388, DOI: 10.1177/0308275X05058655

Malloch, M (2000). Caring for Drug Users? The Experiences of Women Prisoners. The Howard Journal, 39(4):354-368.

Mancall, P., Robertson, P., and Huriwai, T. (2000). Maori and alcohol: a reconsidered history, Australian and New Zealand Journal of Psychiatry, 34(1): 129-134.

Marlowe, D. (2003). Integrating Substance Abuse Treatment and Criminal Justice Supervision, Addiction Science and Clinical Practice, 2(1): 4-14.

Marlowe, D. (2010). Research Update on Adult Drug Courts, NADCP, United States.

Marlowe, D., Festinger, D., Lee, P., Dugosh, K. and Benasutti, K. (2006). Matching Judicial Supervision to Clients' Risk Status in Drug Court, Crime Delinq 52(1): 52-76.

Marlowe, D., Kirby, C., Bonieskie, L', Glass, D., Dodds, S., Husband, J., Platt, J., and Festinger, D. (1996). Assessment of coercive and noncoercive pressures to enter drug abuse treatment. Drug and Alcohol dependence, 42(2):77-84.

Marlowe, D. and Meyer, (2011). The Drug Court Judicial Benchbook, National Drug Court Institute, United States.

Marlowe, Hardin and Fox, (2016). Painting the Current Picture: A National Report on Drug Courts and Other Problem-Solving Court Programs in the United States, National Drug Court Institute, United States.

Marshall, A and Barclay, M. (2003). In Their Own words: How Ordinary People Construct the Legal world, Law and Social Inquiry, 28, (3): 617-628 DOI: 10.1111/j.17474469.2003.tb00209.x

Martin, S. (2001). The Links between Alcohol, Crime and the Criminal Justice System: Explanations, Evidence and Interventions. The American Journal on Addictions 10:136- 158.

Matusow, H., Dickman, S., Rich, J., Fong, C., Dumont, D., Hardin, C., Marlowe, D., and Rosenblum, A. (2013). Medication assisted treatment in US drug courts: Results from a nationwide survey of availability, barriers and attitudes, Substance Abuse Treatment $44,473-480$.

Maurutto, P., and Hannah-Moffatt, K. (2007). Understanding Risk in the Context of the Youth Criminal Justice Act, 466-490. DOI: 10.3138/cjccj.49.4.465.

Maurutto, P., \& Hannah-Moffatt, K. (2016). Aboriginal Knowledges in Specialized Courts: Emerging Practices in Gladue Courts, Law and Society, 31 (3): 451-471 DOI: $10.1017 /$ cls.2016.35 
Mauthner, N. and Doucet, A. (2003). Reflexive Accounts and Accounts of Reflexivity in Qualitative Data Analysis, Sociology, 37(3): 413-431.

Maynard, K., \& Paton, S. (2012). Increasing the use of alcohol screening and brief intervention in New Zealand. Kotuitui: New Zealand Journal of Social Sciences Online, 7(2): 72-82.

McBarnet, D. (1981). Conviction: The Law, the State and the Construction of Justice. Macmillan Press.

McCaffrey, H. (2009). Bitter Pill to Swallow: Portugal's Lessons for Drug Law Reform in New Zealand. (Honours Thesis), Victoria University of Wellington, New Zealand

McColl, W. (2002). Theory and Practice in the Baltimore City Drug Court. J. Nolan, Drug Courts in theory and in practice, pp: 3-27. Aldine De Gruyter: New York.

McDonald, C, and Marston, G. (2006). Workfare as welfare: governing unemployment in the advanced liberal state. Critical Social Policy, 25(3): 374-401.

McKim, A. (2008). 'Getting Gut-Level': Punishment, Gender, and Therapeutic Governance, Gender \& Society, 22: 303. DOI: 10.1177/0891243208317826

McIntosh T and Workman K (2017) Māori and prison. In Deckert A and Sarre R (eds) The Palgrave Handbook of Australian and New Zealand Criminology, Crime and Justice: 725-735. New York: Palgrave Macmillan

McIvor, G. (2009). Therapeutic jurisprudence and procedural justice in Scottish drug courts, Criminology and Criminal Justice, 9 (1): 29-49.

Measham, F. (2002). "Doing gender"-"doing drugs": conceptualizing the gendering of drugs cultures, Contemporary Drug Problems, 29, 335-373.

Measham F. (2006). The new policy mix: Alcohol, harm minimisation, and determined drunkenness in contemporary society, International Journal of Drug Policy 17: 258268

Merry, S. (2001). Rights, Religion, and Community: Approaches to Violence against Women in the Context of Globalization. Law \& Society Review, Vol. 35 (1): 39-88

Miethe, T D., Lu, H and Reese, E. (2000). Reintegrative Shaming and Recidivism Risks in Drug Court: Explanations for Some Unexpected Findings. Crime \& Delinquency 46(4):522-541

Mihaere, R. (2015). A KAUPAPA MĀORI ANALYSIS OF THE USE OF MĀORI CULTURAL IDENTITY IN THE PRISON SYSTEM. (Doctoral Thesis), Victoria University of Wellington, New Zealand

Miller, E. J. (2004). Embracing Addiction: Drug Courts and the False Promise of Judicial Interventionism. Ohio State Law Journal 65: 1479:1480- 1576.

Miller, E. J. (2009). Drugs, Courts, and the New Penology. Stanford Law \& Policy Review 20(2): 417-461. 
Milward, D., and Parkes, D. (2011). Gladue: Beyond Myth and Towards Implementation in Manitoba, Manitoba Law Journal, 35(1), 85-110.

Ministry of Health, (2010). New Zealand Clinical Guidelines for the Use of Buprenorphine (with or without Naloxone) in the Treatment of Opioid Dependence. Wellington: Ministry of Health. Retrieved: https://www.health.govt.nz/system/files/documents/publications/nz-guidelinesbuprenorphine-2010.pdf February 2015.

Ministry of Health, (2012). NGO Request for Tender. Ministry of Health, Wellington: New Zealand. Unpublished.

Ministry of Health, (2014). The National Drug policy 2007-2012. Wellington: New Zealand. Retrieved: http://www.health.govt.nz/our-work/mental-health-and-addictions/drugpolicy/national-drug-policy July, 2014

Ministry of Health, (2014). Addictions. Wellington: New Zealand. Retrieved: http://www.health.govt.nz/your-health/healthy-living/addictions July, 2014

Ministry of Health (2015). National Drug Policy 2015 to 2020. Wellington: New Zealand. Ministry of Health. Retrieved: http://www.health.govt.nz/publication/national-drugpolicy-2015-2020 December, 2015

Ministry of Health (2016). Regulatory Impact Statement - Substance Addiction (Compulsory Assessment and Treatment) Bill. Wellington, New Zealand, Ministry of Health.

Retrieved: http://www.health.govt.nz/about-ministry/legislation-andregulation/regulatory-impact-statements/substance-addiction-compulsory-assessmentand-treatment-bill December, 2016

Ministry of Justice (2009). Drivers of Crime Ministerial Meeting Proceedings: Wellington, New Zealand: Ministry of Justice. Retrieved from: http://www.justice.govt.nz/justicesector/drivers-of-crime/publications-and-backgroundinformation/documents/Addressing\%20the\%20Drivers\%20of\%20Crime\%20Cabinet \%20paper.pdf March, 2013

Ministry of Justice. (2011). Drivers of Crime Investment Package Implementation Plan Cabinet Paper. Wellington, New Zealand: Ministry of Justice. http://www.justice.govt.nz/publications/global-publications/d/drivers-of-crimeinvestment-package-for-alcohol-and-other-drug-assessments-and-interventions-2013implementation-plan-cabinet-paper/publication September 2013

Ministry of Justice, (2012a). Alcohol and Other Drug Treatment Court, Te Whare Whakapiki Wairua, Handbook, version 1. Wellington, New Zealand: Ministry of Justice

Ministry of Justice, (2012b). The Alcohol and Other Drug Treatment Court, Te Whare Whakapiki Wairua Evaluation Plan, Final Report. Unpublished.

Ministry of Justice, (2014). Alcohol and Other Drug Treatment Court, Te Whare Whakapiki Wairua, Handbook, version 2. Wellington, New Zealand: Ministry of Justice 
Ministry of Justice (2017). Specialist Criminal Courts. Retrieved:

http://www.districtcourts.govt.nz/criminal-court/criminal-jurisdiction/specialistcriminal-courts/ August, 2017

Ministry of Justice (2019). Summary of Adults convicted and sentenced. Retrieved: https://www.justice.govt.nz/assets/Documents/Publications/z7rdy8-Adult-datahighlights-jun2019-v1.0.pdf June, 2019

Misuse of Drugs Act, (1975). Retrieved:

http://www.legislation.govt.nz/act/public/1975/0116/latest/DLM436101.html July, 2014

Moore, D., (2007). Translating Justice and Therapy: The Drug Treatment Court Networks. British Journal of Criminology 47, PP. 42-60. DOI:10.1093/bjc/azl028

Moore, D. (2011). The benevolent watch: Therapeutic surveillance in drug treatment court. Theoretical Criminology, 15, 255-268. DOI 10.1177/1362480610396649

Moore, D., and Hirai, H. (2014). Outcasts, performers and true believers: Responsibilized subjects of criminal justice, Theoretical Criminology, 18(1) 5-19. DOI: $10.1177 / 1362480613519287$

Moore, D., and Lyons, T., (2007). 'Sentenced to Treatment/Sentenced to Harm: Women, Risk and Drug Treatment Courts', in Hannah Moffatt, K, and O'Malley, P. (Eds), Gendered Risks, Abingdon: Cavendish, Routledge.

Moore, D., and Maher, L. (2002). Ethnography and multidisciplinary in the drug field. International Journal of Drug Policy, 13, 245-247.

Mullen, J. (2016). Evidence-based principles for prison-based alcohol and other drug treatment. Practice: The New Zealand Corrections Journal, 4 (2). Department of Corrections, Wellington: New Zealand.

Munger, F. (2007). Constitutional Reform, Legal Consciousness, and Citizen Participation in Thailand. Cornell International Law 40(2) 455-475.

Murphy, J. (2011). Drug Court as Both a Legal and Medical Authority. Deviant Behavior 32 (3): 257-291. DOI: 10.1080/01639621003771979

Murphy, J. (2015). Illness or Deviance, Drug Courts, Drug Treatment and the Ambiguity of Addiction. Temple University Press, Unite States.

National Association of Drug Court Professionals, (NADCP), (1997). Defining Drug Courts: The Key Components, Washington: Office of Justice Programs, US Department of Justice.

National Association of Drug Court Professionals, (2010). Resolution of the Board of Directors on the availability of medically assisted treatment (M.A.T.) for addiction in Drug Courts. Alexandria, Virginia, United States.

National Association of Drug Court Professionals, (2013). Adult Drug Court Best Practice Standards, Volume, I. Alexandria, United States. 
National Association of Drug Court Professionals. (2015). Adult Drug Court Best Practice Standards, Volume II. Alexandria, United States.

National Drug Court Institute, (NDCI), (2011). The Drug Court Judicial Benchbook. D. Marlowe and W. Meyer (Eds). Alexandria, United Sates. National Drug Court Institute.

National Committee for Addiction Treatment, (2011). Addiction treatment is everybody's business: Where to from here?. Wellington: New Zealand. Retrieved from: www.ncat.org.nz July, 2013

Newbold, G (2007). The problem of prisons: corrections reform in New Zealand since 1840. Wellington, New Zealand. Dunmore.

New Zealand Bill of Rights Act (1990). Retrieved: http://www.legislation.govt.nz/act/public/1990/0109/latest/DLM224792.html June, 2014

New Zealand Code of Health, and Disability Services Consumers' Rights, (1996). Retrieved: http://www.hdc.org.nz/the-act--code/the-code-of-rights/the-code-(full) June, 2014

New Zealand Drug Foundation (2011). Should New Zealand introduce drug courts? Matters of Substance, 21, (3). Retrieved from: https://www.drugfoundation.org.nz/matters-ofsubstance/august-2011/introduce-drug-courts/. December 2012

New Zealand Herald (1866). The Vagrants Act 1886, Volume III, (912), 16 October, p. 6. Retrieved from: http://paperspast.natlib.govt.nz/cgibin/paperspast?a=d\&d=NZH18661016.2.27 April, 2014

New Zealand Police (2013). NEW ZEALAND CRIME STATISTICS (2012) A Summary of Recorded and Resolved Offence Statistics, PNQ. Retrieved:

https://www.police.govt.nz/sites/default/files/publications/crime-stats-national-20121231.pdf

Nicoll, F. (2012). Bad Habits: Discourses of Addiction and the Racial Politics of Intervention, Griffith Law Review, 21(1): 164-189, DOI: $10.1080 / 10383441.2012 .10854736$

Nielsen, L. (2000). Situating Legal Consciousness: Experiences and Attitudes of Ordinary Citizens about Law and Street Harassment, Law \& Society Review, 34(4):1055-1090

Nilssen, E. (2005). Coercion and justice: a critical analysis of compulsory intervention towards adult substance abusers in Scandinavian social law. International Journal of Social Welfare, 14, 134-144. DOI 10.1111/j.1369-6866.2005.00350.x

Nolan, J. (2001). Reinventing Justice: The American Drug Court Movement. New Jersey: Princeton University Press.

Nolan, J. (2002a). Drug Treatment Courts and the Disease Paradigm. Substance use \& Misuse, 37:1723-1750

Nolan, J. (2002b). Drug Courts in Theory and in Practice (Ed). New York, Aldine de Gruyter. 
Nolan, J. (2002c). Therapeutic Adjudication, society, pp. 29-37 Retrieved from:

http://download.springer.com/static/pdf/368/art\%253A10.1007\%252FBF02717526.p df?auth66=1407285903_609c9f8ea4629c0b869fb25ea2cc957d\&ext=.pdf January 2014

Nolan, J. (2003). Redefining Criminal Courts: Problem-Solving and the Meaning of Justice. 40 American Criminal Law Review 1541.

Nolan, J. (2010). Freedom, Social Control, and the Problem-Solving Court Movement. Sociology of Crime, Law and Deviance, 15:65-89, DOI: 10.1108/S15216136(2010)0000015006

Nordstrom, B. and Marlowe, D. (2016). Medication-assisted treatment for opioid use disorders in drug courts, National Drug Court Institute, XI (2), 1-15.

Nored, L and Carlen, P (2008). Success of Drug Court Programs: Examination of the Perceptions of Drug Court Personnel, Criminal Justice Review, 33:329-342. DOI $10.1177 / 0734016808322050$

Office of Disability Issues, [ODI], (2018). UN Convention on the Rights of Persons with Disabilities. Retrieved: https://www.odi.govt.nz/united-nations-convention-on-therights-of-persons-with-disabilities/read-the-convention/ March 2018.

Olofsson, A, Zinn, J, Griffin, G, Giritli Nygren, K, Cebulla, A and Hannah-Moffatt, K. (2013). The mutual constitution of risk and inequalities: intersectional risk theory, Health, Risk \& Society. DOI: 10.1080/ 13698575.2014.942258

O'Malley, P. (1973). The Amplification of Maori Crime: Cultural and Economic Barriers to Equal Justice in New Zealand, Race, 48-57. Retrieved: http://journals.sagepub.com/doi/pdf/10.1177/030639687301500103 August 2013.

O'Malley, P. (2002). Globalizing risk? Distinguishing styles of 'neo-liberal' criminal justice in Australia and the USA, Criminology and Criminal Justice, 2: 205- 221. DOI: $10.1177 / 17488958020020020501$

O’Hear, M. (2009). Rethinking Drug Courts: Restorative Justice as a Response to Racial Injustice, Law and Policy Review, 20, (2): 1-39.

Orb, A., Eisenhauer, A., Wynaden, D. (2001). Ethics in Qualitative Research, JOURNAL OF NURSING SCHOLARSHIP, 33 (1): 93-96

Parker, L and Lynn, M. (2002). What's Race Got to Do With It? Critical Race Theory's Conflicts With and Connections to Qualitative Research Methodology and Epistemology, Qualitative Inquiry, 8 (1): 7-22.

Peele, S (1987). A Moral Vision Of Addiction: How Peoples Values Determine Whether They Become And Remain Addicts. Journal of Drug Issues, 17(2): 187-215.

Peele, S. Brodsky, and Arnold, M (1992). The Truth about Addiction and Recovery. Fireside, New York

Pere, L and Barnes, A. (2009). New Learnings from Old Understandings: Conducting Qualitative Research with Māori. Qualitative Social Work, 8(4): 449-467. 
Pollack, S. (2008). Locked in, Locked Out: Imprisoning women in the shrinking and punitive welfare state. Waterloo: Wilfred Laurier University

Potter, H. (2013). Intersectional Criminology: Interrogating Identity and Power in Criminological Research and Theory, Critical Criminology, 21:305-318.

Porter, L., Arif, A., and Curran, W. (1986). The Law and the Treatment of Drug and Alcoholdependent Persons: A Comparative Study of Existing Legislation, World Health Organization: 1986. England.

Pratt, J. (1992). Punishment in a perfect society: the New Zealand penal system, 1840-1939. Victoria University Press, Wellington, New Zealand.

Prendergast, M., Farabee, D., Cartier J., and Henkin, S. (2002). INVOLUNTARY TREATMENT WITHIN A PRISON SETTING: Impact on Psychosocial Change during Treatment, CRIMINAL JUSTICE AND BEHAVIOR, 29, (1): 5-26.

Preventing Reoffending (2009). Cabinet Policy Committee, Paper 9, Office of the Minister of Justice. Wellington, New Zealand. Ministry of Justice.

Pritchard, E., Mugavin, J. \& Swan, A. (2007). Compulsory treatment in Australia: a discussion paper on the compulsory treatment of individuals dependent on alcohol and/or other drugs. Australian National Council on Drugs Research Paper 14. Canberra.

Purvis, T and Hunt, A. (1993). Discourse, Ideology, Discourse, Ideology, Discourse, Ideology. British Journal of Sociology, 44(3):473-499.

Quirouette, M., Hannah-Moffat, K. and Maurutto, P. (2015). A PRECARIOUS PLACE': HOUSING AND CLIENTS OF SPECIALIZED COURTS, British Journal of Criminology, 1-19. DOI:10.1093/bjc/azv050

Rafalovich, (1999). Keep Coming Back! Narcotics Anonymous narrative and the recovering addict identity, Contemporary Drug Problems, 26, 131-157.

Reformatory Institutions Act, (1909). No, 30. Retrieved from: http://www.enzs.auckland.ac.nz/docs/1909/1909A030.pdf March, 2014

Reinarman, C. (2005). Addiction as accomplishment: The discursive construction of disease. Addiction Research and Theory 13(4):307-320. DOI: 10.1080/16066350500077728

Renzetti, C. and Lee, R. (1993). Researching sensitive topics. Sage

Reports Lunatics Asylum (1871). National Library of New Zealand, Wellington: New Zealand. Retrieved from: http://natlib.govt.nz/records/20333325 May, 2014

Rethinking Crime and Punishment (2011). Therapeutic Jurisprudence and Problem Solving Courts - A New Direction for Criminal Justice, rethinking crime and punishment newsletter, (94). Robson Hanan Trust, New Zealand.

Richards, L., and Morse, J. (2007). Users Guide to Qualitative Methods, Second edition. Thousand Oaks, CA: Sage.

Roach Anleu, S. (2000). Law and Social Change. London: Sage. 
Roach Anleu, S., Bergman Blix, S and Mac, K. (2015). Researching Emotion in Courts and the Judiciary: A Tale of Two Projects, Emotion Review, 7 (2): 145-150.

Rosenthal, J. (2002). Therapeutic Jurisprudence and Drug Treatment Courts: Integrating Law and Science. Drug Court in Theory and in Practice. In J.L. Nolan. (pp 145-171). New York. Aldine De Gruyter.

Sarat, A. (1990). The law is all over: Power, resistance and the legal consciousness of the welfare poor. Journal of Law and the Humanities, 2(6):1-38.

Sanford, S., and Arrigo, B. (2005). Lifting the Cover on Drug Courts: Evaluation Findings and Policy Concerns, International Journal of Offender Therapy and Comparative Criminology, 49(3), 2005 239-259. DOI: 10.1177/0306624X04273200

Sandberg, S. and Copes, H. (2012). Speaking With Ethnographers: The Challenges of Researching Drug Dealers and Offenders, Journal of Drug Issues, 43(2) 176-197

Saum, C. A., Scarpitti, F. R., Butzin, C. A., Perez, V. W., Jennings, D., \& Gray, A. R., (2002). Drug court participants' satisfaction with treatment and the court experience. Drug Court Review, 4, 39-81.

Schma, W. (2000). Court Review, retrieved from: http://aja.ncsc.dni.us/courtrv/cr37/cr371/cr9schma.pdf December, 2013

Schopp, R. (2013). Mental Health Courts: Competence, Responsibility, and Proportionality, in, R, Wiener, and E, Brank (Eds), Problem Solving Courts, 169-183. New York: Springer.

Scoop Independent News (2012). Alcohol and Other Drug Treatment Court (AODT) pilot launch Thursday 1 November, Retrieved from:

http://www.scoop.co.nz/stories/PA1211/S00006/alcohol-and-other-drug-treatmentcourt-aodt-pilot-launch.htm January, 2014

Scott, C., McKinlay, A., McLellan, T., Britt, E., Grace, R., and MacFarlane, M. (2014). A Comparison of Adult Outcomes for Males Compared to Females Following Paediatric Traumatic Brain Injury. Neuropsychology 29, (4), 501-508.

Searle, W., \& Spier, P. (2006). Christchurch Youth Drug Court Pilot: One-year follow-up study. Wellington: Ministry of Justice.

Seddon, T. (2006). DRUGS, CRIME AND SOCIAL EXCLUSION: Social Context and Social Theory in British Drugs-Crime Research, British Journal of Criminology, 46: 680-703. DOI:10.1093/bjc/azi079

Seddon, T. (2007). Coerced drug treatment in the criminal justice system: Conceptual, ethical and criminological issue. Criminology \& Criminal Justice 7(3):269-286. DOI:

$10.1177 / 1748895807078867$

Sellman, D, Hannifin J, Deering D, Borren P. (1996). Delivery of treatment for people with opioid dependence in New Zealand: Options and recommendations. A commissioned paper for the Ministry of Health, New Zealand, September 1996. 
Sellman, D. (2009). The 10 most important things known about addiction. Addiction 105: 613. DOI:10.1111/j.1360-0443.2009.02673.x

Seron, C., and Silbey, S. (2004). Profession, Science, and Culture: An Emergent Canon of Law and Society Scholarship, Blackwell Companion to Law and Society, Wiley.

Silbey, S. (2005). AFTER LEGAL CONSCIOUSNESS, Annu. Rev. Law Soc. Sci. 1:323-68 doi: 10.1146/annurev.lawsocsci.1.041604.115938

Simon, W. (2003). Criminal Defenders and Community Justice: The Drug Court Example, American Criminal Law Review, 40: 1595-1607.

Simpson, M. (2003). The relationship between drug use and crime: a puzzle inside an enigma. International Journal of Drug Policy, 14 (4):307-319. DOI: 10.1016/S0955 3959(03)00081-1

Singh, R (2012). When punishment and philanthropy mix: Voluntary organizations and the governance of the domestic violence offender, Theoretical Criminology, 16(3):269287 DOI: $10.1177 / 1362480611420904$

Smith, M. (2007). Report on issues involving the criminal justice sector. Office of the Ombudsman, Wellington: New Zealand. Retrieved: http://www.ombudsman.parliament.nz/resources-and-publications/latest-reports May 2014

Spivakovsky, C. (2013). Racialized correctional governance: the mutual constructions of race and criminal justice. Ashgate. Taylor and Francis.

Stanley, E. (2009). Torture, truth and Justice: The Case of Timor-Leste. London. Routledge

Stanley, E. (2011). Human Rights and Prisons: a Review to the Human rights Commission. Auckland: Human Rights Commission Retrieved from https://www.hrc.co.nz/files/5214/2550/8357/Stanley_2011_Human_Rights_and_Prisons.pdf June 2013

Stevens, A. (2012). The ethics and effectiveness of coerced treatment of people who use drugs, Human Rights and Drugs, 22 (1):7-16

Stevens, A, Berto, D., Heckmann, W., Kerschl, V., Oeuvray, K, Van Ooyen, M, Steffan, E., and Uchtenhagen, A. (2005). Quasi-Compulsory Treatment of Drug Dependent Offenders: An International Literature Review, Substance Use \& Misuse, 40:269-283. DOI: $10.1081 / \mathrm{JA}-200049159$

Stevens A., Stover, H. and Brentari, C. (2010). Criminal justice Approaches to Harm Reduction in Europe, pp379-402 in EMCDDA, Harm reduction: evidence, impacts and challenges EMCDDA, Lisbon

Stokes, E., (1985) 'Māori Research and Development', discussion paper prepared for the Social Sciences Committee of the National Research Advisory Council.

Social Science Research Council (SSRC). (2018). Drug Courts in the Americas: A Report by the. Drugs, Security and Democracy Program. 
Tauri, J. (1999). Empowering Maori or Biculturalising the State? Explaining Recent Innovations in New Zealand's Criminal Justice System, The Australian, New Zealand Journal of Criminology 32(2): 153-167.

Tauri J. (2005). 'Indigenous Perspectives and Experiences: Māori and the Criminal Justice System' in Walters R and Bradley T. Introduction to Criminological Thought. Auckland. Pearson Education.

Tauri, J and Webb, R (2012). A critical appraisal of responses to Maori offending. The International Indigenous Policy Journal, 3(4):1-16.

Taxman, F. and Bouffard, J. (2002). Treatment Inside the Drug Treatment Court: The Who, What, Where, and How of Treatment Services. Substance Use and Misuse 37: (12\&13) 1665-1688. DOI: 10.1081/JA-120014426

Te Rau Matatini, (2015). Kaupapa Māori Mental Health and Addiction Services: Best Practice Framework. Wellington. New Zealand.

Thom, K. (2017). EXPLORING TE WHARE WHAKAPIKI WAIRUA/THE ALCOHOL AND OTHER DRUG TREATMENT COURT PILOT: THEORY, PRACTICE AND KNOWN OUTCOMES, Te Wharenga - The New Zealand Criminal Law Review 180-

193

Thom, K and Black, S. (2017). Ngā whenu rāranga/Weaving strands: (1). The therapeutic framework of Te Whare Whakapiki Wairua/The Alcohol and Other Drug Treatment Court. Auckland: University of Auckland.

Thomas, J. (1993). Doing Critical Ethnography. Newbury Park, CA: SAGE Publications, Inc. DOI: $10.4135 / 9781412983945$

Thornton, N. (1991). Injecting Drugs Users: HIV/AIDS, a counselling manual. Department of Health. Wellington: New Zealand. Retrieved: http://www.moh.govt.nz/notebook/nbbooks.nsf/0/522F82FF23C5DB9E4C2565D700 187A8B/\$file/Injecting\%20drug\%20users\%20and\%20HIV\%20AIDS.pdf November, 2014

Tiger, R. (2011). Drug Courts and the Logic of Coerced Treatment, Sociological Forum, 26 (1):169-182. DOI: $10.1111 / \mathrm{j} .1573-7861.2010 .01229 . \mathrm{x}$

Tiger, R. (2013). Judging Addicts: Drug courts and Coercion in the Justice System. New York. New York University Press.

Tinsley, Y and Young, W, (2017). Overuse in the Criminal Justice System in New Zealand International Penal and Penitentiary Foundation series, Cambridge, Intersentia, Forthcoming. At SSRN: https://ssrn.com/abstract=3031128

Toki, V. (2011). Indigenous rights—Hollow rights? Waikato Law Review 19(2): 29-43. DOI $10289 / 9558$.

Tolich, M. and Davidson, C (1999). Starting Fieldwork: An Introduction to Qualitative Research in New Zealand. Auckland. Oxford University Press. 
Trahan, A. (2011). Qualitative Research and Intersectionality, Critical Criminology, 19:1-14. DOI 10.1007/s10612-010-9101-0

Tremewan, Judge L. (2013). What are the hallmarks of such a court and why have we introduced them? Leopards changing spots. Address for the NZLS CLE Criminal Law Symposium, 22 February 2013.

Tulloch, T.C. (1997). State Regulation of Sexuality in New Zealand 1880-1925. Unpublished Doctoral dissertation, University of Canterbury, Christchurch, New Zealand

Urbanoski, K. (2010). Coerced addiction treatment: Client perspectives and the implications of their neglect, Harm Reduction, 7 (13): 1-10

United Nations (2013). Report of the Special Rapporteur on torture and other cruel, inhuman or degrading treatment or punishment, Juan E. Méndez. Retrieved: https://www.ohchr.org/documents/hrbodies/hrcouncil/regularsession/session22/a.hrc.2 2.53 e nglish.pdf. January, 2015

United Nations (2014). Committee on Economic, Social and Cultural Rights. Retrieved: http://www.ohchr.org/EN/HRBodies/CESCR/Pages/CESCRIndex.aspx January, 2015

United Nations, (1992). United Nations Human Rights Committee, General Comment No. 07: Torture or cruel, inhuman or degrading treatment or punishment (Art. 7). Retrieved: http://www.unhchr.ch/tbs/doc.nsf/(Symbol)/7e9dbcf014061fa7c12563ed004804fa?Op endocument. March 2013

United Nations Office of Drugs and Crime, UNODC, (2005). Drug Treatment Courts Work! Vienna. Retrieved from: http://www.unodc.org/pdf/drug_treatment_courts_flyer.pdf, May 2013.

United Nations Office of Drugs and Crime, UNODC, (2009). From coercion to cohesion: Treating drug dependence through health care, not punishment. Vienna. Retrieved: https://www.unodc.org/docs/treatment/Coercion_Ebook.pdf September, 2013

United Nations Office of Drugs and Crime, UNODC (2012). UNODC and the Promotion and Protection of Human Rights. Vienna: United Nations Office on Drugs and Crime.

United Nations of Drugs and Crime \& WHO (2017). International Standards for the Treatment of Drug Use Disorders. Retrieved: https://www.who.int/substance_abuse/activities/msb_treatment_standards.pdf

Unluer, S. (2012). Being an Insider Researcher While Conducting Case Study Research. The Qualitative Report .17(58), 1-14

Valverde, M. (1998). Diseases of the will: Alcohol and the dilemmas of freedom. Cambridge, Cambridge University Press

Valverde, M. (2003). Laws Dream of a Common Knowledge: The Cultural Lives of Law, Princeton, Princeton University Press.

Valverde, M. (2010). Practices of Citizenship and Scales of Governance, New Criminal Law Review: An International and Interdisciplinary Journal, 13(2), 16-240 
Vigilant, (2001). The Stigma Paradox in Methadone Maintenance: Naive and Positive Consequences of A "Treatment Punishment" Approach To Opiate Addiction

von Hirsch, A, and Maher, L (1992). Should Penal Rehabilitationism be Revived? Criminal Justice Ethics, (11), 1: 25-30

von Hirsch, A., and Ashworth, A. (2005). Proportionate Sentencing: Exploring the Principles. United States, Oxford University Press.

Vrecko, S (2010). Birth of a brain disease: science, the state and addiction neuropolitics. History of the Human Sciences, 23(4):52-67. DOI: 10.1177/0952695110371598

Walklate, S. (1995). Gender and Crime: An Introduction, Hemel Hempstead: Prentice Hall.

Walsh-Tapiata, W. (2003). A model for Māori research: Te whakaeke i te ao rangahau o te Māori. In R. Munford \& J. Sanders (Eds.) Making a difference in families: Research that creates change (55-73). Australia: Allen \& Unwin

Wakem, B and McGee, D. (2012). Investigation of the Department of Corrections in relation to the Provision, Access and Availability of Prisoner Health Services, Office of the Ombudsman, Wellington: New Zealand. Retrieved: http://www.ombudsman.parliament.nz/resources-and-publications/latest-reports May 2014

Wakeman, S (2014). Fieldwork, Biography and Emotion: Doing Criminological Autoethnography, British Journal of Criminology, 54: 705-721

Weatherburn, D. (2008). Dilemmas in harm minimization, Addiction, 104: 335-339. doi:10.1111/j.1360-0443.2008.02336.x

Webb, M.B. (2001). Addiction and the Law: A Case Study of the Alcoholism and Drug Addiction Act. Thesis Masters in Laws, University of Canterbury, Christchurch, New Zealand.

Wexler D. B \& Winick B. J. (1996). Law in a Therapeutic Key: Developments in Therapeutic Jurisprudence. Durham. Carolina Academic Press.

Whetstone, S and Gowan, T. (2011). Diagnosing the Criminal Addict: Biochemistry in the Service of the State. Advances in Medical Sociology 12:309-330. DOI: 101108/S1057-6290(2011)0000012018

WHO, (2013). ICD-10 Chapter V Mental and behavioural disorders due to psychoactive substance use. Retrieved: http://apps.who.int/classifications/icd10/browse/2010/en\# December, 2016

WHO, (2013). Model List of Essential Medicines 18th list. Retrieved: http://www.who.int/medicines/publications/essentialmedicines/en/index.html January, 2018.

Wild, T., Roberts, A., and Cooper, E., (2012). Compulsory substance abuse treatment: an overview of recent findings and issues, European Addiction Research, 8:84-93. 
Williams, F. (2007). Reinventing the Courts: The Frontiers of Judicial Activism in the State Courts, Campbell Law Review, 29(3): 591-731.

Williams, I, Mee-Lee, D, Gallagher, J, and Irwin, K. (2017). Rethinking Court-Sanctioned Reintegration Processes: Redemption Rituals as an Alternative to the Drug Court Graduation. The Howard Journal, 56(2) 244-267. DOI: 10.1111/hojo.12203

Wilson, D., Mitchell, O and Mackenzie, D. (2006). A systematic review of drug court effects on recidivism, Journal of Experimental Criminology 2: 459-487. DOI:

10.1007/s11292-006-9019-4

Winick, B.J. (2002). Therapeutic Jurisprudence and Problem Solving Courts, Fordham Urban Law Journal, 30(3): 1055-1103.

Woolhouse, R. (2015). Women in Prison with Traumatic Brain Injury (TBI): Prevalence, Mechanism and Impact on Mental Health. Thesis, Masters of Science in Psychology, University of Canterbury, Christchurch, New Zealand.

Winick, B.J. and Wexler, D.B. (2015). Drug Treatment Court: Therapeutic Jurisprudence Applied, Touro Law Review, 18(3).

Yeomans, H. (2018). Historical context and the criminological imagination: Towards a threedimensional criminology, Criminology \& Criminal Justice, 1-19.

Young, J. (1999). The Exclusive Society: Social Exclusion, Crime and Difference in Late Modernity. London: Sage.

Young, D. (2002). Impacts of Perceived Legal Pressure on Retention in Drug Treatment. Criminal Justice and Behaviour, 29, 27-55. DOI: 10.1177/0093854802029001003

Young, K. (2009). Everyone Knows the Game: Legal Consciousness in the Hawaiian Cockfight, Law \& Society Review, 48(3)499-529.

Young, D. \& Belenko, S. (2002). Program retention and perceived coercion in three models of mandatory drug treatment. Journal of Drug Issues, 32(1), 297-328. 


\section{Appendix A}

*Name*

Participant 1

Participant 2

Participant 3

Participant 4

Participant 5

Participant 6

Participant 7

Participant 8

Participant 9

Participant 10

Participant 11

Participant 12

Participant 15

Participant 16

Participant 17

Participant 18

Total

Participant 13

Participant 14
AODTC participants by Race, Gender and Age

Race

Gender

Age Bracket

Māori

$\mathrm{F}$

$30-40$

Māori

$\mathrm{F}$

25-35

Māori

F

20-30

Māori

$\mathrm{T}$

20-30

Māori

T

20-30

Māori

M

40-50

Māori

M

20-30

Māori

M

$20-30$

Māori

M

25-35

Māori

M

30-39

Māori

M

$50-60$

Māori

M

20-30

Māori

M

20-30

Māori

M

$30-40$

Pākehā

M

$30-40$

Pākehā

M

50-60

Pākehā

M

$30-40$

Pākehā

M

20-30 


\section{Appendix B}

Māori term

Haka

Himene

Karakia

Mimi

Tapu

Wairua

Whanaungatanga
Translation into English

Ceremonial dance, performance

Hymn

Recite a prayer

Pee

Sacred

Spirituality, or the soul of the person.

family and relationships

Source: https://maoridictionary.co.nz/ 


\section{Appendix C}

\section{United States DTC 10 key components and Adult DTC Best Practice Standards}

Defining Drug Courts: The Ten Key Components (NADCP, 1997)

1) Drug courts integrate alcohol and other drug treatment services with justice system case processing

2) Using a non-adversarial approach, prosecution and defense counsel promote public safety while protecting participants'

3) due process rights

4) Eligible participants are identified early and promptly placed in the drug court program

5) Drug courts provide access to a continuum of alcohol, drug, and other related treatment and rehabilitation services

6) Abstinence is monitored by frequent alcohol and other drug testing

7) A coordinated strategy governs drug court responses to participants' compliance

8) Ongoing judicial interaction with each drug court participant is essential

9) Monitoring and evaluation measure the achievement of program goals and gauge effectiveness

10) Continuing interdisciplinary education promotes effective drug court planning, implementation, and operations

11) Forging partnerships among drug courts, public agencies, and community-based organizations generates local support and enhances drug court effectiveness

Adult Drug Court Best Practice Standards Volume I (NADCP, 2013)

- Target populations

- Historically disadvantaged groups and including gender

- Roles and responsibilities of the judge

- Incentives, sanctions and therapeutic adjustments

- Substance abuse treatment.

Adult Drug Court Best Practice Standards Volume II (NADCP, 2015)

- Complementary Treatment and Social Services

- Drug and Alcohol Testing

- Multidisciplinary Team.

- Census and Caseloads

- Monitoring and Evaluation 


\title{
Appendix D
}

\section{这 \\ Alcohol \& Other Drug Treatment Court (AODT Court)}

\author{
Te Whare Whakapiki Wairua
}

Participant Agreement

\begin{tabular}{|r|r|}
\hline Participant: & \\
\hline Date of Birth: & \\
\hline PRN: & \\
\hline $\begin{array}{r}\text { Date of this agreement: } \\
\text { Programme start date: }\end{array}$ & \\
\hline
\end{tabular}

I understand that I have been accepted for the Alcohol and Other Drug Treatment Court (AODT Court) programme. The AODT Court Judge and team will supervise me. I understand that if I leave the programme I will be sentenced in a normal court. I understand that I can withdraw my consent to take part in the AODT Court programme at any time and that, if I do, I will be sentenced in a normal court. I have been given a copy of the AODT Court Participant Handbook.

I agree to the following:

- to be honest about any breaches of this agreement;

- to take part in alcohol and/or other drug treatment, educational and/or rehabilitation programmes as directed by the AODT Court, including any residential treatment programme if required;

- to comply with my AODT Court programme plan;

- to attend all court appearances, treatment sessions and all other scheduled appointments on time;

- to comply with my bail conditions;

- if I do not appear for a Court appearance, or a scheduled appointment, or comply with conditions, or if I commit further offending, I may be sanctioned, arrested or required to leave the AODT Court programme;

- the AODT Court team discussing my programme participation and sharing information about it in my absence; 
- the AODT Court team and service providers will share information about me except that subject to lawyer - client privilege;

- that my Court appearances will take place in open court and may be reported, recorded or videotaped;

- not to use or possess any alcohol or illegal drugs;

- only to use or possess prescription medications in my own name for a current condition and in the prescribed dose. I agree to immediately tell my case manager of any prescription given to me;

- not to use or possess any legal or illegal mind-altering and/or synthetic drugs;

- to random alcohol and drug testing to assist the court and treatment providers in assessing my progress. I understand this may include urine testing, breath tests and dermal (skin) alcohol testing devices among others. I understand that there will be sanctions for a positive test;

- to provide an on-the-spot sample of my own urine upon request and at a minimum of two times per week;

- not to take any substances that may result in a false test, to cooperate with the AODT Court programme and members of the AODT Court team;

- not to be physically violent, not to threaten physical violence or engage in threatening behaviour, or be verbally abusive to anyone; and

- not to commit any further criminal offences.

I understand that if 1 fail to comply with this agreement and / or fail to make satisfactory progress to complete the programme, I may be required to leave the AODT Court. I can also withdraw my consent to take part in the AODT Court at any time, and understand that, if $I \mathrm{do}, I$ will be required to leave the AODT Court and will be sentenced for my current offence(s) in a normal court.

Participant Signature

Defence Counsel

Signature

Judicial Oticer

Signature 